\title{
toen
}

Autarquia Associada à Universidade de São Paulo

\section{IMAGEAMENTO DE EQUIPAMENTOS DE PROCESSOS INDUSTRIAIS PELA TÉCNICA DE PERFILAGEM POR RAIOS GAMA}

Marcio Issamu Haraguchi

Dissertação apresentada como parte
dos requisitos para obtenção do Grau
de Mestre em Ciências na Área
de Tecnologia Nuclear - Aplicações

Orientador:

Dr. Wilson Aparecido Parejo Calvo 


\section{INSTITUTO DE PESQUISAS ENERGÉTICAS E NUCLEARES}

Autarquia associada à Universidade de São Paulo

Imageamento de equipamentos de processos industriais pela técnica de perfilagem por raios gama

\section{Marcio Issamu Haraguchi}

Dissertação apresentada como parte dos requisitos para obtenção do Grau de Mestre em Ciências na Área de Tecnologia Nuclear - Aplicações

Orientador:

Prof. Dr. Wilson Aparecido Parejo Calvo 
À coragem dos meus avôs.

Ao exemplo dos meus pais.

Ao amor da minha Giovana.

Ao futuro, meus filhos. 


\section{AGRADECIMENTOS}

Agradeço antes de tudo ao meu orientador e parceiro em tantos outros projetos, Dr. Wilson Aparecido Parejo Calvo cujo apoio e principalmente incentivo foram vitais para que, enfim, iniciasse este trabalho científico após 15 anos afastado do meio acadêmico.

Agradecimento mais que especial deve ser feito ao Dr. Hae Yong Kim, da Escola Politécnica na Universidade de São Paulo (EPUSP), cujo conhecimento e ferramentas computacionais foram absolutamente imprescindíveis ao desenvolvimento deste trabalho.

Agradeço ao Eng. Francisco Edmundo Sprenger e ao projetista José Jorge Ambiel pelo elaborado, preciso e muito bem construído projeto dos componentes e protótipos das colunas de processos industriais. Agradeço também ao Dr. Carlos Alberto Zeituni pela fabricação e montagem da fonte radioativa selada no portafonte.

Agradeço ao M.Sc. Pedro Eiti Aoki, pela utilização do Laboratório de Aplicações de Radiotraçadores e ao técnico Valdir Cosmos da Silva pelo apoio, e ajuda nos preparativos da montagem dos experimentos laboratoriais.

Agradeço finalmente aos meus sócios na Tricom Tecnologia e Serviços de Manutenção Industrial Ltda., Eng. Joel Ligiéro Vargas e Dra. Graça Belo, pelo apoio e compreensão, para que pudesse me dedicar a este trabalho científico. 


\title{
IMAGEAMENTO DE EQUIPAMENTOS DE PROCESSOS INDUSTRIAIS PELA TÉCNICA DE PERFILAGEM POR RAIOS GAMA
}

\section{Marcio Issamu Haraguchi}

\section{Resumo}

\begin{abstract}
A perfilagem de colunas por raios gama (column gamma scan) é uma técnica nuclear empregada para solucionar problemas em equipamentos de processos industriais, nas refinarias e petroquímicas. Consiste na utilização de uma fonte selada e um detector de radiação [Nal(TI)], obtendo-se o perfil de densidade unidimensional (1D) do equipamento. Nas últimas décadas, ocorreram algumas melhorias na técnica de perfilagem, tais como, na digitalização contínua das informações e nos sistemas de detecção da radiação (wireless). Novos aplicativos melhoraram a qualidade da apresentação dos resultados. Entretanto, a condição da técnica não mudou drasticamente, desde sua criação. Seu resultado é simplesmente um gráfico 1D da densidade média, em função da altura do equipamento industrial. A tecnologia inovadora proposta neste trabalho de Mestrado utiliza a reconstrução tomográfica industrial, via algoritmos iterativos derivados da ART (Algebraic Reconstruction Technique) e do MART (Multiplicative Algebraic Reconstruction Technique), para apresentar o resultado de perfilagem como uma imagem bidimensional (2D) da distribuição de densidade, ao invés de um gráfico 1D. Nitidamente, uma imagem 2D possui mais informações técnicas do equipamento em análise, permitindo um avanço na tecnologia de ensaios não destrutivos (END). Assim, muitos problemas operacionais não detectáveis em equipamentos de processos industriais podem ser descobertos e solucionados de forma on-line, usando-se o imageamento 2D. Esta tecnologia permitiu que um pedido de patente fosse depositado junto ao Instituto Nacional de Propriedade Industrial (INPI).
\end{abstract}




\section{INDUSTRIAL PROCESS EQUIPMENT TROUBLESHOOTING WITH IMAGING TECHNIQUE IMPROVED GAMMA-RAY ABSORPTION SCANS}

\section{Marcio Issamu Haraguchi}

\section{Abstract}

Column gamma scan is one of the most common nuclear techniques on troubleshooting industrial process equipments like distillation columns and reactors. With a very simple concept, the technique is easy to implement. Searching for a competitive edge the industry has been long developing solutions to achieve better results. On the last decades, significant development has been done with the advent of new hardware, electronics, portable computers and software. Continuous scanning and wireless detection systems are examples of successful field solutions, while new software aid on reporting and data presentation. However the type and quality of the results itself has not dramatically changed since its beginning. A scan profile is simple to understand, although the process to build it can be very complex as it requires a specific blend of knowledge and abilities. Process engineering, chemical engineering, internal hydraulic project, nuclear engineering and field abilities are pre requisites for of any scan specialist. Correct data gathering, interpretation and reporting are abilities often difficult to match or requires a long time of training. The industry faces a similar difficult on the customer side, as it is always necessary to train end users to understand a report and how to use its best. This scientific work describes our effort on developing a new approach on the gamma column scan test using image reconstruction techniques that would result on a graphic image rather than a XY plot. Direct and easier to understand, a report with graphic images would be also be accessible to a wider audience, not limited to the customers experienced with gamma scan interpretation. 


\section{SUMÁRIO}

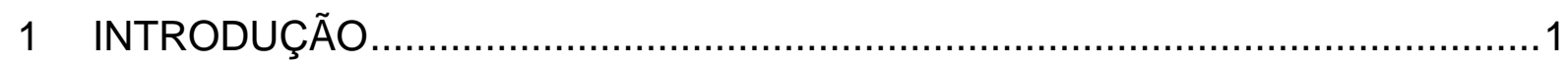

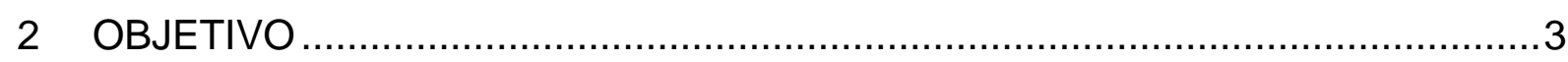

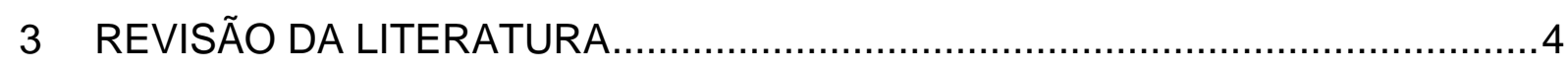

3.1 ANALISE ON-LINE DE EQUIPAMENTOS DE PROCESSO ......................4

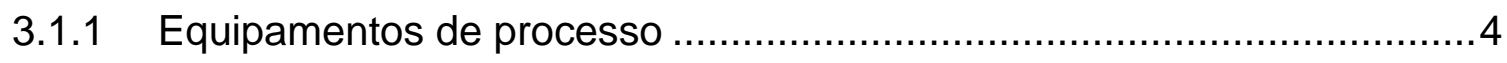

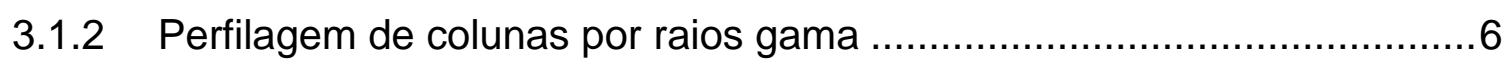

3.1.3 Tomografia computadorizada ............................................... 11

3.2 PROJETO DE TOMOGRAFIA INDUSTRIAL .................................. 16

3.3 IMAGEAMENTO DE EQUIPAMENTOS DE PROCESSOS INDUSTRIAIS .18

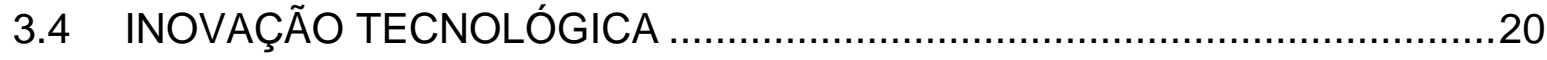

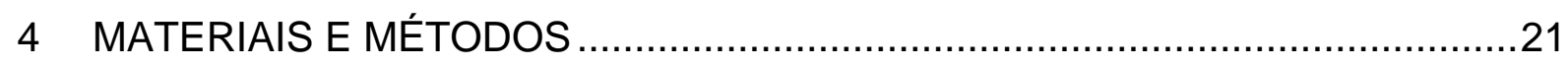

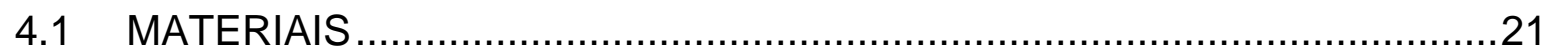

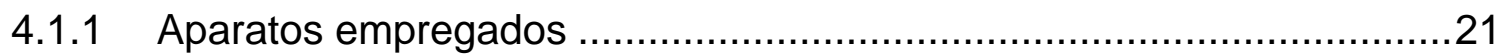

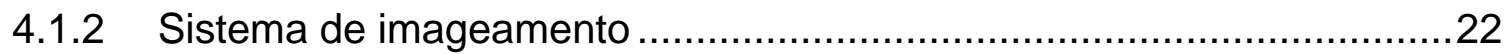

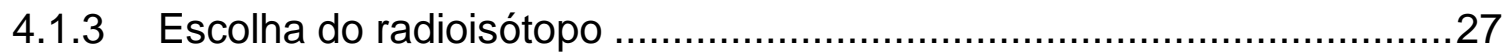

4.1.4 Sistema de aquisição de dados ...................................................29

4.1.5 Modelos de coluna de destilação....................................................30

4.1.6 Metodologia de calibração e verificação ...........................................32

4.1.7 Colimação eletrônica ............................................................ 40

4.1.8 Estatística de contagem ........................................................40 
4.1.9 Estudo de radioproteção............................................................42

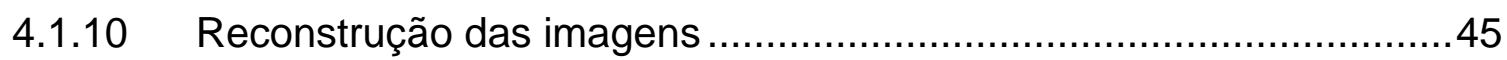

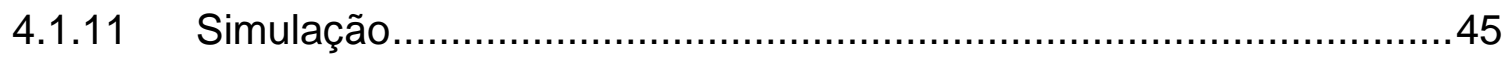

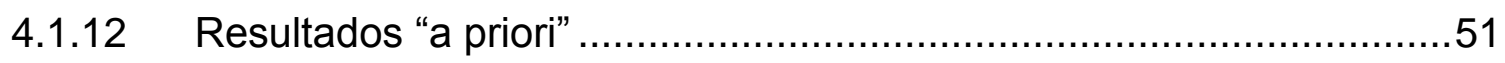

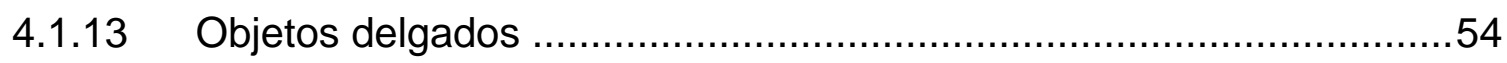

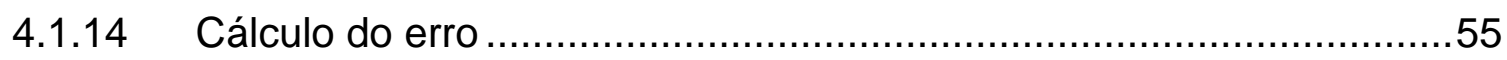

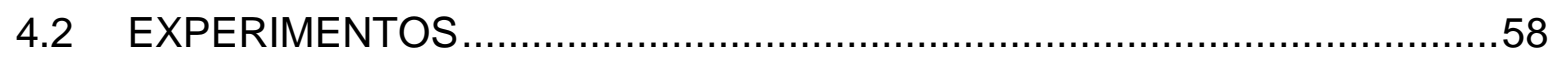

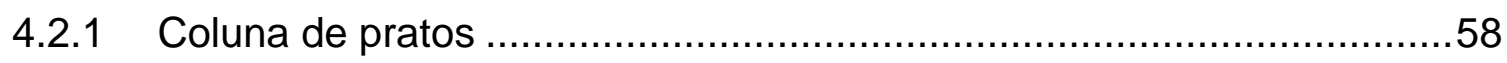

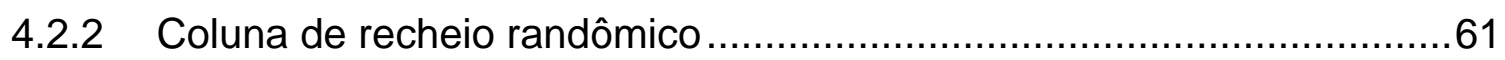

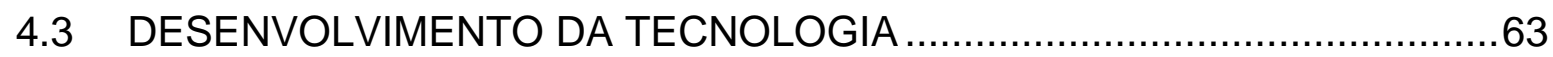

4.3.1 Reconstrução da coluna de pratos com modelos "a priori" ....................63

4.3.2 Reconstrução da coluna de recheio com modelos "a priori" ...................67

4.3.3 Proposta das próximas etapas de trabalho .........................................71

4.3.4 Desenvolvimento da tecnologia ......................................................

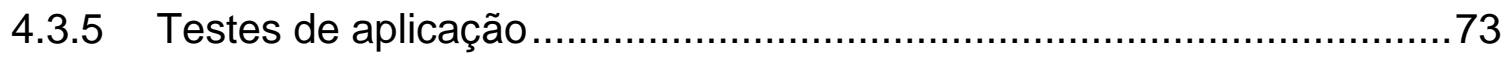

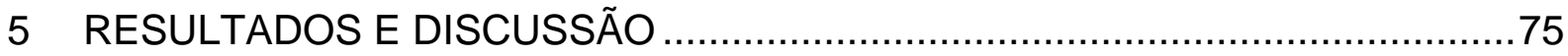

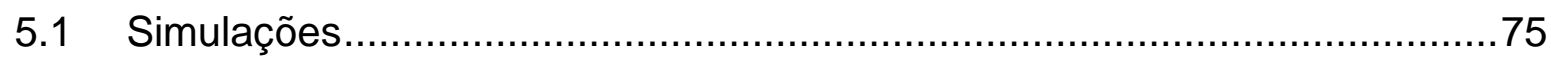

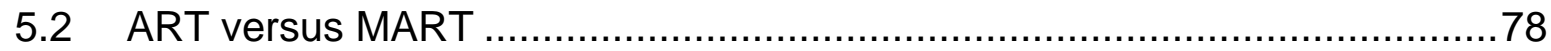

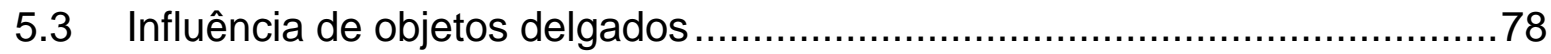

5.4 Coluna de pratos escaneada com detector de radiação de 1" .....................79

5.5 Coluna de pratos escaneada com detector de radiação de 2" .....................81

5.5.1 Imagens geradas após ajuste nos programas ....................................8 
5.6 Coluna de recheio escaneada com detector de radiação de 2" .92

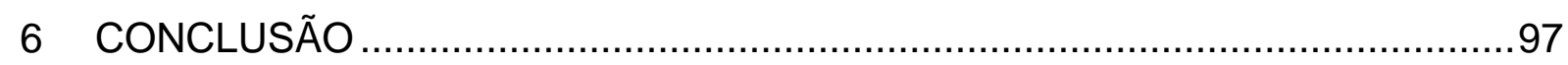

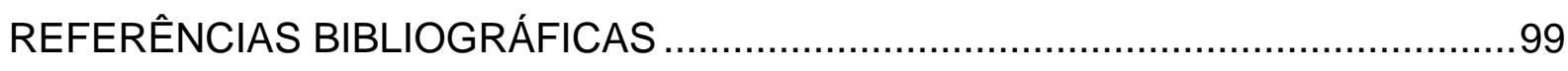

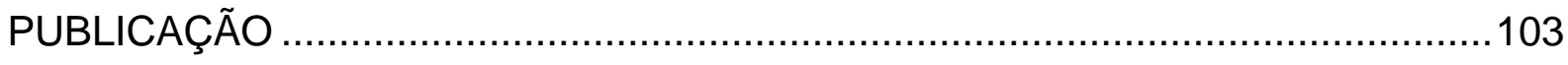

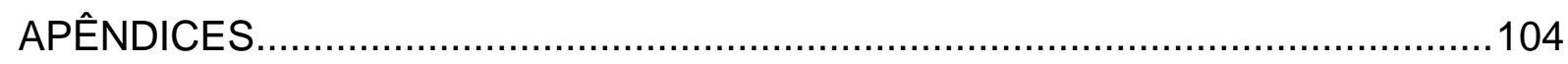

Apêndice 1 - Desenhos de conjunto do sistema de imageamento ........................105

Apêndice 2 - Cálculo do raio de isolamento convencional ...............................106

Apêndice 3 - Depósito do pedido de patente junto ao Instituto Nacional de

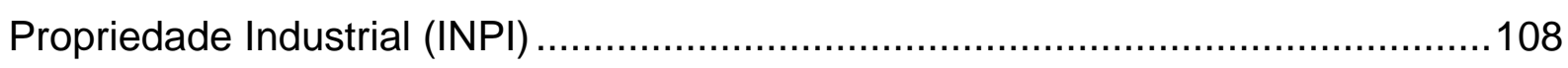




\section{LISTA DE FIGURAS}

Figura 1 - Esquema geral de um equipamento de processo industrial.....................5

Figura 2 - Gráfico de uma perfilagem de coluna por raios gama............................

Figura 3 - Modelo geral de posicionamento de um column gamma scan...................7

Figura 4 - Reconstrução tridimensional a partir das projeções ortogonais...............11

Figura 5 - Esquema da atenuação da radiação na matéria.....................................13

Figura 6 - Esquema da atenuação da radiação num caminho dentro do objeto. .....13

Figura 7 - Medidas discretas de atenuação da radiação com reconstrução da imagem.

Figura 8 - Lei de Beer-Lambert para atenuação da radiação.

Figura 9 - Modalidades gerais de tomografia, do Radioisotope Gauges for Industrial Process Measurements ${ }^{[20]}$

Figura 10 - Reconstruções tomográficas obtidas em um tambor metálico: (a) vazio com cilindro de chumbo; (b) cheio de água com cilindro de chumbo; (c) cheio de água com cilindro metálico vazio (ar) e cilindro de poliuretano. As cores representam as densidades relativas obtidas. 16

Figura 11 - Projetos desenvolvidos nas indústrias: (a) tubo de 6 polegadas com coque; (b) demister com obstrução; (c) trocador de calor de 1,2m de diâmetro e (d) linha de transferência de forno. As cores representam uma escala de valores das densidades relativas obtidas.

Figura 12 - Simulação de irradiações: imagem reconstruída por simulação (a) e imagem do objeto perfilado por raios gama com a presença de defeito (b). 18

Figura 13 - Esquema geral e simulação do imageamento de um equipamento industrial pela técnica de perfilagem por raios gama.

Figura 14 - Conceito de montagem geral do sistema de imageamento. .23 
Figura 15 - Conceito de montagem e detalhes do sistema de imageamento.

Figura 16 - Vista geral do pórtico e sistema de alinhamento fonte-detector de radiação. .25

Figura 17 - Detalhe de montagem da fonte radioativa no porta-fonte (a) e detalhe do sistema colimador da fonte selada (b) .26

Figura 18 - Detalhe do carro deslizante e colimador do detector de 1 polegada (a) e detector de radiação $[\mathrm{Nal}(\mathrm{TI})]$ de 1 polegada, montado no colimador (b). .26

Figura 19 - Talha para movimentação do carro deslizante (a) e detalhe da webcam empregada para a leitura da posição (b). .27

Figura 20 - Diagrama de blocos do layout dos instrumentos de medida. .30

Figura 21 - Tela do laptop durante coleta de dados (a) e vista geral do dos instrumentos e arranjo eletrônico (b), para coleta dos dados experimentais no laboratório.

Figura 22 - Esquema da coluna de pratos (a) e coluna com recheio (b). .31

Figura 23 - Modelo de coluna de pratos (a) e detalhes dos pratos e vertedores (b).31

Figura 24 - Modelo (a) e detalhe da distribuição (b) de coluna de recheio .32

Figura 25 - Arranjo com fonte de atividade "A", a uma distância "d" do centro do cristal de um detector de radiação.

Figura 26 - Determinação experimental da eficiência geral " $\varepsilon$ ". .34

Figura 27 - Atenuação causada por um meio de espessura "x" e coeficiente de atenuação linear " $\mu$ ". .35

Figura 28 - Espectro obtido com um detector de radiação [Nal(TI)] de 1 polegada..36

Figura 29 - Efeitos da saturação nas contagens, em escalas logarítmicas. 37

Figura 30 - Calibração para perfilagem por raios gama. 38

Figura 31 - Primeira proposta de calibração para sistemas tomográficos. 39 
Figura 32 - Espectros de energia do ${ }^{137} \mathrm{Cs}$ e ${ }^{60} \mathrm{Co}$ na calibração otimizada, para detectores de radiação $[\mathrm{Nal}(\mathrm{TI})]$ de 1 polegada (a) e 2 polegadas (b) 40

Figura 33 - Mapa de exposição no sentido axial (a) e transversal (b). 44

Figura 34 - Mapa de posicionamento das irradiações para um ângulo de abertura de $45^{\circ}$, no modelo da coluna de pratos. .46

Figura 35 - Detalhe da medida de espessuras (milímetros). 46

Figura 36 - Imagens reconstruídas resultantes dos modelos em AutoCAD para as colunas de pratos: método ART (a), método MART (b) e coluna de recheio (c).......47

Figura 37 - Modelo discretizado da coluna de pratos. 48

Figura 38 - Estudo de resolução da imagem versus qualidade das informações: (a) $1.000 \times 2.000$ pixels, (b) $2.000 \times 4.000$ pixels e (c) $3.000 \times 6.000$ pixels. 48

Figura 39 - Mapa de dados da irradiação simulada: AutoCAD (a), discretizada com $1.000 \times 2.000$ pixels (b), $2.000 \times 4.000$ pixels (c) e $3.000 \times 6.000$ pixels (d). 49

Figura 40 - Qualidade das imagens reconstruídas em função da escala de discretização: gerada em AutoCAD (a), simulação de $1.000 \times 2.000$ pixels (b), simulação de $2.000 \times 4.000$ pixels (c) e simulação de $3.000 \times 6.000$ pixels (d).......50

Figura 41 - Irradiação simulada da coluna de pratos (a) e imagem obtida (b)..........50

Figura 42 - Modelo simulado de uma coluna de recheio (a) e imagem obtida (b)...51

Figura 43 - Aumento da espessura no material absorvedor, em função do ângulo relativo $(\alpha)$. .52

Figura 44 - Resultados da limitação do ângulo relativo. 53

Figura 45 - Verificação dos valores de " $\mu$ "obtidos: modelo simulado (a), resultado sem "a priori" (b) e com "a priori" (c). .54

Figura 46 - Efeito do aumento do " $\mu$ " aparente pelo mascaramento de objetos delgados. 
Figura 47 - Modelo de coluna de pratos (a), com pratos e vertedores preenchidos com uma mistura de água e gel (b).

Figura 48 - Croqui do arranjo experimental da coluna de pratos (milímetros). .59

Figura 49 - Modelo de leito de recheio randômico irradiado.

Figura 50 - Croquis do arranjo experimental da coluna de recheio (milímetros). .....61

Figura 51 - Modelos "a priori" empregados para a coluna de recheio: simplificado (a) e complexo (b).

Figura 52 - Imagens reconstruídas com os dados de irradiação com passo de $5 \mathrm{~cm}$ : reconstrução direta (a), reconstrução com modelo "a priori" simplificado (b) e reconstrução com modelo "a priori" complexo (c).

Figura 53 - Imagens reconstruídas com os dados de irradiação com passo de $10 \mathrm{~cm}$ : reconstrução direta (a), reconstrução com modelo "a priori" simplificado (b) e reconstrução com modelo "a priori" complexo (c).

Figura 54 - Imagens reconstruídas com os dados de irradiação com passo de $15 \mathrm{~cm}$ : reconstrução direta (a), reconstrução com modelo "a priori" simplificado (b) e reconstrução com modelo "a priori" complexo (c).

Figura 55 - Modelos "a priori" empregados para a coluna de recheio: simplificado (a) e complexo (b). .68

Figura 56 - Imagens reconstruídas com os dados de irradiação com passo de $5 \mathrm{~cm}$ : reconstrução direta (a), reconstrução com modelo "a priori" simplificado (b) e reconstrução com modelo "a priori" complexo (c). .68

Figura 57 - Imagens reconstruídas com os dados de irradiação com passo de $10 \mathrm{~cm}$ : reconstrução direta (a), reconstrução com modelo "a priori" simplificado (b) e reconstrução com modelo "a priori" complexo (c).

Figura 58 - Imagens reconstruídas com os dados de irradiação com passo de $15 \mathrm{~cm}$ : reconstrução direta (a), reconstrução com modelo "a priori" simplificado (b) e reconstrução com modelo "a priori" complexo (c). 
Figura 59 - Teste de aplicação com equipamento de perfilagem por raios gama. Layout do teste (a), gráfico de perfilagem (b) e imagem reconstruída (c). .74

Figura 60 - Modelo simulado de uma coluna de pratos (a), perfil de densidades obtido do escaneamento (b) e imagem reconstruída (c). 75

Figura 61 - Modelo simulado de uma coluna de recheio (a), perfil de densidades obtido do escaneamento (b) e imagem reconstruída (c). .76

Figura 62 - Regiões com menor fidelidade na reconstrução na coluna de pratos. ...77

Figura 63 - Regiões com menor fidelidade na reconstrução na coluna de recheio...78

Figura 64 - Perfil de densidades obtido experimentalmente (a), imagem reconstruída usando detector de radiação $[\mathrm{Nal}(\mathrm{Tl})]$ de 1 polegada e passo de $10 \mathrm{~cm}$ (b) e imagem obtida de simulação inicial (c).

Figura 65 - Perfil de densidades (a) e imagem obtida usando detector de radiação $[\mathrm{Nal}(\mathrm{TI})]$ de 2 polegadas, passo de $5 \mathrm{~cm}$ e filtragem média (b).

Figura 66 - Perfil de densidades (a) e imagem obtida usando detector de radiação $[\mathrm{Nal}(\mathrm{TI})]$ de 2 polegadas, passo de $5 \mathrm{~cm}$ e filtragem mediana (b). .83

Figura 67 - Perfil de densidades (a) e imagem obtida usando detector de radiação $[\mathrm{Nal}(\mathrm{TI})]$ de 2 polegadas e passo de $10 \mathrm{~cm}(\mathrm{~b})$.

Figura 68 - Perfil de densidades (a) e imagem obtida usando detector de radiação $[\mathrm{Nal}(\mathrm{TI})]$ de 2 polegadas e passo de $15 \mathrm{~cm}(\mathrm{~b})$.

Figura 69 - Principais características observadas na imagem reconstruída da coluna de pratos com passo de $5 \mathrm{~cm}$. 85

Figura 70 - Comparação entre imagens geradas com detectores de radiação [Nal(TI)] de 1 polegada (a) e 2 polegadas (b), com passo de $10 \mathrm{~cm}$. .86

Figura 71 - Imagem obtida usando detector de radiação [Nal(TI)] de 2 polegadas e passo de $5 \mathrm{~cm}$ (a) e imagem obtida por dados simulados (b) .89

Figura 72 - Imagem obtida usando detector de radiação [Nal(TI)] de 2 polegadas e passo de $10 \mathrm{~cm}$ (a) e imagem obtida por dados simulados (b). 89 
Figura 73 - Imagem obtida usando detector de radiação [Nal(TI)] de 2 polegadas e passo de $15 \mathrm{~cm}$ (a) e imagem obtida por dados simulados (b).

Figura 74 - Experiência na coluna com recheio randômico e passo de $5 \mathrm{~cm}$ : perfil de densidades (a), imagem reconstruída a partir de irradiação (b) e imagem obtida por simulação (c).

92

Figura 75 - Experiência na coluna com recheio randômico e passo de $10 \mathrm{~cm}$ : perfil de densidades (a), imagem reconstruída a partir de irradiação (b) e imagem obtida por simulação (c). .93

Figura 76 - Experiência na coluna com recheio randômico e passo de $15 \mathrm{~cm}$ : perfil de densidades (a), imagem reconstruída a partir de irradiação (b) e imagem obtida por simulação (c). .93

Figura 77 - Principais características observadas na imagem reconstruída da coluna com recheio randômico irradiada com passo de $5 \mathrm{~cm}$. .94

Figura 78 - Imagens obtidas com diferentes ângulos relativos: $35^{\circ}$ (a), $45^{\circ}$ (b) e $55^{\circ}(\mathrm{c})$ .94 


\section{LISTA DE TABELAS}

Tabela 1 - Valores de erros de " $\mu$ "e " $\Delta \mu$ " para o exemplo da Figura 44. .56

Tabela 2 - Relação contagens versus background (BG). 60

Tabela 3 - Erro observado entre o maior valor e a variação total de " $\mu$ " na imagem reconstruída da primeira reconstrução e das geradas com modelo "a priori". .66

Tabela 4 - Valores do erro MAE (Mean Absolute Error) em função do passo e tipo de reconstrução.

Tabela 5 - Valores do erro RMSE (Root Mean Square Error) em função do passo e tipo de reconstrução.

Tabela 6 - Erro observado entre o maior valor e a variação total de " $\mu$ " na imagem reconstruída da primeira reconstrução e das geradas com modelo "a priori"..... .70

Tabela 7 - Valores do erro MAE (Mean Absolute Error) em função do passo e tipo de reconstrução.

Tabela 8 - Valores do erro RMSE (Root Mean Square Error) em função do passo e tipo de reconstrução.

Tabela 9 -Quadro comparativo do número de pontos e tempo despedido versus qualidade de resultado da segunda experiência.

Tabela 10 - Erro observado entre o maior valor e a variação total de " $\mu$ " na imagem reconstruída com relação aos valores do modelo

Tabela 11 - Erro observado entre o maior valor e a variação total de " $\mu$ " na imagem reconstruída com relação aos valores do modelo, após correção de programas. ....91

Tabela 12 - Erro observado entre o maior valor e a variação total de " $\mu$ " na imagem reconstruída com relação aos valores do modelo.

Tabela 13 - Diferença entre os valores de " $\mu$ " obtidos por simulação e irradiação...96 


\section{INTRODUÇÃO}

Nas plantas de produção contínua, tais como, refinarias e petroquímicas, o desempenho dos equipamentos de processos industriais é analisado com o auxílio de um modelo de processo, em função das suas variáveis operacionais, da qualidade dos insumos e produtos ${ }^{[1]}$. Com o advento dos processos, projetos e das operações cada vez mais complexas e com limites restritos, o uso das tecnologias de ensaios não destrutivos (END) tem sido empregado para validar, verificar ou diagnosticar de forma on-line o modelo de processo.

Dentre as tecnologias atualmente disponíveis, as técnicas nucleares destacam-se por não perturbar ou alterar o processo em análise, permitindo que sejam feitos exames em linha ou de forma on-line, como é apresentado por CHARLTON, J. S., em Radioisotope Techniques For Problem Solving In Industrial Process Plants ${ }^{[2]}$. Métodos e aparatos mais modernos permitiram também que técnicas nucleares que eram citadas apenas em literatura, artigos científicos ou aplicações de ponta migrassem aos poucos para o uso no campo ${ }^{[3,4]}$. Técnicas como a perfilagem de colunas por raios gama ${ }^{[5,6]}$, retroespalhamento de nêutrons, traçadores químicos e radioativos e a tomografia industrial computadorizada ${ }^{[7,8,9]}$ tornam-se práticas cada vez mais comuns e representam as mais poderosas ferramentas para análise dos equipamentos de processos industriais em operação.

Dentre estas técnicas, a de perfilagem de colunas de destilação consolidou-se como uma das melhores opções no diagnóstico mecânico operacional destes equipamentos. Nesta técnica, uma fonte radioativa e um detector de radiação são posicionados ao redor do equipamento e movimentados simultaneamente ao longo de seu comprimento. Os valores de atenuação da radiação medidos permitem que seja obtido um perfil de densidades longitudinal do equipamento. Em seguida, o perfil de densidades ou gráfico de escaneamento é analisado, para elaboração do relatório de ensaio. 
Apesar de basear-se em princípios simples, sua aplicação mostra-se complexa em função do vasto conhecimento especifico requerido em suas diversas fases. Esta barreira demonstrou-se também um impedimento para a maior divulgação e aceitação da técnica pelo mercado, visto que o cliente final também deve ter um bom domínio da técnica.

Em busca das formas de suplantar esta dificuldade e limitações técnicas, conseguindo alguma vantagem competitiva, as empresas do segmento desenvolveram diversas soluções que, no entanto, não resultaram numa melhor qualidade de informação. Todas as tecnologias presentes no mercado baseiam-se no mesmo princípio: leitura de atenuação da radiação gama, gerando um perfil de densidade médio. Este paradigma seria quebrado com uma tecnologia que apresentasse um resultado mais direto, compreensível e, portanto, de melhor aceitação. 


\section{OBJETIVO}

Desenvolver sistema de imageamento e metodologia que permitam observar melhor os detalhes internos de equipamentos de processos industriais, usando técnicas de reconstrução tomográfica de imagens, resultando em informações mais simples de interpretar e mais ricas em detalhes quando comparadas com a técnica tradicional de perfilagem caracterizando, assim, um avanço sobre os métodos atualmente disponíveis no mercado. 


\section{REVISÃO DA LITERATURA}

\subsection{ANALISE ON-LINE DE EQUIPAMENTOS DE PROCESSO}

\subsubsection{Equipamentos de processo}

O desempenho de equipamentos pode ser medido, compreendido e projetado através de um modelo de processo, cujas variáveis de entrada podem ser medidas diretamente (temperatura, pressão, vazão e nível) ou determinadas (composição, consumo de calor, mistura, reação e insumos). Na Figura 1 é mostrada uma coluna de destilação típica com algumas de suas variáveis de processo. Estes modelos, elaborados considerando algumas premissas de projeto, normalmente são robustos o suficiente para levar em conta todos os erros normais de medição e variação advindos da leitura de seus parâmetros. Todavia ainda não existem modelos capazes de sozinhos alterarem suas premissas de projeto.

Modelos de processo baseiam-se em algumas características, consideradas constantes, controladas e conhecidas:

- Físicas - dimensões, área, volume, funcionamento do equipamento e componentes, nivelamento e vibração;

- De processo - pureza, fenômeno físico-químico preponderante e composição; e

- De operação - tempo de residência, distribuição, temperatura, pressão e vazão, entre outras. 


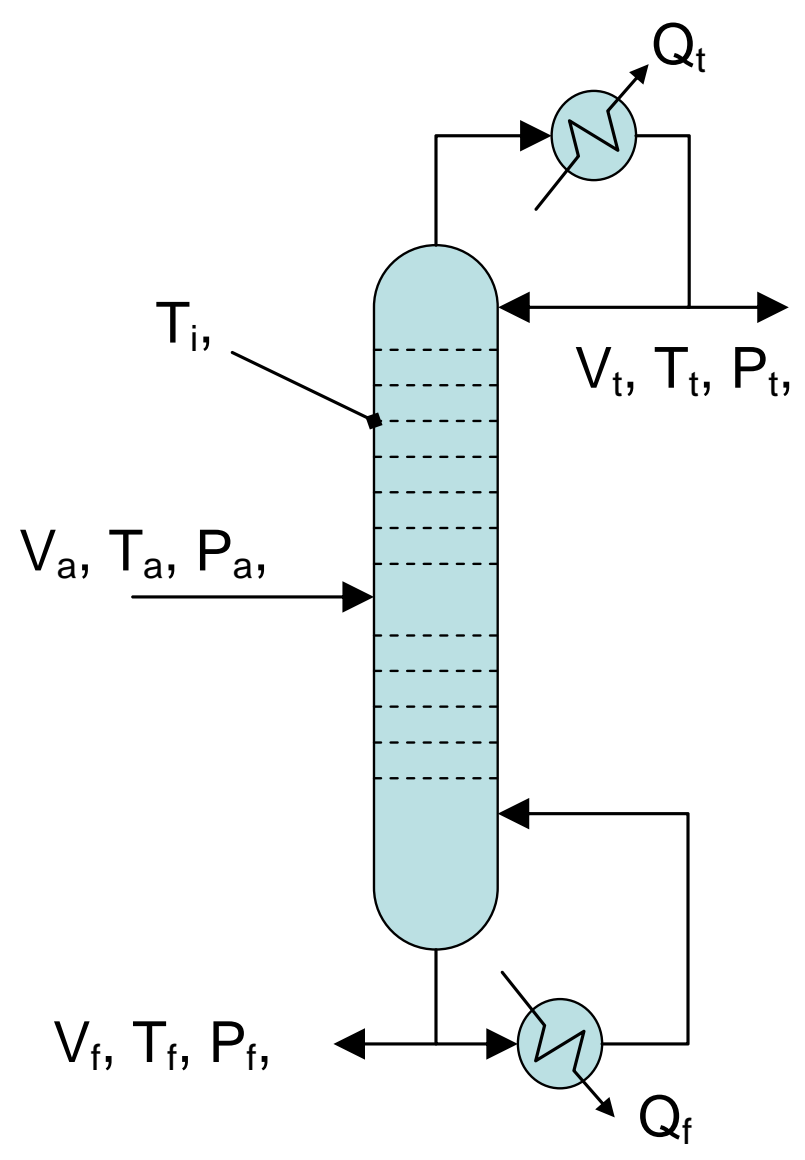

Figura 1 - Esquema geral de um equipamento de processo industrial.

Obviamente, modelos não levam em conta tudo o que tem caráter aleatório, incontrolado, desconhecido ou até humano:

- Físicas - corrosão, danos mecânicos e problemas de montagem;

- De processo - contaminação, fenômeno físico-químico inesperado, sedimentação e saturação;

- De operação - distúrbios operacionais, erro de leitura de instrumentos e coqueamento; e

- Humanos - problemas de projeto, adaptações e esquecimentos, entre outros.

Neste contexto é que alguns ensaios não destrutivos (END) especiais tem seu principal foco de atuação, pois permitem validar processos e avaliar problemas de equipamentos enquanto estão em operação. 
Atualmente, o uso destas técnicas tem se espalhado, para além das engenharias de processos e operações, para outros campos de engenharia das plantas industriais:

- Manutenção - avaliação on-line de equipamentos;

- Planejamento de parada - abertura de equipamentos, compra de insumos e extensão de trabalhos;

- Projetos e revamps - verificação de gargalos, acompanhamento de partidas, baselines e estudo de desempenho; e

- Práticas preditivas - monitoramento de equipamentos críticos, entre outros.

\subsubsection{Perfilagem de colunas por raios gama}

A perfilagem de colunas por raios gama ou column gamma scan é uma das técnicas de ensaios não destrutivos (END) mais empregadas para avaliar o funcionamento mecânico-operacional em linha ou on-line ${ }^{[10,11]}$, de equipamentos de processo ${ }^{[12,13]}$. Nesta técnica, uma fonte radioativa e um detector de radiação são posicionados ao redor do equipamento e movimentados ao longo de seu comprimento. Os valores de atenuação da radiação medidos permitem que um perfil de densidades longitudinal do equipamento seja obtido. Em seguida, o perfil de densidades ou gráfico de escaneamento é analisado, a fim de que um relatório do ensaio realizado possa ser redigido.

Na Figura 2 é mostrado um gráfico de escaneamento real, com o perfil de densidades e o croqui da coluna de processo. 


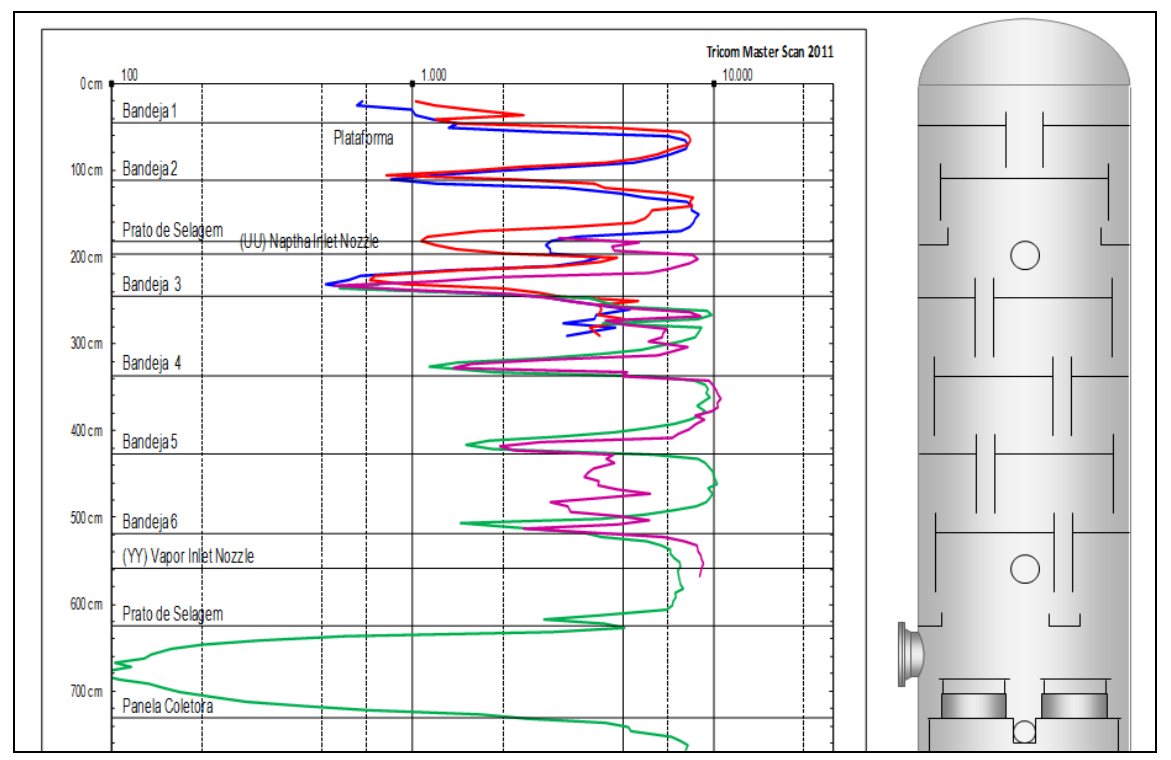

Figura 2 - Gráfico de uma perfilagem de coluna por raios gama.

$\mathrm{Na}$ Figura 3 é ilustrada uma representação de um escaneamento de colunas, apresentando à esquerda a orientação do escaneamento e a direita o perfil de densidades obtido.
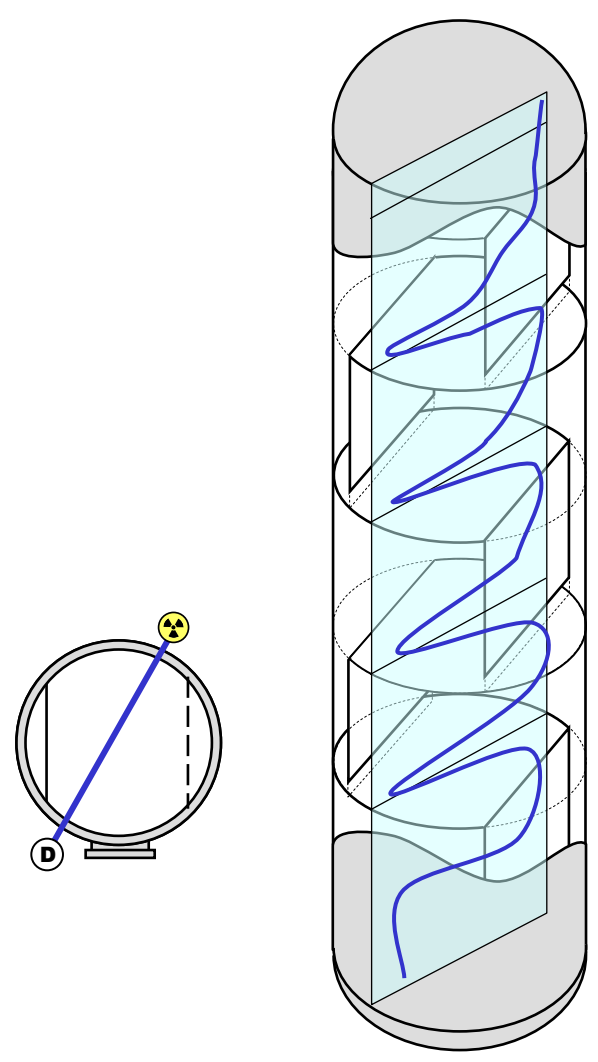

Figura 3 - Modelo geral de posicionamento de uma perfilagem (column gamma scan). 


\subsubsection{Limitações da técnica}

A técnica de perfilagem gama apresenta algumas limitações que restringem seu uso a algumas aplicações:

- Taxa de contagem - como o tempo disponível para testes de campo é limitado, a perfilagem limita se a casos aonde é possível medir valores de contagem estatisticamente válidos. Assim, a atividade da fonte, sua energia, a eficácia dos detectores, a espessura, o tamanho e a constituição do equipamento em análise são parâmetros fundamentais na analise de viabilidade de um projeto. Critérios de radioproteção são igualmente relevantes em função da limitação de dose equivalente da equipe de trabalho;

- Densidade média - cada ponto obtido numa perfilagem relaciona se à densidade média do caminho percorrido pelo feixe de radiação. Assim, qualquer analise de uma perfilagem deve ser feito considerando o comportamento médio e não pontual do perfil de densidades. Adicionalmente, a perfilagem tende a esconder problemas e fenômenos em equipamentos de maior diâmetro, que apresentam estruturas de suporte pesadas e baixa vazão de liquido. Para contornar isto, já é pratica comum realizarem-se testes de referência ou baselines, nos equipamentos mais críticos das unidades. Baselines podem ser feitos com 0 equipamento parado (registro da parte física) ou em condições ótimas de operação (registro da parte física e processo);

- Posicionamento - Como uma perfilagem é um registro de densidades médias, uma interpretação destes dados só será possível se as características do objeto em estudo forem, aproximadamente, uniformes ao longo do caminho percorrido pelo feixe de radiação. Isso limita bastante as possibilidades de posicionamento e os tipos de perfil de densidades que podem ser obtido. Muitas vezes, equipamentos de constituição complexa são difíceis, de análise limitada ou até impossíveis de serem analisados ${ }^{[14]}$; e 
- Dimensão - a perfilagem oferece apenas uma visão unidimensional (em função da elevação) da densidade média de um equipamento. Múltiplos escaneamentos, ou escaneamentos na forma de grelha (grid-scans) são efetuados com o intuito de obter alguma noção de distribuição espacial de densidades.

\subsubsection{A arte da perfilagem (column gamma scan)}

Apesar de conceitualmente simples a técnica de perfilagem, requer conhecimentos, aptidões e afinidades especiais da equipe de trabalho que interferem diretamente na qualidade das informações obtidas e na veracidade do relatório redigido. Em geral um especialista em perfilagem de columas por raios gama deve dominar os seguintes temas:

- Avaliação preliminar - limitações e alcance da técnica, estimativa de resultados possíveis e informações de interesse, avaliação preliminar de atividade de fonte e taxa de contagem, estratégia de trabalho e coleta de dados;

- Trabalho em campo - problemas mecânicos, elétricos, eletrônicos, interferências, ruídos, trabalhos em ambientes externos, intempéries, longas jornadas;

- Radiação - cuidados com dose, manuseio de fontes radioativas, atenuação da radiação, saturação do detector, colimação, espalhamento e retroespalhamento, conhecimentos sobre fontes, energia, calibração, instrumentação;

- Conhecimento prévio - conhecimento sobre o processo e equipamento em investigação, experiência com casos semelhantes, proposições de testes alternativos;

- Interpretação de dados - experiência para julgar e filtrar todo o tipo de interferências nos dados resultantes de problemas ou características do equipamento; 
- Redação - habilidade em explanar e transcrever para um texto técnico a técnica e suas limitações, os problemas encontrados, propostas de soluções; e

- Interpessoais - trabalho em equipe e com outras equipes envolvidas no projeto, relacionamento com equipes de segurança, mito da radiação, capacidade de comunicação e convencimento, habilidade em apresentações, domínio de outras línguas, capacidade de liderança e calma.

Estas características fazem com que o perfil de um especialista em perfilagem por raios gama seja tão restrito que o treinamento de pessoal é historicamente um dos maiores problemas enfrentados pelo segmento ${ }^{[15]}$. O numero de especialistas em todo mundo não deve passar de algumas dezenas, e não raro, seu trabalho é informalmente referido como a "arte do gamma scan".

Frente a este problema, a indústria de perfilagem por raios gama tem investido em algumas soluções:

- Trabalho em campo - sistemas automatizados ou automáticos de movimentação ${ }^{[16]}$, sistemas de comunicação wireless para detectores, sistemas eletrônicos pré-ajustados; e

- Visualização dos resultados - automatização da geração de gráficos e relatórios, visualização on-line via web da tomada de dados.

Não obstante o nítido avanço obtido por algumas destas melhorias, existem ressalvas a serem feitas:

(a) A simplificação de aparatos e procedimentos tornou o sistema menos flexível e, consequentemente, mais difícil de ajustar em campo;

(b) A maior facilidade no treinamento resultou em equipes menos experientes e mais sujeitas a erros;

(c) O acompanhamento à distância de um projeto não pode eliminar a presença de um especialista, pois muitos testes não podem ser repetidos; 
(d) Não raro, as melhorias resultaram na perda da qualidade dos dados coletados.

\subsubsection{Tomografia computadorizada}

O processo de obter imagens espaciais de um objeto a partir de suas projeções é chamado de reconstrução. O cérebro humano é altamente especializado em converter imagens bidimensionais num mapa tridimensional. Assim, sabemos qual o formato espacial de uma cadeira, por exemplo, simplesmente olhado para ela, pois nosso cérebro combina duas imagens bidimensionais numa visão estereoscópica. Quando analisamos um desenho técnico, fazemos o mesmo, construindo uma imagem tridimensional de um objeto a partir das vistas bidimensionais dele.

Na Figura 4 é mostrado como se pode visualizar um objeto tridimensional a partir de suas projeções ortogonais.

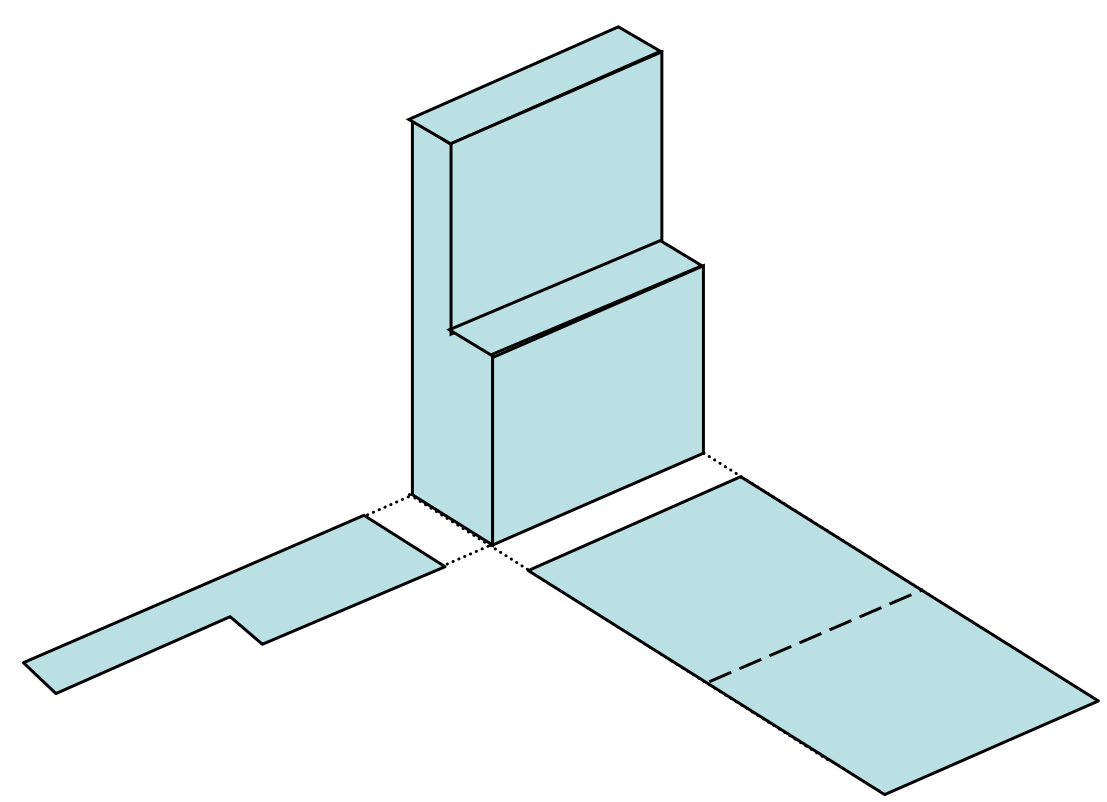

Figura 4 - Reconstrução tridimensional a partir das projeções ortogonais.

Apesar de bastante intuitivo, um processo matemático que permitiria a reconstrução de imagens só foi publicado em 1963/64 pelo físico sul africano Allan Cormack e implementado na primeira máquina tomográfica em 1972, feita nos laboratórios da EMI, por Godfrey Hounsfield. Este trabalho que Ihes rendeu o prêmio 
Nobel de Medicina em 1979 foi curiosamente financiado com os lucros obtidos do famoso álbum Sergeant Pepper's Lonely Heart's Club Band dos Beatles.

Atualmente, tomógrafos hospitalares, de pesquisa e de bancada tem altíssima sofisticação e apresentam ótima qualidade de imagens e velocidade das imagens reconstruídas ${ }^{[17]}$. Os primeiros tomógrafos funcionavam medindo a atenuação da radiação, mas outros princípios físicos podem ser empregados para gerar imagens como resistividade elétrica ${ }^{[18]}$ e a velocidade de propagação do som ${ }^{[19]}$.

\subsubsection{Princípios físicos}

Qualquer objeto em estudo (um paciente, uma coluna de destilação, um tronco de árvore ou uma peça fundida) é analisado com maior facilidade se obtivermos imagens da qual possamos visualizar os eventuais problemas que podem ocorrer (um câncer, entupimento, uma trinca ou falha de fundição, respectivamente). Por isso a reconstrução fiel de imagens para diagnóstico é muito importante.

Assim, podemos usar vários princípios físicos:

- Atenuação da radiação - tomografia convencional;

- Velocidade de propagação do som - tomografia sísmica, acústica e oceânica;

- Resistividade, impedância e capacitância - tomografia elétrica; e

- Absorção de luz - tomografia ótica.

Usualmente, analisa-se alguma grandeza física que possa ser medida no objeto e que varia apenas com a constituição deste meio. Na Figura 5 é mostrada a atenuação da radiação na matéria. 


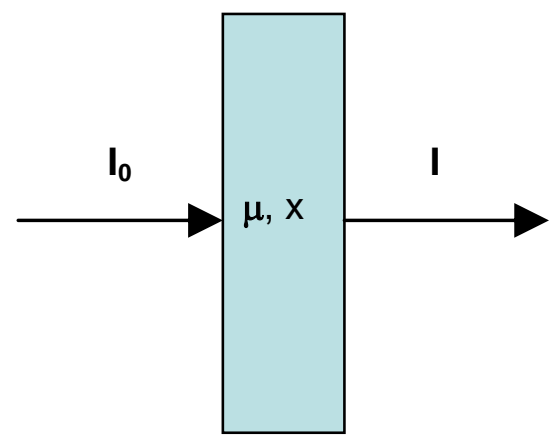

Figura 5 - Esquema da atenuação da radiação na matéria.

A atenuação da radiação pode se expressa com a Equação (1):

$$
I=I_{0} \cdot f(\mu, x)
$$

$\mathrm{Na}$ qual $\mathrm{I}_{0}$ é a intensidade inicial do feixe de radiação, $\mu$ é o coeficiente de atenuação linear do meio para uma determinada energia, x é a espessura do objeto e I é a intensidade de radiação medida.

Se esta propriedade física varia ao longo de um caminho dentro do objeto, podemos representar a função como um produto de funções, conforme mostrado na Figura 6.

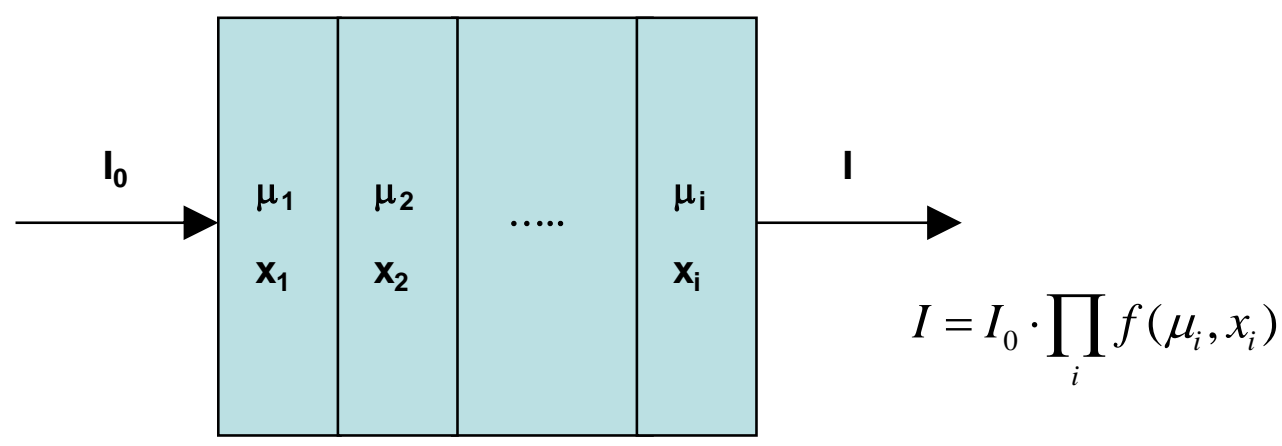

Figura 6 - Esquema da atenuação da radiação num caminho dentro do objeto.

O processo de reconstrução de imagens garante que podemos obter a distribuição desta propriedade dentro de uma região em análise, com um número limitado de medidas, usando um algoritmo matemático ou iterativo. Na Figura 7 é ilustrado, de modo representativo, o processo de reconstrução de uma distribuição $G$ $(\mathrm{x}, \mathrm{y})$ a partir de medidas discretas. 

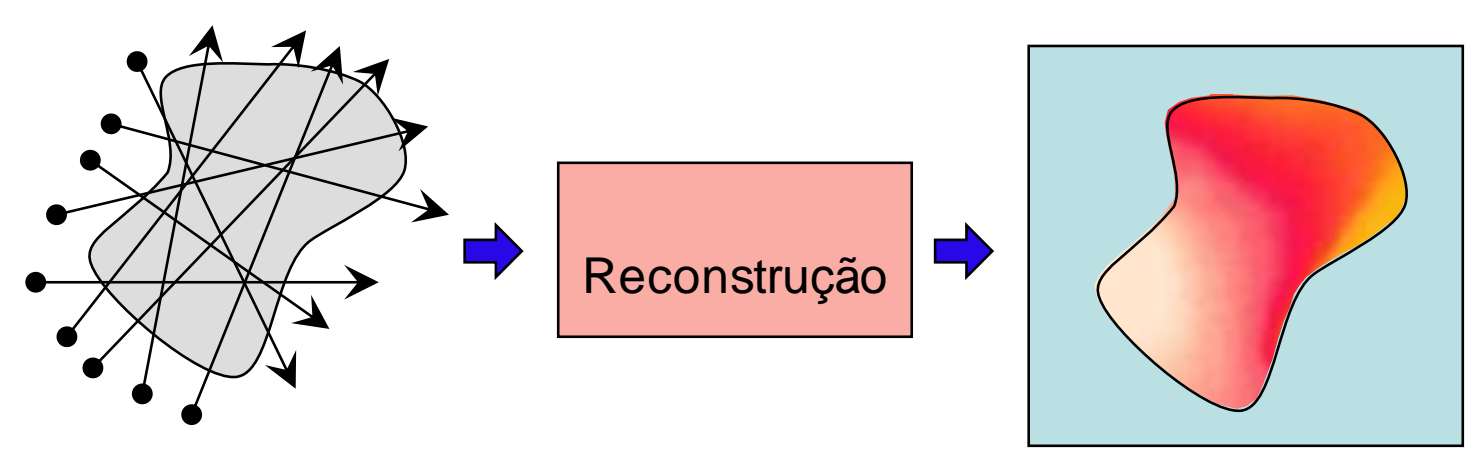

$\mu=G(x, y)$

Figura 7 - Medidas discretas de atenuação da radiação com reconstrução da imagem.

\subsubsection{Tomografia convencional e fundamentos}

Em princípio, desde que sejam conhecidos os pontos de emissão e recepção de sinais, uma imagem tomográfica pode ser obtida de qualquer tipo de arranjo espacial. Em muitos casos, a própria constituição do sistema de medição impõe uma geometria ou parte-se de uma geometria conhecida por facilidade de implementação de uma rotina de tratamento de dados.

Um pouco mais especificamente a este trabalho, os tomógrafos convencionais funcionam através do princípio da atenuação da radiação, analiticamente expressada pela lei de Beer-Lambert, mostrada na Figura 8:

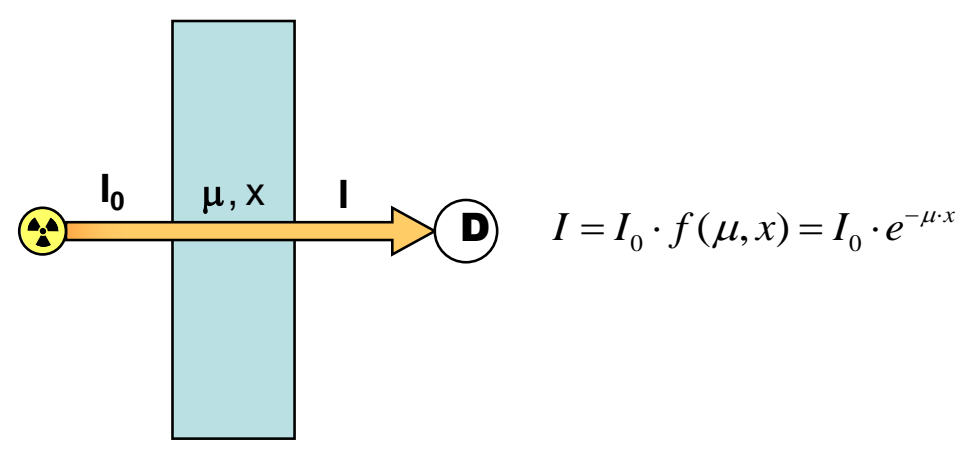

Figura 8 - Lei de Beer-Lambert para atenuação da radiação. 
Diversas configurações de tomógrafos industriais podem ser encontradas. Nos tomógrafos de $1^{\text {a }}$ geração, o conjunto fonte-detector transladava linearmente para efetuar as medições, depois todo o sistema é rotacionado para que um novo conjunto de medições seja tomado em outra direção de translação. Num sistema de $2^{\text {a }}$ geração, uma fileira de detectores substitui o detector simples. Todo o sistema ainda pode transladar e rotacionar em torno do objeto. Num tomógrafo de $3^{\mathrm{a}}$ geração a fileira de detectores é mais larga havendo, logo, apenas rotação em torno do objeto. Num sistema de $4^{a}$ geração um anel de detectores é posicionado ao redor do objeto e apenas a fonte movimenta-se ao redor do mesmo. A configuração de tomógrafos instantâneos (sem escaneamento) considera o uso de múltiplas fontes e bancos de detectores de radiação. Na Figura 9 são ilustradas estas cinco gerações de tomógrafos.

As principais diferenças entre estas configurações estão no tempo necessário para a amostragem de dados, na complexidade crescente e flexibilidade decrescente. Assim um tomógrafo de primeira geração é mais versátil, mas pode levar horas para completar a amostragem; enquanto que já existem tomógrafos instantâneos que podem registrar 10 mil quadros por segundo.

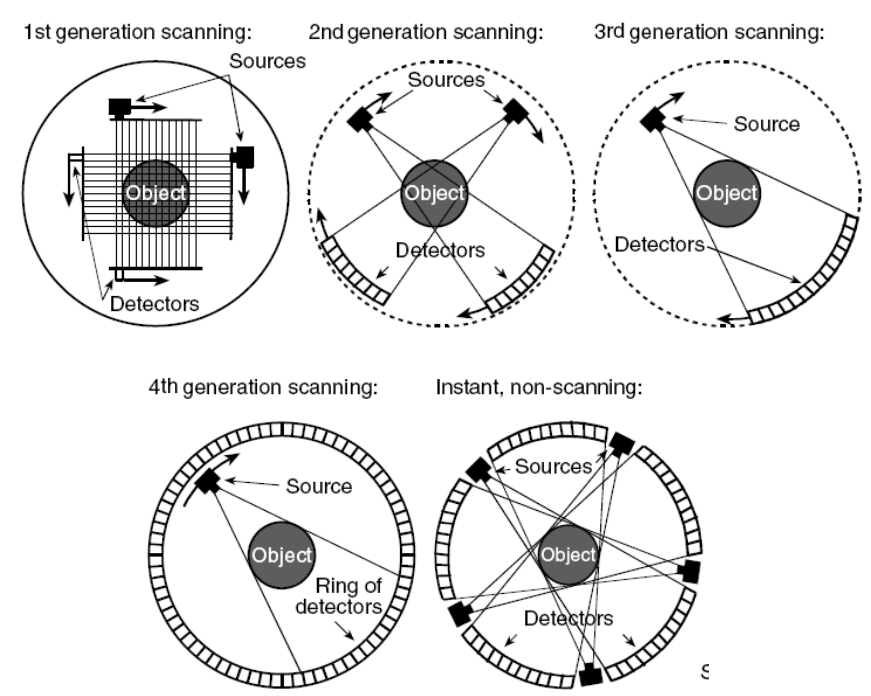

Figura 9 - Modalidades gerais de tomografia, do Radioisotope Gauges for Industrial Process Measurements ${ }^{[20]}$. 


\subsection{PROJETO DE TOMOGRAFIA INDUSTRIAL}

A Tricom Tecnologia é uma empresa nacional especializada no diagnóstico de processos de equipamentos industriais. Em 2008, iniciou-se uma linha de pesquisa e desenvolvimento para um sistema de tomografia computadorizada de equipamentos de processos industriais, que complementasse as técnicas de perfilagem de colunas por raios gama e gerasse novas oportunidades para a empresa ${ }^{[21]}$. Em colaboração com a Escola Politécnica da Universidade de São Paulo (EPUSP), a Tricom Tecnologia desenvolveu protótipos de tomógrafos de primeira e segunda gerações para equipamentos industriais ${ }^{[22,7]}$.

Realizaram-se diversas experiências nas instalações da Tricom Tecnologia, com o objetivo de obter conhecimento e testar soluções para a montagem de sistemas tomográficos. Utilizou-se um tambor metálico de 200 litros, nos diversos testes com um sistema tomográfico de segunda geração. Os espécimes (cilindro metálico vazio, de chumbo e de poliuretano) simulavam algumas condições encontradas na indústria. Algumas das imagens reconstruídas são mostradas na Figura 10.

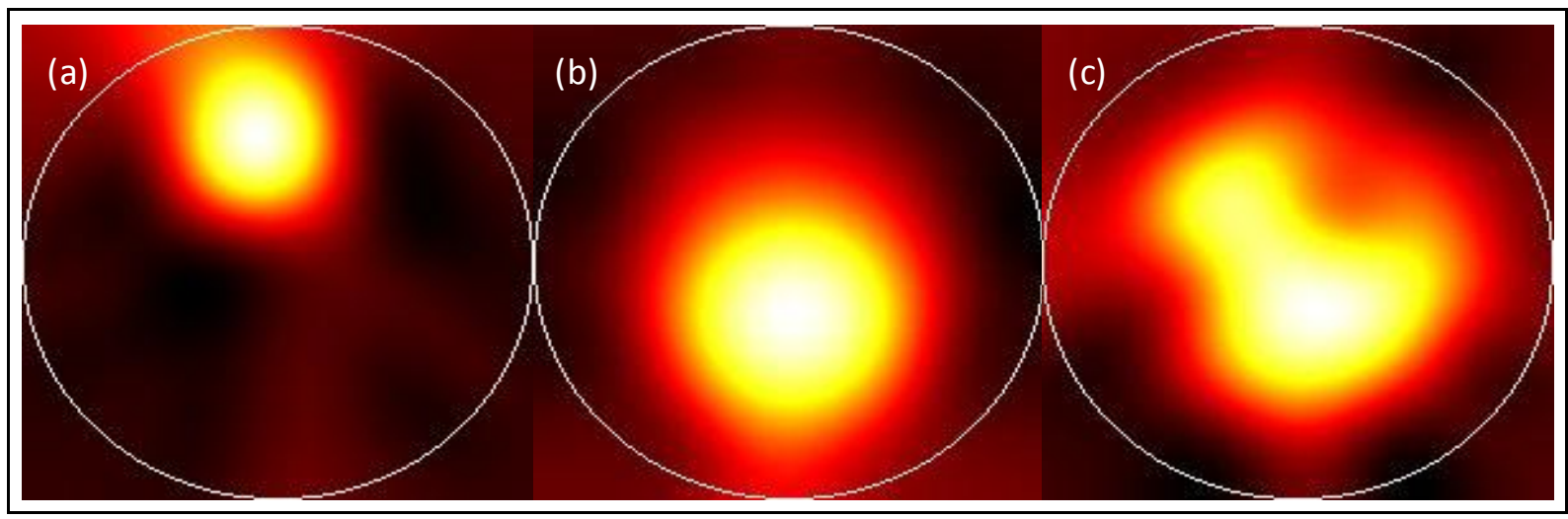

Figura 10 - Reconstruções tomográficas obtidas em um tambor metálico: (a) vazio com cilindro de chumbo; (b) cheio de água com cilindro de chumbo; (c) cheio de água com cilindro metálico vazio (ar) e cilindro de poliuretano. As cores representam as densidades relativas obtidas.

A partir destes resultados realizaram-se diversos projetos nas indústrias com a técnica, conforme mostrado na Figura 11. 


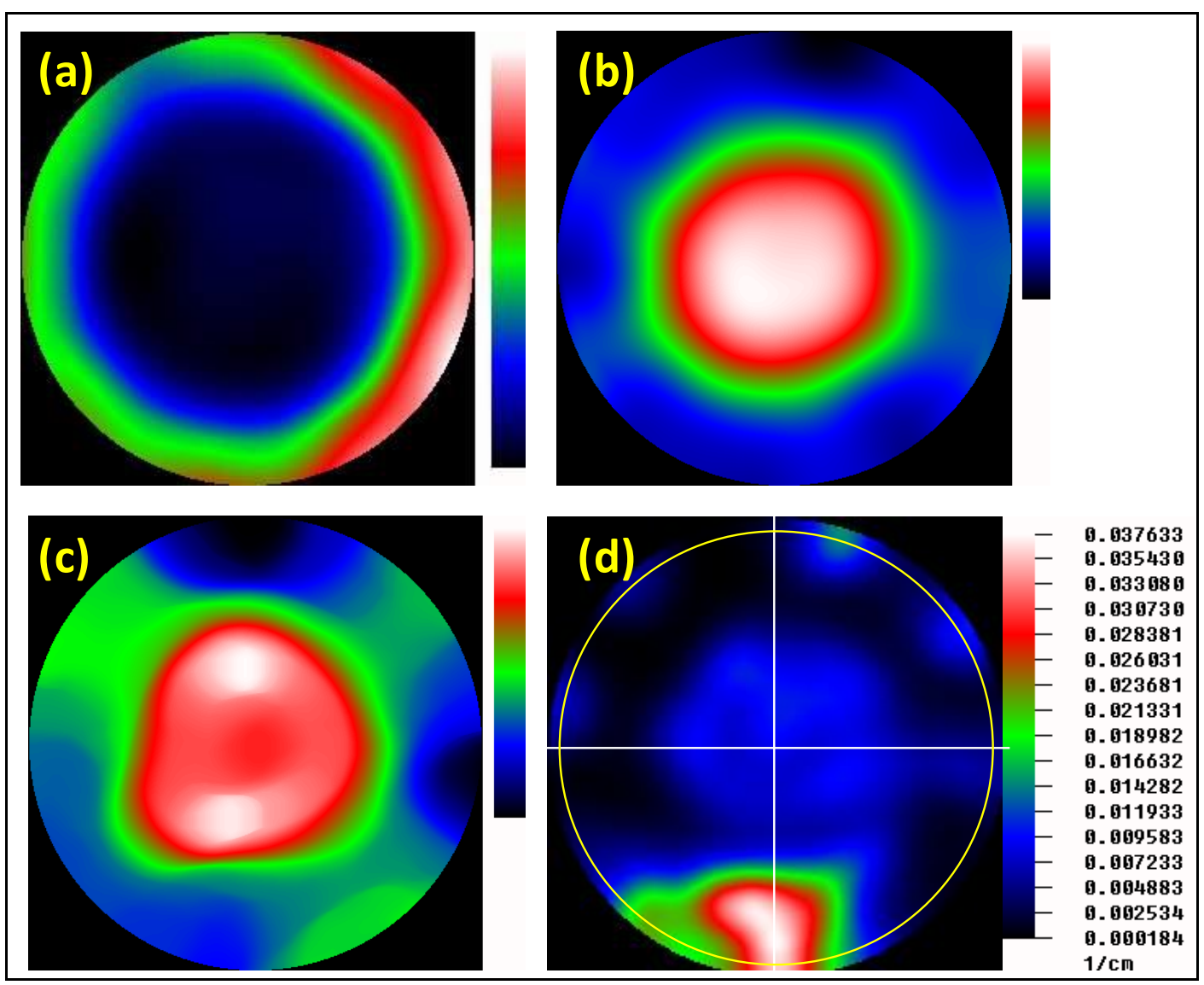

Figura 11 - Projetos desenvolvidos nas indústrias: (a) tubo de 6 polegadas com coque; (b) demister com obstrução; (c) trocador de calor de 1,2m de diâmetro e (d) linha de transferência de forno. As cores representam uma escala de valores das densidades relativas obtidas.

No desenvolvimento de um dos projetos criou-se o embrião do conceito de simulação de irradiações que permitiu a visualização de resultados e o ajuste dos parâmetros de reconstrução, mostrado na Figura 12. 


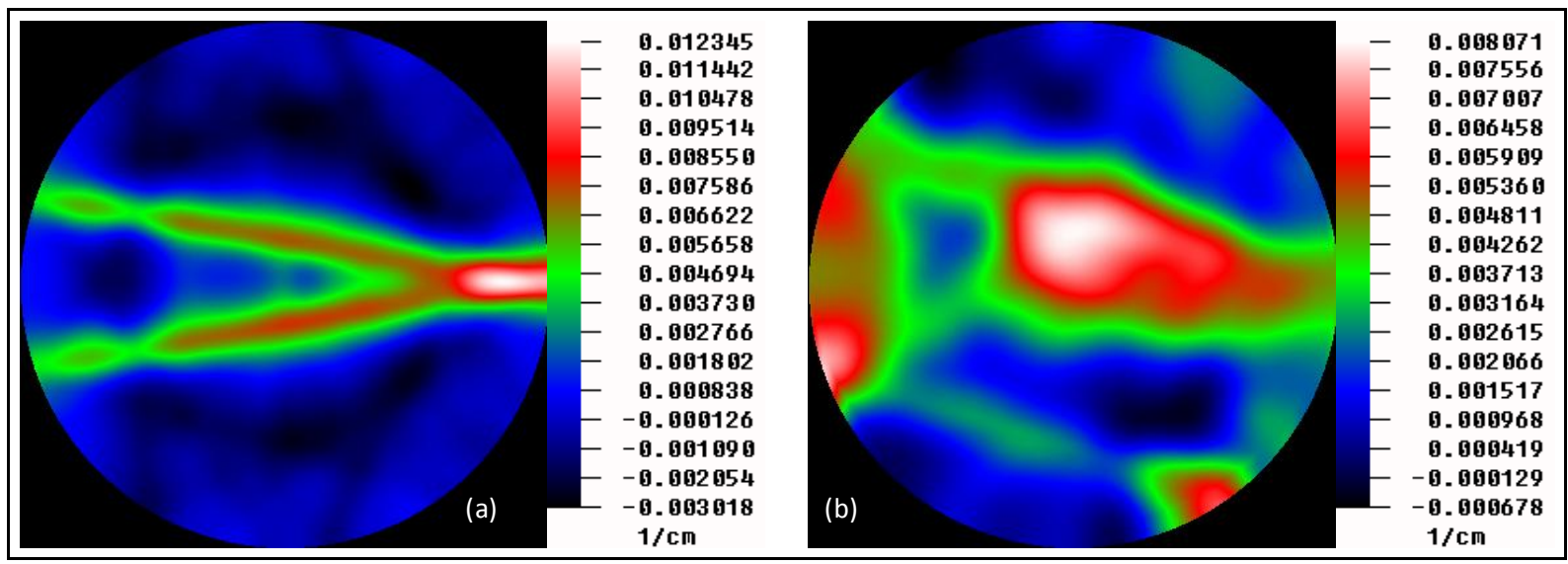

Figura 12 - Simulação de irradiações: imagem reconstruída por simulação (a) e imagem do objeto perfilado por raios gama com a presença de defeito (b).

A habilidade em simular experimentos abriu novas possibilidades de aprimoramento técnico ao permitir a comparação dos resultados obtidos por simulação, em diferentes posicionamentos das irradiações. Neste ponto surgiu também o conceito de utilizar resultados "a priori", que nada mais são do que proposições iniciais para as imagens a serem reconstruídas.

Atualmente, o projeto está em fase de automação, com a construção de dispositivos para tomografia de primeira e segunda gerações.

\subsection{IMAGEAMENTO DE EQUIPAMENTOS DE PROCESSOS INDUSTRIAIS}

O conhecimento obtido no trabalho científico com a EPUSP serviu de ponto de partida para este trabalho de Mestrado. O desenvolvimento do "Sistema de Imageamento de Equipamentos de Processos Industriais pela Técnica de Perfilagem por Raios Gama", realizado em parceria com a Escola Politécnica da Universidade de São Paulo (EPUSP) e o Centro de Tecnologia das Radiações (CTR), do IPENCNEN/SP, propõe obter a distribuição bidimensional de densidades num plano longitudinal do objeto. Pelo fato dos equipamentos de processos industriais terem um eixo longitudinal muitas vezes maior que suas outras dimensões (largura, profundidade ou diâmetro), a movimentação da fonte radioativa e do detector de 
radiação fica limitada nesta aplicação a um plano. Na Figura 13 é mostrado um modelo de implementação e simulação do possível resultado.
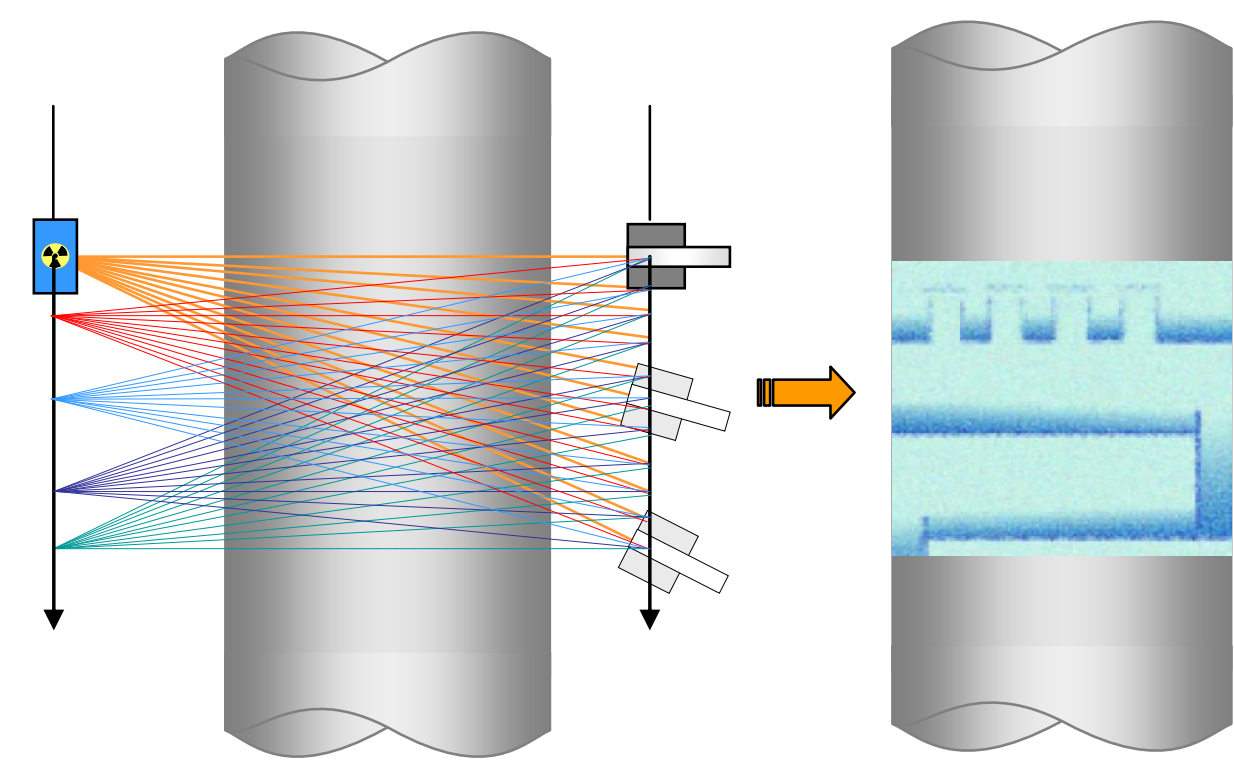

Figura 13 - Esquema geral e simulação do imageamento de um equipamento industrial pela técnica de perfilagem por raios gama.

Num primeiro momento, o imageamento possibilitará um avanço na tecnologia de ensaios não destrutivos (END) para equipamentos de processos industriais, por apresentar uma série de vantagens sobre a técnica convencional de perfilagem (column gamma scan):

- Dimensão - a distribuição bidimensional de densidades facilita a visualização e identificação dos problemas, processos e fenômenos em um equipamento;

- Posicionamento - ao adicionar mais uma dimensão ao resultado, reduzse a quantidade de posicionamentos necessários entre a fonte radioativa e o detector de radiação. Adicionalmente, feições que na tecnologia de perfilagem (column gamma scan) ficariam ocultas, pelos valores de densidade média, podem ser reveladas no imageamento. Do exposto, perfis de densidade ou equipamentos que antes não poderiam ser perfilados por radiação gama, passam a ter possibilidades de teste; e 
- Interpretação - o imageamento possui maior facilidade de apresentação e interpretação que o método tradicional de perfilagem (column gamma scan). Isto poderá resultar numa melhor aceitação deste desenvolvimento pelo mercado, bem como facilitar o treinamento de pessoal.

\subsection{INOVAÇÃO TECNOLÓGICA}

O conceito apresentado neste trabalho de Mestrado foi proposto pela primeira vez para a avaliação de equipamentos de processos industriais. Seu caráter inovador justificou um pedido de patente, em fase de depósito junto ao Instituto Nacional de Propriedade Industrial (INPI) e é fruto da parceria neste projeto da Tricom Tecnologia com a Escola Politécnica da Universidade de São Paulo (EPUSP) e o Centro de Tecnologia das Radiações (CTR), do IPEN-CNEN/SP. O depósito do pedido de patente junto ao INPI é apresentado no Apêndice 3. 


\section{MATERIAIS E MÉTODOS}

\subsection{MATERIAIS}

\subsubsection{Aparatos empregados}

Boa parte da infraestrutura laboratorial necessária ao desenvolvimento deste trabalho de Mestrado destinou-se aos experimentos de perfilagem por raios gama. $\mathrm{O}$ processo de irradiação e reconstrução das imagens foi realizado através da colaboração entre a Escola Politécnica da Universidade de São Paulo (EPUSP), o Centro de Tecnologia das Radiações (CTR), do IPEN-CNEN/SP e a Tricom Tecnologia, que forneceram os materiais, aparatos e aplicativos necessários, incluindo:

- Sistema de imageamento por raios gama;

- Protótipos das colunas de destilação (prato e recheio);

- Fonte radioativa selada de ${ }^{60} \mathrm{Co}$ com atividade de $17,945 \mathrm{MBq}(0,485 \mathrm{mCi})$, em maio/2012;

- Fonte radioativa selada de ${ }^{137} \mathrm{Cs}$ com $10 \mu \mathrm{Ci}(0,37 \mathrm{MBq})$ de atividade para calibração;

- Analisadores Monocanal Ludlum 2200 e sondas de $\mathrm{Nal}(\mathrm{Tl}) 1 \times 1$ polegada e 2x2 polegadas;

- Laptop para coleta de dados e Software ScanBoy para coleta automática de dados;

- Cabos de conexão, comunicação e alimentação elétrica; 
- Instalações radiativas para a realização dos testes experimentais;

- Softwares de reconstrução;

- Softwares de simulação;

- Webcam para monitoramento da elevação; e

- Talha mecânica para movimentação.

\subsubsection{Sistema de imageamento}

O protótipo do sistema de irradiação para imageamento foi concebido para simular a movimentação relativa proposta entre a fonte e do detector. O principal componente estrutural foi um pórtico aonde as colunas serviram também de guia para o movimento vertical do sistema. Um conjunto de furos igualmente espaçados nestas colunas permitiu mover os instrumentos em incrementos de $5 \mathrm{~cm}$.

Em cada coluna do pórtico foi montado um carro deslizante, cada qual com um suporte para receber o colimador da fonte radioativa e do detector cintilador. Para que os sistemas de colimação da fonte e do detector ficassem axialmente alinhados, uma barra de alinhamento estava rigidamente conectada aos eixos de rotação dos suportes, conforme mostrado nas Figuras 14 a 17. O sistema foi dimensionado para poder irradiar objetos com 1,9m de altura por 1,0m de largura e $0,5 \mathrm{~m}$ de profundidade. 


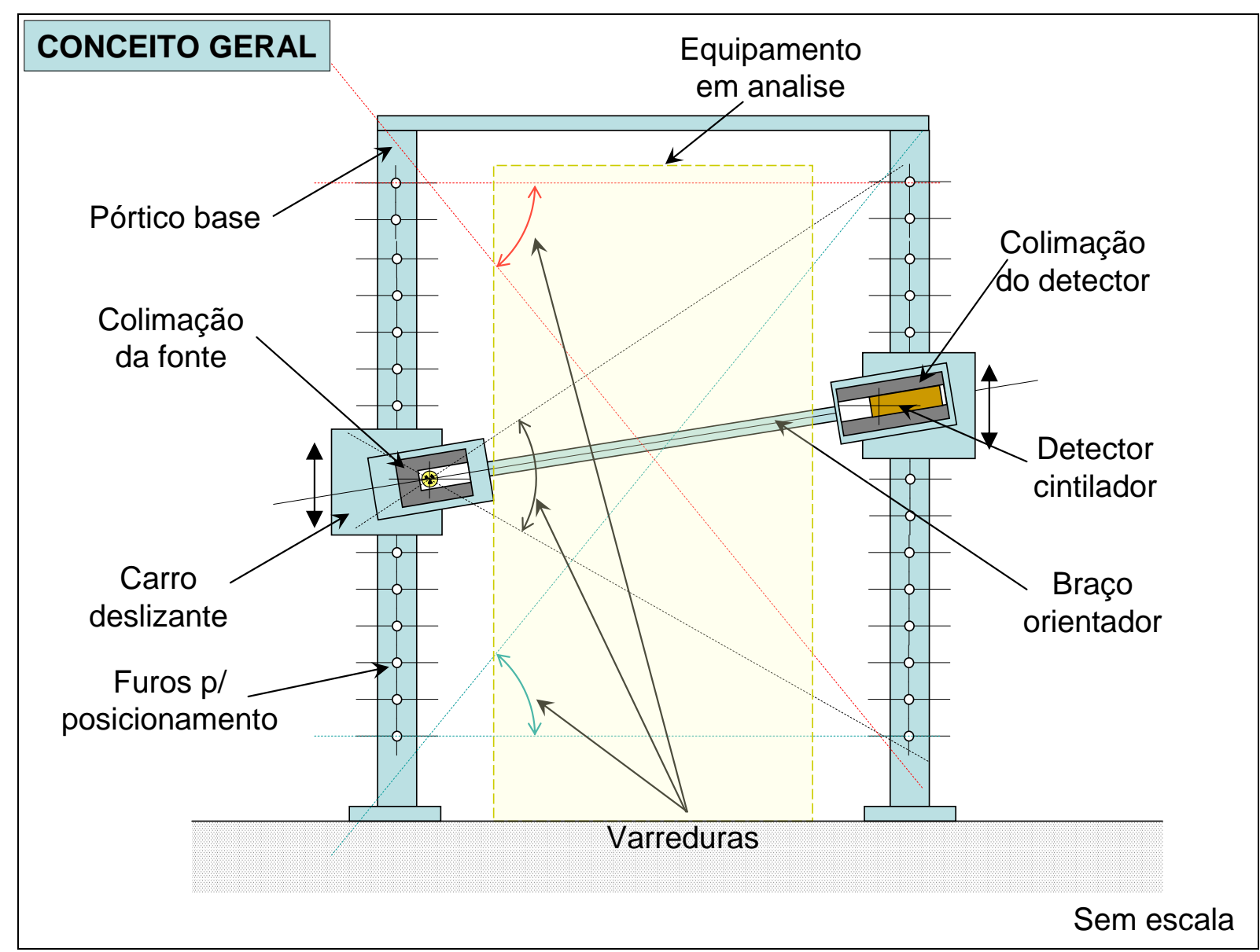

Figura 14 - Conceito de montagem geral do sistema de imageamento. 


\section{MATERIAIS E MÉTODOS - 24}

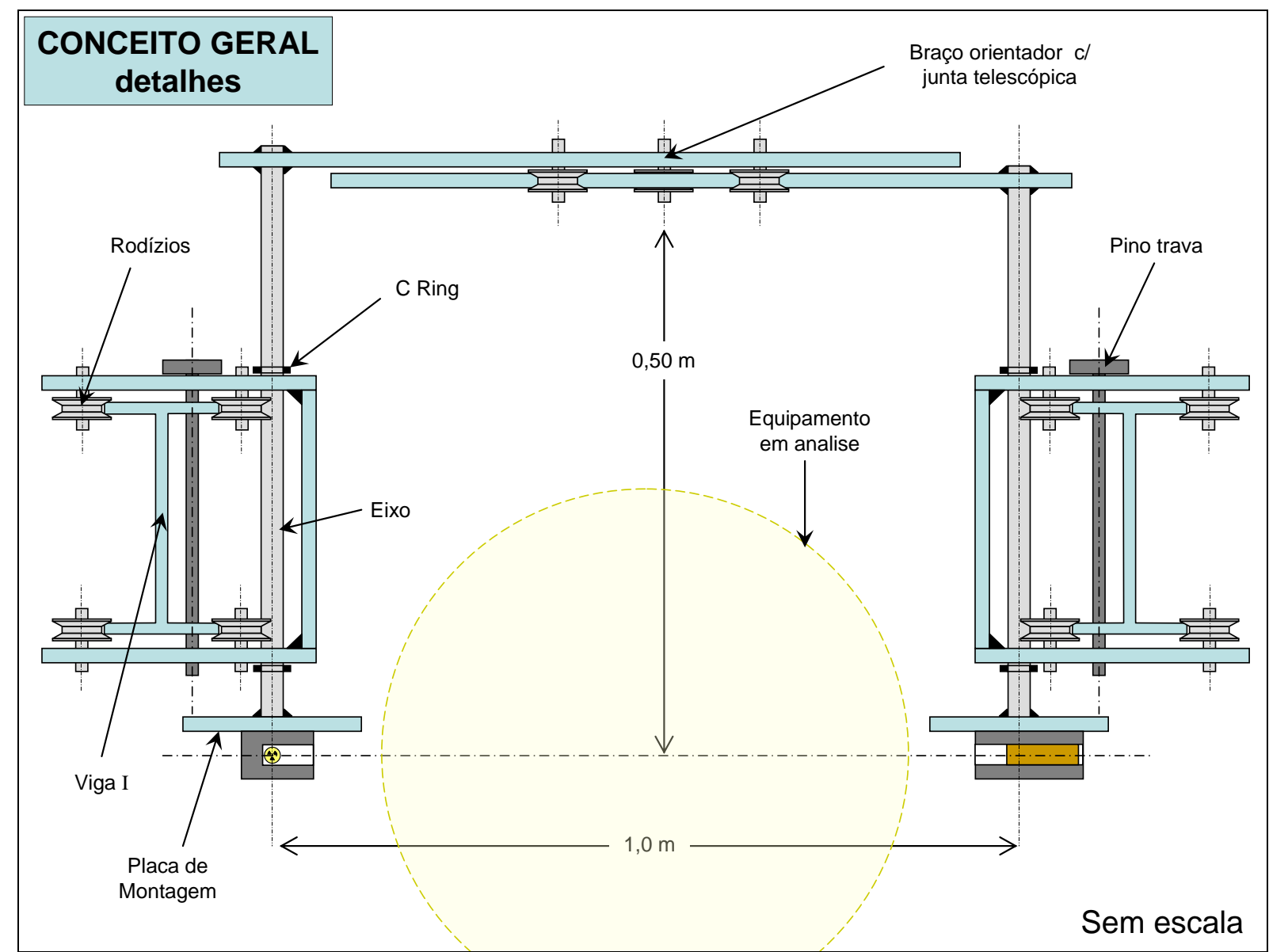

Figura 15 - Conceito de montagem e detalhes do sistema de imageamento.

Desenhos de conjunto do sistema de imageamento são apresentados no Apêndice 1. 


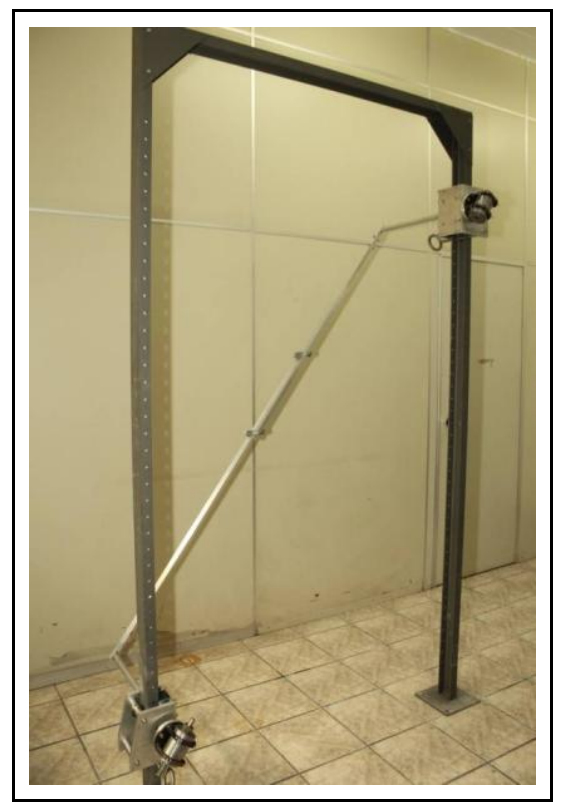

Figura 16 - Vista geral do pórtico e sistema de alinhamento fonte-detector de radiação.

A fonte radioativa selada de ${ }^{60} \mathrm{Co}$, com atividade de $17,945 \mathrm{MBq}(0,485 \mathrm{mCi})$ foi montada numa cápsula em aço inoxidável AISI 304, modelo X54 do IPEN-CNEN/SP, em maio/2012 e inserida num porta-fonte padrão da Tricom Tecnologia. As dimensões do porta-fonte facilitaram sua manipulação e visualização. Adicionalmente, a construção do tipo rosca com pino trava aumentou também a segurança física do sistema, dificultando uma perda acidental. O porta-fonte contou ainda com um sistema de trava de esfera, que o manteve numa posição fixa dentro do sistema colimador, impedindo também sua perda acidental, como mostrado na Figura 17a. O sistema colimador possuía abertura fixa de $10 \mathrm{~mm}$, conforme mostrado naFigura17b. 


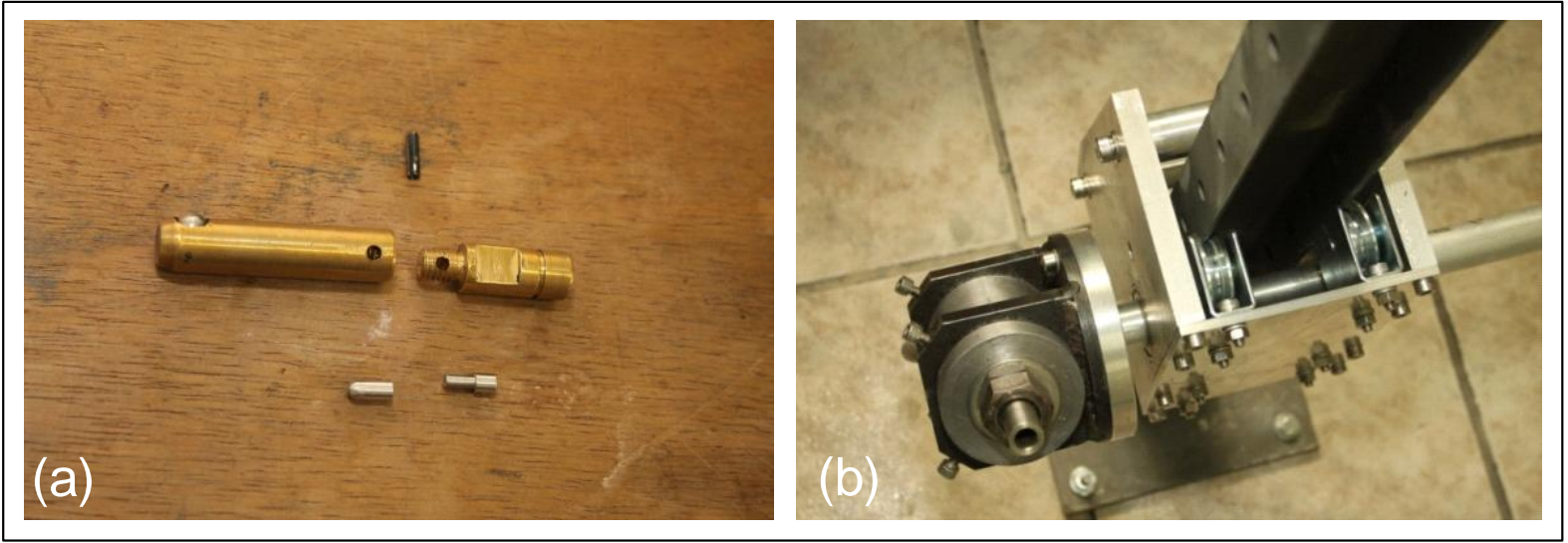

Figura 17 - Detalhe de montagem da fonte radioativa no porta-fonte (a) e detalhe do sistema colimador da fonte selada (b).

O sistema de colimação do detector de radiação $[\mathrm{Nal}(\mathrm{TI})]$ empregou janelas de 1/2, 1 ou 2 polegadas, como mostrado na Figura 18.

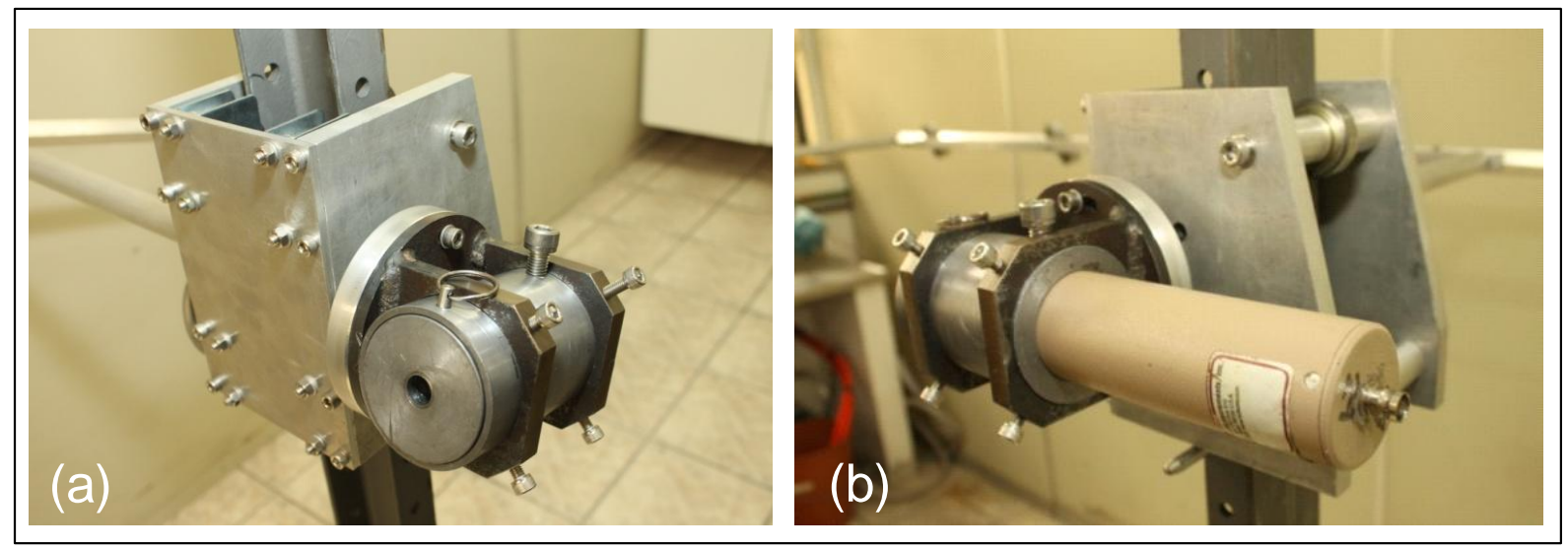

Figura 18 - Detalhe do carro deslizante e colimador do detector de 1 polegada (a) e detector de radiação [Nal(TI)] de 1 polegada, montado no colimador (b).

O sistema original de posicionamento do detector de radiação foi modificado para incluir uma talha para movimentação manual do carrinho e uma webcam para visualizar remotamente sua posição (precisão $\pm 1 \mathrm{~mm}$ ), facilitando bastante a tomada de dados, como mostrado na Figura 19. 


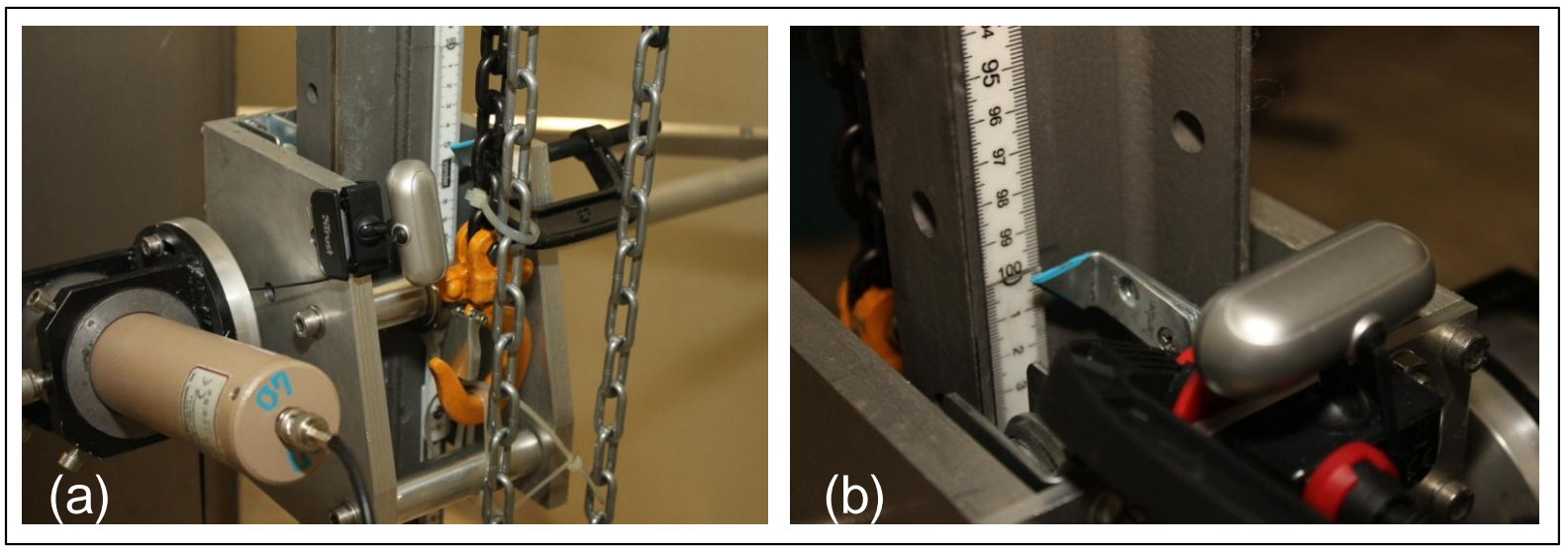

Figura 19 - Talha para movimentação do carro deslizante (a) e detalhe da webcam empregada para a leitura da posição (b).

\subsubsection{Escolha do radioisótopo}

A escolha do radioisótopo empregado foi uma das partes mais importantes do projeto, e provavelmente uma das primeiras definições que devem ser feitas. No projeto de medidores nucleares de densidade, um dos parâmetros comumente considerados é o de escolher uma fonte específica para um meio de tal forma que o produto $\mu x$ seja o mais próximo de 2 , como demonstrado por JOHANSEN, G. A. e JACKSON, P. em Radioisotope Gauges For Industrial Process Measurements [20]. Todavia, neste projeto a ampla variação dos valores de $\mu$ s e das dimensões das colunas, nos forçou a analisar os parâmetros de forma separada. Os principais parâmetros envolvidos na escolha incluíram:

- Energia e partícula - numa aplicação industrial, o tamanho dos equipamentos analisados limita o alcance das partículas no meio. Para o caso específico de sistemas de perfilagem, a escolha limita se aos raios gama de maior energia e intensidade. A escolha da energia dita o projeto de colimação e blindagem, o tipo e tamanho dos detectores empregados e, por conseguinte, as taxas de contagem e tempo de resposta obtido. Usualmente pode se considerar o uso de alguma fonte radioativa de menor energia $\left({ }^{137} \mathrm{Cs}-0,662 \mathrm{MeV}\right)$ para sistemas menores, de maior energia $\left({ }^{60} \mathrm{Co}-1,173 \mathrm{MeV}\right.$ e $\left.1,332 \mathrm{MeV}\right)$ para sistemas de tamanho médio ou grande. Equipamentos de grande porte e espessuras podem ser até analisados com fontes de maior energia ainda $\left({ }^{24} \mathrm{Na}-1,369 \mathrm{MeV}\right.$ e $2,754 \mathrm{MeV})$; 
- Atividade - escolhidos o radioisótopo e o sistema de medição ideal, pode se determinar a taxas máximas de contagem admissíveis para o projeto. Usualmente a taxa máxima indicará qual a menor distância fonte-detector ou atividade a ser empregado para um determinado arranjo. Limitações de tempo de contagem e estatística ditam, por outro lado, a menor fonte que pode ser empregada. Na prática industrial, normalmente dispõe se de fontes com atividades diferentes empregando se aquela que melhor se adéqua ao estudo;

- Meia-vida - neste tipo de aplicação, a meia-vida do radioisótopo está mais relacionada à diminuição da depreciação do investimento em fontes do que nos ajustes necessário para compensar a diminuição da atividade da fonte no transcorrer do ensaio;

- Custo - preço de aquisição, depreciação e o gerenciamento de resíduos tem impacto significativo na escolha da fonte. Gastos com frete, aduana, transporte, documentação aumentam o custo de aquisição. Fontes com elevada meia-vida apresentam pouca depreciação e são as principais alternativas para uso industrial. Fontes sólidas geram pouco ou quase nenhum resíduo que deve ser corretamente segregado, destinado ou descartado. A fabricação local e pronta disponibilidade para entrega de fontes é um item a ser considerado também;

- Tamanho - a fim de garantir um feixe estreito e otimizar o tamanho de blindagens, requere se que a fonte seja a menor possível. Fontes sólidas são aquelas que permitem a montagem mais compacta, pela ausência de sistemas de proteção física e contra vazamento; e

- Forma física - A forma física preferível é a solida como no ${ }^{60} \mathrm{Co}$, vindo os pós em segundo lugar, como no ${ }^{137} \mathrm{Cs}$. Líquidos e gases, requerem manipulação e cuidados especiais e não são adequadas a este tipo de trabalho. Fontes sólidas permitem a montagem de sistemas robustos e próprios para o ambiente industrial aonde impacto e intempéries, entre outras condições adversas, são comuns. 
Para este trabalho de Mestrado, optou-se por empregar uma fonte selada de ${ }^{60} \mathrm{Co}$ que pode ser irradiada e montada dentro das dependências do IPENCNEN/SP, apresentava bom poder de penetração para os modelos de colunas propostos, e apesar de não ser a fonte ideal para o cristal de $\varnothing 1$ "x1", tinha boa resposta para o detector de Ø2"x2" (o alcance dos fótons do ${ }^{60} \mathrm{Co}$ no $\mathrm{Nal}(\mathrm{TI}$ ) é de cerca de $5,3 \mathrm{~cm}$ ). Devido à pequena dimensão do conjunto fonte radioativa-carrinhocolimador ficou bastante robusto, compacto e fácil de movimentar.

\subsubsection{Sistema de aquisição de dados}

Mesmo sem dispor de um mecanismo totalmente automático para a movimentação e tomada de dados, o uso da webcam e da talha permitiu que quase toda operação do protótipo fosse feita de uma posição fixa, diminuindo bastante o deslocamento e esforço físico do operador para movimentar o sistema. O carro da fonte ainda foi posicionado manualmente. Dessa forma pode-se empregar o software para escaneamento ScanBoy para comandar o analisador monocanal Ludlum 2200 de forma automática, uma vez que o deslocamento do carrinho do detector pode ser feito num intervalo de tempo entre 3 a 6 segundos.

O sistema para coleta de dados foi bastante simples, consistindo de um detector de radiação [ $\mathrm{Nal}(\mathrm{TI})$ ] de 1 ou 2 polegadas conectado por cabo coaxial a um analisador multicanal Ludlum 2200 que, por sua vez, comunicava-se com o software para escaneamento ScanBoy por meio de uma interface USB-serial. Uma webcam instalada no carrinho do detector monitorava uma escala métrica fixa, indicando a elevação exata do carrinho. Complementando, numa planilha MS-Excel uma tabela indicava os pontos iniciais e finais de escaneamento para cada posição da fonte. $\mathrm{Na}$ Figura 20 é mostrado um diagrama de blocos da montagem e a Figura 21 uma tela típica com os diversos programas abertos durante o escaneamento e uma visão geral da montagem do sistema. 


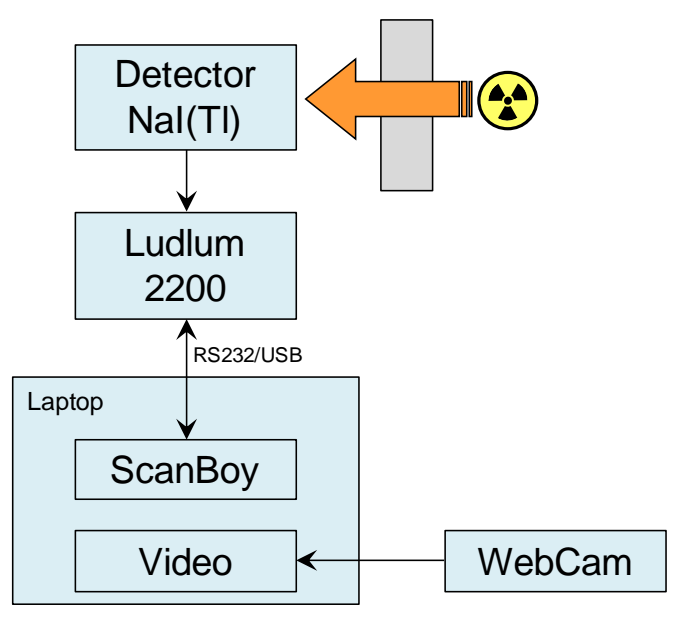

Figura 20 - Diagrama de blocos do layout dos instrumentos de medida.

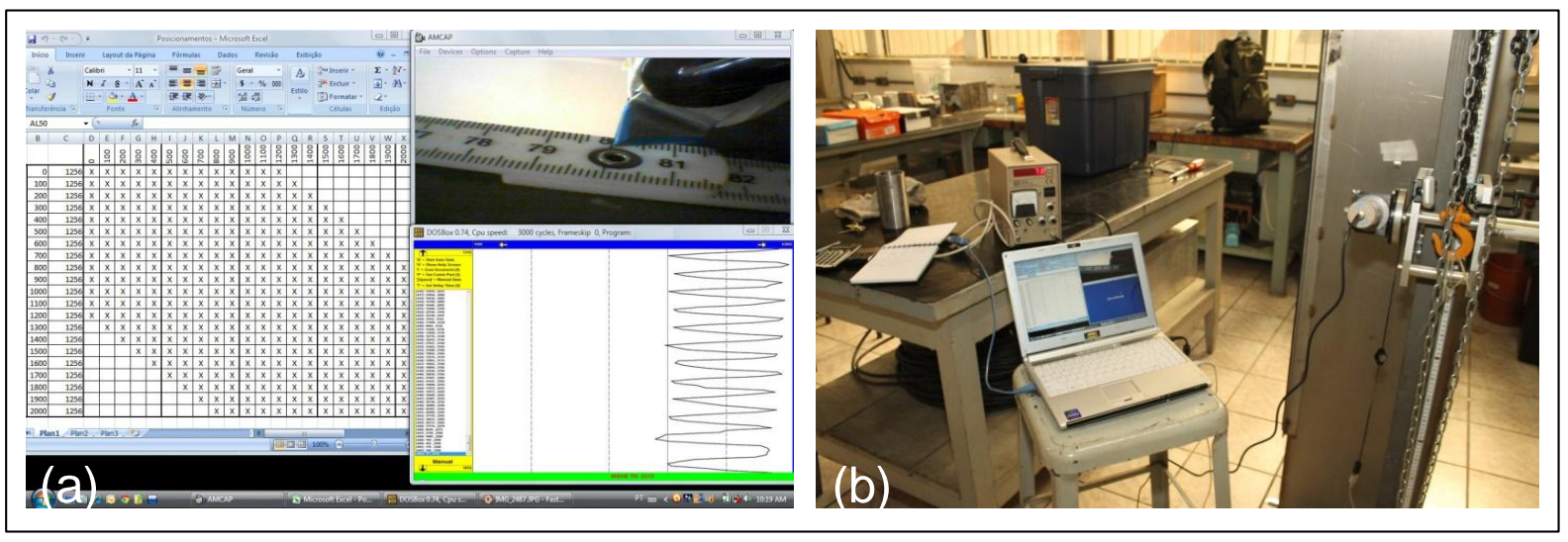

Figura 21 - Tela do laptop durante coleta de dados (a) e vista geral do dos instrumentos e arranjo eletrônico (b), para coleta dos dados experimentais no laboratório.

\subsubsection{Modelos de coluna de destilação}

Dois modelos de colunas de destilação foram projetados de modo a abranger ambos os tipos de configurações de internos de processo comumente encontrados na indústria: pratos e recheio como podem ser visto na Figura 22. Cada tipo de tem características próprias que o sistema de imageamento deve visualizar como posicionamento de internos e nível de líquido nos pratos e distribuição de líquido no caso de recheio. 


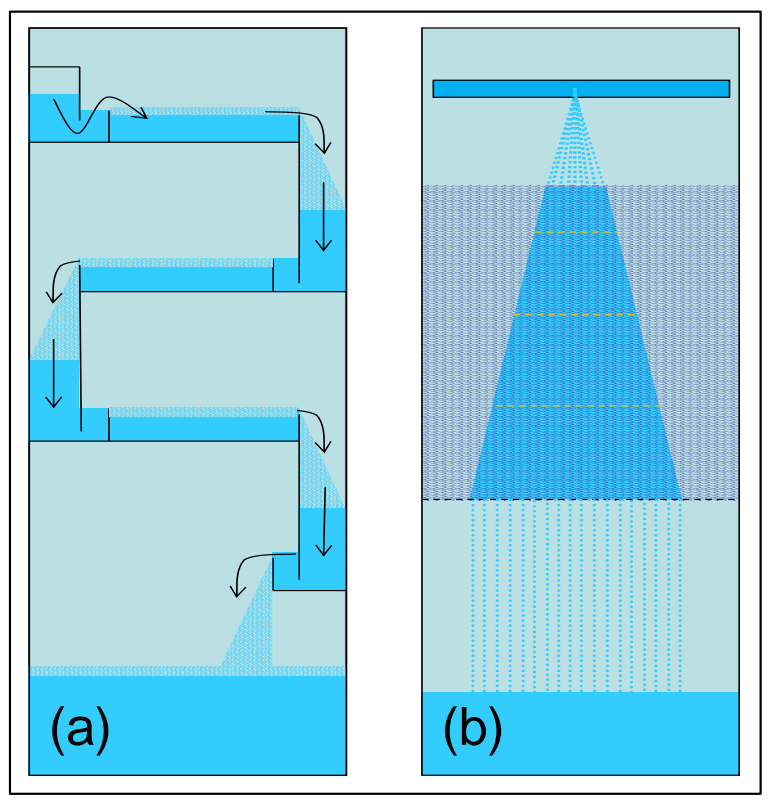

Figura 22 - Esquema da coluna de pratos (a) e coluna com recheio (b).

Numa primeira etapa, montou-se um sistema contendo três pratos de um passe com vertedores e nível de fundo como mostrado na Figura 23. Os pratos e vertedores foram construídos de forma a sustentar diferentes níveis de líquido para simular o carregamento hidráulico típico de uma coluna.

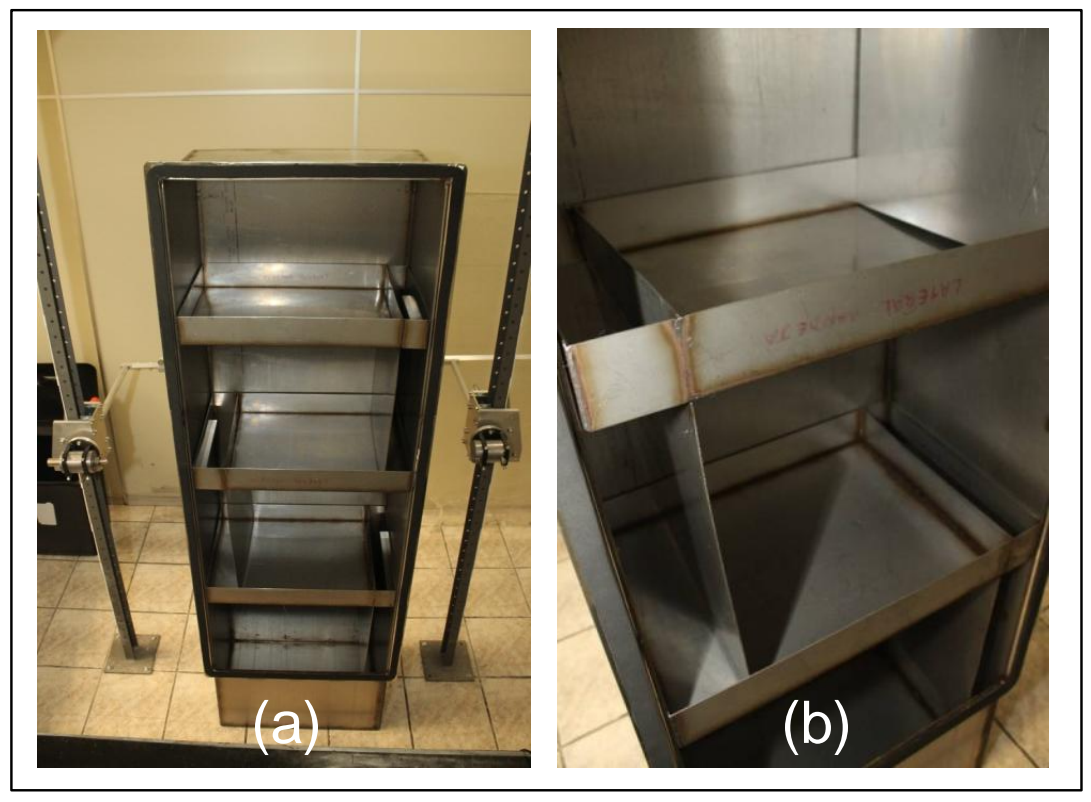

Figura 23 - Modelo de coluna de pratos (a) e detalhes dos pratos e vertedores (b).

A seguir montou-se um modelo de coluna equipada com recheio de anéis de PVC, simulando um leito com severa má distribuição de líquido, vazios e irregularidade na altura de recheio como mostrada na Figura 24. 

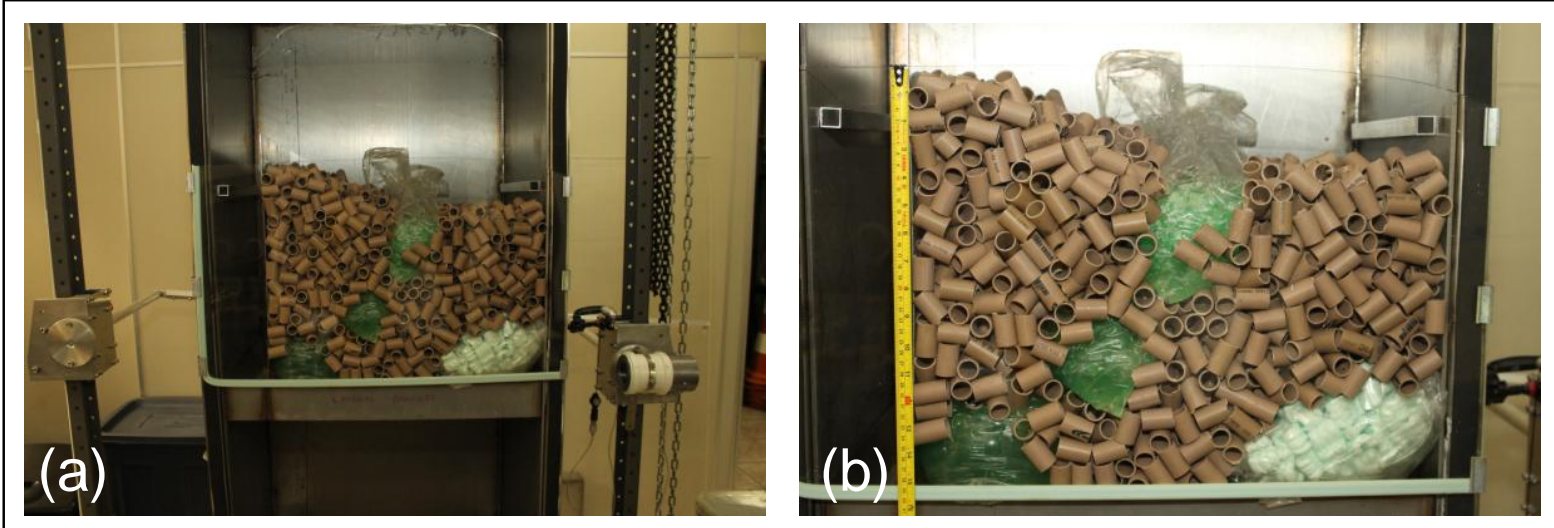

Figura 24 - Modelo (a) e detalhe da distribuição (b) de coluna de recheio

\subsubsection{Metodologia de calibração e verificação}

A parceria científica Tricom Tecnologia e EPUSP no projeto de tomografia industrial foi importante como ponto de partida para definir uma metodologia e procedimentos práticos de calibração e detecção da radiação que permitiam:

- Calibrar os instrumentos para máxima eficiência de leitura;

- Ajustar a energia de corte para efetuar colimação eletrônica, já que o medidor Ludlum 2200 é monocanal;

- Determinar a eficiência $(\varepsilon)$ do sistema de medição;

- Verificar a linearidade das medidas;

- Comparar valores medidos com atenuação do meio; e

- Verificar efeitos de saturação.

\subsubsection{Contagem da radiação ionizante}

A Figura 25 ilustra um arranjo fonte radioativa-detector de radiação, nos quais consideramos as seguintes variáveis:

- A - atividade da fonte em Bequereis [1/s]; 
- $\mathrm{f}$ - produto fator de ramificação (branching factor) com razão de ramificação (branching ratio) do radioisótopo $\left(0,85\right.$ para ${ }^{137} \mathrm{Cs}$ e 2 para $\left.{ }^{60} \mathrm{Co}\right)$;

- $r$ - distância fonte-detector [cm], tomadas de seus centros geométricos, considerando aqui que "r" é muito maior que as dimensões da fonte e do cristal do detector;

- D - diâmetro do detector de radiação [cm];

- $\mu \mathrm{s}$ - coeficientes de atenuação linear $[1 / \mathrm{cm}]$ dos meios (invólucros da fonte e detector, ar, do cristal de $\mathrm{Nal}(\mathrm{TI})$ e dos absorvedores);

- M1 - Atenuação dos invólucros e do ar, Equação 2;

$$
M 1=e^{\left(-\mu_{a r} \cdot x_{a r}-\mu_{i-\text { fone }} \cdot x_{i-\text { fonte }}-\mu_{i} \text { detectoro } \cdot x_{i-\text { decector }}\right)}
$$

- M2 - Absorção do cristal de Nal(TI), Equação 3;

$$
M 2=1-e^{\left(-\mu_{\text {Nal }(T)} \cdot x_{\text {Nal }(T)}\right)}
$$

- G - Eficiência geométrica do arranjo, definido como a área frontal do detector de diâmetro "D" dividido pela área da esfera de raio "r", Equação $4 ; \mathrm{e}$

$$
G=\frac{\pi \cdot D^{2} / 4}{4 \cdot \pi \cdot r^{2}}
$$

- $\varepsilon$ - Eficiência geral do fotomultiplicador e sistema de contagem.

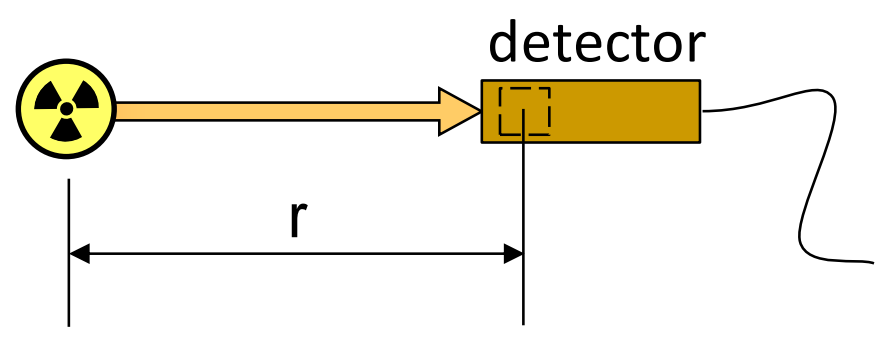

Figura 25 - Arranjo com fonte de atividade "A", a uma distância "d" do centro do cristal de um detector de radiação. 
A taxa de contagem obtida no cristal num dado arranjo fonte radioativadetector de radiação, com as características mostradas, pode ser estimada pela Equação 5:

$$
C=\frac{A \cdot f}{r^{2}} \cdot M 1 \cdot M 2 \cdot G
$$

Assim, a intensidade de radiação medida pode ser obtida conhecendo-se 0 valor da eficiência geral do sistema de medição, conforme Equação 6:

$$
I_{0}=C \cdot \varepsilon
$$

Devido às diferenças de eficiência entre detectores e sistemas de contagem, o valor da eficiência geral " $\varepsilon$ " varia e, na prática, deve ser determinado experimentalmente. Um dos métodos trata de tomar contagens de radiação em função da distância no ar e calcular o fator de multiplicação entre uma curva ajustada que representa os dados medidos e os valores de " $\mathrm{C}$ ", como mostrado na Figura 26.

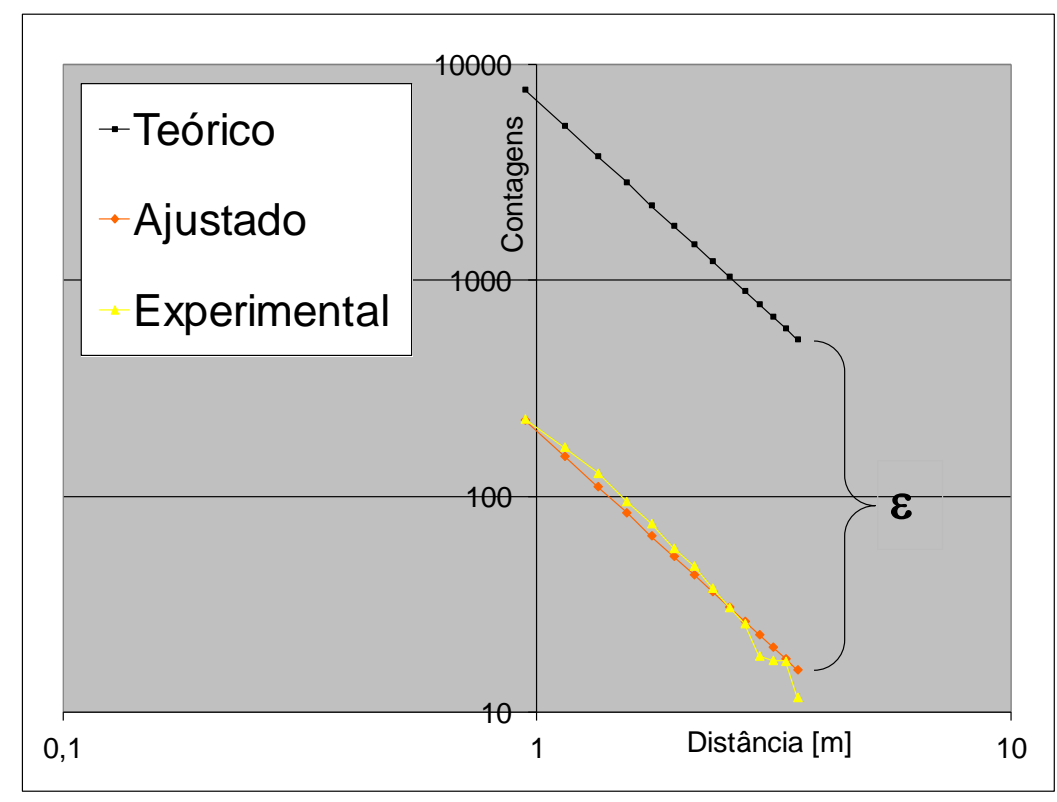

Figura 26 - Determinação experimental da eficiência geral " $\varepsilon$ ".

Conhecido o valor da eficiência geral de um sistema de medição, as contagens obervadas em outras medições foram empregadas para calcular 0 coeficiente de atenuação linear do meio ou a sua densidade, conforme a Equação 7 , ou equação de Beer-Lambert: 


$$
I=I_{0} \cdot \mathrm{e}^{-\mu \cdot x}
$$

Graficamente, isso pode ser visualizado na Figura 27. O fator de multiplicação entre o valor ajustado $\left(I_{0}\right)$ e o atenuado (I) advém da atenuação do meio.

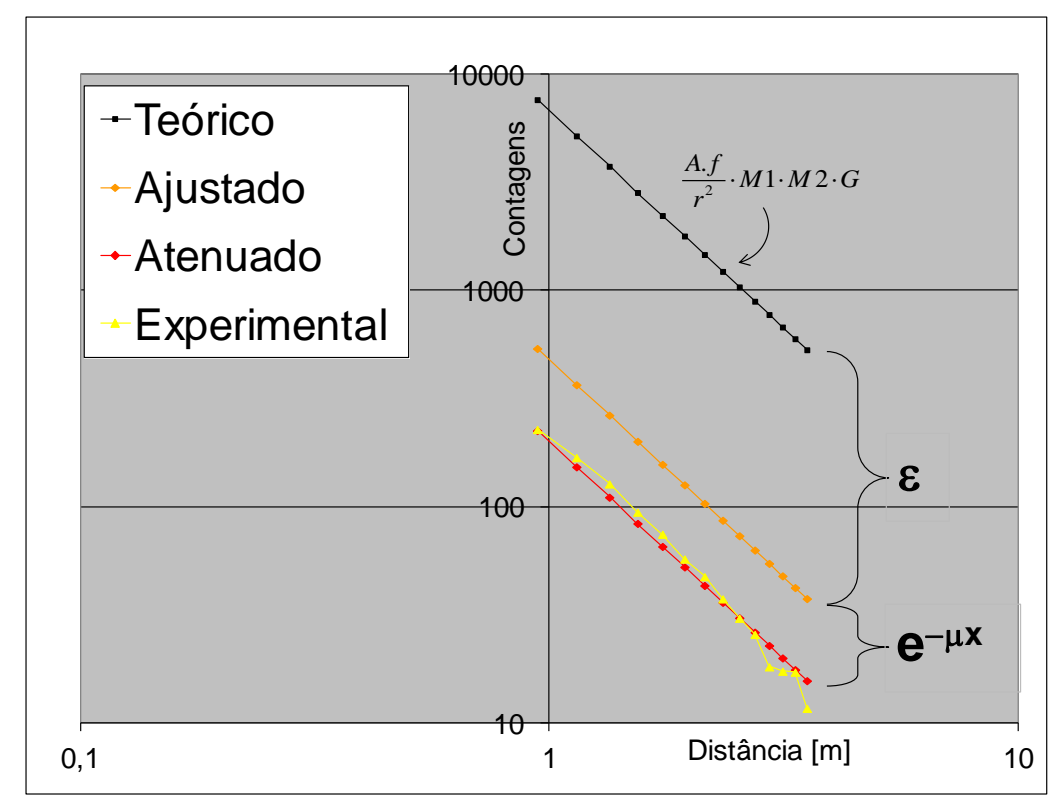

Figura 27 - Atenuação causada por um meio de espessura "x" e coeficiente de atenuação linear " $\mu$ ".

\subsubsection{Espectro de energia}

O espectro de energia dos radioisótopos é discreto, ou seja, tem energias definidas. Ao atravessar diferentes meios, interagindo de diferentes formas, até ser detectado e contado, ele vai tornando-se difuso. Adicionando o efeito da radiação de fundo e de ruídos eletrônicos, o espectro original deixa de ter picos isolados e passa a ter a forma de uma curva. Características intrínsecas do sistema de medição, tal como a resolução de energia, ditam também o formato do espectro obervado por um detector, como é mostrado na Figura 28.

Para o cálculo de densidades, a área em destaque, abaixo do fotopico do ${ }^{137} \mathrm{Cs}$, corresponde às contagens de radiação que se desejam medir. Esta é definida por dois parâmetros de calibração: a energia de corte (threshold) e a largura de janela (window). Parte do trabalho de ajuste de calibração consiste em encontrar seus valores ótimos para que a variação desta área, decorrente dos materiais 
absorvedores, corresponda aos valores calculados da atenuação exponencial de " $\mu \mathrm{x}$ ".

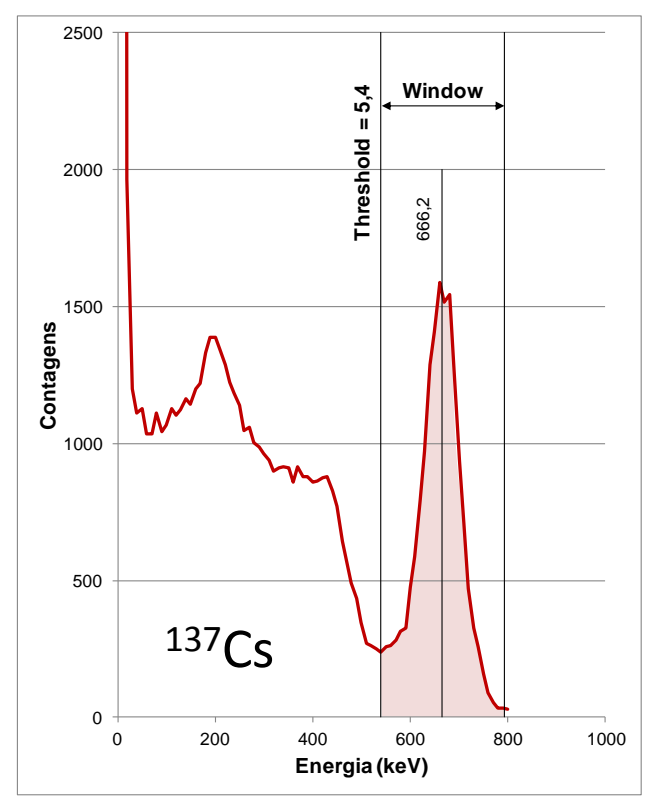

Figura 28 - Espectro obtido com um detector de radiação [Nal(TI)] de 1 polegada.

\subsubsection{Verificação de saturação}

Numa instalação radioativa, normalmente o inventário de fontes é limitado, de forma que nem sempre está disponível a fonte mais adequada para um ensaio. Como a distância fonte radioativa-detector de radiação mínima está determinada pelo equipamento sendo inspecionado, não há usualmente muita margem de manobra com essa variável, seja por questões de acesso ou obstruções aos instrumentos. Desta forma, muitas vezes, a fonte disponível para um determinado arranjo tem atividade alta o suficiente para saturar a saída do detector.

A saturação de uma fotomultiplicadora acoplada a um cristal de $\mathrm{Nal}(\mathrm{TI})$ ocorre quando a quantidade de fótons oriundos do cristal chegando à fotomultiplicadora é tão grande, que ocorre um curto circuito nos dipolos, reduzindo a alta tensão aplicada e resultando, por fim, numa queda das contagens registradas e perda da linearidade de resposta. Fotomultiplicadoras de menor diâmetro tem maior propensão à saturação.

Para detectar o inicio da saturação e determinar a sua distância, o melhor teste consiste em analisar graficamente contagens no ar a diferentes distâncias. $\mathrm{Na}$ 
Figura 29 são mostrados os resultados de um sistema em saturação, num gráfico em escalas logarítmicas. O efeito da saturação é mais evidente para energias de corte maior, justamente as que são empregadas para testes de tomografia. Para a perfilagem, que trabalha com limiar menor e, portanto, resulta em maiores contagens, a perda de linearidade é menos sentida e o limite à saturação é maior. Para definir a distância mínima, pode-se definir uma variação de inclinação máxima permissível, ou o ponto a partir do qual o ajuste de reta tem um erro mínimo permissível.

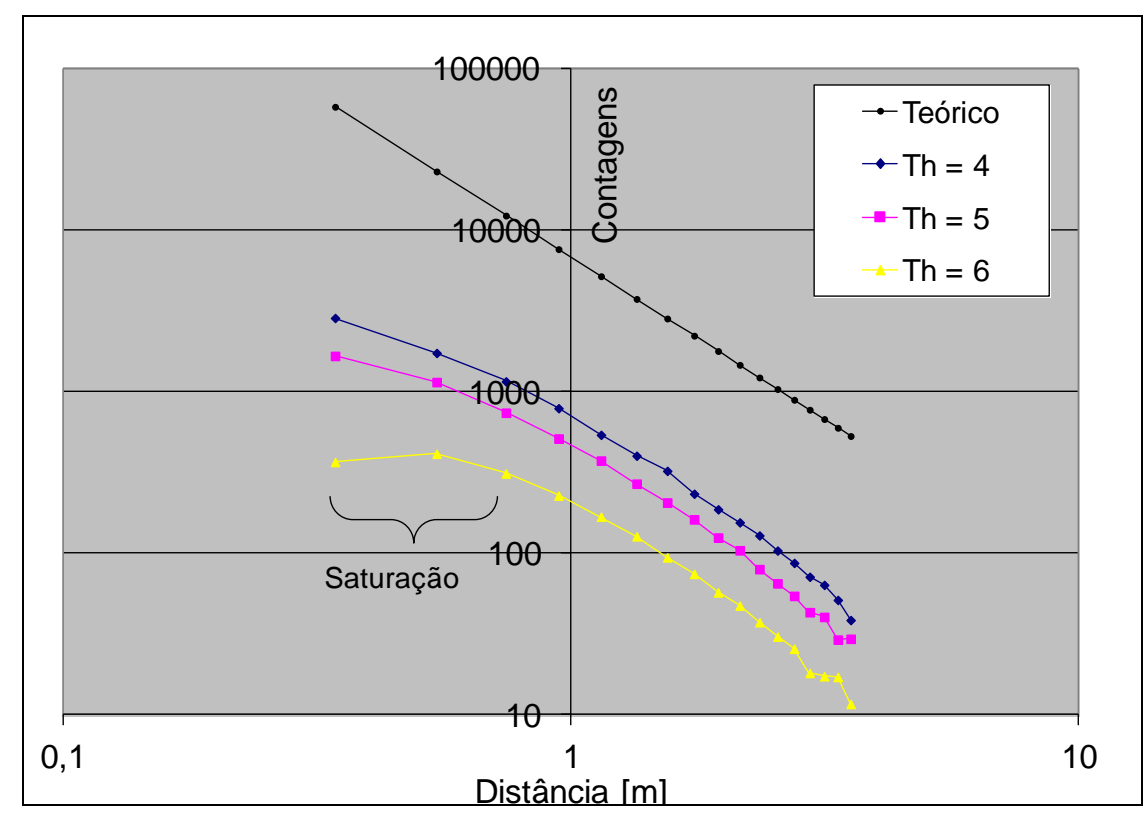

Figura 29 - Efeitos da saturação nas contagens, em escalas logarítmicas (Th: Threshold).

Detectada a distância mínima que um conjunto fonte-detector pode trabalhar, procura se trabalhar a maiores distâncias ou empregando alguma forma de atenuação na fonte radioativa ou colimação no detector de radiação.

\subsubsection{Calibração para perfilagem de colunas}

A calibração para perfilagem gama procura maximizar as contagens obtidas. Como seu foco não é o de determinar o valor das densidades absolutas, mas sim observar o comportamento da densidade relativa, através da variação de contagens, sua calibração envolve o uso de energias de corte baixas a depender do meio que está sendo analisado, como mostrado na Figura 30. Os primeiros testes com sistemas de tomografia foram feitos, empregando-se esta calibração. Todavia, não 
se recomenda empregar este tipo de calibração para tomografias, por gerarem imagens sem definição de borda.

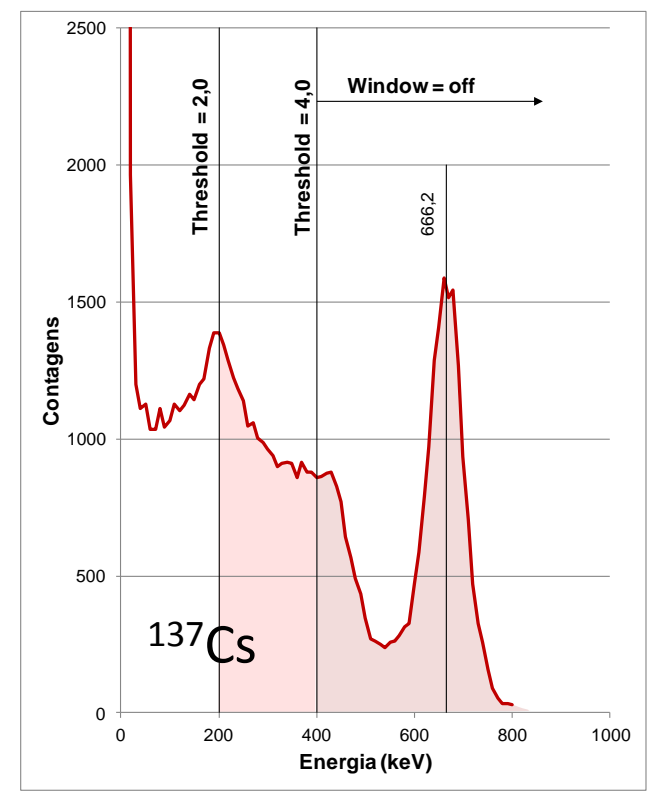

Figura 30 - Calibração para perfilagem por raios gama.

\subsubsection{Calibração padrão para tomografia industrial}

No método anterior, com o fotopico do ${ }^{137} \mathrm{Cs}$ na marca de 6,62, os fotopicos do ${ }^{60} \mathrm{Co}$ posicionavam-se fora da escala do dial, que vai até 10 apenas. Para melhorar a qualidade da imagem e já limitando o espectro de energia medido, convencionou-se neste método calibrar o sistema com o fotopico do ${ }^{137} \mathrm{Cs}$, na marca de 4,7 no dial do threshold. Com isto, os fotopicos do ${ }^{60} \mathrm{Co}$ podiam ser vistos no espectro de energia gerados para o detector de radiação [Nal(TI)] de 2 polegadas, mostrados na Figura 31(a). 

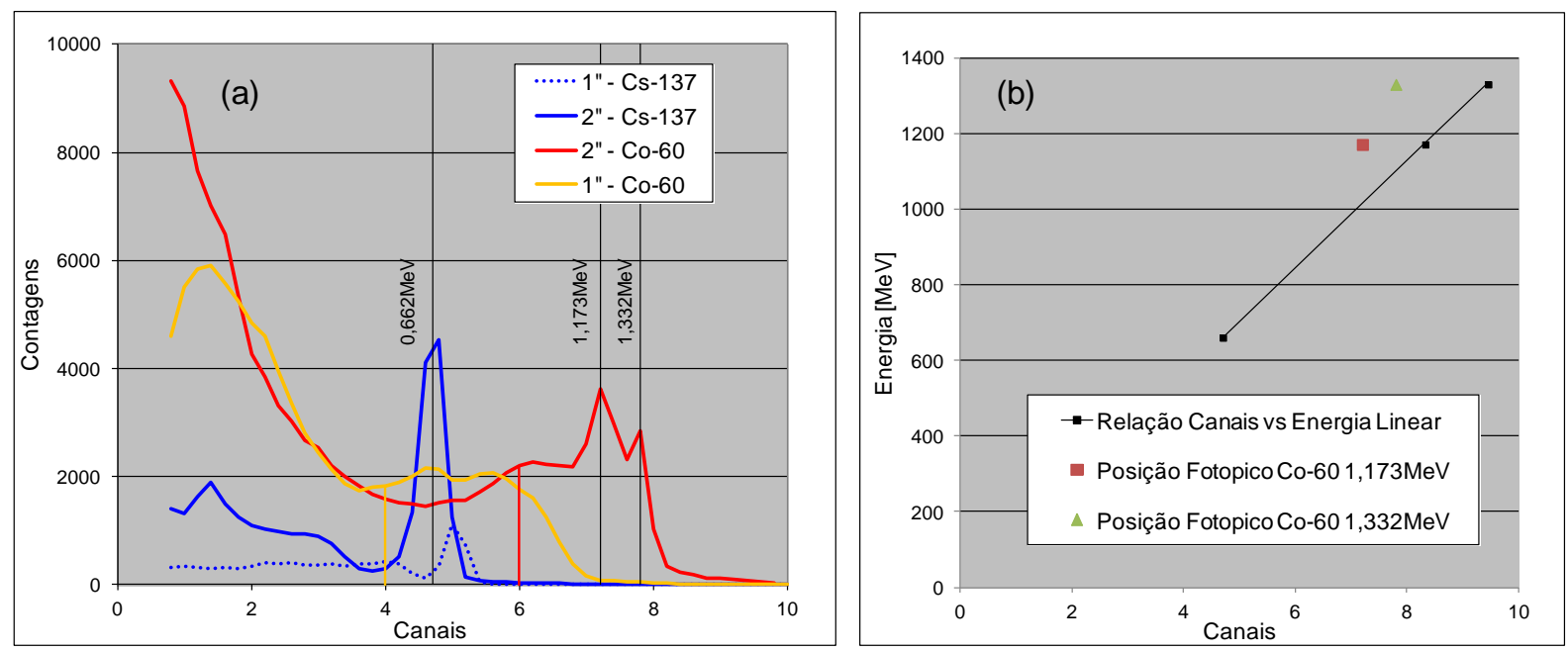

Figura 31 - Primeira proposta de calibração para sistemas tomográficos $\left({ }^{137} \mathrm{Cs}\right.$ e $\left.{ }^{60} \mathrm{Co}\right)$.

As energias de corte para o detector de radiação $[\mathrm{Nal}(\mathrm{TI})]$ de 1 polegada foram definidas em $\mathrm{Th}=4(568 \mathrm{keV})$ e para o detector de 2 polegadas em $\mathrm{Th}=6$ $(848 \mathrm{keV})$. Apesar dos valores reconstruídos dos " $\mu \mathrm{s}$ " não serem precisos, a diferença relativa dos valores era satisfatória e as imagens geradas com detectores de 1 e 2 polegadas similares, provavelmente, porque as áreas sob os espectros delimitadas pelos valores de threshold eram similares. O método não apresenta correspondência das energias dos fotopicos do ${ }^{60} \mathrm{Co}$ com os canais de energia esperados (linearidade) como é observado na Figura 31(b) aonde os picos aparecem em canais ligeiramente menores.

\subsubsection{Calibração otimizada para tomografia industrial}

Para contornar as limitações impostas pelo método de calibração anterior melhorando, consequentemente, os valores dos " $\mu s$ " reconstruídos, alguns estudos sobre as influencias das variáveis de calibração foram efetuados, de modo que uma nova sistemática de calibração foi proposta. Com o fotopico do ${ }^{137} \mathrm{Cs}$ posicionado na marca de 3,33 do dial do threshold, obtemos uma resposta energética bastante linear para o espectro do ${ }^{60} \mathrm{Co}$, quando medido tanto como detectores de radiação [Nal(TI)] 1 ou 2 polegadas, como mostrado na Figura 32. A energia de corte foi ajustada em 1.080keV (Th=5,4), logo antes do primeiro fotopico. Para comparação, a energia de corte da calibração anterior também é mostrada na Figura 32 (linha 
azul), donde se depreende que o sistema novo restringe ainda mais a faixa de energia medidas.
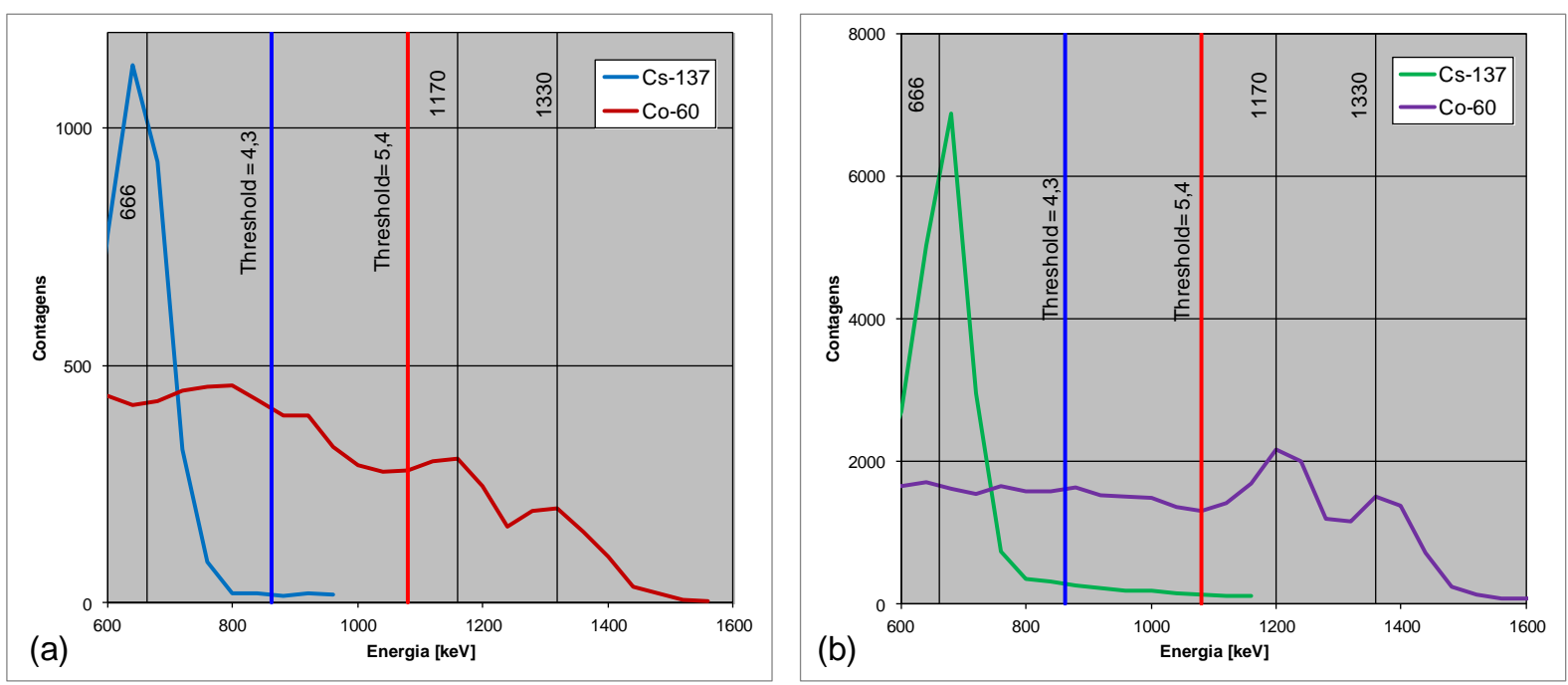

Figura 32 - Espectros de energia do ${ }^{137} \mathrm{Cs}$ e ${ }^{60} \mathrm{Co}$ na calibração otimizada, para detectores de radiação [Nal(TI)] de 1 polegada (a) e 2 polegadas (b).

\subsubsection{Colimação eletrônica}

A colimação eletrônica emprega o sistema de limiar (threshold) e janela (window) dos analisadores monocanal de forma que apenas uma parte do espectro de energia seja medida. Trata-se de uma ótima opção para tornar o sistema de imageamento leve e compacto, permitindo seu desenvolvimento para uso industrial. Kim, J. et al, em Industrial Gamma-Ray Topographic Scan Method For Large Scale Industrial Plants ${ }^{[23]}$ compara a qualidade da imagem reconstruída com o uso de dados obtidos em todo o espectro e apenas sob o fotopico. A colimação eletrônica, ainda que resulte em dados com maior variação, apresenta melhor resultado. $O$ uso de colimação eletrônica permite que a blindagem requerida nos instrumentos seja menor, em geral, o suficiente para atender os critérios de radioproteção. Um sistema mais leve permitiria maior flexibilidade de construção, movimentação e possível automação do protótipo.

\subsubsection{Estatística de contagem}

A fim de se conseguirem os melhores resultados, os dados obtidos devem satisfazer alguns critérios: 
- Relação contagem / background (BG) e

- Desvio padrão da contagem.

Idealmente, os parâmetros do experimento como atividade da fonte, taxas de contagem no detector, tamanho do detector, tempo de amostragem, colimação e dimensões podem ser ajustados para se obterem os melhores valores.

No entanto, num arranjo definido, ou seja, aquele que tem uma fonte de atividade conhecida, dimensões do experimento fixas, taxas de contagem do detector determinadas, estabilidade do modelo e tempo limitado de teste, não é possível utilizar sempre os melhores valores, de modo que algum critério de tomada e descarte de dados deve ser empregado.

Dessa forma, é comum adotar os seguintes critérios:

- O tempo total de teste não deve exceder a uma jornada normal (8 horas) ou estendida de trabalho de campo (12 horas);

- O tempo total de teste deve ser menor que o tempo médio de estabilidade do sistema medido;

- Adotar uma base de tempo que seja compatível com o fenômeno em estudo. Tomar todos os dados com relação a esta base de tempo;

- Adotar um limite mínimo aceitável para a relação contagem / BG; e

- Adotar um limite mínimo aceitável para a relação $\sigma$ / contagem.

Alguns critérios têm valores práticos adotados como relação contagem / BG maior que 10 ou relação $\sigma /$ contagem menor de $3 \%$. No entanto, outros valores podem ser adotados, ponderando-se que a qualidade dos resultados será influenciada. 


\subsubsection{Estudo de radioproteção}

\subsubsection{Cálculo usual na indústria}

$\mathrm{Na}$ indústria, é pratica comum utilizar a norma Petrobras N-2344 - Segurança em Trabalhos de Radiografia Industrial ${ }^{[24]}$, como referência para as diretrizes do cálculo do raio de isolamento em trabalhos de gamagrafia e, por conseguinte, qualquer outro trabalho envolvendo o uso de algum tipo de fonte radioativa. Segundo a norma, o raio de isolamento deve ser calculado através da Equação 8:

$$
\mathrm{R}=\sqrt{\frac{\mathrm{A} \times \Gamma \times \mathrm{T} \times \mathrm{f}}{0,0004}}
$$

Na qual "R" é o raio de isolamento em metros, "A" é a atividade da fonte, "T" é tempo real de exposição ao longo de um dia de 8 horas, "f" é o fator de colimação e " $\Gamma$ " é a constante do radioisótopo empregado. A taxa de exposição de $0,0004 \mathrm{R} / \mathrm{h}$ é obtida considerando o limite de indivíduo de público de $1 \mathrm{mSv} / \mathrm{ano}(0,1 \mathrm{R} / \mathrm{ano})^{[25]}$, tempo de exposição de 2.000 horas por ano e jornada de trabalho de 8 horas ao dia, conforme pode ser visto na Equação 9.

$$
\mathrm{H}=\frac{0,1 \mathrm{R} / \text { Ano }}{2.000 \mathrm{~h} / \mathrm{Ano}} \cdot 8 \mathrm{~h} / \mathrm{dia}=0,0004 \mathrm{R} / \mathrm{dia}
$$

Dessa forma, o raio de isolamento para uma fonte de ${ }^{60} \mathrm{Co}\left(\mathrm{G}=13,2 \mathrm{R} . \mathrm{cm}^{2}\right.$ / h.mCi), com atividade de $74 \mathrm{MBq}(2 \mathrm{mCi})$, tempo de irradiação de 3,27 horas e "f" igual a 1 (pior evento) é:

$$
R=4,64 m(f=1)
$$

A grande limitação deste método é a falha em considerar um grupo critico e uma limitação de dose para este grupo, já que é bem pouco plausível que um indivíduo ocupacionalmente exposto (IOE) fique 2.000 horas por ano nas imediações de um trabalho com fontes radioativas.

\subsubsection{Cálculo convencional}

$O$ raio de isolamento para uma fonte radioativa de constante " $\Gamma$ ", atividade "A", tempo de exposição "T", fator de colimação "f', fator de buildup "B", limitada a 
uma taxa de exposição "H", pode ser calculado mais adequadamente pela Equação (10) ${ }^{[26] \text { : }}$

$$
\mathrm{R}=\sqrt{\frac{\mathrm{A} \times \Gamma \times \mathrm{T} \times \mathrm{f} \times \mathrm{B}}{\mathrm{H}}}
$$

Um valor de "H" razoável pode ser obtido, restringindo-se a dose efetiva anual para o indivíduo de público do grupo crítico (aipgc) em 3/10 do limite anual:

$$
\mathrm{L}_{\text {aipgc }}=0,3 \mathrm{mSv} \text { (30mrem). }
$$

E adotando-se 1/10 desse limite por operação:

$$
\mathrm{L}=0,03 \mathrm{mSv}(3 \mathrm{mrem})
$$

Para o protótipo do irradiador, pode se determinar o raio de isolamento na direção do feixe, considerando "f" igual a 1 (um) e, perpendicularmente à blindagem da fonte, considerando se "f" igual à atenuação da blindagem $(2,25 \mathrm{~cm}$ em Pb). Desta forma, o raio de isolamento para uma fonte de ${ }^{60} \mathrm{Co}\left(\mathrm{G}=13,2 \mathrm{R} . \mathrm{cm}^{2} / \mathrm{h} . \mathrm{mCi}\right) \mathrm{com}$ atividade de $74 \mathrm{MBq}(2 \mathrm{mCi})$, tempo de irradiação de 3,27 horas e "H" limitada a 0,003 $\mathrm{R} / \mathrm{h}$ é (vide Apêndice 1 ):

$$
\begin{gathered}
R_{\text {direção_feixe }}=2,2 m(f=1 \text { e } B=1) \\
R_{\text {perpendicular_feixe }}=1,1 \mathrm{~m}(f=0,1322 \text { e } B=1,5516) .
\end{gathered}
$$

Este método limita-se aos casos onde é difícil determinar um fator de colimação, ou onde a colimação é variável. Também aplica-se apenas para fontes fixas, que para o caso de perfilagem de colunas, tomografias, e deste trabalho de Mestrado fica muito aquém de simular apropriadamente as condições reais de aplicação destas técnicas.

\subsubsection{Cálculo por simulação de exposição}

O cálculo convencional, no entanto, apresenta algumas limitações, que podem resultar num raio de isolamento por demasiado grande em algumas circunstâncias. Apesar de empregarmos neste trabalho fontes de pequena atividade, numa pratica industrial real as atividades devem ser bem maiores na ordem de $7,4 \mathrm{GBq}$ a $11,1 \mathrm{GBq}(200 \mathrm{mCi}$ a $300 \mathrm{mCi})$. Assim, um raio de isolamento muito grande 
dificultaria demais o controle de uma área de acesso restrita e interferiria muito nas outras atividades das plantas industriais.

Para obter uma melhor estimativa do raio de isolamento, empregou-se o método utilizado pela Tricom Tecnologia, no qual se estima o raio de isolamento através do calculo de exposição ao redor da instalação, considerando os movimentos de translação e rotação da fonte, colimação da fonte e buildup da blindagem. $O$ cálculo é feito através de um programa de computador, no qual o raio de isolamento é definido como o maior raio onde a exposição é maior que $0,03 \mathrm{mSv}$. Um fator de colimação " $f$ " é determinado para adequar a fórmula convencional ao raio calculado. Obtemos assim os gráficos mostrados na Figura 33.
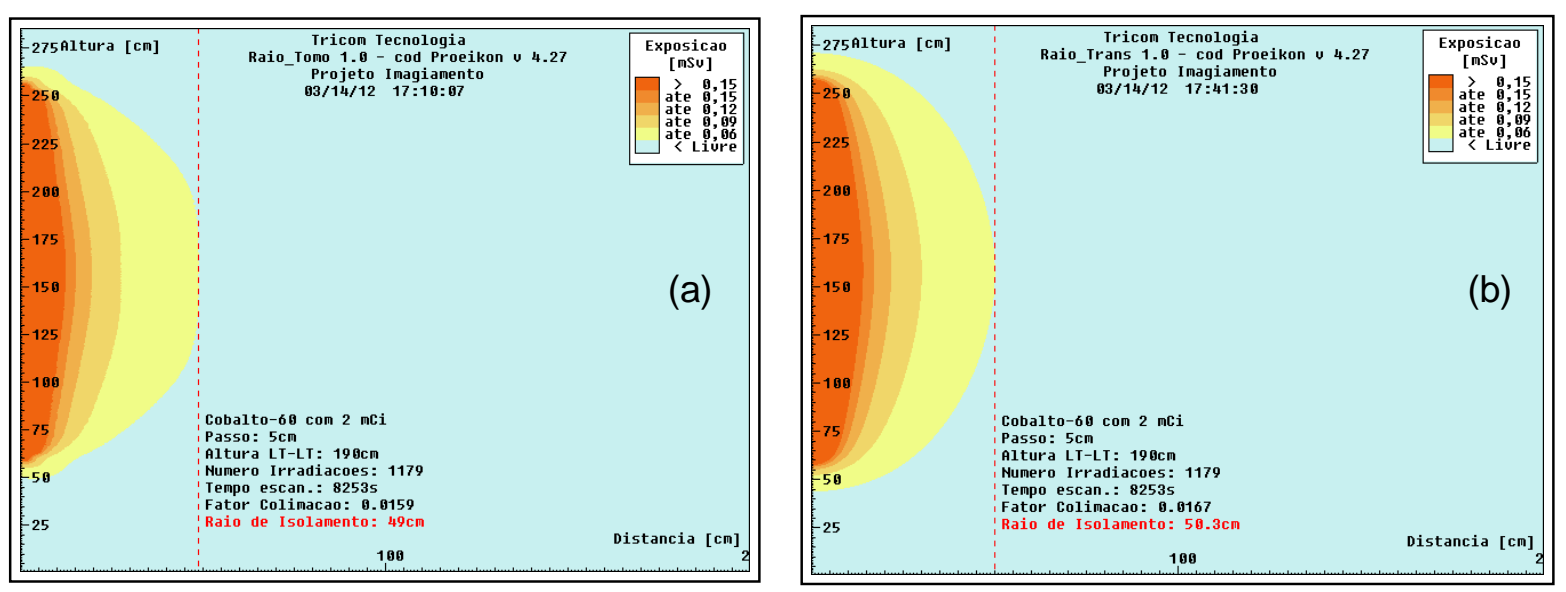

Figura 33 - Mapa de exposição no sentido axial (a) e transversal (b).

Assim:

$$
\begin{gathered}
R_{\text {direção_feixe }}=0,49 \mathrm{~m} \mathrm{e} \\
R_{\text {perpendicular_feixe }}=0,50 \mathrm{~m} .
\end{gathered}
$$




\subsubsection{Reconstrução das imagens}

O processo de reconstrução das imagens conta com a colaboração da Escola Politécnica da Universidade de São Paulo (EPUSP), com rotinas de programação de softwares e testes com filtros eletrônicos, entre outras técnicas.

As reconstruções apresentadas neste trabalho foram feitas através de algoritmos iterativos derivados do ART (Algebraic Reconstruction Technique) e do MART (Multiplicative Algebraic Reconstruction Technique), utilizando conceitos semelhantes aos da teoria Compressed Sensing, recentemente desenvolvida. O primeiro método gera imagens mais difusas e suaves, privilegiando a obtenção de densidade média; enquanto que o segundo método gera imagens mais nítidas, privilegiando a visualização de gradientes de densidades, ou seja, contornos.

Conforme Kim, J., et al, em Industrial Gamma-Ray Topographic Scan Method For Large Scale Industrial Plants ${ }^{[23]}$, os métodos iterativos apesar de lentos tem algumas vantagens sobre os métodos aritméticos nas aplicações industriais, aonde o número de projeções é limitado, assimétrico e diferente da disposição padrão das tomografias. Oliveira, E. F., et al, em Comparison among tomographic reconstruction algorithms with a limited data ${ }^{[27]}$ comparam os resultados dos métodos iterativos com relação ao comumente empregado FBP (Fourrier Back Projection), indicando que os primeiros tem apresentado melhores resultados nestes casos também.

\subsubsection{Simulação}

\subsubsection{Modelo em AutoCAD}

A fim de acelerar o desenvolvimento do software de reconstrução de imagens, seus parâmetros e seleção de filtros, foram geradas algumas séries de dados simulados em modelos virtuais das colunas. 


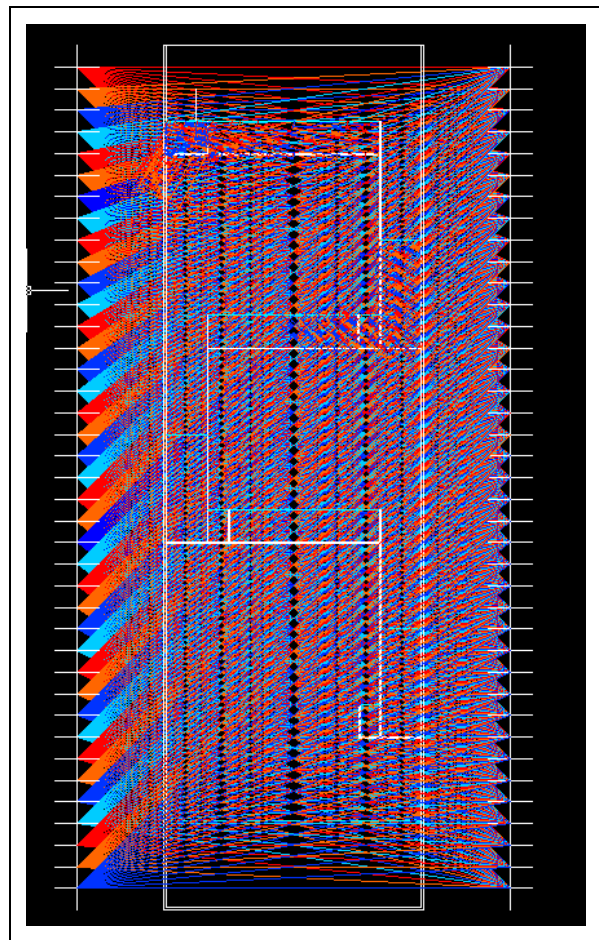

Figura 34 - Mapa de posicionamento das irradiações para um ângulo de abertura de $45^{\circ}$, no modelo da coluna de pratos.

Modelos de ambas as colunas foram inteiramente feito em AutoCAD, onde foram medidas todas as espessuras dos meios absorvedores, para cada posição de feixe. Um mapa do posicionamento dos feixes de radiação (raios gama) pode ser visto na Figura 34. A atenuação da radiação em cada caminho foi determinada em uma planilha no MS-Excel, a partir da medida de espessuras em cada feixe, como mostrado na Figura 35. Imagens reconstruídas a partir destes dados podem ser vistas na Figura 36.

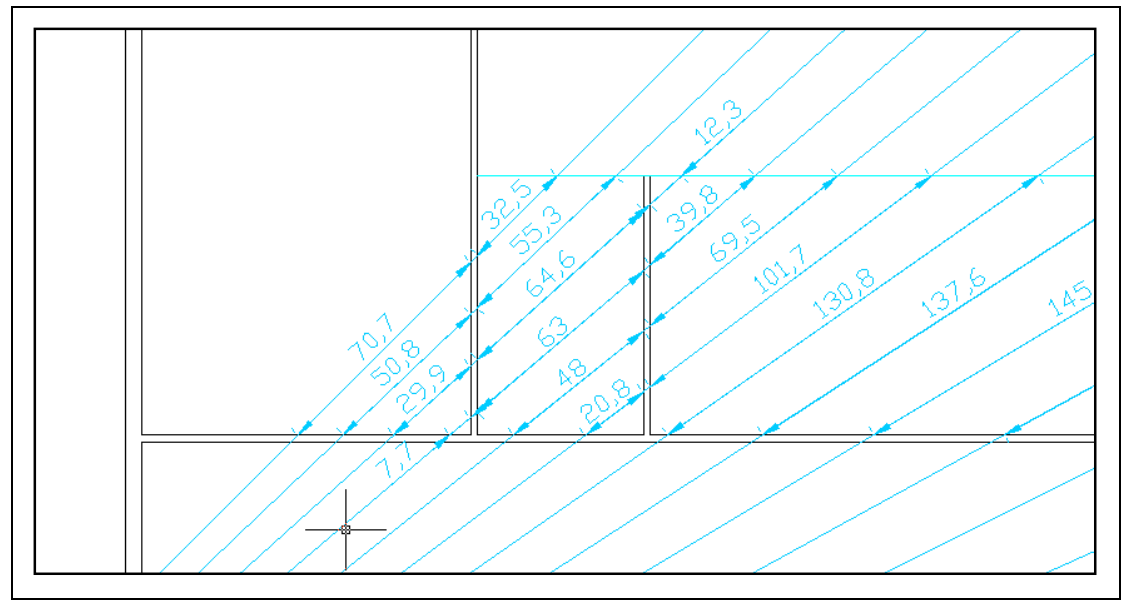

Figura 35 - Detalhe da medida de espessuras (milímetros). 


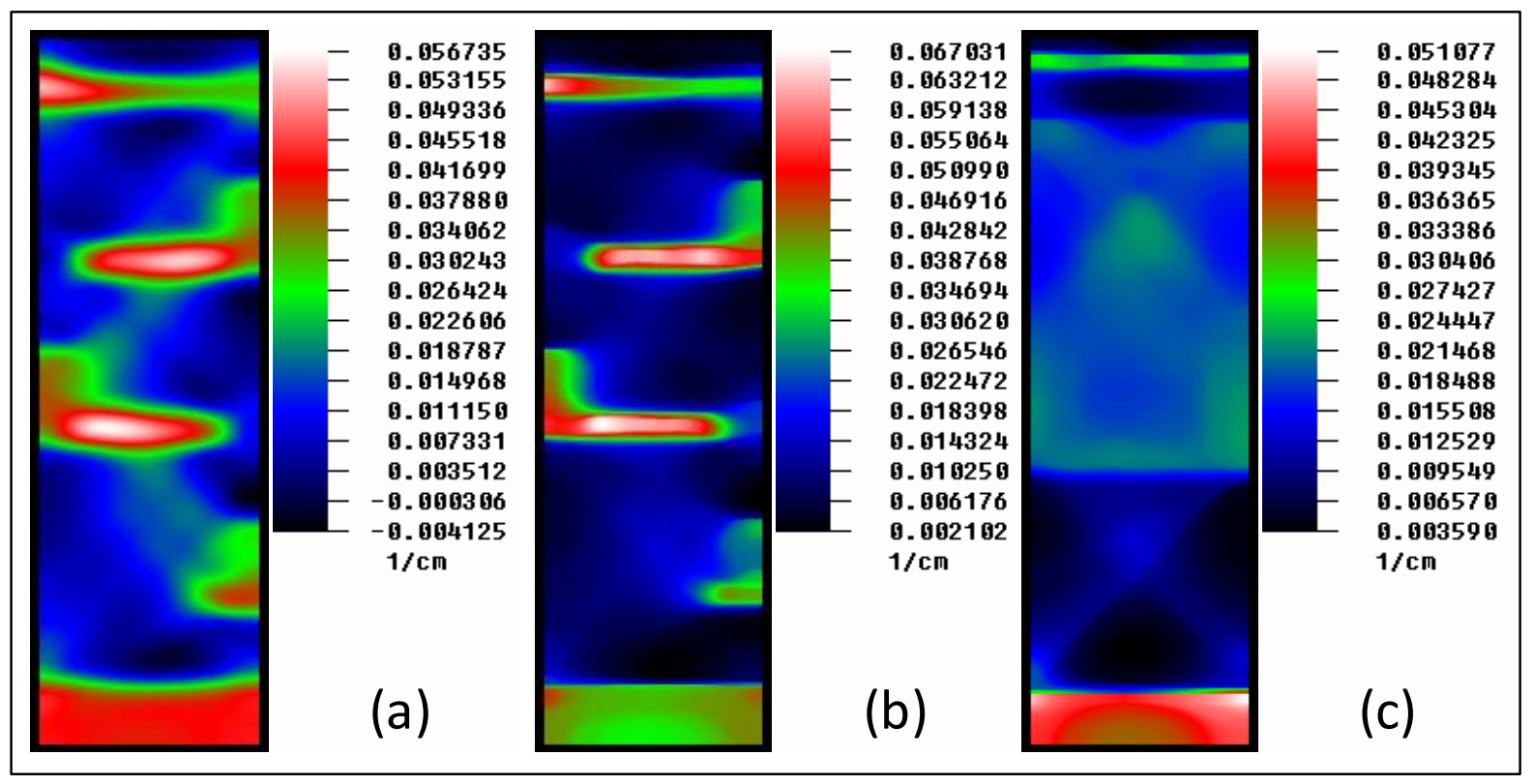

Figura 36 - Imagens reconstruídas resultantes dos modelos em AutoCAD para as colunas de pratos: método ART (a), método MART (b) e coluna de recheio, método ART (c).

\subsubsection{Modelos discretizados}

Os modelos obtidos em AutoCAD são bastante precisos, pois é possível medir a espessura dos meios com qualquer numero de algarismos significativos. No entanto, sua aplicação é bastante complexa, exigindo bastante tempo e atenção, uma vez que todo o trabalho é feito manualmente. Para simular irradiações de maneira mais rápida foram codificados alguns programas para discretizar e simular irradiações, facilitando o trabalho. O primeiro programa discretiza o arranjo das colunas de destilação na forma de uma imagem, como pode ser visto na Figura 37. Nesta imagem, cada cor de pixel da imagem representa um material de coeficiente de atenuação diferente. 


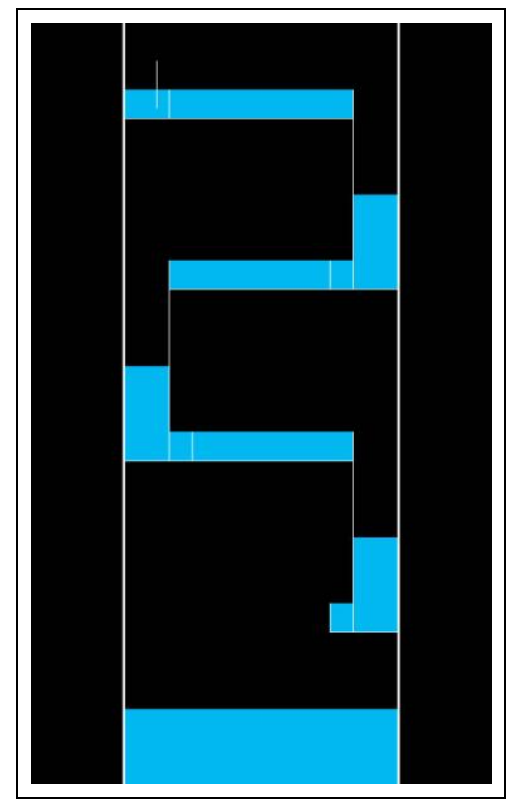

Figura 37 - Modelo discretizado da coluna de pratos.

Outro programa discretiza o caminho do feixe de radiação entre a fonte e o detector, e calcula a atenuação sofrida a partir da intensidade " $\mathrm{I}_{0}$ " em cada uma das posições de irradiação. A atenuação ao longo de um caminho é determinada conhecendo-se apenas por quais pixels a reta passa.

Avaliou-se a qualidade dos dados obtidos, comparando-se a densidade de pixels da imagem com o modelo em AutoCAD, para se verificar qual seria uma densidade razoável da discretização. Na Figura 38 é mostrado detalhe de um modelo de pratos apresentando diferenças no tamanho dos pixels e caminhos percorridos, devido às diferentes escalas de discretização.

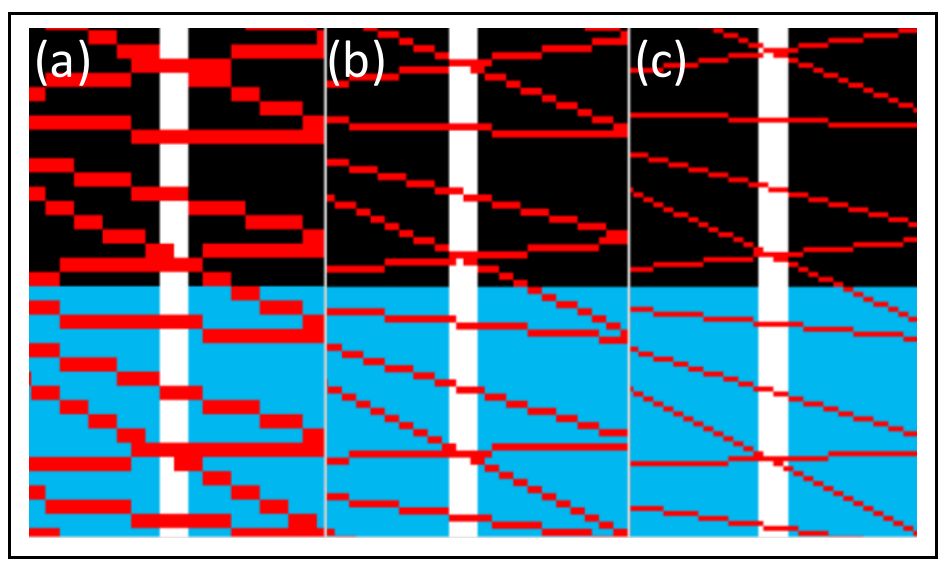

Figura 38 - Estudo de resolução da imagem versus qualidade das informações: (a) $1.000 \times 2.000$ pixels, (b) $2.000 \times 4.000$ pixels e (c) $3.000 \times 6.000$ pixels. 
Uma comparação na qualidade dos dados gerados pode ser feita também através de um mapa de dados, similar a um sinograma, que representa os valores obtidos numa imagem bidimensional, aonde cada pixel representa uma posição de irradiação, com a coordenada vertical representando a posição do detector e a horizontal à posição da fonte. Os valores obtidos foram normalizados numa escala de 0 a 255, representando diferentes tons de cinza, aonde 0 (negro) corresponde a maior contagem e 255 (branco) corresponde a menor contagem, como pode ser visto na Figura 39.

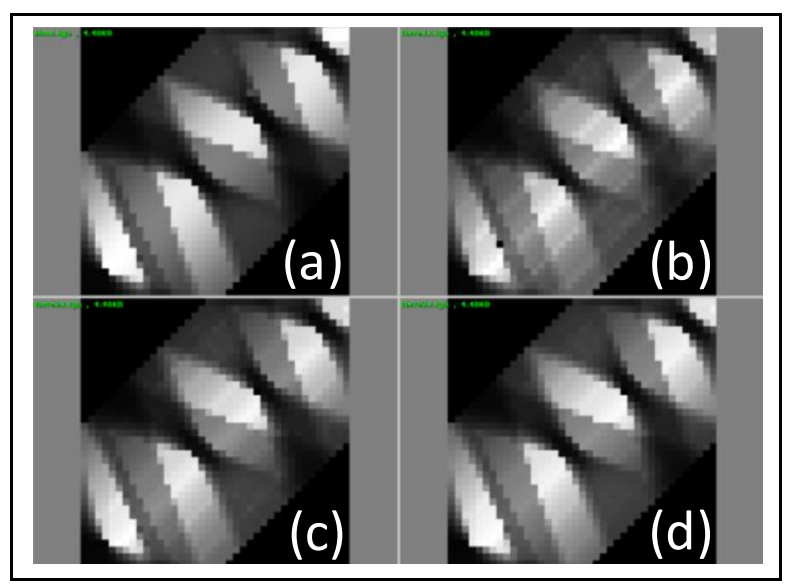

Figura 39 - Mapa de dados da irradiação simulada: AutoCAD (a), discretizada com $1.000 \times 2.000$ pixels (b), $2.000 \times 4.000$ pixels (c) e $3.000 \times 6.000$ pixels (d).

A qualidade da discretização pode ser vista comprando-se as imagens reconstruídas, como mostrado na Figura 40. 


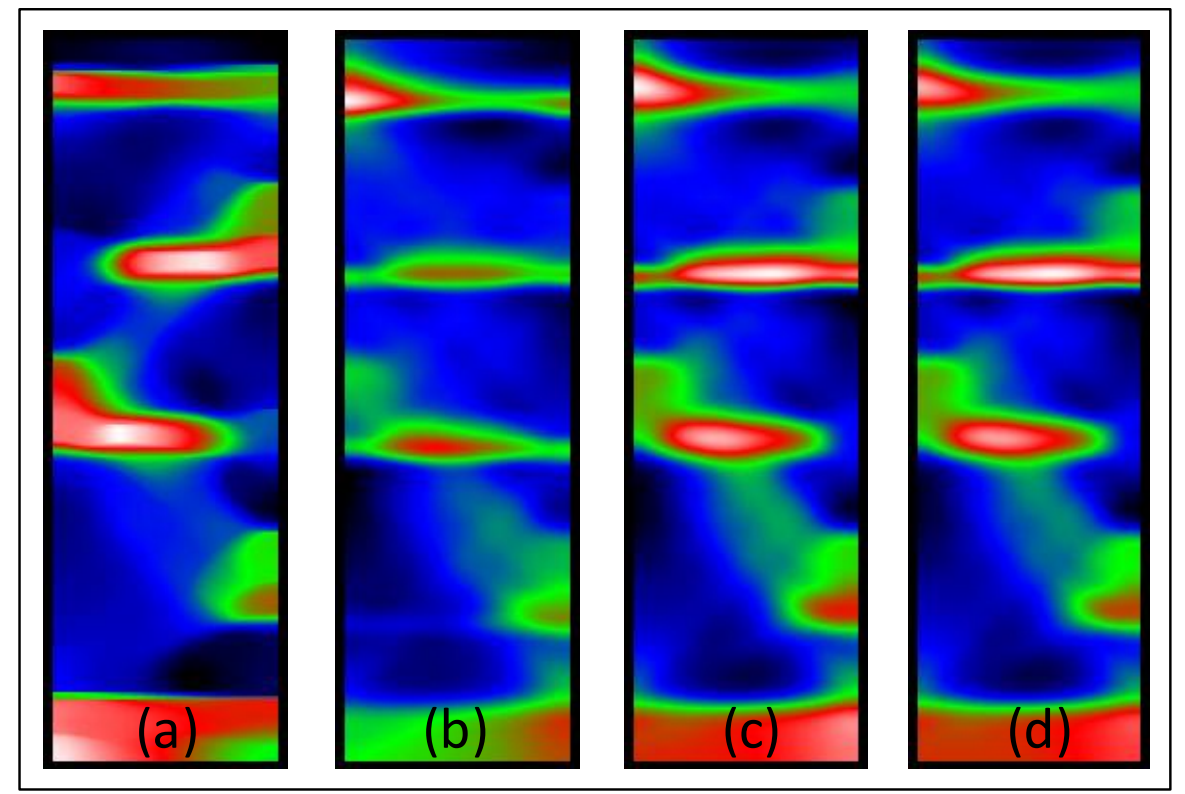

Figura 40 - Qualidade das imagens reconstruídas em função da escala de discretização: gerada em AutoCAD (a), simulação de $1.000 \times 2.000$ pixels (b), simulação de $2.000 \times 4.000$ pixels (c) e simulação de $3.000 \times 6.000$ pixels (d).

Com estes programas simularam-se, rapidamente, diferentes configurações de colunas, para se verificar qual a qualidade da imagem reconstruída, seja para ajuste dos programas de reconstrução e filtragem, seja para intercomparação com aqueles obtidos no protótipo. Na Figura 41 é mostrado o modelo simulado e a imagem tomográfica reconstruída, para a coluna de pratos.

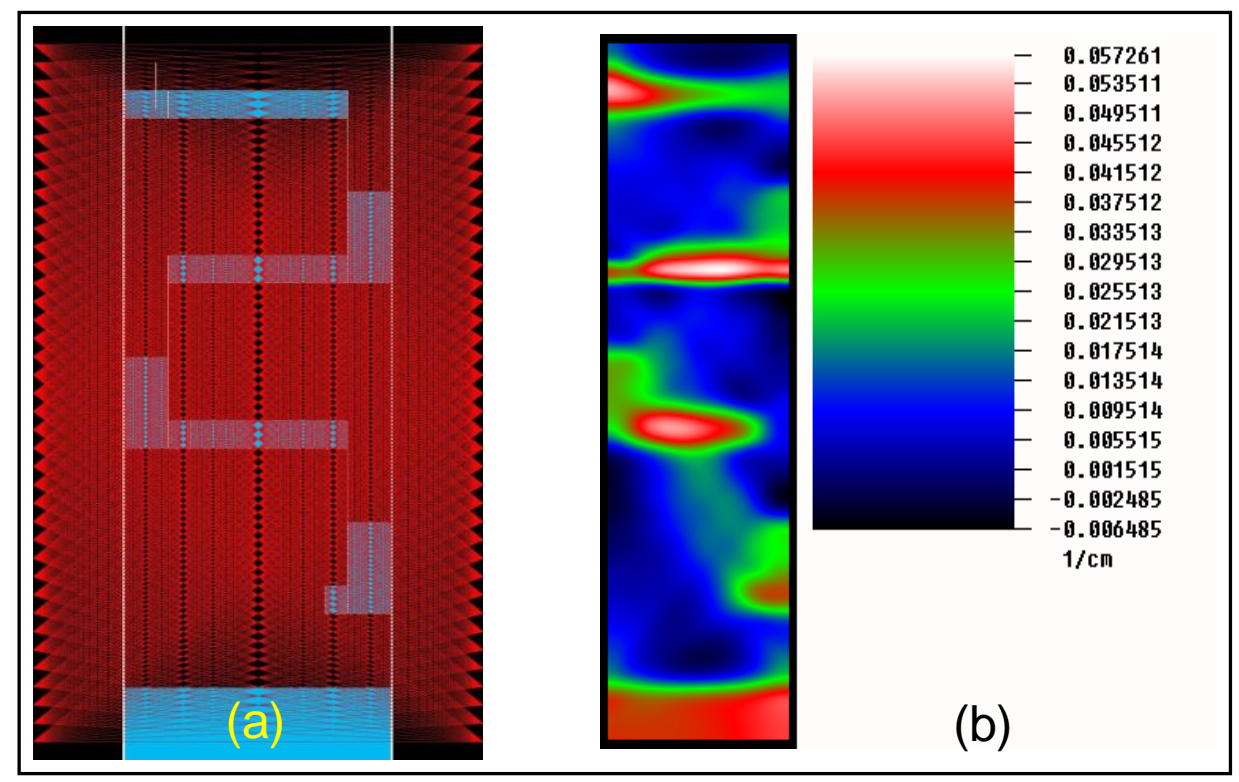

Figura 41 - Irradiação simulada da coluna de pratos (a) e imagem obtida (b). 
$\mathrm{Na}$ Figura 42 é mostrado o esquema de distribuição de densidades, empregado num modelo de coluna de recheio e a imagem reconstruída correspondente.

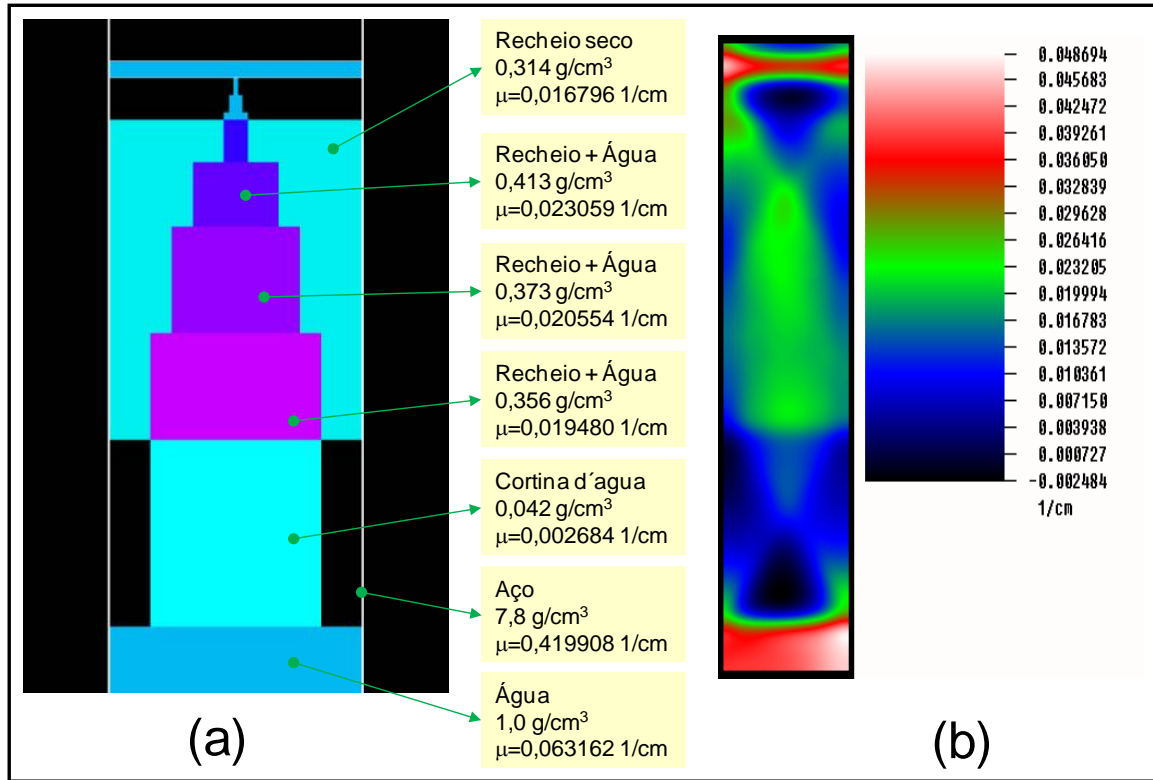

Figura 42 - Modelo simulado de uma coluna de recheio (a) e imagem obtida (b).

\subsubsection{Resultados "a priori"}

O ângulo relativo " $\alpha$ " é definido como o ângulo formado entre a fonte e o detector, com relação a horizontal. Nesta tecnologia, o ângulo relativo tem uma limitação prática, pois quanto maior o ângulo maior será a espessura dos meios absorvedores e menores serão os valores de contagem obtidos, como pode ser visto na Figura 43. Adicionalmente, a atividade da fonte, o tempo disponível de contagem, o nível da radiação de fundo e uma boa estatística de contagem limitam também o maior ângulo que pode ser praticamente empregado. 


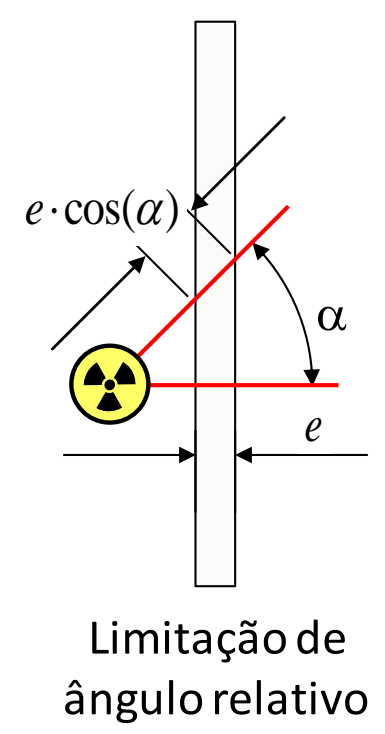

Figura 43 - Aumento da espessura no material absorvedor, em função do ângulo relativo $(\alpha)$.

Deste modo, as imagens reconstruídas apresentam alguns sinais da limitação do ângulo relativo, como pode ser visto na Figura 44:

- Valores de " $\mu s$ " menores, em função do espalhamento de valores, que aparecem na forma de manchas e listras na imagem; e

- Menor definição de contorno nas bordas de sentido vertical, com relação às bordas de sentido horizontal, dada a maior quantidade de irradiações no sentido horizontal do que às próximas no sentido vertical. 


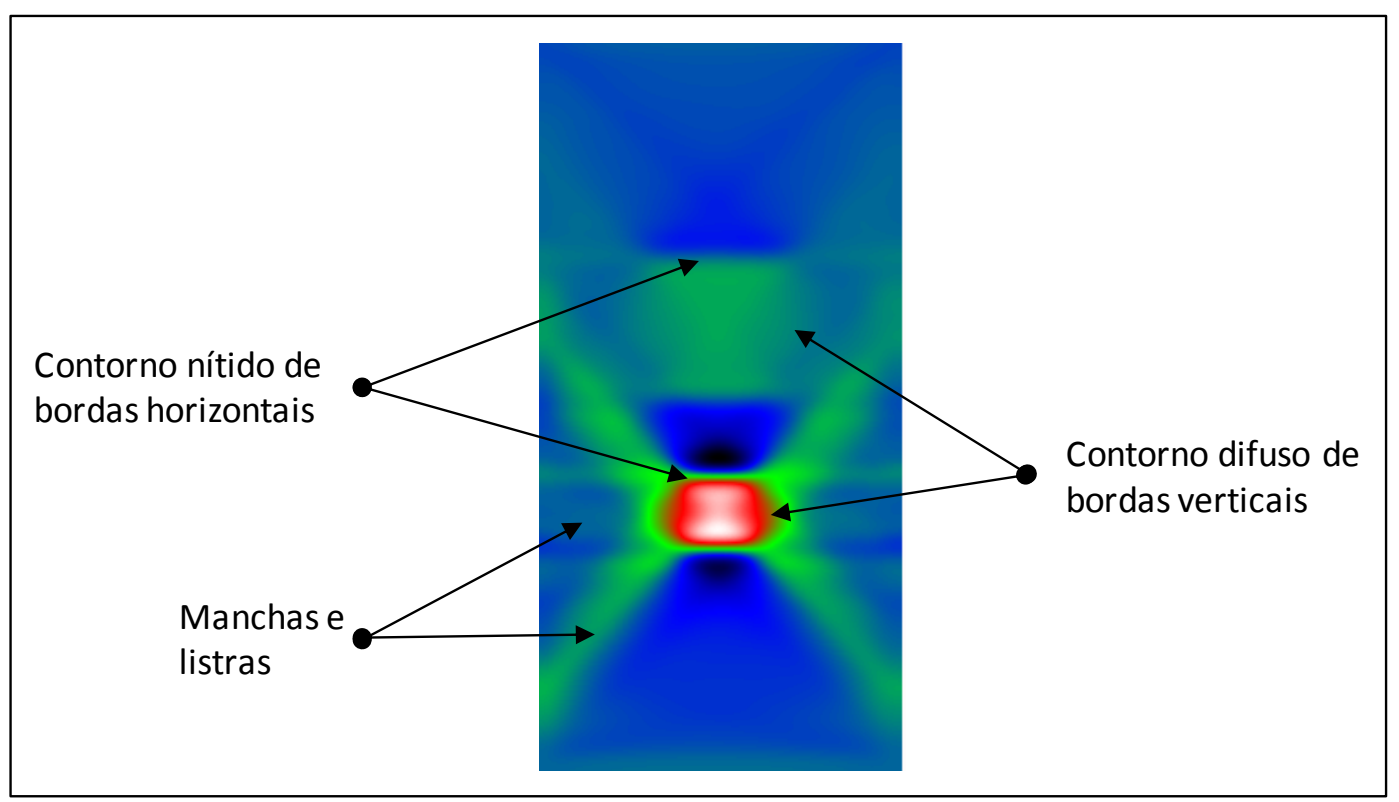

Figura 44 - Resultados da limitação do ângulo relativo.

Para contornar as limitações práticas impostas pelo ângulo relativo, e neste ponto, já além do escopo inicial deste trabalho de Mestrado, introduziu-se o conceito de resultados "a priori" na reconstrução das imagens. Um resultado "a priori" nada mais é do que uma proposição inicial para os resultados a serem obtidos, que pode vir do conhecimento prévio do modelo, o que é bastante plausível no caso de equipamentos de processos industriais ou baseado numa imagem reconstruída inicialmente obtida, permitindo o refinamento da solução.

Foram feitos alguns experimentos teóricos, cujos resultados demonstraram que os programas de simulação e reconstrução de imagem conseguem obter bons valores de " $\mu$ " com o uso modelos "a priori". Como pode ser visto na Figura 45, obteve-se uma melhora significativa nos valores calculados dos " $\mu \mathrm{s}$ ", como também diminuição das manchas e listras nas imagens e melhora no contorno das bordas dos objetos na imagem. 


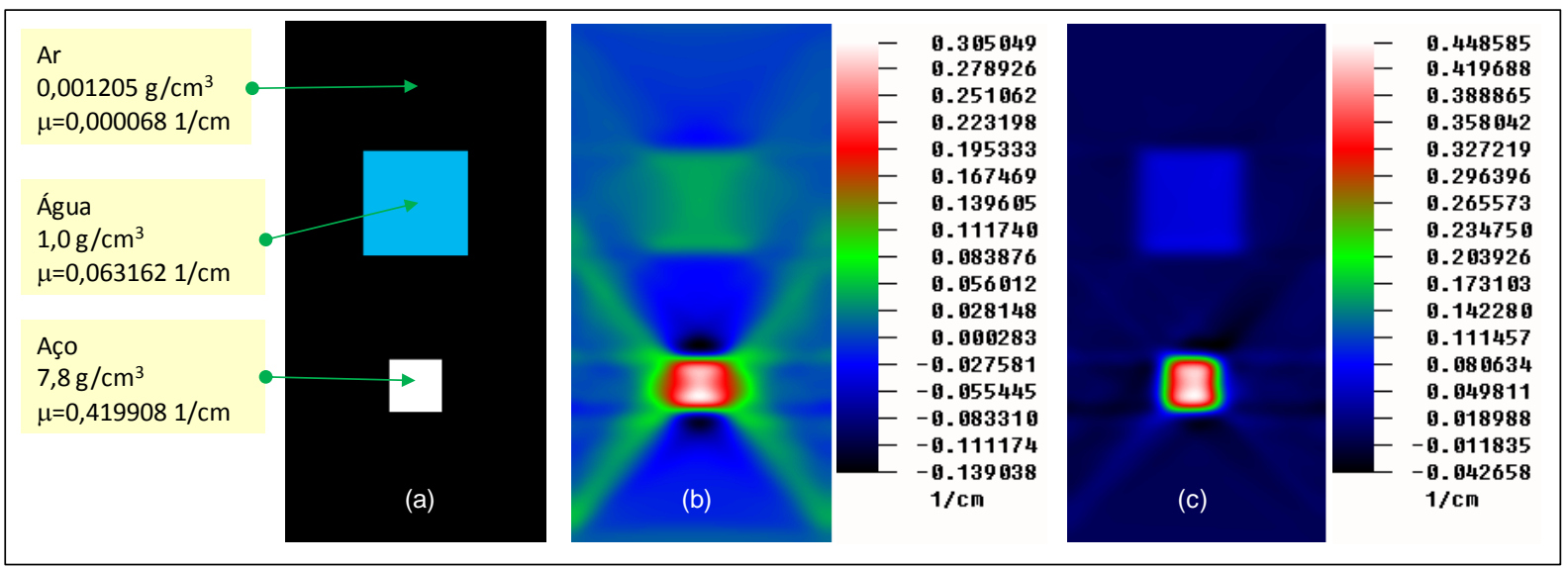

Figura 45 - Verificação dos valores de " $\mu$ "obtidos: modelo simulado (a), resultado sem "a priori" (b) e com "a priori" (c).

\subsubsection{Objetos delgados}

Como a proposta deste trabalho foi obter o perfil de densidades geral do equipamento, objetos de menor escala ou espessura tendem a desaparecer na imagem gerada. A limitação do ângulo relativo praticamente elimina da imagem final de qualquer objeto delgado, disposto no sentido vertical. Todavia, a absorção de radiação destes objetos não pode ser desprezada, pois a atenuação causada pela espessura de paredes ou de filmes de líquidos pode ser significativa.

Neste momento adotaram-se duas estratégias:

- Manter os dados originais durante a reconstrução. A principal consequência é que os valores dos " $\mu$ s" gerados são diferentes dos reais, ficando maiores se o objeto é mais denso que o restante do meio; ou menores se o objeto é menos denso. Outro sintoma é o aparecimento das manchas de espalhamento, que é o resultado da tentativa do algoritmo de acomodar os valores de " $\mu$ s" excedentes. A alteração do valor de " $\mu$ " da reconstrução de um vaso com espessura de parede "e", com coeficiente de atenuação " $\mu_{1}$ " mais diâmetro interno "d" e coeficiente de atenuação " $\mu_{2}$ " é mostrada na Figura 46; e 


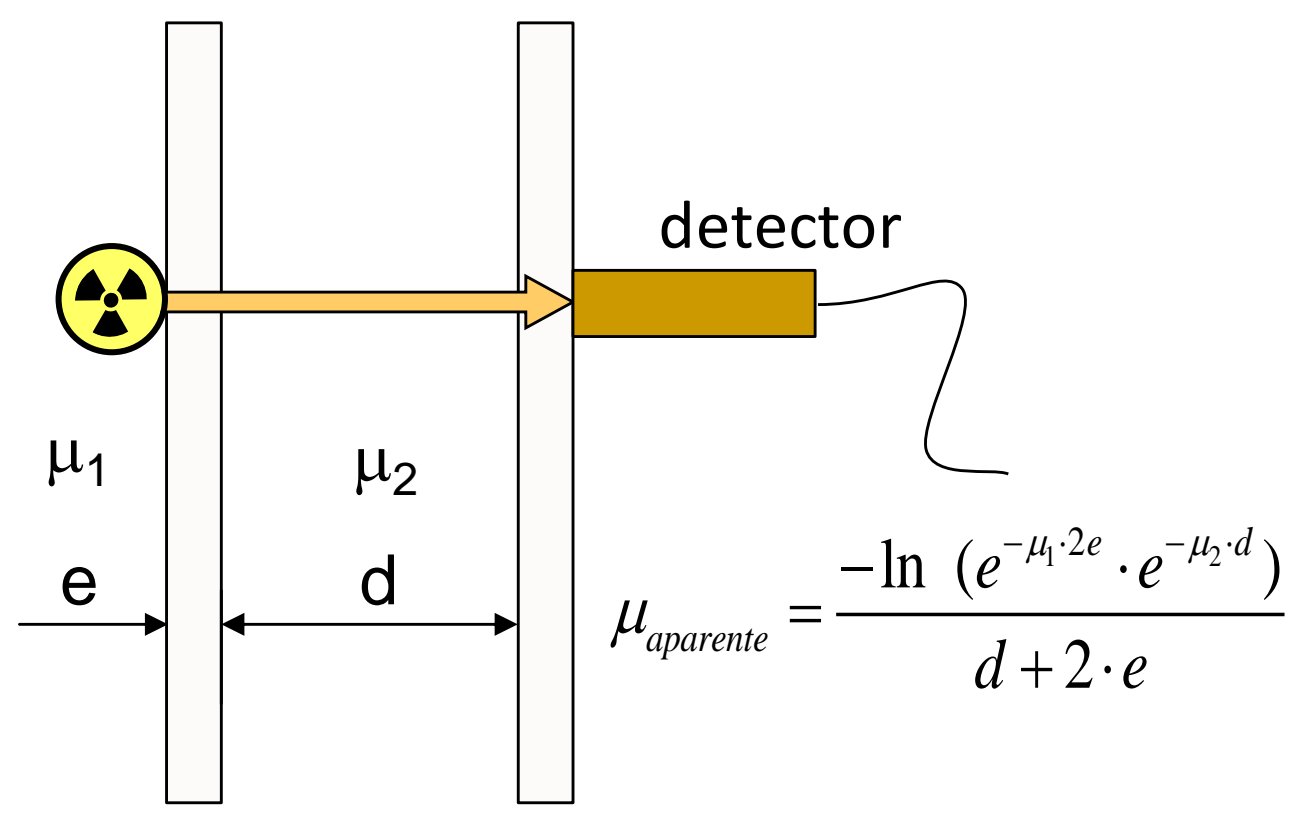

Figura 46 - Efeito do aumento do " $\mu$ " aparente pelo mascaramento de objetos delgados.

- Normalizar os valores, eliminando a influencia de um determinado meio absorvedor. A imagem gerada resulta em valores de " $\mu s$ " mais próximos aos reais e a ocorrência de manchas de espalhamento deve diminuir. Mas os valores ainda podem estar mascarados pelo espalhamento dos " $\mu$ " de outros objetos dentro da região e que não foram considerados na normalização. Notar que os objetos devem ter características conhecidas (disposição, dimensões e material, dentre outras).

\subsubsection{Cálculo do erro}

Para comparar as imagens geradas por diferentes métodos e parâmetros foi preciso adotar alguma forma analítica, para julgar a qualidade das imagens obtidas. A depender da situação, uma base comparativa pode não estar disponível, pois os valores de " $\mu s$ " podem ser desconhecidos como também sua distribuição. Assim, duas alternativas de avaliação são apresentadas a seguir sem, no entanto, representar uma solução definitiva para esta análise.

\subsubsection{Medida de erros}

Desde que os valores de " $\mu$ s" do objeto sejam conhecidos ou presumidos, uma proposta inicial consistiu em comparar o maior valor de " $\mu$ " obtido na imagem, 
com o maior valor presente no modelo, conforme Equação 11. Pode-se comparar também a variação total de " $\mu$ " na imagem com a do modelo, conforme Equação 12. Isso indicaria a capacidade do processo de reconstruir o valor de " $\mu$ " real e sua faixa de valores nas imagens. Considerando-se o exemplo da Figura 45, os valores de erros de " $\mu$ " e " $\Delta \mu$ " são apresentados na Tabela 1.

$$
\begin{gathered}
\text { Erro } \mu=\frac{\mu_{\text {maximo_obrido }}-\mu_{\text {máximo_real }}}{\mu_{\text {máximo_real }}} \times 100 \\
\text { Erro } \Delta \mu=\frac{\left(\mu_{\text {maximo_obtido }}-\mu_{\text {minimo_obtido }}\right)-\left(\mu_{\text {maximo_real }}-\mu_{\text {minimo_real }}\right)}{\left(\mu_{\text {maximo_real }}-\mu_{\text {minimo_real }}\right)} \times 100
\end{gathered}
$$

Tabela 1 - Valores de erros de " $\mu$ "e " $\Delta \mu$ " para o exemplo da Figura 45.

\begin{tabular}{ccccc}
\hline & \multicolumn{2}{c}{$\mu[1 / \mathrm{cm}]$} & \multicolumn{2}{c}{$\Delta \mu[1 / \mathrm{cm}]$} \\
\cline { 2 - 5 } Experimento & Encontrado & Erro [\%] & Encontrado & Erro [\%] \\
\hline $\begin{array}{c}\text { Reconstrução } \\
\text { ART }\end{array}$ & 0,305049 & $-27,8$ & 0,444087 & 5,8 \\
\hline $\begin{array}{c}\text { Reconstrução } \\
\text { "a priori" - ART }\end{array}$ & 0,448585 & 6,2 & 0,491243 & 17,0 \\
\hline
\end{tabular}

Esse método foi útil para comparar imagens obtidas com a variação de algum parâmetro e também naquelas que não se conhece os valores ou sua distribuição de densidades "a priori".

\subsubsection{Medidas de distorção das imagens}

Duas imagens (ou matrizes) podem ser comparadas pixel a pixel (ou posição a posição). Supondo que " $F$ " é a imagem de entrada (ou original) de tamanho " $\times \times$ " e, que $\hat{F}$ é a imagem de saída (processada ou estimada) também de tamanho " $J \times K$ ", os erros podem ser avaliados de diversas formas, como exposto: 
- Mean Absolute Error (MAE) (Equação 13)

$$
M A E=\frac{\sum_{j} \sum_{k}|F(j, k)-\hat{F}(j, k)|}{J \times K}
$$

- Mean Square Error (MSE) (Equação 14)

$$
M S E=\frac{\sum_{j} \sum_{k}(F(j, k)-\hat{F}(j, k))^{2}}{J \times K}
$$

- Root Mean Square Error (RMSE) (Equação 15)

$$
R M S E=\sqrt{M S E}
$$

- Peak Signal to Noise Ratio (PSNR). Há duas definições diferentes em uso, sendo que a mais utilizada (para imagens em níveis de cinza) seria a segunda definição:

a) Primeira definição (Equação 16)

$$
P S N R=10 \log _{10}\left(\frac{[\max \{F(j, k)\}]^{2}}{M S E}\right)=20 \log _{10}\left(\frac{\max \{F(j, k)\}}{\sqrt{M S E}}\right)
$$

b) Definição mais amplamente usada (Equação 17)

$$
P S N R=10 \log _{10}\left(\frac{255^{2}}{M S E}\right)=20 \log _{10}\left(\frac{255}{R M S E}\right)
$$




\subsection{EXPERIMENTOS}

\subsubsection{Coluna de pratos}

Realizaram-se dois experimentos no modelo de coluna de pratos de um passe, cujos pratos e vertedores foram preenchidos com uma mistura de água e gel, simulando a aparência de uma coluna de processo real, conforme é mostrado na Figura 47.

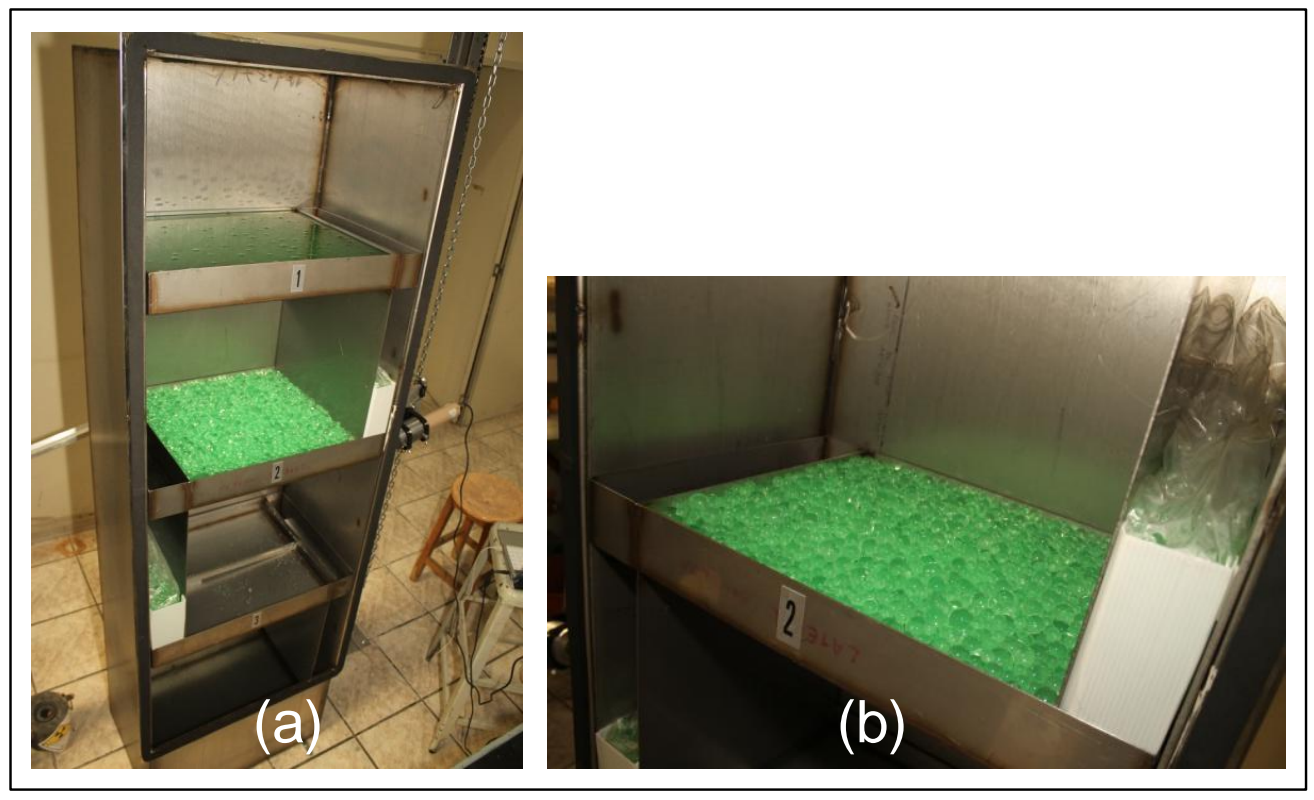

Figura 47 - Modelo de coluna de pratos (a), com pratos e vertedores preenchidos com uma mistura de água e gel (b).

$\mathrm{Na}$ Figura 48 é mostrado o layout final empregado, com dimensões dos internos e do meio absorvedor. 


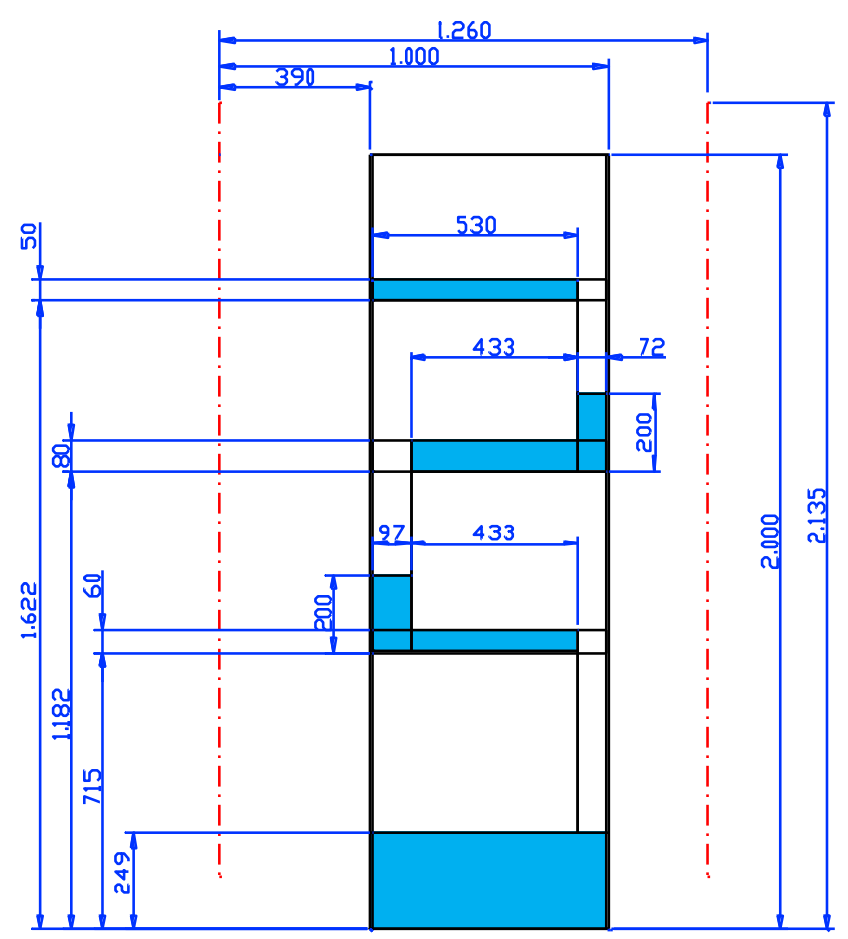

Figura 48 - Croqui do arranjo experimental da coluna de pratos (milímetros)

No primeiro experimento empregou-se um detector de radiação $[\mathrm{NaI}(\mathrm{TI})]$ de 1 polegada de diâmetro e janela de 1 polegada. Detectores desta dimensão tem baixa eficiência de contagem, já que o alcance dos fótons do ${ }^{60} \mathrm{Co}$ no $\mathrm{Nal}(\mathrm{TI})$ é maior que o tamanho do cristal. Ainda que este tamanho de detector não seja ideal a fonte radioativa e ao tipo de testes proposto, trata-se de uma sonda bastante empregada na indústria pelo custo e dimensão reduzidos. Esperavam-se, assim, baixas contagens de radiação e, por isso, o ponto ótimo de operação do instrumento de medição foi feito comparando a razão da taxa de contagem obtida no centro de uma bandeja cheia de líquido com relação ao background (BG). Esta é uma abordagem tradicional de calibração empregada em trabalhos de perfilagem, que visa maximizar as contagens obtidas em detrimento da precisão do calculo de densidade. Como o fotopico do ${ }^{60} \mathrm{Co}$ não pode ser nitidamente visto neste caso, não há uma grande diferenciação nos valores, e o valor ótimo de threshold (Th) acaba sendo o menor valor admissível adotado que é 4, como apresentado na Tabela 2. 
Tabela 2 - Relação contagens versus background (BG).

\begin{tabular}{cccccc}
\hline Valores de Th & $\mathbf{4 , 0}$ & $\mathbf{4 , 5}$ & $\mathbf{5 , 0}$ & $\mathbf{5 , 5}$ & $\mathbf{6 , 0}$ \\
\hline $\begin{array}{c}\text { Contagens (300s) } \\
\text { na Bandeja (BG) }\end{array}$ & 574 & 499 & 466 & 416 & 394 \\
\hline $\begin{array}{c}\text { Contagens (300s) } \\
\text { na Bandeja (C) }\end{array}$ & 1.151 & 1.101 & 988 & 873 & 840 \\
\hline Relação C/BG & 2,47 & 2,31 & 2,38 & 2,36 & 2,11 \\
\hline
\end{tabular}

A taxa de contagem obtida no ar na direção horizontal foi de 14.106 contagens/minuto, a taxa de contagem no liquido foi de 414 contagens/minuto e o valor de background (BG) foi de 207,6 contagens/minuto. O tempo de amostragem em cada ponto foi de 10 s, limitado arbitrariamente para permitir que toda a amostragem pudesse ser feita em aproximadamente 4 horas de irradiação. Os dados para este primeiro experimento foram tomados em passos de $10 \mathrm{~cm}$, gerando 355 posições de irradiação.

O segundo experimento empregou um detector de radiação $[\mathrm{Nal}(\mathrm{TI})]$ de 2 polegadas de diâmetro e janela de 2 polegadas. Neste caso, o alcance dos fótons do ${ }^{60} \mathrm{Co}$ no Nal(Tl) foi similar ao tamanho do cristal, da onde esperava-se obter maiores taxas contagem de radiação. O ponto ótimo de operação do instrumento de medição pode ser obtido usando a calibração de tomografia padrão.

A taxa de contagem obtida no ar na direção horizontal foi de 63.180 contagens/minuto, a taxa de contagem no liquido foi de 2.380 contagens/minuto e o valor de $B G$ foi de 1.050 contagens/minuto. $O$ tempo de amostragem em cada ponto foi de 3s, limitado arbitrariamente para permitir que toda a amostragem pudesse ser feita em, aproximadamente, 4 horas e 21 minutos de irradiação. Três conjuntos de dados foram gerados considerando passos de $5 \mathrm{~cm}, 10 \mathrm{~cm}$ e $15 \mathrm{~cm}$, resultando em 1388, 356 e 149 posições de irradiação, respectivamente. 


\subsubsection{Coluna de recheio randômico}

Realizaram-se alguns experimentos no modelo de coluna equipada com recheio de anéis de PVC, simulando um leito com severa má distribuição de líquido, vazios e diferenças na altura de recheio, como mostrada na Figura 49.

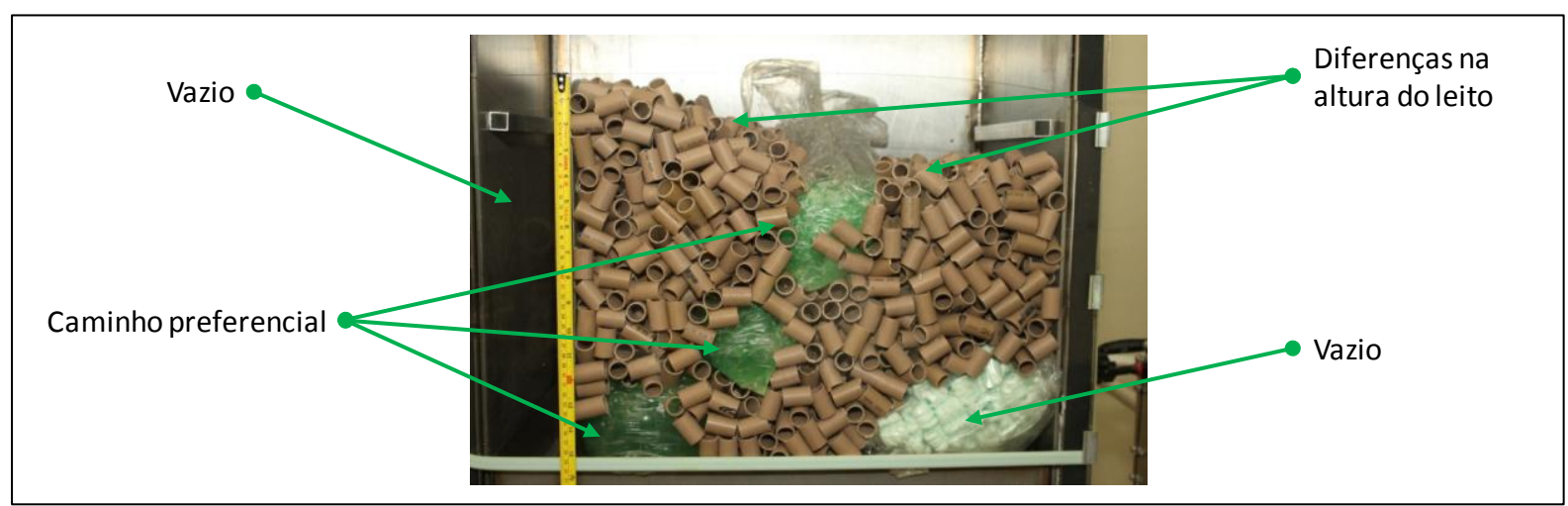

Figura 49 - Modelo de leito de recheio randômico irradiado.

$\mathrm{Na}$ Figura 50 é mostrado o layout com as dimensões dos internos e dos meios absorvedores.

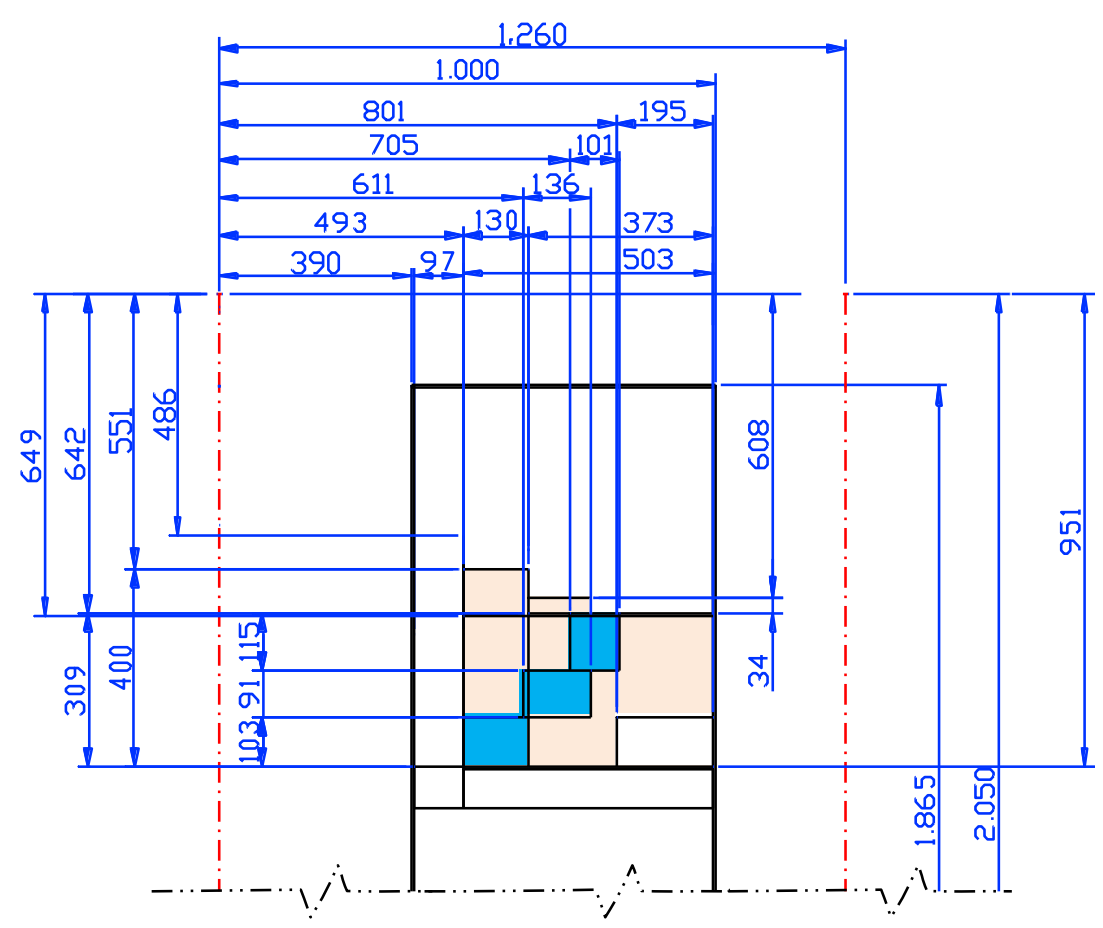

Figura 50 - Croquis do arranjo experimental da coluna de recheio (milímetros).

O experimento prático empregou um detector de radiação $[\mathrm{Nal}(\mathrm{TI})]$ de 2 polegadas de diâmetro e janela de 2 polegadas, usando o procedimento de 
calibração tomográfica otimizado. A taxa de contagem obtida no ar na direção horizontal foi de 31.307 contagens/minuto e o valor de BG foi de 526 contagens/minuto. O tempo de amostragem em cada ponto foi de $3 \mathrm{~s}$, limitado arbitrariamente para permitir que toda a amostragem pudesse ser feita em, aproximadamente 3 horas e 34 minutos de irradiação. Três conjuntos de dados foram gerados, com o ângulo relativo de $\pm 45^{\circ}$, considerando passos de $5 \mathrm{~cm}, 10 \mathrm{~cm}$ e $15 \mathrm{~cm}$ resultando em, respectivamente, 1.286, 331 e 149 posições de irradiação.

Para estudar os efeitos do ângulo relativo na qualidade das imagens reconstruídas, dois outros conjuntos de dados foram obtidos para o passo de $5 \mathrm{~cm}$ com ângulo relativos de $\pm 35^{\circ}$ (1.022 posições) e $\pm 55^{\circ}$ (1.436 posições). 


\subsection{DESENVOLVIMENTO DA TECNOLOGIA}

Demonstrada a viabilidade da tecnologia, trabalhou-se em melhorar e avaliar as imagens, para levar a tecnologia numa aplicação real de campo.

Para melhorar a qualidade das imagens, resultando em imagens mais fieis, obtendo-se valores de " $\mu s$ " próximos aos reais e contornando as limitações do ângulo relativo foram realizadas simulações com o uso de resultados "a priori". Dois tipos de resultados "a priori" foram empregados. Um modelo simplificado pode ser elaborado, através do conhecimento prévio do sistema como desenhos mecânicos, informações de processo e operação ou um modelo complexo surgiu do modelo anterior, como refinamento dos resultados de uma primeira simulação.

As medidas de erro apresentadas são resultados preliminares que representam o esforço para se determinar uma ferramenta, que ajude a julgar a qualidade da imagem obtida.

\subsubsection{Reconstrução da coluna de pratos com modelos "a priori”"}

A Figura 51, ilustra os dois modelos "a priori" empregados no refinamento das reconstruções do experimento na coluna de pratos, com o detector de radiação $[\mathrm{Nal}(\mathrm{TI})]$ de 2 polegadas.

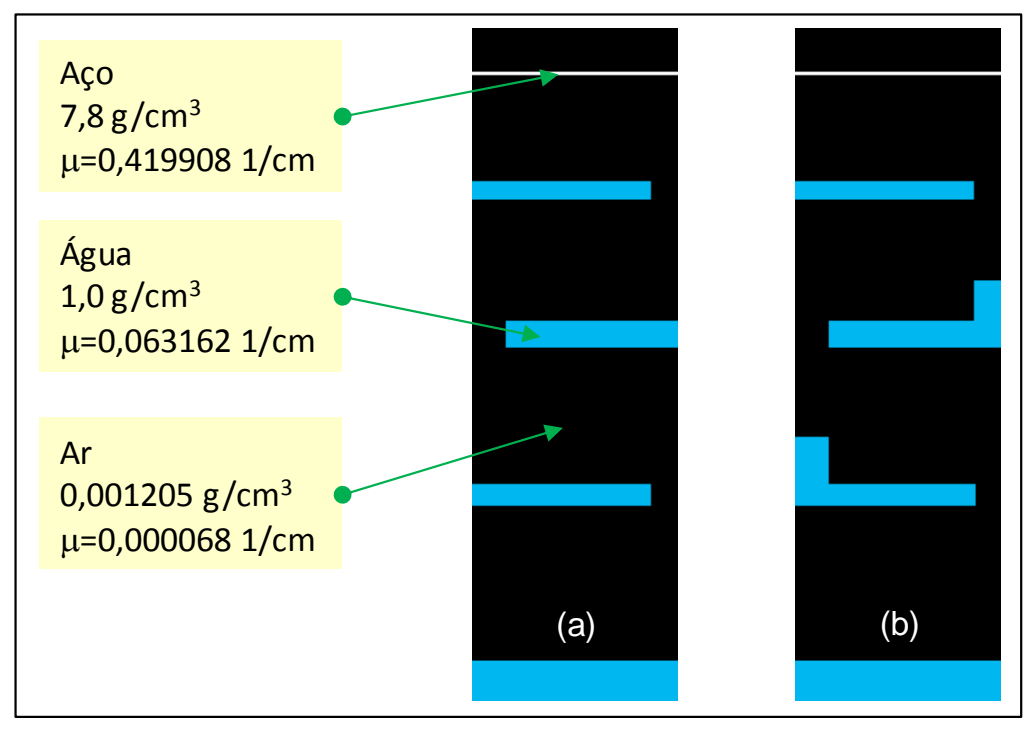

Figura 51 - Modelos "a priori" empregados para a coluna de recheio: simplificado (a) e complexo (b). 
Nas Figuras 52 a 54 comparam-se as primeiras imagens obtidas da coluna de pratos com as imagens reconstruídas com os modelos "a priori". Numa primeira análise, o processo parece surtir bom resultado, ao melhorar a definição das bordas, tanto nos contornos horizontais como verticais. A região de entrada dos vertedores $\mathrm{e}$ o liquido no fundo dos vertedores pode ser identificado com bastante clareza. Também, nota-se que a região de vapor tem uma densidade mais homogênea, dada à diminuição do espalhamento dos valores de " $\mu$ " na imagem.

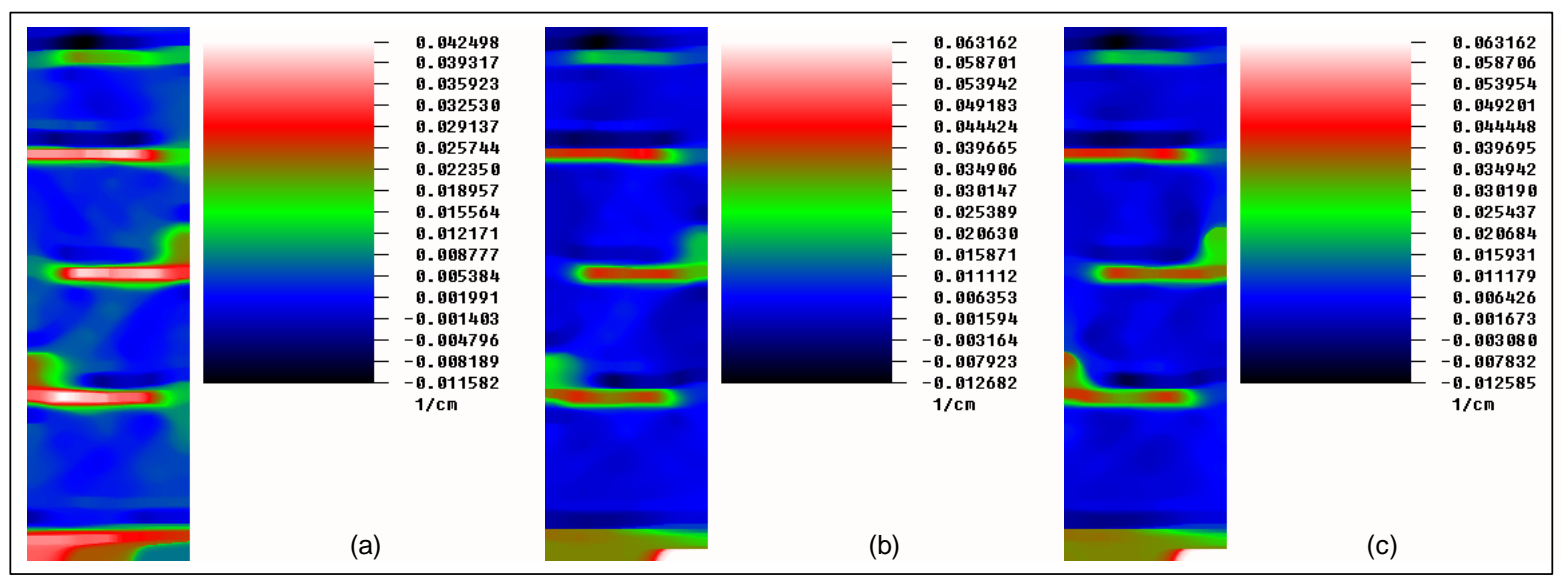

Figura 52 - Imagens reconstruídas com os dados de irradiação com passo de $5 \mathrm{~cm}$ : reconstrução direta (a), reconstrução com modelo "a priori" simplificado (b) e reconstrução com modelo "a priori" complexo (c).

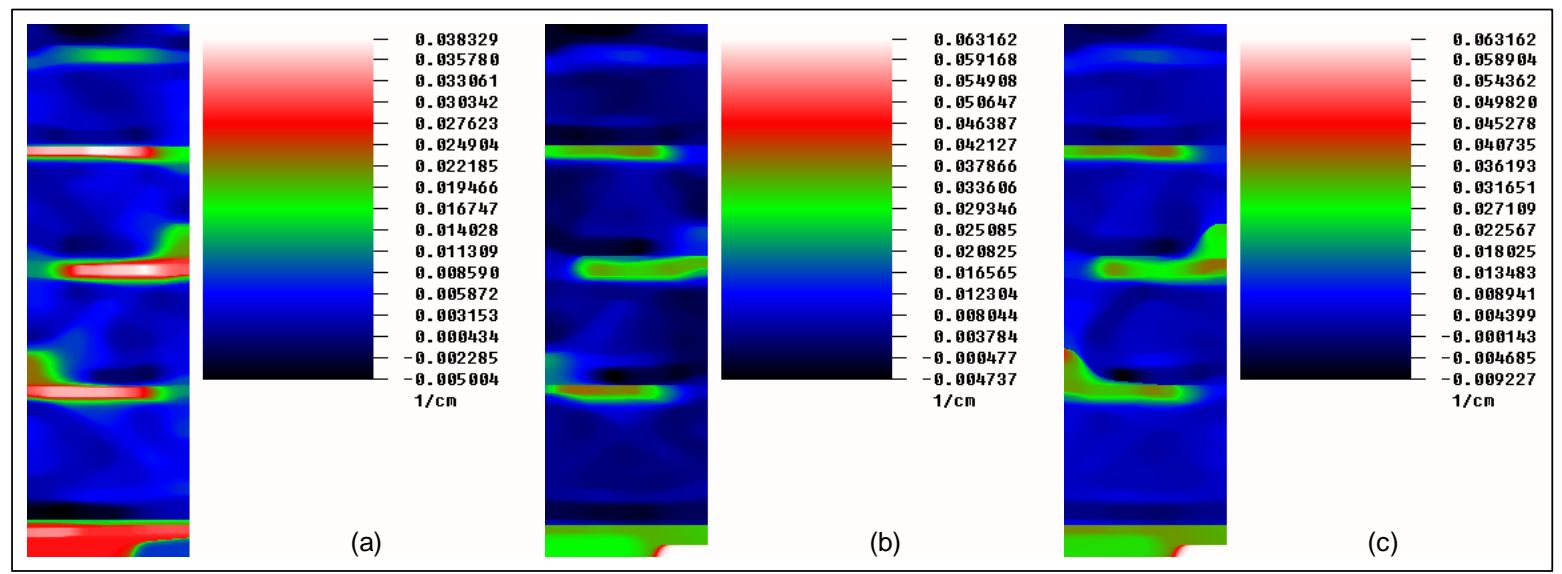

Figura 53 - Imagens reconstruídas com os dados de irradiação com passo de $10 \mathrm{~cm}$ : reconstrução direta (a), reconstrução com modelo "a priori" simplificado (b) e reconstrução com modelo "a priori" complexo (c). 


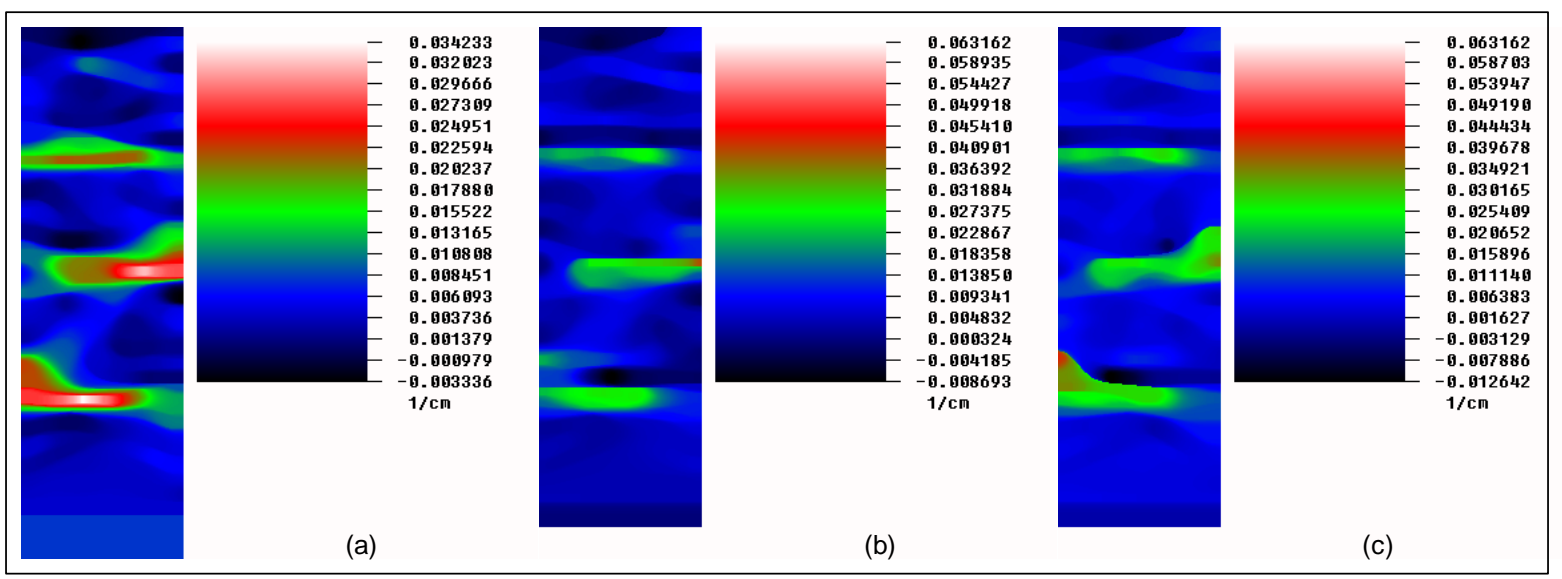

Figura 54 - Imagens reconstruídas com os dados de irradiação com passo de $15 \mathrm{~cm}$ : reconstrução direta (a), reconstrução com modelo "a priori" simplificado (b) e reconstrução com modelo "a priori" complexo (c).

\subsubsection{Medidas de erro}

As Tabelas 3 a 5 indicam que os modelos "a priori" apresentaram resultados melhores do que os simulados diretamente e que o aumento do passo resulta numa imagem de pior qualidade. 
Tabela 3 - Erro observado entre o maior valor e a variação total de " $\mu$ " na imagem reconstruída da primeira reconstrução e das geradas com modelo "a priori".

\section{Experimento}

$$
\mu[1 / \mathrm{cm}] \quad \Delta \mu[1 / \mathrm{cm}]
$$

\section{Encontrado Erro [\%] Encontrado Erro [\%]}

$\operatorname{Nal}(T I)$ 2" $-5 \mathrm{~cm}$

ART

0,042498

$-35,5$

0,054080

$-14,3$

$\mathrm{Nal}(\mathrm{TI}) 2 "-5 \mathrm{~cm}$

ART com "a priori" simples

0,063162

$-4,1$

0,075844

20,2

$\mathrm{Nal}(\mathrm{TI})$ 2" - $5 \mathrm{~cm}$

ART com "a priori" complexo

0,063162

$-4,1$

0,075747

20,1

$\mathrm{Nal}(\mathrm{TI}) 2 "-10 \mathrm{~cm}$

ART

0,038329

$-41,8$

0,043333

$-31,3$

$\mathrm{Nal}(\mathrm{TI}) 2 "-10 \mathrm{~cm}$

ART com "a priori" simples

0,063162

$-4,1$

0,067899

7,6

$\mathrm{Nal}(\mathrm{TI}) 2 "-10 \mathrm{~cm}$

ART com "a priori" complexo

0,063162

$-4,1$

0,072389

14,7

$\mathrm{Nal}(\mathrm{TI}) 2 "-15 \mathrm{~cm}$

ART

0,034233

$-48,0$

0,037569

$-40,5$

$\mathrm{Nal}(\mathrm{Tl}) 2 "-15 \mathrm{~cm}$

ART com "a priori" simples

0,063162

$-4,1$

0,071855

13,9

$\mathrm{Nal}(\mathrm{TI}) 2 "-15 \mathrm{~cm}$

ART com "a priori" complexo

0,063162

$-4,1$

0,075804

20,1 
Tabela 4 - Valores do erro MAE (Mean Absolute Error) em função do passo e tipo de reconstrução.

\section{Passo [cm]}

MAE

\begin{tabular}{cccc}
\cline { 2 - 4 } & $\mathbf{5}$ & $\mathbf{1 0}$ & $\mathbf{1 5}$ \\
\hline $\mathrm{Nal}(\mathrm{TI})$ 2" - ART & 0.0122 & 0.0123 & 0.0142 \\
\hline $\begin{array}{c}\mathrm{Nal}(\mathrm{TI}) \text { 2" - ART } \\
\text { com "a priori" simples }\end{array}$ & 0.0112 & 0.0113 & 0.0105 \\
\hline $\begin{array}{c}\mathrm{Nal}(\mathrm{TI}) \text { 2" - ART } \\
\text { com "a priori" complexo }\end{array}$ & 0.0110 & 0.0111 & 0.0103 \\
\hline
\end{tabular}

Tabela 5 - Valores do erro RMSE (Root Mean Square Error) em função do passo e tipo de reconstrução.

\begin{tabular}{cccc}
\hline RMSE & \multicolumn{3}{c}{ Passo [cm] } \\
\hline Nal(TI) 2" - ART & 0.0331 & 0.0333 & 0.0356 \\
\hline $\begin{array}{c}\text { Nal(TI) 2" - ART } \\
\text { com "a priori" simples }\end{array}$ & 0.0322 & 0.0325 & 0.0328 \\
\hline $\begin{array}{c}\text { Nal(TI) 2" - ART } \\
\text { com "a priori" complexo }\end{array}$ & 0.0321 & 0.0324 & 0.0326 \\
\hline
\end{tabular}

\subsubsection{Reconstrução da coluna de recheio com modelos "a priori"}

$\mathrm{Na}$ Figura 55 são mostrados os dois modelos "a priori" empregados no refinamento das reconstruções do experimento na coluna de recheio, com o detector de radiação $[\mathrm{Nal}(\mathrm{TI})]$ de 2 polegadas. 


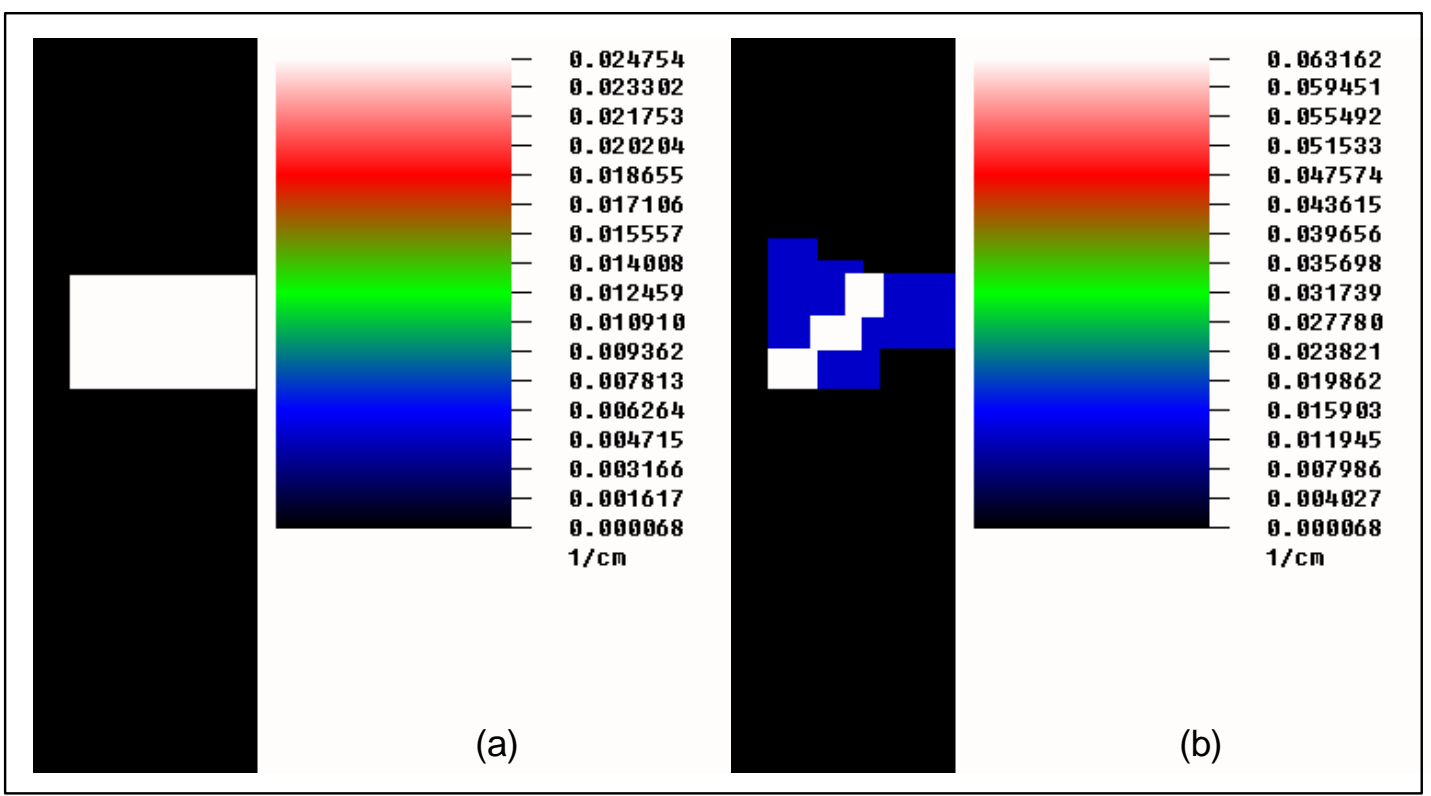

Figura 55 - Modelos "a priori" empregados para a coluna de recheio: simplificado (a) e complexo (b).

Nas Figuras 56 a 58 comparam-se as primeiras imagens obtidas da coluna com recheio randômico, com as imagens reconstruídas com os modelos "a priori". À primeira vista, os resultados não parecem tão bons como no caso da coluna de pratos. A definição dos contornos das áreas vazias, aparentemente, melhorou com o uso dos modelos "a priori", como também o contorno do desnivelamento no topo do leito de recheio. A posição dos bolsões de líquido nas imagens geradas ocorre, provavelmente, porque o modelo complexo teve suas dimensões estimadas, o que deve ter prejudicado a reconstrução da imagem.

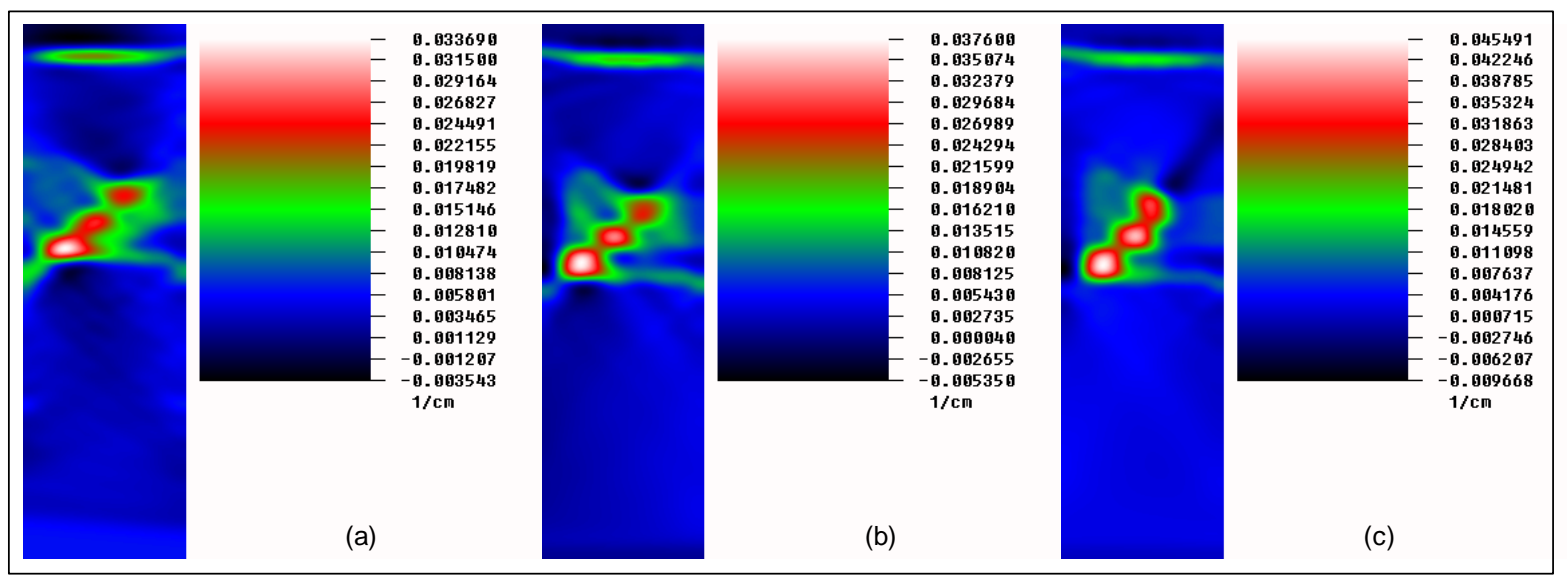

Figura 56 - Imagens reconstruídas com os dados de irradiação com passo de $5 \mathrm{~cm}$ : reconstrução direta (a), reconstrução com modelo "a priori" simplificado (b) e reconstrução com modelo "a priori" complexo (c). 


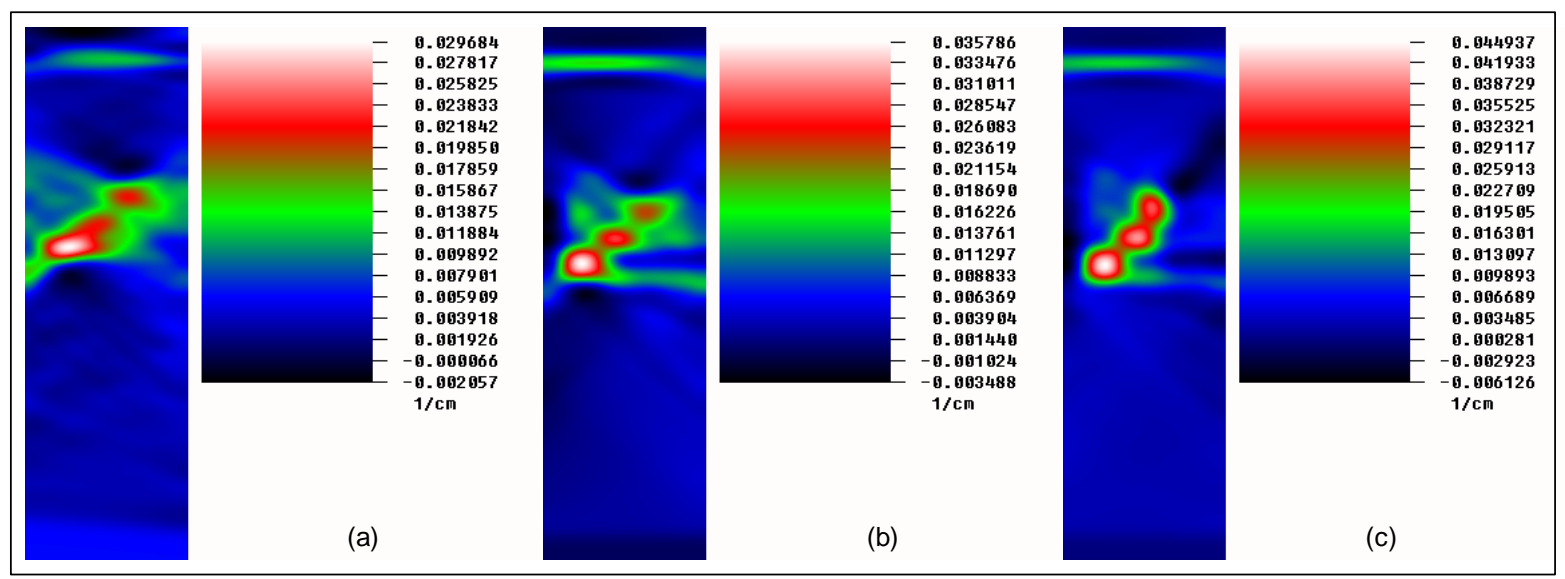

Figura 57 - Imagens reconstruídas com os dados de irradiação com passo de $10 \mathrm{~cm}$ : reconstrução direta (a), reconstrução com modelo "a priori" simplificado (b) e reconstrução com modelo "a priori" complexo (c).

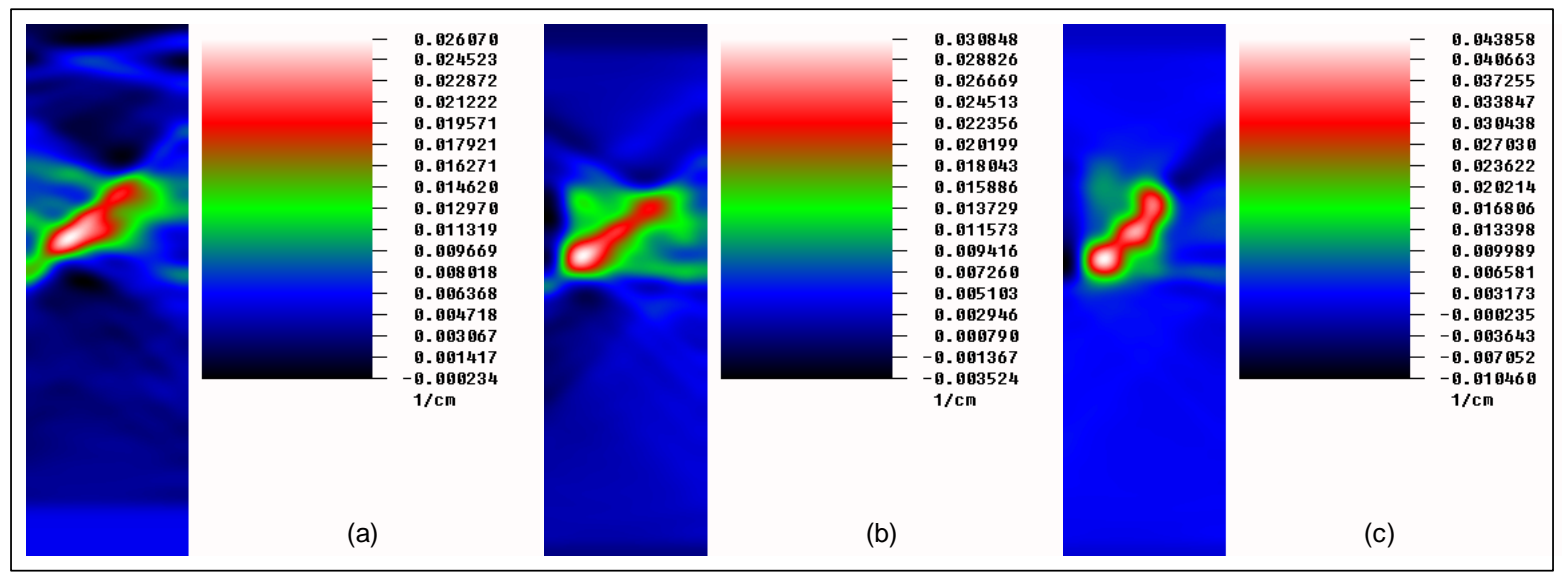

Figura 58 - Imagens reconstruídas com os dados de irradiação com passo de $15 \mathrm{~cm}$ : reconstrução direta (a), reconstrução com modelo "a priori" simplificado (b) e reconstrução com modelo "a priori" complexo (c).

\subsubsection{Medidas de erro}

As Tabelas 6 a 8 indicam que os modelos "a priori" apresentaram resultados melhores do que os simulados diretamente e que o aumento do passo resulta numa imagem de pior qualidade. Na Tabela 6, o modelo "a priori" complexo obteve o melhor resultado, ainda que o modelo não corresponda bem à distribuição dos bolsões de liquido observados. Neste caso, uma nova simulação deve ser feita utilizando-se um modelo "a priori" ajustado. 
As Tabelas 6 a 8 indicam que os modelos "a priori" têm melhor desempenho em geral, Na ultima é possível observar que o modelo complexo tem desempenho pior que o simples.

Tabela 6 - Erro observado entre o maior valor e a variação total de " $\mu$ " na imagem reconstruída da primeira reconstrução e das geradas com modelo "a priori".

Experimento $\quad \mu[1 / \mathrm{cm}] \quad \Delta \mu[1 / \mathrm{cm}]$

\section{Encontrado Erro [\%] Encontrado Erro [\%]}

\begin{tabular}{|c|c|c|c|c|}
\hline $\begin{array}{l}\mathrm{Nal}(\mathrm{TI}) 2 "-5 \mathrm{~cm} \\
\text { ART }\end{array}$ & 0,033690 & $-48,8$ & 0,037233 & $-41,0$ \\
\hline $\begin{array}{c}\mathrm{Nal}(\mathrm{Tl}) 2 \text { " }-5 \mathrm{~cm} \\
\text { ART com "a priori" simples }\end{array}$ & 0,037600 & $-42,9$ & 0,042950 & $-31,9$ \\
\hline $\begin{array}{c}\mathrm{Nal}(\mathrm{TI}) 2 \text { 2" }-5 \mathrm{~cm} \\
\text { ART com "a priori" complexo }\end{array}$ & 0,045491 & $-30,9$ & 0,055159 & $-12,6$ \\
\hline $\begin{array}{l}\mathrm{Nal}(\mathrm{TI}) 2^{\prime \prime}-10 \mathrm{~cm} \\
\mathrm{ART}\end{array}$ & 0,029684 & $-54,9$ & 0,031741 & $-49,7$ \\
\hline $\begin{array}{c}\mathrm{Nal}(\mathrm{Tl}) 2 \text { 2" }-10 \mathrm{~cm} \\
\text { ART com "a priori" simples }\end{array}$ & 0,035786 & $-45,7$ & 0,039274 & $-37,8$ \\
\hline $\begin{array}{c}\mathrm{Nal}(\mathrm{TI}) 2 \text { " }-10 \mathrm{~cm} \\
\text { ART com "a priori" complexo }\end{array}$ & 0,044937 & $-31,8$ & 0,051063 & $-19,1$ \\
\hline $\begin{array}{l}\mathrm{Nal}(\mathrm{TI}) 2^{\prime \prime}-15 \mathrm{~cm} \\
\mathrm{ART}\end{array}$ & 0,026070 & $-60,4$ & 0,026304 & $-58,3$ \\
\hline $\begin{array}{c}\mathrm{Nal}(\mathrm{Tl}) 2 \text { " }-15 \mathrm{~cm} \\
\text { ART com "a priori" simples }\end{array}$ & 0,030848 & $-53,2$ & 0,034372 & $-45,5$ \\
\hline $\begin{array}{c}\mathrm{Nal}(\mathrm{TI}) 2 \text { 2" }-15 \mathrm{~cm} \\
\text { ART com "a priori" complexo }\end{array}$ & 0,043858 & $-33,4$ & 0,054318 & $-13,9$ \\
\hline
\end{tabular}


Tabela 7 - Valores do erro MAE (Mean Absolute Error) em função do passo e tipo de reconstrução.

\section{Passo [cm]}

\section{MAE}

$\begin{array}{lll}5 & 10 & 15\end{array}$

\begin{tabular}{cccc}
\hline Nal(TI) 2" - ART & 0,0048 & 0,0051 & 0,0049 \\
\hline $\begin{array}{c}\text { Nal(TI) 2" - ART } \\
\text { com "a priori" simples }\end{array}$ & 0,0044 & 0,0044 & 0,0042 \\
\hline $\begin{array}{c}\text { Nal(TI) 2" - ART } \\
\text { com "a priori" complexo }\end{array}$ & 0,0044 & 0,0045 & 0,0042 \\
\hline
\end{tabular}

Tabela 8 - Valores do erro RMSE (Root Mean Square Error) em função do passo e tipo de reconstrução.

\begin{tabular}{cccc}
\hline & \multicolumn{3}{c}{ Passo [cm] } \\
\cline { 2 - 4 } RMSE & $\mathbf{5}$ & $\mathbf{1 0}$ & $\mathbf{1 5}$ \\
\hline Nal(TI) 2" - ART & 0,0086 & 0,0090 & 0,0090 \\
\hline $\begin{array}{c}\text { Nal(TI) 2" - ART } \\
\text { com "a priori" simples }\end{array}$ & 0,0075 & 0,0078 & 0,0074 \\
\hline $\begin{array}{c}\text { Nal(TI) 2" - ART } \\
\text { com "a priori" complexo }\end{array}$ & 0,0082 & 0,0086 & 0,0086 \\
\hline
\end{tabular}

\subsubsection{Proposta das próximas etapas de trabalho}

Dando continuidade aos trabalhos desenvolvidos, ainda com a estrutura laboratorial atualmente disponível, as seguintes atividades são propostas para 
complementar os resultados obtidos, investigar limitações e lançar novos desafios no desenvolvimento da técnica:

- Aprimoramento de metodologia e aplicativo para verificação de erro dos valores de " $\mu$ " obtidos;

- Experimentos com colunas de pratos e de recheio - distribuição de líquido, entupimento e prato danificado, dentre outros;

- Melhorar o processo de calibração;

- Verificação da menor diferença de densidade registrável;

- Verificação da relação resolução espacial e passo; e

- Testes com diferentes diâmetros de janela para os detectores de radiação $[\mathrm{Nal}(\mathrm{TI})]$ de 1 e 2 polegadas.

\subsubsection{Desenvolvimento da tecnologia}

Os resultados obtidos até o momento permitem vislumbrar desenvolvimentos potenciais relacionados aos sistemas auxiliares, na estrutura laboratorial, que permitirão aumentar o conhecimento sobre a técnica e até facilitar sua aplicação real em campo:

- Comparação com sistemas multicanais - melhor ajuste da energia medida (calibração), possível melhora na linearidade de resposta e erro nos valores de " $\mu$ " obtidos;

- Uso de sistema multifontes radioativas - melhorar cálculo de densidades, realizar mais medidas por posição do detector de radiação [Nal(TI)];

- Sistemas multidetectores e detectores de radiação wireless;

- Uso de detectores com maior resolução em energia;

- Observar fenômenos de processo reais, tais como, espuma, arraste, entre outros; 
- Automação da tomada de dados, permitindo variações no passo, maior tempo de amostragem e menor dose do operador; e

- Testes de aplicação e adaptação para indústria.

\subsubsection{Testes de aplicação}

Testes de aplicação tem a função de preparar a tecnologia para uso real em campo, determinando:

- A adequação dos aparatos e instrumentos empregados usualmente à proposta da tecnologia;

- As alterações ou adaptações na tecnologia atual que devem ser feitas; e

- Balanço entre simplificação da técnica, qualidade dos resultados obtidos com as necessidades imediatas para potenciais aplicações.

Na Figura 59 é mostrado um experimento prático, empregando-se um sistema de perfilagem industrial num vaso contendo cilindros de espuma e de poliuretano. $O$ experimento foi efetuado nas instalações da Tricom Tecnologia, antes do início dos trabalhos no laboratório do Centro de Tecnologia das Radiações (CTR), do IPENCNEN/SP. Por isso, muitas das inovações apresentadas neste trabalho de mestrado não foram aplicadas neste teste na Tricom Tecnologia. A imagem reconstruída foi obtida a partir de 180 irradiações com um ângulo relativo de $35^{\circ}$, que provavelmente apresentaram alguma interferência da colimação mecânica do sistema de escaneamento. A altura de escaneamento foi de apenas $1 \mathrm{~m}$ (I) ao invés de $1,28 \mathrm{~m}$ $[1+d \cdot \tan (\alpha)]$, para que toda a região de interesse tivesse o melhor resultado.

Ainda que os resultados obtidos tenham sido bastante imprecisos e simplificados, este teste na Tricom Tecnologia abriu possibilidades para a migração da técnica na aplicação real em campo. Espera-se que com o conhecimento adquirido desde então, possam se obter imagens de melhor qualidade e precisão. 


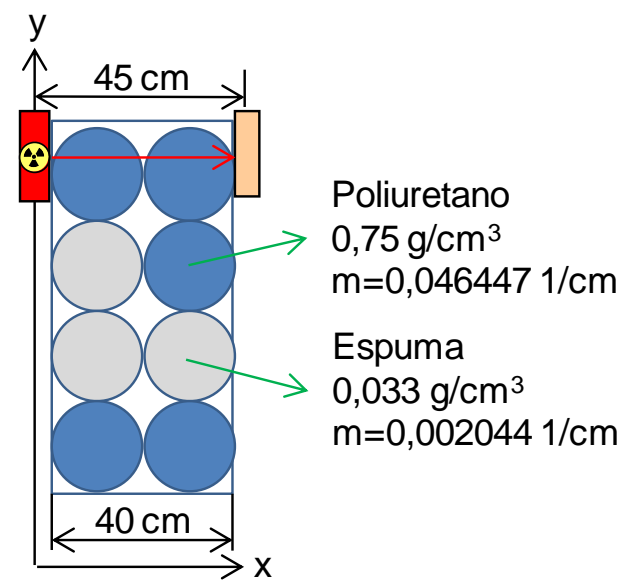

(a)

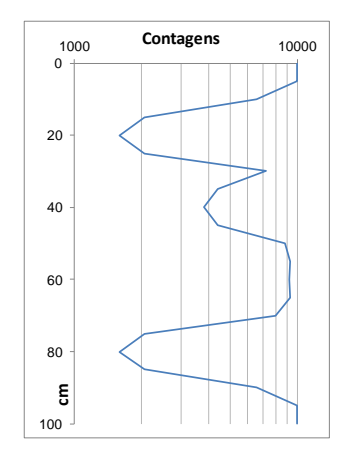

(b)

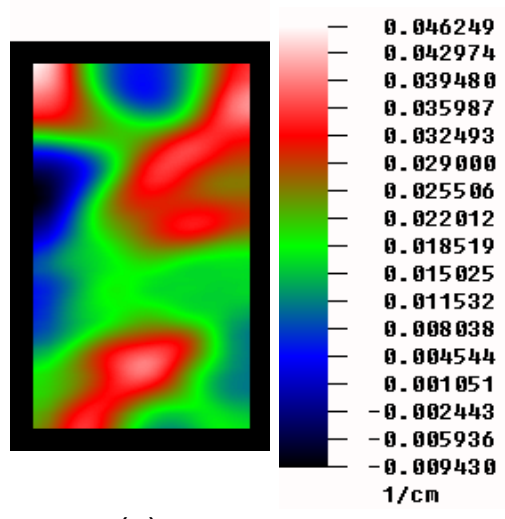

(c)

Figura 59 - Teste de aplicação empregando sistema de perfilagem por raios gama. Layout do teste (a), gráfico de perfilagem (b) e imagem reconstruída (c). 


\section{RESULTADOS E DISCUSSÃO}

O desenvolvimento deste trabalho científico foi efetuado em fases. Cada nova imagem gerada levavam às discussões que resultaram em propostas de testes ou melhorias, as quais foram aplicadas aos próximos experimentos. Esta seção apresenta os resultados dos experimentos propostos neste trabalho de Mestrado, em ordem cronológica de execução.

\subsection{Simulações}

Os resultados das primeiras simulações apresentam imagens reconstruídas ricas em detalhes e que podem ser entendidas sem maiores explanações, já que se assemelham muito aos modelos originais, como pode ser visto na simulação da coluna de pratos da Figura 60.

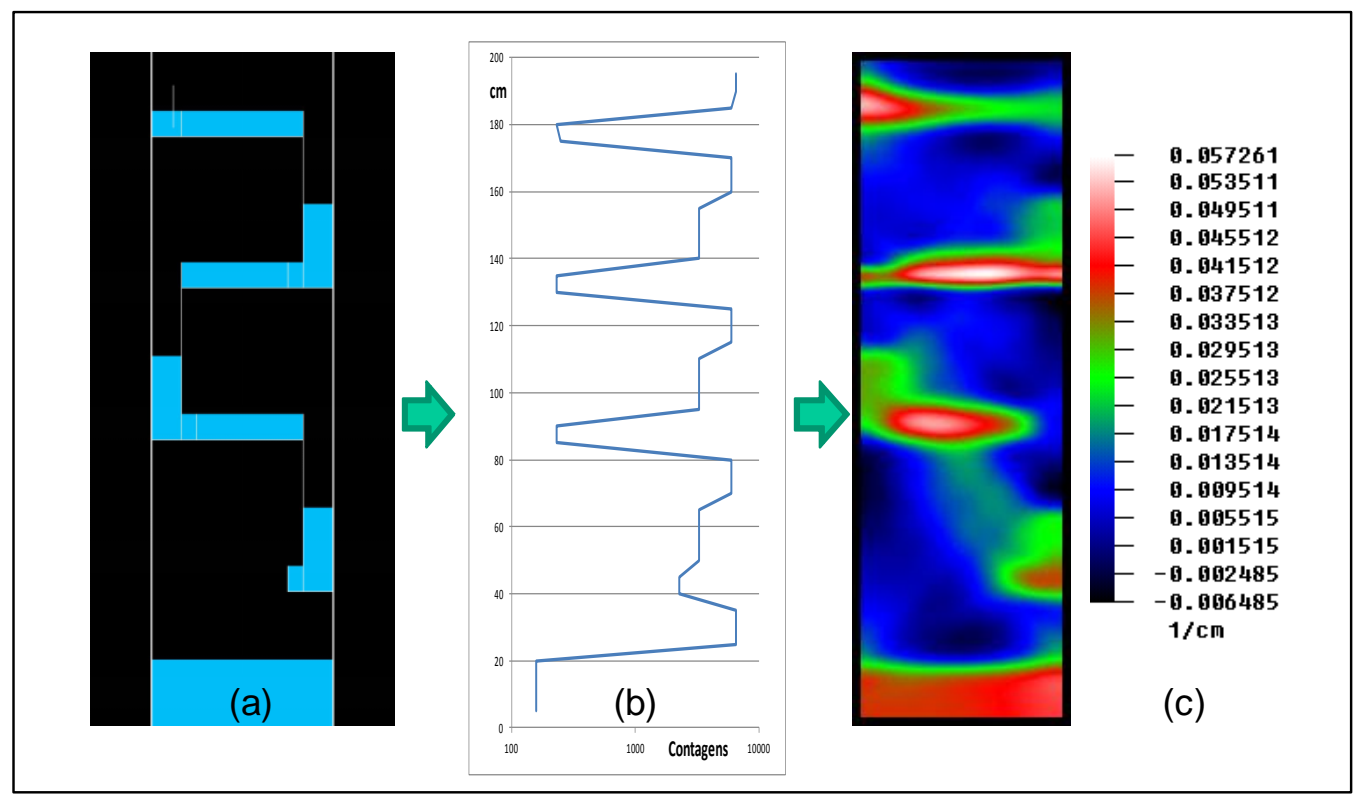

Figura 60 - Modelo simulado de uma coluna de pratos (a), perfil de densidades obtido do escaneamento (b) e imagem reconstruída (c). 
Observa-se também que tomando como base apenas as perfilagens, uma visualização da distribuição de densidades nos modelos fica bastante limitada e difícil de avaliar sem lançar mão de mais informações, outros testes e suposições. $\mathrm{Na}$ simulação da coluna de recheio, mostrada na Figura 61, mesmo diferentes perfis de densidades não dariam pista sobre a distribuição concêntrica de liquido no recheio e tenderiam a indicar um problema de retenção de líquido no topo o que, de fato, não ocorre.

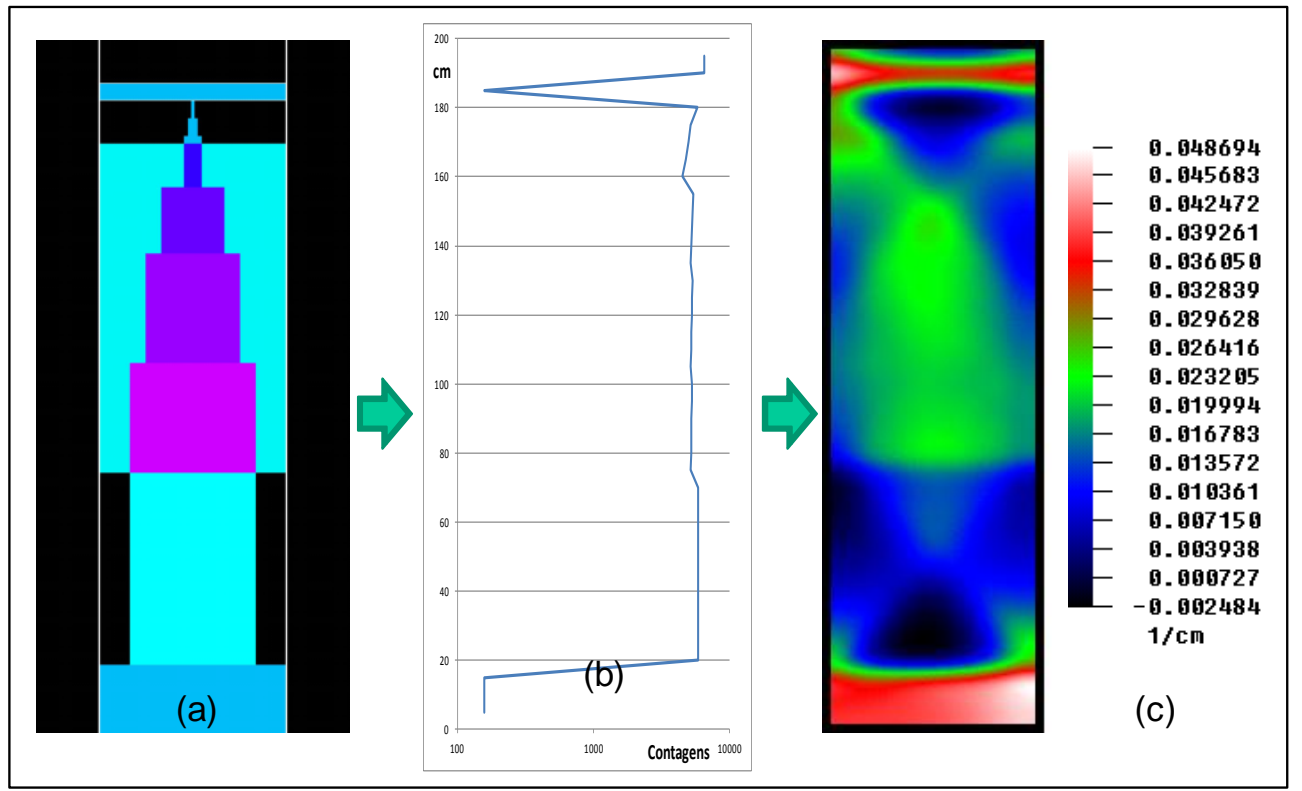

Figura 61 - Modelo simulado de uma coluna de recheio (a), perfil de densidades obtido do escaneamento (b) e imagem reconstruída (c).

Observa-se também que a qualidade das imagens obtidas é melhor para as regiões aonde a quantidade de cruzamentos entre os diversos feixes é maior. Nos experimentos, com o ângulo relativo limitado, existem duas regiões triangulares nas extremidades superiores e inferiores da imagem aonde a quantidade de cruzamentos de feixes é menor e, consequentemente, a fidelidade da imagem reconstruída é menor, conforme mostrado na Figura 62. 


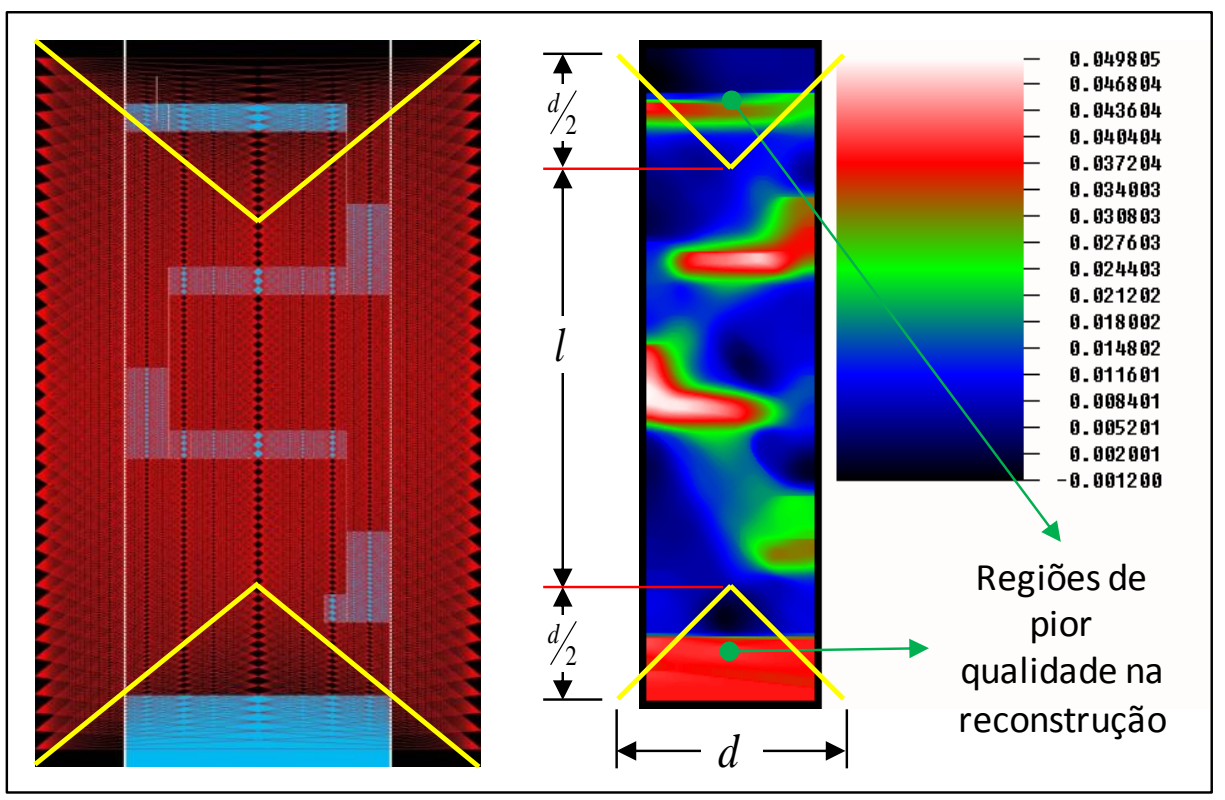

Figura 62 - Regiões com menor fidelidade na reconstrução na coluna de pratos.

Dessa forma, se a distância horizontal entre a fonte e o detector é "d", o comprimento de interesse para analise for "I" e o ângulo de abertura limitado a " $\alpha$ " graus, deve se percorrer uma distância total de escaneamento "I+d.tan( $\alpha)$ ". Quando limitado a $45^{\circ}$ a distância passa a ser "I+d", como mostrada na Figura 62.

A limitação do ângulo relativo resulta num maior erro na obtenção de valores corretos de " $\mu$ ", na definição dos contornos no sentido vertical da imagem e na presença de manchas na imagem. Para a coluna de pratos, a perda na qualidade da imagem não pareceu significativa, provavelmente pelo fato do arranjo apresentar regiões de vapor (maior contagem) entre os pratos, permitindo ao algoritmo manter as regiões de maior densidade desconexas. Para a coluna de recheio, o algoritmo apresenta dificuldade de determinar a distribuição em partes dessas regiões, conforme mostrado na Figura 63. 


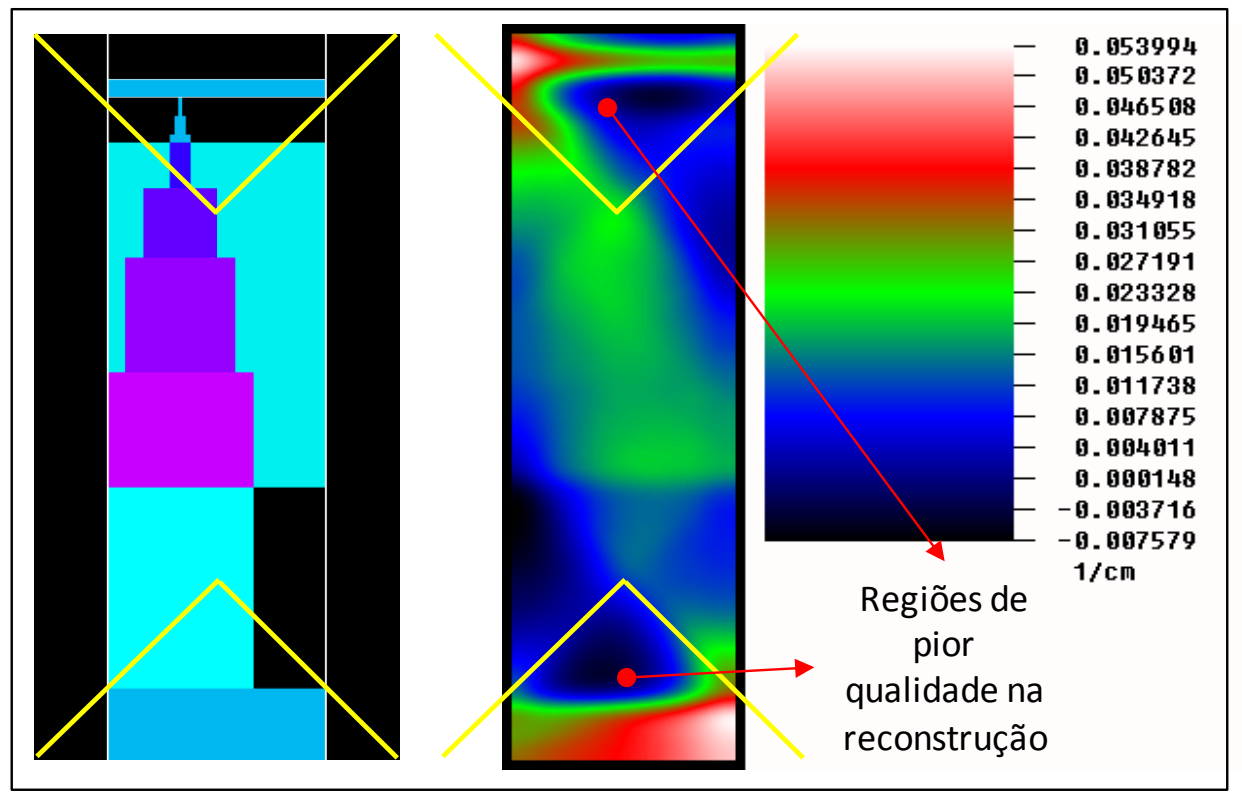

Figura 63 - Regiões com menor fidelidade na reconstrução na coluna de recheio.

\subsection{ART versus MART}

Como podem ser observados nos detalhes (a) e (b) da Figura 36, as reconstruções obtidas pelo método MART (detalhe b) resultam em imagens mais nítidas e com melhor contorno de borda. Contudo, uma limitação do método MART (Multiplicative Algebraic Reconstruction Technique) é que ele não aceita densidades negativas em nenhuma etapa do processamento. Sua aplicação mostrou-se difícil nas irradiações obtidas neste trabalho, pois valores negativos aparecem no processamento pela limitação das medidas decorrentes do ângulo relativo reduzido e da dificuldade do algoritmo resolver a contribuição no aumento dos " $\mu \mathrm{s}$ " decorrentes dos objetos delgados.

Assim, no restante do trabalho, nas reconstruções de imagens, empregaramse apenas o método ART (Algebraic Reconstruction Technique).

\subsection{Influência de objetos delgados}

Neste trabalho de Mestrado, os dados empregados para gerar as imagens tomográficas não foram normalizados. A espessura da parede lateral do protótipo de colunas de $0,4 \mathrm{~cm}$ é o principal meio absorvedor delgado, que resulta no aumento dos valores de " $\mu$ " obtidos. Assim, conhecendo a espessura e de $0,8 \mathrm{~cm}$, a distância 
"d" de 125,2cm, $\mu_{1}=\mu_{\text {aço, }} \mu_{2}=\mu_{\text {ar }}$; podemos calcular $o$ aumento geral dos valores de " $\mu$ " a serem obtidos nas imagens (Equação 18).

$$
\Delta \mu=\mu_{\text {aparente }}-\mu_{a r}=\frac{-\ln \left(e^{-\mu_{1} \cdot 2 e} \cdot e^{-\mu_{2} \cdot d}\right)}{d+2 \cdot e}-\mu_{a r}=0,0026831 / \mathrm{cm}
$$

Logo, os valores de referência que devem ser encontrados são:

- $\mu_{\text {aço }}^{\prime}=\mu_{\text {aço }}+0,002683=0,4225911 / \mathrm{cm}$;

- $\mu_{\text {água }}=\mu_{\text {água }}+0,002683=0,0658451 / \mathrm{cm}$; e

- $\mu_{\mathrm{ar}}^{\prime}=\mu_{\mathrm{ar}}+0,002683=0,0027511 / \mathrm{cm}$.

\subsection{Coluna de pratos escaneada com detector de radiação de 1"}

O primeiro experimento prático da tecnologia resultou numa imagem de qualidade bastante similar àquela obtida pelo processo de simulação, como pode ser vista na Figura 64, e indica que a técnica é bastante robusta e promissora, pois mesmo empregando um detector não ideal para a energia da fonte radioativa (cobalto-60) e aplicação propostas, com taxas de contagens pequenas e ainda que os valores reconstruídos dos " $\mu$ s" não estejam perto dos valores corretos; obteve-se um perfil de densidades 2D, que já supera em qualidade e quantidade de informações obtidas em qualquer gráfico de perfilagem. 


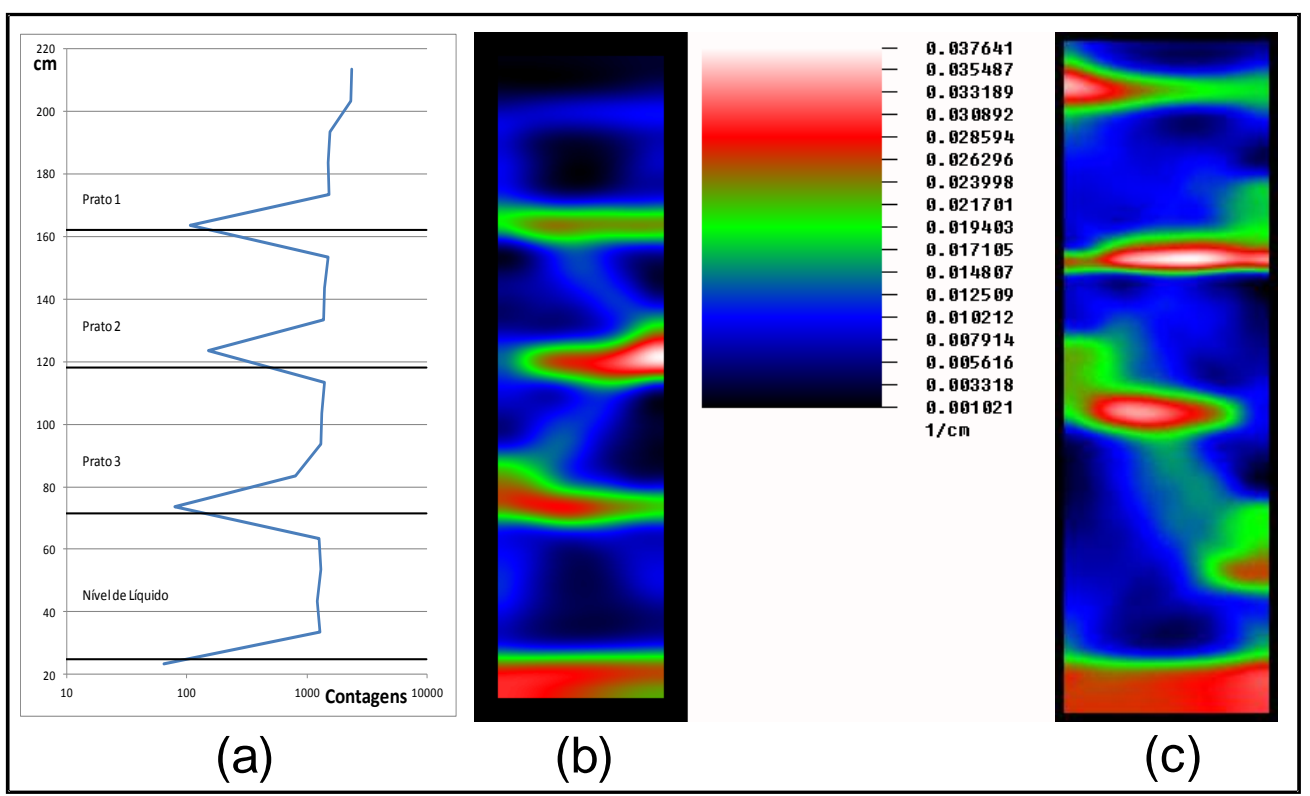

Figura 64 - Perfil de densidades obtido experimentalmente (a), imagem reconstruída utilizando-se detector de radiação [ $\mathrm{Nal}(\mathrm{TI})]$ de 1 polegada e passo de $10 \mathrm{~cm}$ (b) e imagem obtida de simulação inicial, com modelo em AutoCAD (c).

Os resultados indicam alguns pontos a considerar na sequencia de experimentos deste trabalho:

- Para reduzir o tempo de teste, aumentar a quantidade de irradiações e empregar janelas de menor tamanho será necessário empregar uma fonte radioativa de maior atividade;

- Um dos objetivos indiretos deste é de lidar com as limitações práticas imposta nos trabalhos de campo reais, verificando qual a qualidade de resultados obtidos. Uma contraproposta, para aplicação em laboratório, seria dotar o protótipo de automação, para facilitar a tomada de dados e eliminar qualquer limitação de tempo imposta;

- Foi possível obter uma boa imagem empregando o detector de 1 polegada. Provavelmente em sistemas de menor dimensão e empregando fontes de menor energia, possa se obter imagens de melhor qualidade com valores mais corretos dos " $\mu \mathrm{s}$ "; e 
- Mostra-se necessário criar um método para mensurar a qualidade da imagem de forma analítica, ainda que neste momento uma avaliação visual e subjetiva da imagem pareça mais precisa.

\subsection{Coluna de pratos escaneada com detector de radiação de 2"}

Nas imagens obtidas na segunda experiência prática pode-se observar o efeito do passo na tomada de dados na qualidade da imagem gerada, como pode ser visto nas Figuras 65 a 68. À medida que se aumenta o passo, mais difusas ficam as bordas e menos detalhes podem ser observados na imagem. Apesar disto, as principais feições são observadas em todas as imagens e a quantidade de informações obtidas na imagem reconstruída é maior do que no correspondente perfil de densidades.

Uma consequência pratica disto é que, a depender da qualidade de imagem final considerada suficiente, provavelmente não seja necessário tomar dados no menor passo disponível para obter informações superiores a uma perfilagem tradicional. O maior tempo gasto na tomada de dados talvez seja compensado pelo melhor resultado, e baseado em resultados de simulações possa ser feita uma analise para a escolha da melhor opção de ensaio, como apresentada na Tabela 9.

Tabela 9 - Quadro comparativo do número de pontos e tempo despedido versus qualidade de resultado da segunda experiência.

\begin{tabular}{crcc}
\hline Teste & Pontos & Tempo de teste [s] & Qualidade análise \\
\hline Perfilagem tradicional & 40 & 370 & Limitada \\
\hline Imageamento $-5 \mathrm{~cm}$ & 1.388 & 12.840 & Ótima \\
\hline Imageamento $-10 \mathrm{~cm}$ & 356 & 3.293 & Boa \\
\hline Imageamento $-15 \mathrm{~cm}$ & 149 & 1.378 & Razoável \\
\hline
\end{tabular}


Neste ponto, a capacidade de simular irradiações mostra seu potencial, pois torna possível desenvolver uma sequencia específica nas tomadas de dados, que maximize a qualidade da imagem numa determinada região de interesse.

Nas Figuras 65 a 66 foram empregados dois mecanismos de filtragem na obtenção das imagens. A filtragem média, empregada na Figura 65, privilegia a visualização de transições de densidade e a filtragem mediana privilegia a visualização de arestas. Como pode ser visto na Figura 66, a filtragem mediana revelou uma boa definição da interface de liquido sobre os pratos, nos vertedores e na região do fundo da coluna. Também é possível observar com clareza o abaulamento existente no fundo dos pratos, que é justamente mais proeminente nos pratos 2 e 3 .

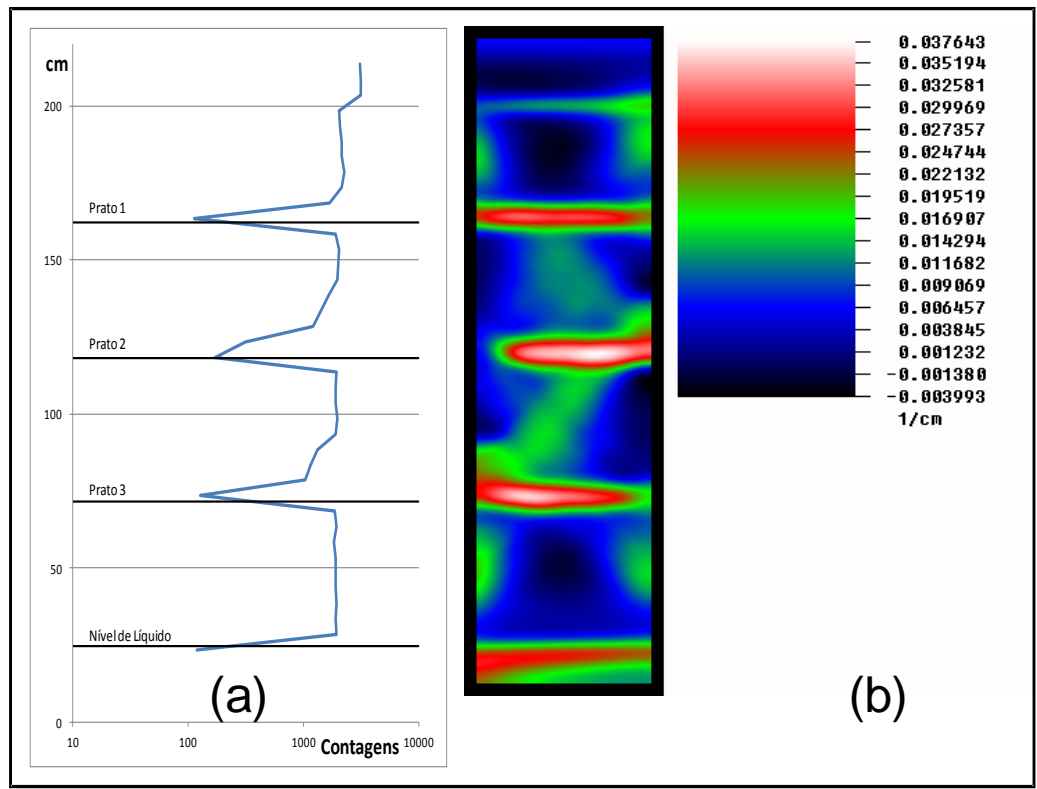

Figura 65 - Perfil de densidades (a) e imagem obtida usando detector de radiação $[\mathrm{Nal}(\mathrm{TI})]$ de 2 polegadas, passo de $5 \mathrm{~cm}$ e filtragem média (b). 


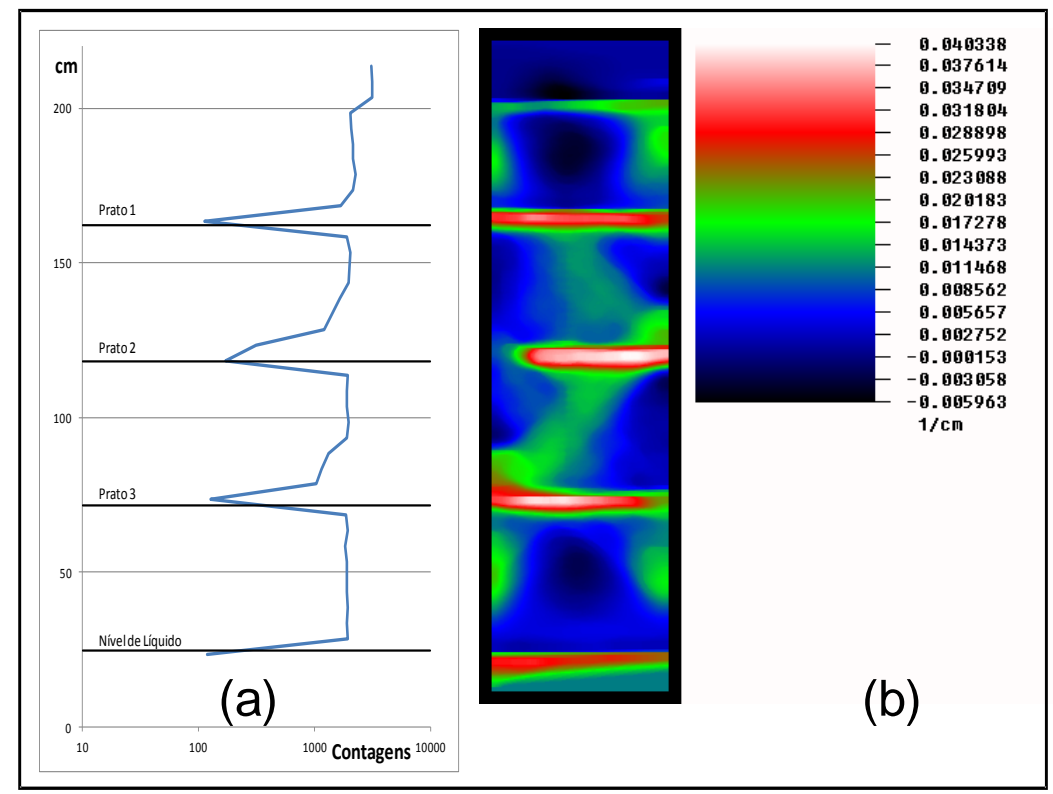

Figura 66 - Perfil de densidades (a) e imagem obtida usando detector de radiação $[\mathrm{Nal}(\mathrm{TI})]$ de 2 polegadas, passo de $5 \mathrm{~cm}$ e filtragem mediana (b).

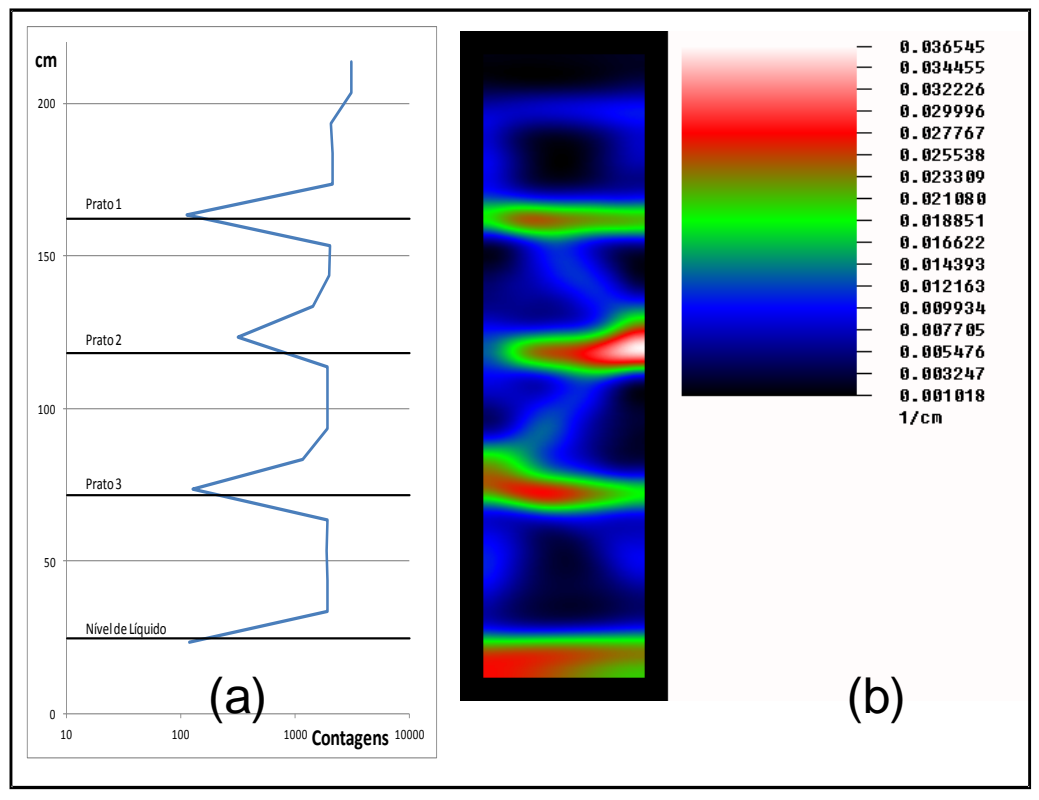

Figura 67 - Perfil de densidades (a) e imagem obtida usando detector de radiação [Nal(TI)] de 2 polegadas e passo de $10 \mathrm{~cm}(b)$. 


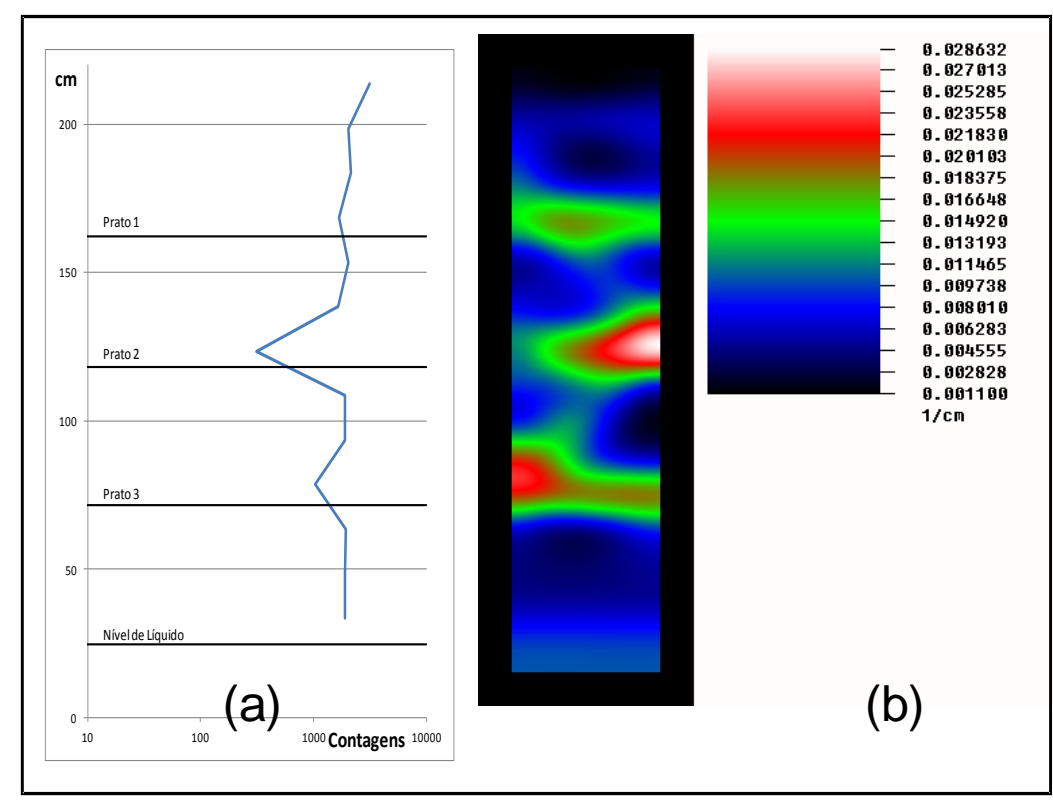

Figura 68 - Perfil de densidades (a) e imagem obtida usando detector de radiação [Nal(TI)] de 2 polegadas e passo de $15 \mathrm{~cm}(\mathrm{~b})$.

Na Figura 69 são mostradas algumas das características da coluna de pratos, que podem ser identificadas com facilidade na imagem reconstruída com passo de $5 \mathrm{~cm}$. Todavia, mesmo nas outras imagens reconstruídas com passo $10 \mathrm{~cm}$ ou $15 \mathrm{~cm}$ é possível visualizar feições como a presença de líquido nos pratos e regiões de vapor. A entrada do vertedor 2 , de maior dimensão, é claramente visível, enquanto que a dos pratos 1 e 3 , não é muito nítida. 


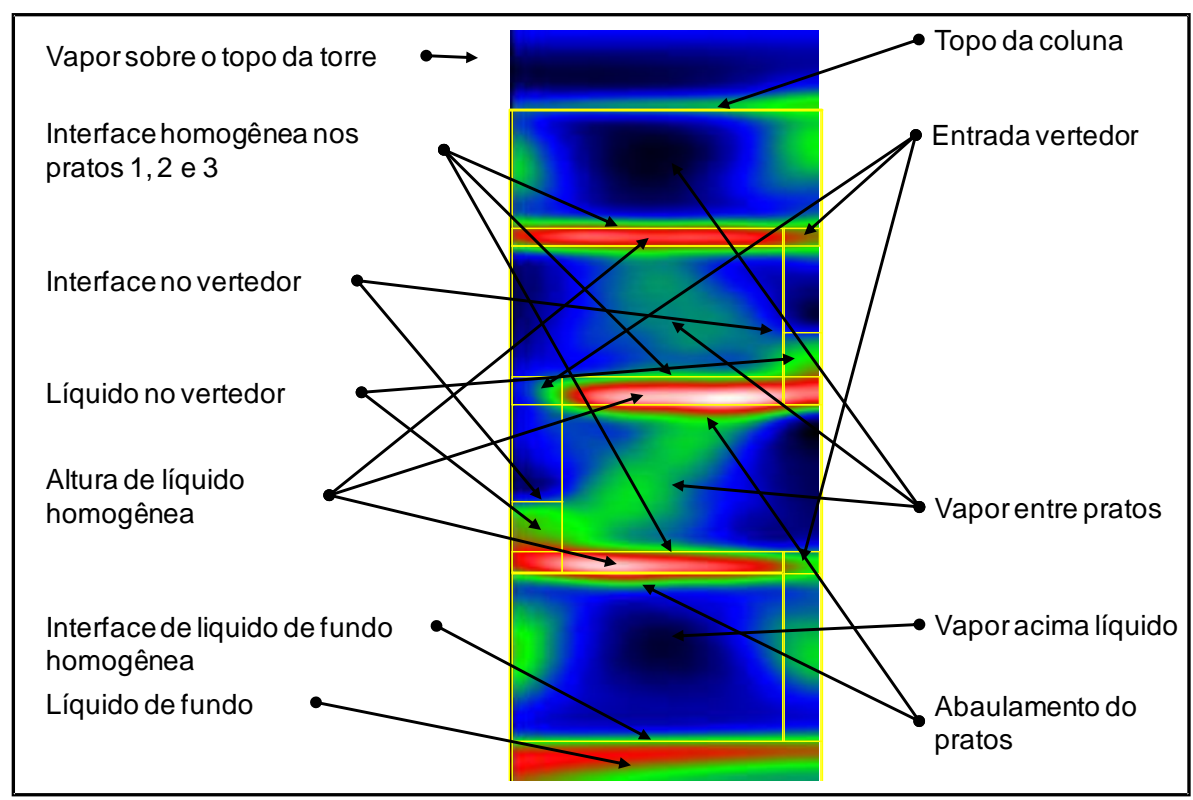

Figura 69 - Principais características observadas na imagem reconstruída da coluna de pratos com passo de $5 \mathrm{~cm}$.

Intuitivamente pode-se esperar que a resolução espacial da técnica, ou seja, a menor feição que ela pode identificar seja menor ou da ordem do passo aplicado, uma vez que o processo de reconstrução das imagens parece agregar definição nas imagens. Todavia, dadas as limitações do ângulo relativo, provavelmente a resolução espacial na direção horizontal seja maior do que na direção vertical. Neste segundo experimento, os pratos 1 , 2 e 3 apresentavam $5 \mathrm{~cm}, 8 \mathrm{~cm}$ e $6 \mathrm{~cm}$ de altura de líquido, respectivamente, sendo possível visualizar nas Figuras 65 a 69, que os pratos realmente têm diferentes alturas de líquido. Por outro lado, a entrada do vertedor do prato 2 , com $9,2 \mathrm{~cm}$ de largura é nitidamente visível, enquanto que a dos outros pratos, com $7,2 \mathrm{~cm}$, não estão nítidas ou definidas. Novamente, à medida que o passo aumenta essa diferenciação fica menos evidente, como pode ser observado comparando-se as Figuras 65 a 69.

Na Figura 70 são mostradas as imagens reconstruídas a partir dos dados de detectores de radiação $[\mathrm{Nal}(\mathrm{TI})]$ de 1 e 2 polegadas, com passo de $10 \mathrm{~cm}$. Ainda que uma avaliação quantitativa dos resultados não tenha sido feita, as imagens geradas, bem como os valores de " $\mu$ s" obtidos parecem bastante similares. 


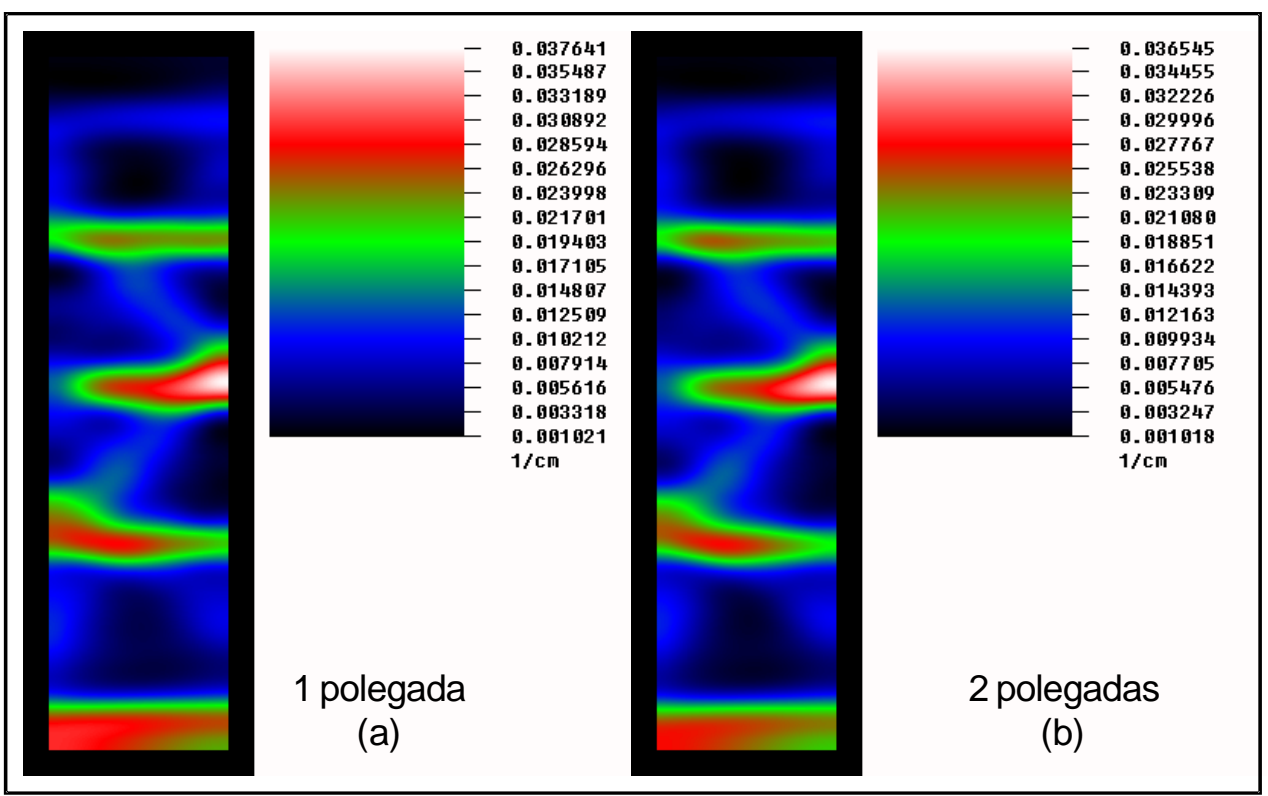

Figura 70 - Comparação entre imagens geradas com detectores de radiação [Nal(TI)] de 1 polegada (a) e 2 polegadas (b), com passo de $10 \mathrm{~cm}$.

Ainda que os dois conjuntos de dados tivessem valores e, por conseguinte, estatísticas bem distintas, o resultado das imagens é surpreendentemente parecido. Uma hipótese é que no conjunto a estatística das quase 360 tomadas de dados fique fortalecida.

A relação dos volumes dos detectores de radiação $[\mathrm{Nal}(\mathrm{TI})]$ de 1 e 2 polegadas é de 4 , valor bem similar a razão encontrada entre as medidas de radiação feitas nos experimentos. Isso indica que os espectros de energia medidos foram parecidos, daí a semelhança nos resultados.

Na Tabela 10 são apresentados os resultados obtidos no cálculo do erro nas imagens geradas. 
Tabela 10 - Erro observado entre o maior valor e a variação total de " $\mu$ " na imagem reconstruída com relação aos valores do modelo.

Experimento

$$
\mu[1 / \mathrm{cm}]^{*} \quad \Delta \mu[1 / \mathrm{cm}]
$$

\section{Encontrado Erro [\%] Encontrado Erro [\%]}

$\begin{array}{lllll}\text { ART } & 0,056735 & -13,8 & 0,060860 & -3,5\end{array}$

Modelo

Auto CAD

\begin{tabular}{ccccc} 
MART & 0,067031 & 1,8 & 0,064929 & 2,9 \\
$\begin{array}{c}1.000 \times 2.000 \\
\text { pixels }\end{array}$ & 0,080690 & 22,5 & 0,095033 & 50,6 \\
\hline
\end{tabular}

Modelo

Simulação

ART

$\begin{array}{ccccc}\begin{array}{c}2.000 \times 4.000 \\ \text { pixels }\end{array} & 0,054759 & -16,8 & 0,061306 & -2,8\end{array}$

$5 \mathrm{~cm}$

$3.000 \times 6.000$ pixels

0,057261

$-13,0$

0,063746

1,0

\begin{tabular}{ccccc}
\hline $\begin{array}{c}\text { Nal(TI) 1"- } 10 \mathrm{~cm} \\
\text { ART }\end{array}$ & 0,037641 & $-42,8$ & 0,037539 & $-40,5$ \\
\hline $\begin{array}{c}\text { Nal(TI) 2" - } 5 \mathrm{~cm} \\
\text { ART - média }\end{array}$ & 0,037643 & $-42,8$ & 0,041636 & $-34,0$ \\
\hline $\begin{array}{c}\text { Nal(TI) 2" - 5cm } \\
\text { ART - mediana }\end{array}$ & 0,040338 & $-38,7$ & 0,046301 & $-26,6$ \\
\hline $\begin{array}{c}\text { Nal(TI) 2"- } 10 \mathrm{~cm} \\
\text { ART }\end{array}$ & 0,036545 & $-44,5$ & 0,035527 & $-43,7$ \\
\hline $\begin{array}{c}\text { Nal(TI) 2"-15cm } \\
\text { ART }\end{array}$ & 0,028632 & $-56,5$ & 0,027532 & $-56,4$ \\
\hline
\end{tabular}

$* \mu_{\text {água }}^{\prime}=0,065485 \frac{1}{\mathrm{~cm}}$ e $\mu_{\text {ar }}^{\prime}=0,002751 \frac{1}{\mathrm{~cm}}$.

Os resultados desta análise indicam que: 
- Apesar da limitação de usar o método MART, quando aplicável ele resulta em melhores imagens;

- Os modelos gerados em AutoCAD resultaram em imagens melhores do que os simulados. Isto pode apontar para algum problema na simulação dos dados;

- Uma parcela do erro nos valores gerados dos " $\mu s$ " deve se às limitações do ângulo relativo e das paredes da coluna, que resulta em manchas e espalhamento de valores pela imagem. Alguma falha no programa de reconstrução não pode ser descartada;

- Os resultados dos modelos simulados são melhores quanto mais precisa for a discretização do modelo;

- Os resultados dos modelos irradiados foram piores que os simulados. Isto pode indicar algum problema na obtenção dos dados ou calibração do sistema detector;

- Ainda que ligeiramente inferior, o resultado da reconstrução empregando detector de 2 polegada e passo de $10 \mathrm{~cm}$ é similar ao encontrado com o detector de 1 polegadas e passo de $10 \mathrm{~cm}$;

- A reconstrução com filtro mediana é melhor do que com o filtro médio;

- O aumento do passo diminuiu a qualidade da imagem; e

- Uma melhor avaliação das imagens provavelmente será possível com o uso de outro algoritmo, que compare a imagem com algum modelo.

\subsubsection{Imagens geradas após ajuste nos programas}

As imagens entre as Figuras 71 a 73 foram obtidas após verificação, correção e recompilação dos programas de simulação e reconstrução de imagens. Os dados de irradiação são os mesmos do item 5.5 e o modelo para simulação empregado tem 1.260 x 2.000 pixels e possui a mesma configuração de internos do protótipo de coluna de pratos experimental. 


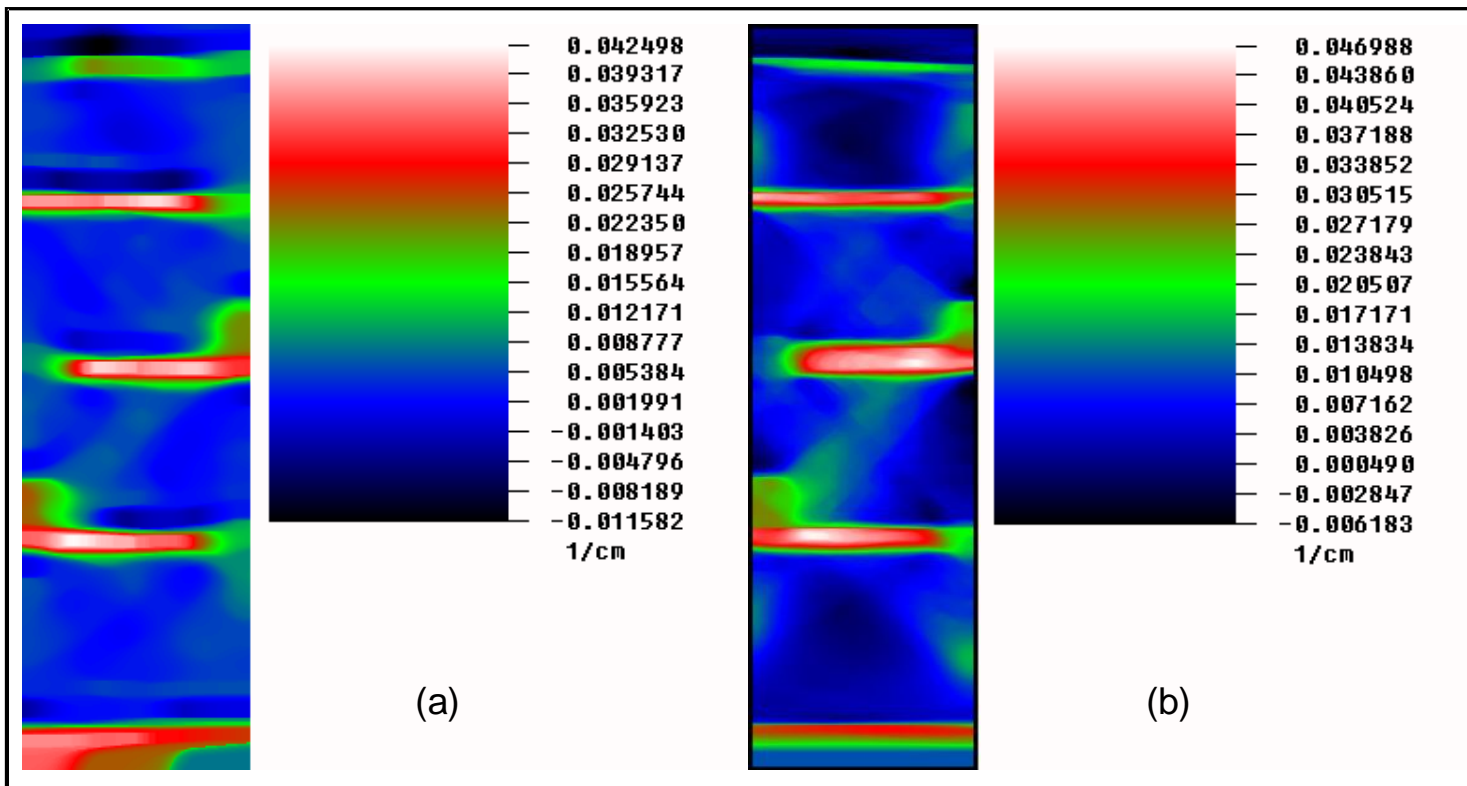

Figura 71 - Imagem obtida usando detector de radiação [Nal(TI)] de 2 polegadas e passo de $5 \mathrm{~cm}$ (a) e imagem obtida por dados simulados (b).

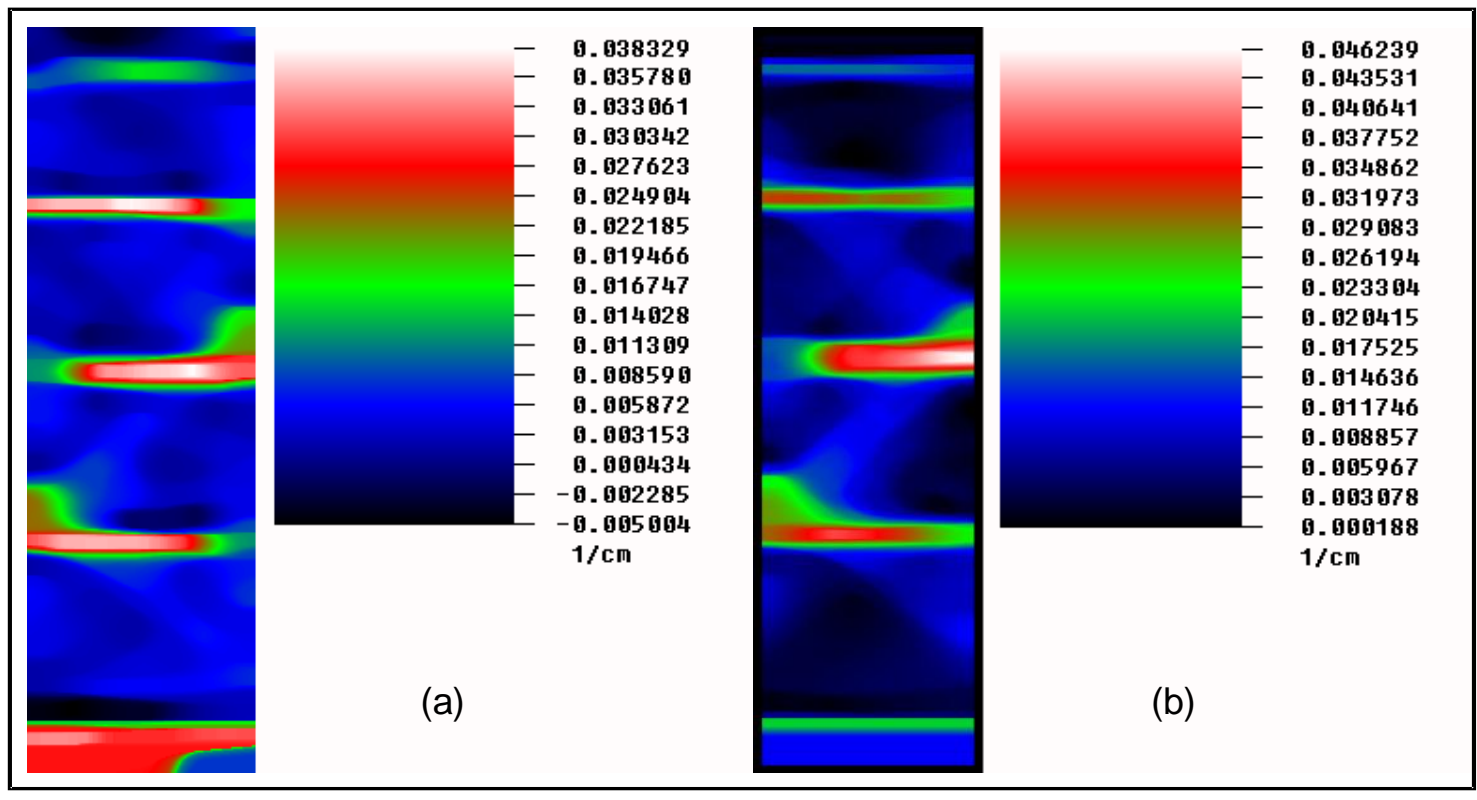

Figura 72 - Imagem obtida usando detector de radiação [Nal(TI)] de 2 polegadas e passo de $10 \mathrm{~cm}$ (a) e imagem obtida por dados simulados (b). 


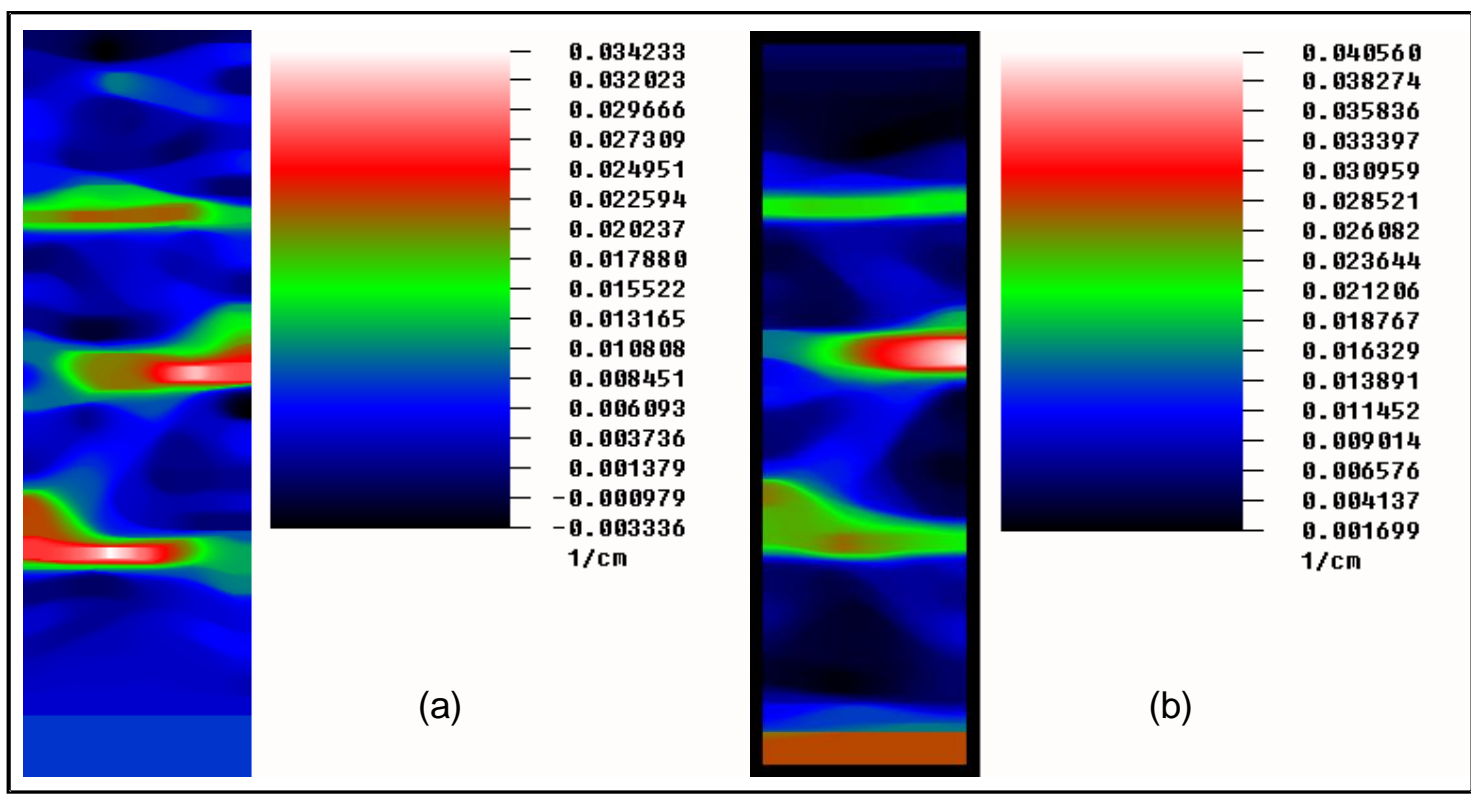

Figura 73 - Imagem obtida usando detector de radiação [Nal(TI)] de 2 polegadas e passo de $15 \mathrm{~cm}$ (a) e imagem obtida por dados simulados (b).

A Tabela 11 resume o cálculo do erro no valor do maior " $\mu$ " e da variação total de " $\mu$ " encontrado entre as Figuras 71 a 73. 
Tabela 11 - Erro observado entre o maior valor e a variação total de " $\mu$ " na imagem reconstruída com relação aos valores do modelo, após correção de programas.

\begin{tabular}{|c|c|c|c|c|}
\hline \multirow{2}{*}{ Experimento } & \multicolumn{2}{|c|}{$\mu[1 / \mathrm{cm}]$ * } & \multicolumn{2}{|c|}{$\Delta \mu[1 / \mathrm{cm}]$} \\
\hline & Encontrado & Erro [\%] & Encontrado & Erro [\%] \\
\hline $\begin{array}{c}\text { Simulação }-5 \mathrm{~cm} \\
\text { ART }\end{array}$ & 0,046988 & $-28,6$ & 0,053171 & $-15,7$ \\
\hline $\begin{array}{c}\text { Simulação }-10 \mathrm{~cm} \\
\text { ART }\end{array}$ & 0,046239 & $-29,8$ & 0,046051 & $-27,0$ \\
\hline $\begin{array}{c}\text { Simulação }-15 \mathrm{~cm} \\
\text { ART }\end{array}$ & 0,040560 & $-38,4$ & 0,038861 & $-38,4$ \\
\hline $\begin{array}{c}\mathrm{Nal}(\mathrm{TI}) 2 "-5 \mathrm{~cm} \\
\mathrm{ART}\end{array}$ & 0,042498 & $-35,5$ & 0,054080 & $-14,3$ \\
\hline $\begin{array}{c}\mathrm{Nal}(\mathrm{TI}) 2 "-10 \mathrm{~cm} \\
\mathrm{ART}\end{array}$ & 0,038329 & $-41,8$ & 0,043333 & $-31,3$ \\
\hline $\begin{array}{c}\mathrm{Nal}(\mathrm{TI}) 2 "-15 \mathrm{~cm} \\
\mathrm{ART}\end{array}$ & 0,034233 & $-48,0$ & 0,037569 & $-40,5$ \\
\hline
\end{tabular}

Os resultados desta análise indicam que:

- Os modelos simulados possuem dimensões e configurações de internos distintas o que impossibilita uma comparação direta. $O$ erro do modelo simulado provavelmente deve cair quanto mais precisa for a discretização adotada, como observado na Tabela 10;

- Observar que no limite a discretização da coluna deve convergir para o modelo simulado em AutoCAD;

- Tanto nos modelos simulados como nos irradiados a qualidade da imagem piora com o aumento do passo; 
- Novamente, o erro nos valores gerados dos " $\mu \mathrm{s}$ " provavelmente devem-se às limitações do ângulo relativo e à parede da coluna, que resulta em manchas e espalhamento de valores pela imagem;

- As manchas normalmente aparecem como borrões na mesma inclinação do ângulo relativo máximo. O espalhamento da radiação é visto como uma cor de fundo uniforme, cujo valor de " $\mu$ " é maior que o do ar; e

- Os resultados dos modelos irradiados ainda são piores que os simulados. Isto pode indicar algum problema de calibração do sistema detector.

\subsection{Coluna de recheio escaneada com detector de radiação de 2"}

As imagens reconstruídas a partir dos dados da terceira experiência são mostradas entre as Figuras 74 a 76. Para cada passo são apresentados o perfil de densidades correspondente, a imagem reconstruída a partir dos dados de irradiação e uma imagem obtida por simulação.

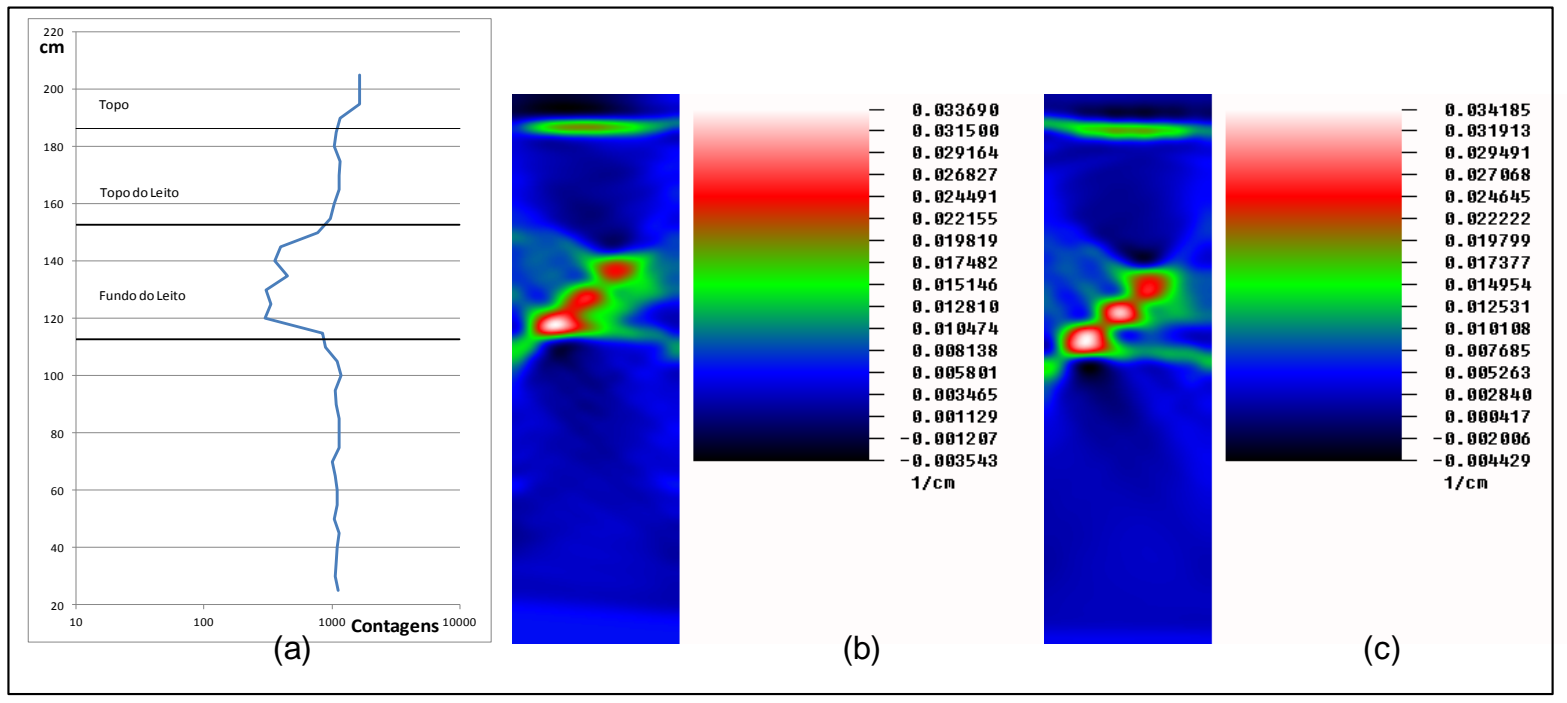

Figura 74 - Experiência na coluna com recheio randômico e passo de $5 \mathrm{~cm}$ : perfil de densidades (a), imagem reconstruída a partir de irradiação (b) e imagem obtida por simulação (c). 


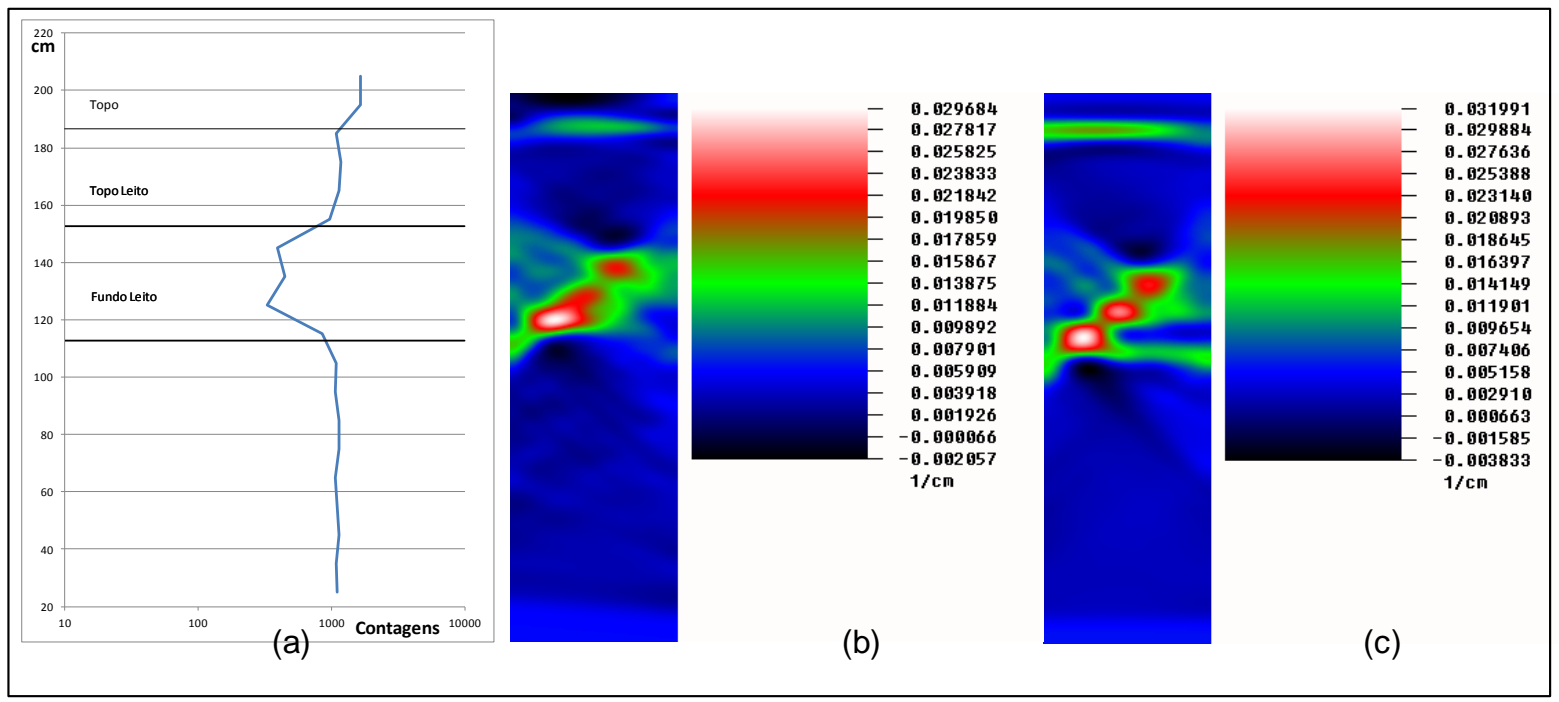

Figura 75 - Experiência na coluna com recheio randômico e passo de $10 \mathrm{~cm}$ : perfil de densidades (a), imagem reconstruída a partir de irradiação (b) e imagem obtida por simulação (c).

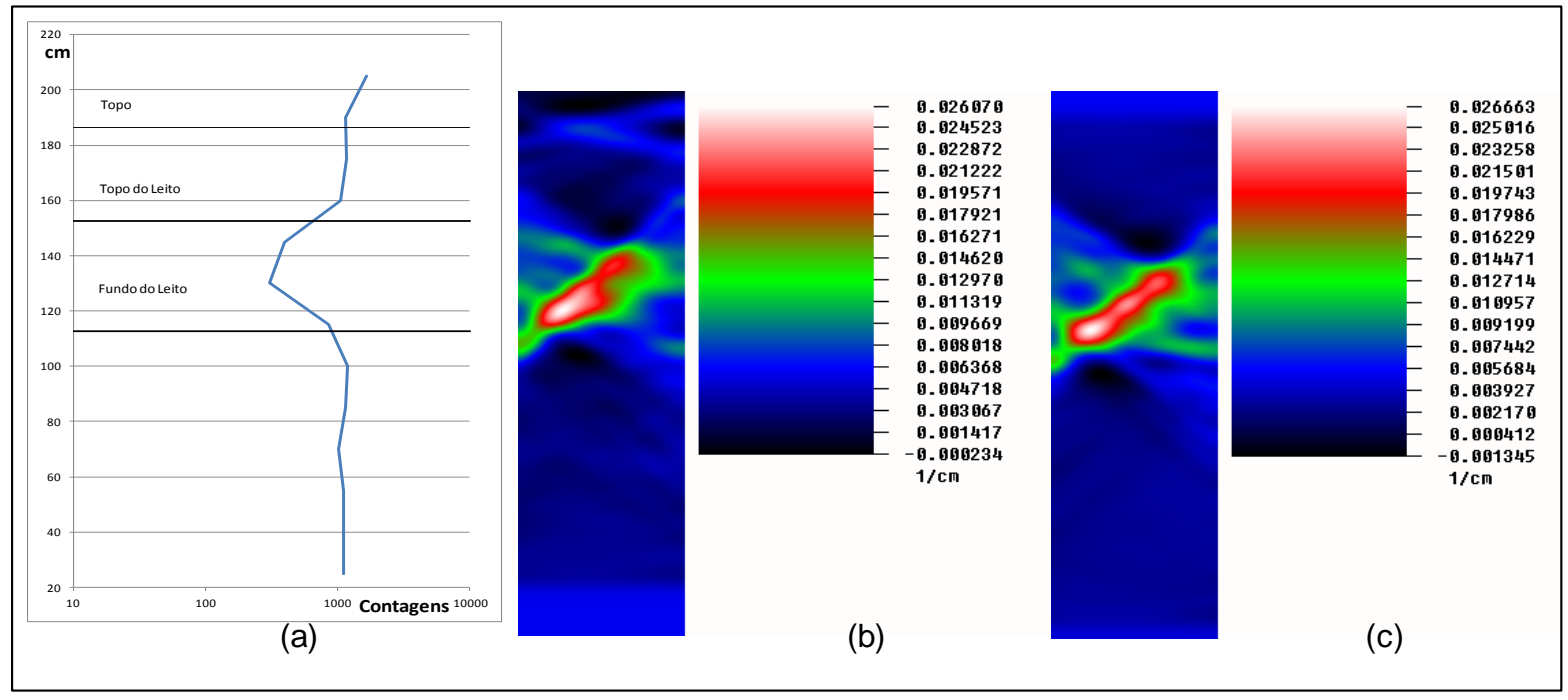

Figura 76 - Experiência na coluna com recheio randômico e passo de $15 \mathrm{~cm}$ : perfil de densidades (a), imagem reconstruída a partir de irradiação (b) e imagem obtida por simulação (c).

Novamente, pode-se observar que à medida que se aumenta o passo, mais difusas ficam as bordas e menos detalhes podem ser observados nas imagens. Neste experimento, o modelo de recheio empregado para simulação teve dimensões estimadas, daí a maior disparidade entre as imagens obtidas por simulação e aquelas por irradiação. 
Não obstante, as principais feições são observadas em todas as imagens e a quantidade de informações obtidas na imagem reconstruída é maior do que no correspondente perfil de densidades. Na Figura 77 apontam-se as principais características observadas na imagem reconstruída da coluna.

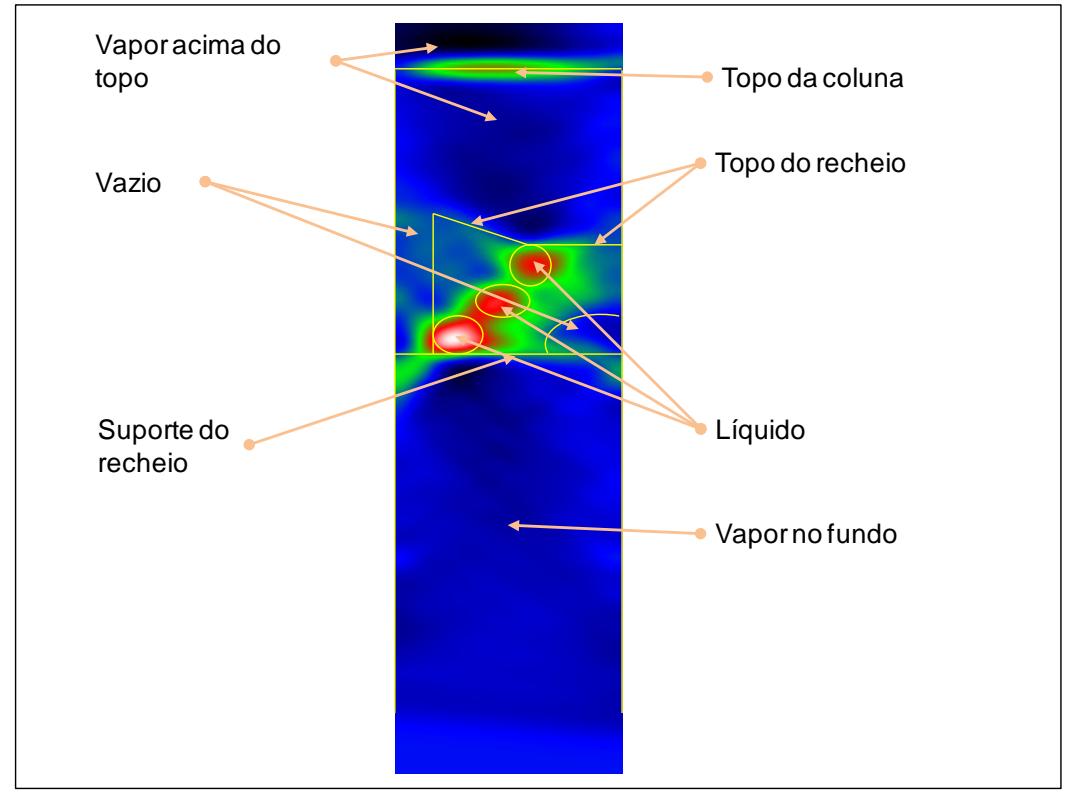

Figura 77 - Principais características observadas na imagem reconstruída da coluna com recheio randômico irradiada com passo de $5 \mathrm{~cm}$.

Na Figura 78 são mostradas as imagens reconstruídas, obtidas com o uso de ângulos relativos de $35^{\circ}, 45^{\circ}$ e $55^{\circ}$. Devido a maior largura final da abertura do protótipo para irradiação, de $1,26 \mathrm{~m}$ em vez de $1,00 \mathrm{~m}$, não foi possível irradiar a coluna num ângulo maior que $55^{\circ}$.

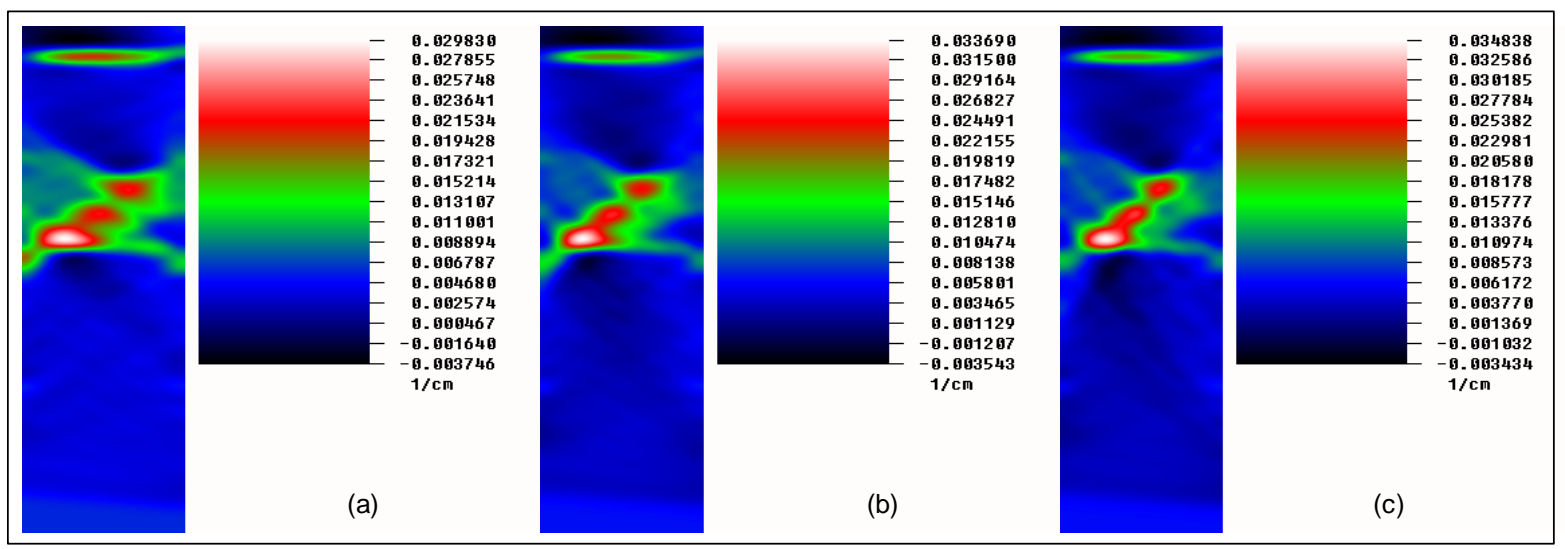

Figura 78 - Imagens obtidas com diferentes ângulos relativos: $35^{\circ}$ (a), $45^{\circ}$ (b) e $55^{\circ}$ (c). 
A Tabela 12 resume o cálculo do erro no valor do maior " $\mu$ " e da variação total de " $\mu$ " encontrado nas Figuras 74 a 76 e Figura 78.

Tabela 12 - Erro observado entre o maior valor e a variação total de " $\mu$ " na imagem reconstruída com relação aos valores do modelo.

Experimento
$\mu[1 / \mathrm{cm}]$ *
$\Delta \mu[1 / \mathrm{cm}]$

\section{Encontrado Erro [\%] Encontrado Erro [\%]}

Simulação $-5 \mathrm{~cm}$

ART

0,034185

$-48,1$

0,038614

$-38,8$

Simulação $-10 \mathrm{~cm}$ ART

$0,031991 \quad-51,4$

0,035824

$-43,2$

Simulação $-15 \mathrm{~cm}$ ART

0,026663

$-59,5$

0,028008

$-55,6$

$\mathrm{Nal}(\mathrm{TI}) 2 "-5 \mathrm{~cm}$

ART $-35^{\circ}$

0,029830

$-54,7$

0,033576

$-46,8$

$\mathrm{Nal}(\mathrm{TI}) 2 "-5 \mathrm{~cm}$

ART $-45^{\circ}$

0,033690

$-48,8$

0,037233

$-41,0$

$\mathrm{Nal}(\mathrm{TI}) 2 "-5 \mathrm{~cm}$

ART $-55^{\circ}$

0,034838

-47,

0,038272

$-39,3$

$\mathrm{Nal}(\mathrm{Tl}) 2 "-10 \mathrm{~cm}$

ART $-45^{\circ}$

0,029684

$-54,9$

0,031741

$-49,7$

$\mathrm{Nal}(\mathrm{TI}) 2 "-15 \mathrm{~cm}$ ART $-45^{\circ}$

0,026070

$-60,4$

0,026304

$-58,3$

* $\mu_{\text {água }}^{\prime}=0,065485 \% \frac{1}{\mathrm{~cm}}, \mu_{\text {ar }}^{\prime}=0,002751 \% \frac{1}{\mathrm{~cm}}$ e $\mu_{\text {recheio_pvc }}^{\prime}=0,015227 \frac{1}{\mathrm{~cm}}$.

Os resultados da análise indicam que:

- Não foi possível ver com nitidez todo o contorno do leito de recheio; 
- Tanto nos modelos simulados como nos irradiados a qualidade da imagem piora com o aumento do passo;

- A qualidade da imagem piora com a diminuição do ângulo relativo;

- Não há muita diferenciação nos resultados obtidos com $45^{\circ}$ e $55^{\circ}$, por causa da limitação física do protótipo;

- O erro nos valores gerados dos " $\mu s$ ", provavelmente, devem-se às limitações do ângulo relativo e à parede da coluna, que resulta em manchas e espalhamento de valores pela imagem; e

- Os resultados dos modelos irradiados estão semelhantes aos simulados. Isto indica que a simulação e a calibração do sistema detector estão melhores ajustados, como apresentado na Tabela 13.

Tabela 13 - Diferença entre os valores de " $\mu$ " obtidos por simulação e irradiação.

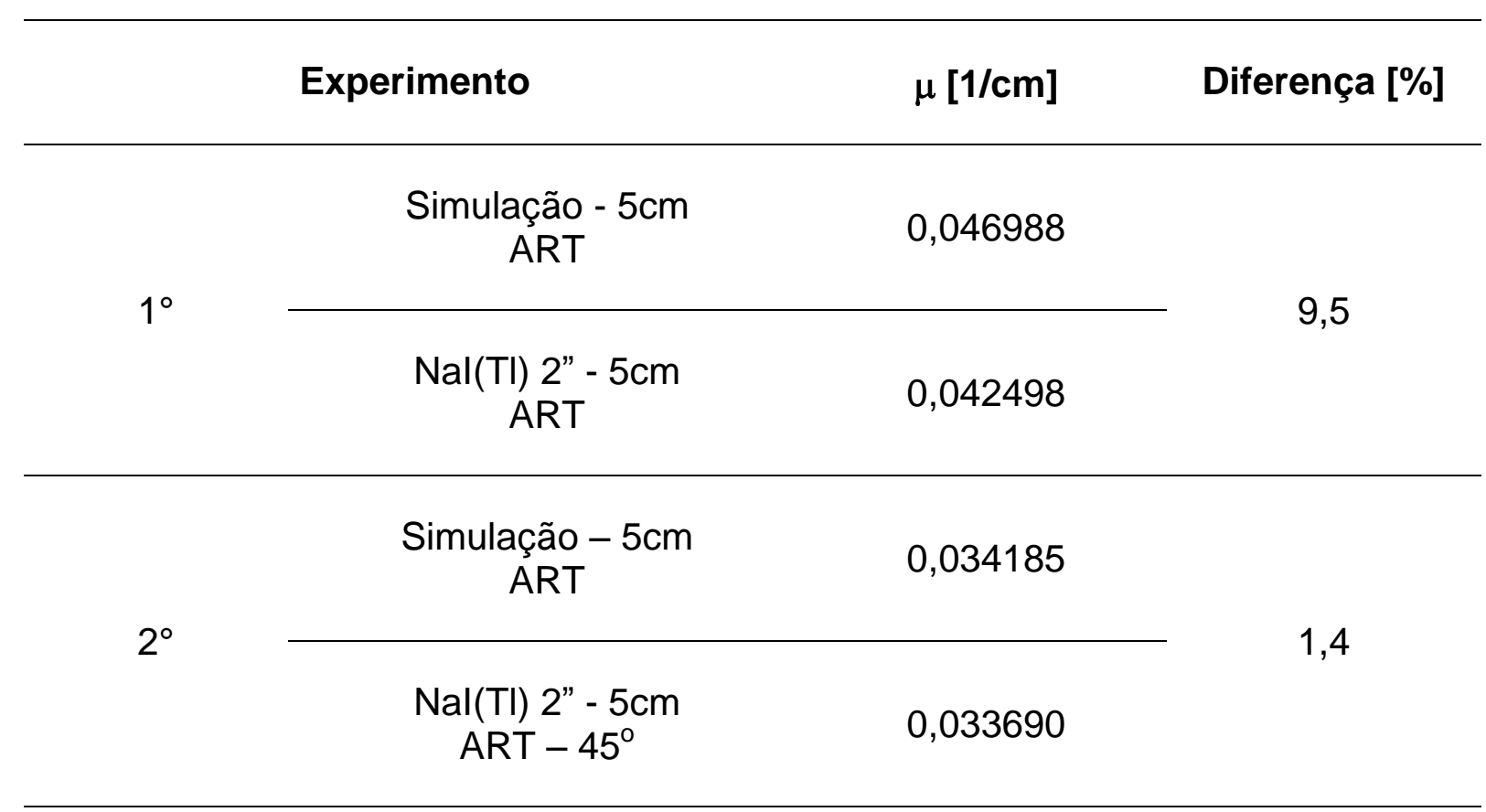




\section{CONCLUSÃO}

A proposta deste trabalho de Mestrado em gerar imagens da distribuição de densidades 2D longitudinais, a partir da técnica de perfilagem de colunas pode ser considerada cumprida. Ainda que modelos funcionais das colunas de processo industrial, com fenômenos reias que ocorrem na indústria e diferenças graduais de densidade não tenham sido analisadas, as imagens tomográficas geradas revelaram, de forma clara, as principais feições dos modelos construídos, facilitando a interpretação dos resultados obtidos de forma precisa e direta.

A técnica de imageamento de equipamentos industriais utilizando perfilagem por raios gama mostra-se, assim, bastante promissora representando um nítido avanço sobre as técnicas atualmente disponíveis no mercado de ensaios não destrutíveis para a indústria.

No processo de desenvolvimento, o conhecimento adquirido em vários campos deve beneficiar outras técnicas de ensaios não destrutivos (END). Novas técnicas de calibração e radioproteção podem ser tanto empregadas na perfilagem de colunas tradicional como em projetos de tomografia industrial convencional. Avanços relacionados à capacidade de simular irradiações permite planejar, antever e comparar com os resultados de experimentos práticos tem aplicação imediata na tomografia industrial convencional. Melhorias no sistema de reconstrução de imagens e o uso de resultados "a priori" também devem ser aplicados na tomografia industrial.

O trabalho aponta também a necessidade de desenvolvimento em diversas frentes sejam para aperfeiçoar a tarefa em escala laboratorial com aplicativos, simuladores, sistemas de automação e de simulação de processo ou para adquirir informações sobre a própria técnica, como no cálculo de " $\mu \mathrm{s}$ " e de determinação da resolução espacial. A aplicação e a investigação do uso de outras tecnologias para 
as necessidades específicas desta técnica, também abre potencial para outras atividades tecnológicas e acadêmicas. Finalmente, também é necessário preparar a tecnologia para uso real em campo, através de testes de aplicação para vislumbrar limitações e novos desafios. 


\section{REFERÊNCIAS BIBLIOGRÁFICAS}

[1] ELDRIDGE, Bruce R. Advanced hydraulic and mass transfer models for distillation column optimization and design. Final Project Report. The University of Texas and Oak Ridge National Laboratory, Austin, 2006.

[2] CHARLTON, John. S. Radioisotope techniques for problem solving in industrial process plants: gamma-ray absorption techniques. $1^{\text {a }}$ ed. Houston: Gulf. 1986. p. 226-245.

[3] XU, Simon X. Gamma cat-scans for distillation columns- from theory to practice. $4^{\text {TH }}$ TOPICAL CONFERENCE ON SEPARATION SCIENCE AND TECHNOLOGY, AICHE ANNUAL MEETING, November 4th, 1999, Dallas, TX.

[4] INTERNATIONAL ATOMIC ENERGY AGENCY. IAEA-TECDOC-1459, Technical Data on Nucleonic Gauges, Viena, 2005.

[5] TRICOM TECNOLOGIA E SERVIÇOS DE MANUTENÇÃO INDUSTRIAL LTDA. Brochura IG-01: Informativo Geral - escaneamento de colunas de destilação, 2009, Piquete, SP. Disponível em: www.tricomtecnologia.com.br. Acesso: 27/11/2012.

[6] TRICOM TECNOLOGIA E SERVIÇOS DE MANUTENÇÃO INDUSTRIAL LTDA. Brochura IT-01: Informativo Técnico 01 - escaneamento de colunas de destilação, 2009, Piquete, SP. Disponível em: www.tricomtecnologia.com.br. Acesso: 27/11/2012.

[7] TRICOM TECNOLOGIA E SERVIÇOS DE MANUTENÇÃO INDUSTRIAL LTDA. Brochura IT-05: Informativo Técnico 05 - tomografia industrial computadorizada, 2009, Piquete, SP. Disponível em: www.tricomtecnologia.com.br. Acesso: 27/11/2012.

[8] KIM, J., JUNG, S., KIM, J. A study on industrial gamma ray ct with a single source-detector pair. Daejeon: Korea Atomic Energy Research Institute (KAERI). Nuclear Engineering and Technology, Vol.38, No.4, June, 2006. 
[9] XU, S., KENNEDY G., CONFORTI C., MARUT, T., DUSSEAULT, J. Troubleshooting industrial packed columns by gamma-ray tomography. CE EXPO'99, Houston, October, 1999.

[10] HARAGUCHI, Marcio. I.; COLUSSI, Leandro.; GREGGIANIN, Luis. C. Testes on-line da 12-T-22 torre de lavagem caustica. XXVI CONAEND \& IEV, 9-12 de junho, 2008, São Paulo, SP. Anais do XXVI CONAEND \& IEV, São Paulo : ABENDE, 2008

[11] HARAGUCHI, Marcio. I. Testes on-line para colunas de destilação, reatores e fornos industriais. $4^{\circ}$ Congresso de Equipamentos e Automação da Indústria Química, 4-7 de maio, 1999, São Paulo. Anais do 4 Congresso de Equipamentos e Automação da Indústria Química. São Paulo : ABIQUIM, 1999.

[12] HARAGUCHI, Marcio. I.; PLESS, Lowell. T.; STRANGMEIER, David. Diagnóstico de colunas de destilação. XVI ENCONTRO DE PRODUTORES E CONSUMIDORES DE GASES INDUSTRIAIS, 18-20 de Setembro, 2001, Salvador. Anais do XVI ENCONTRO DE PRODUTORES E CONSUMIDORES DE GASES INDUSTRIAIS, São Paulo : ABM, 2001.

[13] PLESS Lowell T.; XU, Simon X.. Flooding phenomenon in distillation columns and its diagnosis. SEMINÁRIO DE DESTILAÇÃO DA PETROBRAS, 10 de Agosto, 2001, Belo Horizonte, MG.

[14] URBANSKI, Nicholas. F.; RESETARITS, Michael R.; SHAKUR, Mohamed S. M.; MONKELBAAN, Daniel R.; BUCIOR David A. Gamma scanning a column containing closely spaced trays. ANNUAL MEETING AICHE 1999: SEPARATIONS TOPICAL CONFERENCE. Session \#T1007 - Distillation Hardware and Applications II. $4^{\text {th }}$ November, 1999, Dallas, TX, U.S.A..

[15] SPEAR, M. Gamma scanning seeks an inside edge. Disponível em: http://www.chemicalprocessing.com/articles/2007/088/. Acesso: 08/02/2013.

[16] TRACERCO. RapidScan System. Disponível em: http://www.tracerco.com/Tower Rapid Scan System. Acesso: 08/02/2013.

[17] INTERNATIONAL ATOMIC ENERGY AGENCY. IAEA-TECDOC-1589 Industrial Process Gamma Tomography, Viena, 2008. 
[18] PEYTON, A. J.; BECK, M. S., BORGES A. R.; OLIVEIRA, J. E.; LYON, G. M.; YU, Z. Z.;BROWN, M. W.; FERRERRA ,J. Development of electromagnetic tomography (EMT) for industrial applications: Part 1: Sensor Design and Instrumentation. 1ST WORLD CONGRESS ON INDUSTRIAL PROCESS TOMOGRAPHY, April 14-17, 1999, Buxton, Greater Manchester.

[19] WIENS, T., BEHRENS, P. Turbulent flow sensing using acoustic tomography. INTER NOISE 2009, 23-26 August, 2009, Otawa, Canada.

[20] JOHANSEN, Geir A.; JACKSON, Peter. Radioisotope gauges for industrial process measurements: aplications, Chippenham, John Wiley, 2004. p.144-146, p. 240-243.

[21] XU, Simon X., Quantitatively measure and assess misdistribution in industrial packed towers. In: CE EXPO'2000, 7-8 June, 2000.

[22] HARAGUCHI, Marcio I.; KIM, Hae Y.; MACHADO, Ronaldo O. Tomografia industrial computadorizada. In: XXVIII CONGRESSO NACIONAL DE ENSAIOS NÃO DESTRUTIVOS E INSPEÇÃO, 22-25 de junho, 2010, Santos, SP.

[23] KIM, J., JUNG, S., MOON, J., CHO, G., Industrial gamma-ray tomographic scan method for large scale industrial plants. NUCLEAR INSTRUMENTS AND METHODS IN PHYSICS RESEARCH A, 640 (2011) p 139-150, 2011.

[24] PETROBRAS. Norma PETROBRAS N-2344 Rev. A - Segurança em trabalho de radiografia industrial - Segunda Emenda, Rio de Janeiro, 2006. (N2344)

[25] COMISSÃO NACIONAL DE ENERGIA NUCLEAR, Diretriz Básica de Proteção Radiológica Rio de Janeiro, 2006. (CNEN NN-3.01)

[26] SANCHES, Mathias. P.; HARAGUCHI, Marcio. I.; BECKMANN, Francis. S.; CALVO, Wilson. A. P. Radiological safety in the gamma scan procedures. INTERNATIONAL NUCLEAR ATLANTIC CONFERENCE (INAC-2007), 30 de Setembro -5 de Outubro, 2007, Santos, SP. Proceedings of INTERNATIONAL NUCLEAR ATLANTIC CONFERENCE, Santos : ABEN, 2007. 
[27] OLIVEIRA, Eric F.; MELO, Sílvio. B.; DANTAS, Carlos C.; VASCONCELOS, Daniel A. A.; CADIZ, Luís F. Comparison among tomographic reconstruction algorithms with a limited data. INTERNATIONAL NUCLEAR ATLANTIC CONFERENCE (INAC-2011), 24-28 de outubro, 2011, Belo Horizonte, MG. Proceedings, ISBN: 978-85-99141-04-5. 
PUBLICAÇÃO 


\title{
Industrial Equipment Troubleshooting with Imaging Technique Improved Gamma-ray Absorption Scans
}

\author{
Marcio Issamu Haraguchi ${ }^{1}$, Hae Yong $\mathrm{Kim}^{2}$, Francisco Edmundo Sprenger ${ }^{3}$ and Wilson Aparecido Parejo Calvo ${ }^{3}$ \\ 1. Process Diagnostics Division, Tricom Tecnologia Ltda., Sao Paulo, 12620-000, Brazil \\ 2. Polytechnic School, Department of Electronic Systems Engineering (LPS), Sao Paulo University (USP), Sao Paulo, 05508-900, \\ Brazil \\ 3. Radiation Technology Centre, Nuclear and Energy Research Institute, National Nuclear Energy Commission (IPEN-CNEN/SP),
}

Sao Paulo, 05508-000, Brazil

Received: June 02, 2012 / Accepted: August 08, 2012 / Published: September 15, 2012.

\begin{abstract}
Gamma scanning is one of the most common nuclear techniques on troubleshooting industrial equipments like distillation columns and reactors. With a very simple concept, the technique is easy to implement. Searching for a competitive edge the industry has been long developing solutions to achieve better results. On the last decades, significant development has been done with the advent of new equipments, electronics, portable computers and software. Continuous scanning and wireless detection systems are examples of successful field solutions, while new software aid on reporting and data presentation. However the type and quality of the results itself has not dramatically changed since its beginning. A scan profile is simple to understand, although the process to build it can be very complex as it requires a specific blend of knowledge and abilities. Process engineering, chemical engineering, internal hydraulic project, nuclear engineering and field abilities are pre requisites for of any scan specialist. Correct data gathering, interpretation and reporting are abilities often difficult to match or requires a long time of training. The industry faces a similar difficult on the customer side, as it is always necessary to train end users to understand a report and how to use its best. This paper describes our effort on developing a new approach on the gamma scan test using image reconstruction techniques that would result on a graphic image rather than a XY plot. Direct and easier to understand, a report with graphic images would be also be accessible to a wider audience, not limited to the customers experienced with gamma scan interpretation.
\end{abstract}

Key words: Industrial equipments, gamma ray, troubleshooting, image reconstruction, gamma scanning.

\section{Introduction}

In continuous production plants like refineries and petrochemical sites, the process equipment performance are analyzed with the help of a process model, according to this operational variables, quality of feed and products [1]. With increasing complexity and restricted boundaries of process, design and operations, the use of non-destructive testing (NDT) has been widely used to on-line validate, check and troubleshoot these process models.

Corresponding Author: Marcio Issamu Haraguchi, mechanical engineer, radiation safety officer and technical director at tricom tecnologia, research fields: gammascaning, industrial tomography and process troubleshooting. E-mail: marcio@tricomtecnologia.com.br.
Among the available technologies, nuclear techniques stand out by not perturbing or affecting the process in analysis, allowing that on-line testing be performed. Modern equipments and methods permit that nuclear techniques found only in literature migrate to the field. Distillation column gamma scanning, neutron backscattering, chemical and radioactive tracers and industrial computerized tomography are common practices nowadays and represents one of the most powerful techniques to on-line analyze process equipments.

Within these technologies, the distillation column profiling consolidated as one of the best options to perform a mechanical and operational troubleshoots. 
However, although it relies on simple principles, the practical use is complex due to the high specific knowledge required on all phases of a typical project. This barrier also turn out to be an extra difficulty for a wider divulgation and acceptance on the market, as the final customer need to have a good experience with the technique.

To solve technical difficulties and in the search of a competitive edge, the industry developed several solutions. However they did not resulted on higher quality information. All technologies on the market are based on the same principle: register gamma ray attenuation to generate a median density profile. This paradigm would be brake if a new technology presents a more direct and comprehensive result, with much better acceptance.

The computerized tomography is available for medical use for more than 30 years and, to this date, reaches a surprising level of complexity and precision. Imaging industrial equipment with the gamma scan profiling technique appears as a good alternative for a new approach. Although it users the same concepts, imaging industrial equipments faces a series of new challenges, difficulties and limitations, which imposes the need of a development plan to transpose the technique from lab scale to the field.

\section{Process Equipment Analysis}

\subsection{Process Equipment}

The performance of equipments can be measured, understood and designed trough a process model, which input variables can be directly measured (temperature, pressure and flow rate) or determinate (composition, heat consume, mixture, reaction and feed stock). Fig. 1 shows a typical layout of a distillation column, with some of the process variables. These models are built, considering some projects premises, and are robust enough to account the normal measuring errors and parameter variations. However there are not models capable of change their project premises.

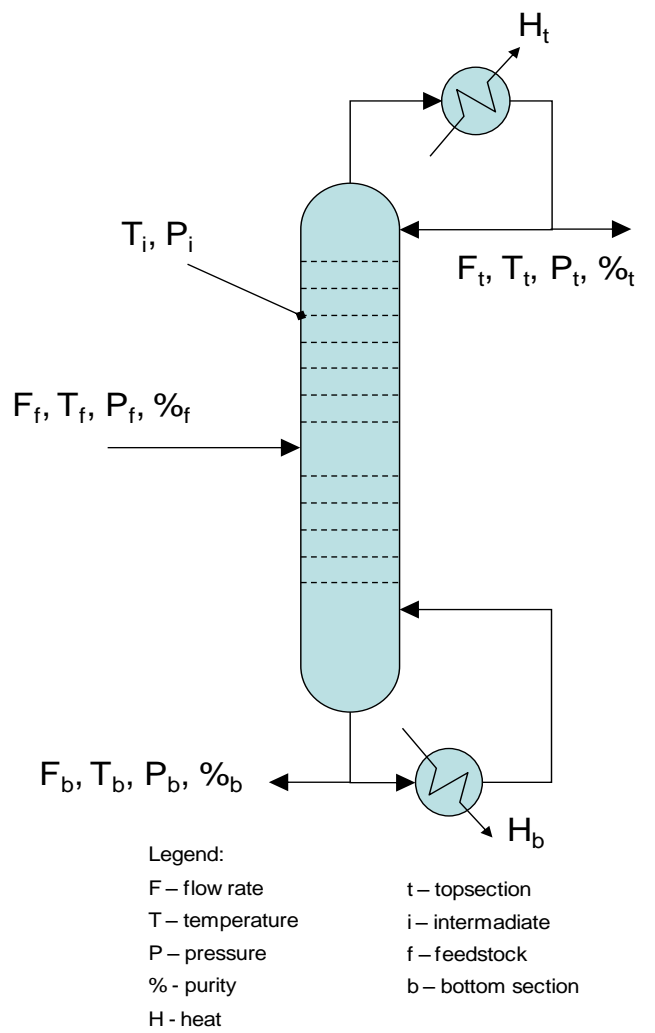

Fig. 1 Typical layout of industrial process equipment.

The process models are based on certain known characteristics considered constant and controlled:

- Physics: dimensions, area, volume, equipment and component functioning, level and vibration;

- Process: purity, preponderant physical-chemical phenomena and composition; and

- Operation: resident time, pressure, temperature and distribution.

Obviously the process model cannot account for characteristics of random, uncontrolled, unknown and even human nature:

- Physical: corrosion, mechanical damage and assembly faulty;

- Process: contamination, unexpected physical-chemical phenomena, fouling and saturation;

- Operational: operational disturb, instrument lecture error and coking;

- Human: project problems, in house solutions and human mistakes.

This is the context where some special Non-Destructive Testing (NDT) has their main focus, 
because it is possible to validate process and troubleshoot problems in equipments, while they are on-line [2]. Nowadays the use of these techniques had been spread beyond the process and operations engineering to other fields of industrial plant engineering [3]:

- Maintenance: on-line evaluation of equipments;

- Shutdown planning: opening equipments, supply parts purchasing and extent of field work;

- Projects and revamps: critical points verification, start up monitoring, baselines and performance study; and

- Predictive practices: critical equipment monitoring.

\subsection{Gamma ray Profiling or Gamma Scan}

Gamma ray column profiling or gamma scan is one of the most used NDT techniques to evaluate the on-line mechanical and operational behavior of process equipments. On this technique, a radioactive source and detector are positioned around the equipment and simultaneously moved along its length. The radiation attenuation values measured thought the vessel results on a density longitudinal profile. The profile or scan plot is then analyzed and the results are present on a report $[4,5,6]$.

The Fig. 2 shows a schematic view of a column scan. On the left side there is an orientation view of the scanning and on the right side a representation of the density profile obtained. On a real gamma scan plot the density profile is on the felt side and a sketch of the column is on the right side.

\subsubsection{Limitations of the Technique}

Column scan gamma scanning has some disadvantages that restrict it use to some applications:

- Count rate: as the available time on field tests are finite, gamma scans are limited to those cases where a statistical count rate can be obtained. Source activity and energy, detector size and efficiency, column diameter and lenght, wall thickness and constitution of the analyzed equipment are fundamental variable on
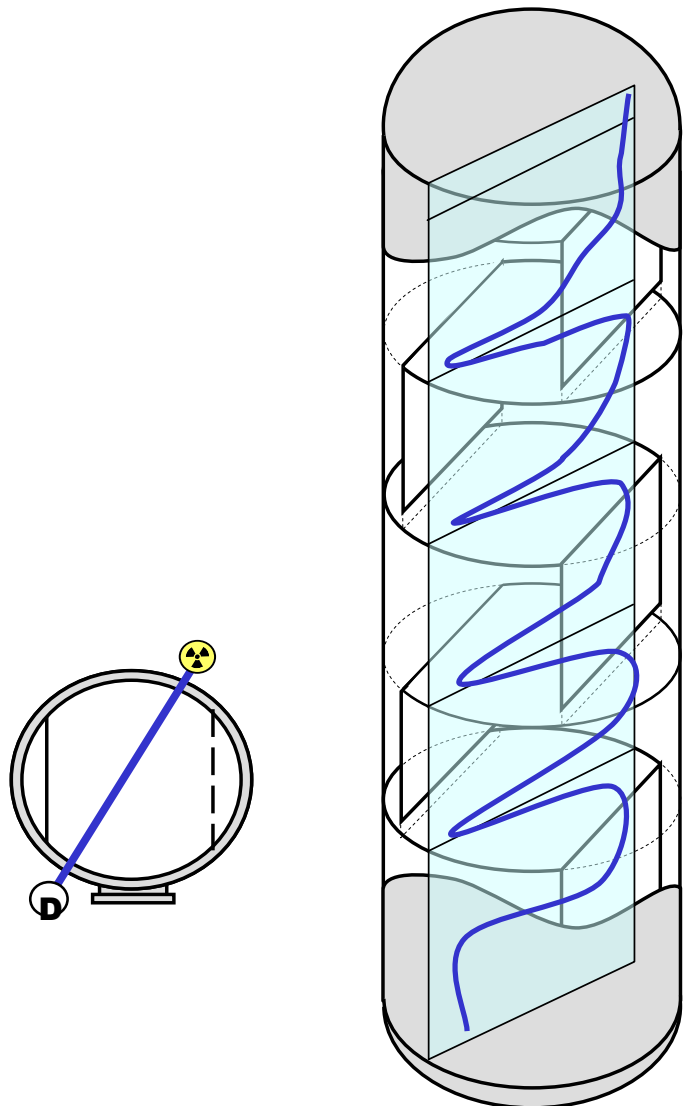

Fig. 2 A general sketch of gamma ray scans positioning and profile.

verifying the viability of a project. Radiation safety issues are equally relevant due to limitation of personal equivalent dosis [7];

- Mean density: every single point on a gamma scan plot are related to the mean density along the scan cord. Any analysis of a gamma scan data should take into account the mean behavior, not the punctual, of the density profile. Additionally, on bigger or trickier equipments the gamma ray profile tends to smooth problems and phenomena. This limitation has been partially contoured with baseline scanning, a common practice for the most critical equipments. Baselines can be performed with equipment off-line (dry-scan) or on-line (operational baseline) at optimum operational conditions;

- Positioning: since the gamma scan is a mean density profile, a data interpretation is possible only where the proprieties of the object are constant along the gamma ray path. That would considerably limit the 
positioning possibilities and the type of density profile that can be obtained. Many times, complex design equipments are hard, limited or impossible to be properly analyzed; and

- Dimensions: a density profile offers a unidimensional view (elevation wise) of the mean density of equipment. Multiple scans or grid pattern scans are often utilized to obtain some space notion of the density distribution.

\subsubsection{The art of Gamma Scanning}

Although conceptually simple, the technique of gamma scanning requires a combination of knowledge, skills and talent of the work team, that directly interfere on the quality of the gathered information and trueness of the written report. In general, a gamma scanning specialist should master the following subjects:

- Preliminary evaluation: limitations and possibilities of the technique, possible results and relevant information estimation, preliminary evaluation of required source and count rate obtained, work and data collection strategy;

- Field work: mechanical, electrical, electronic, interference and noise problems, outdoor field work and weather, long and strenuous work journeys, self independence and manual skills;

- Radiation: absorbed doses care, radioactive source handling, radiation attenuation, detector saturation, collimation, scattering, back scattering, radiation physics, source energy and nuclear instrumentation;

- Previous knowledge: knowledge about the process and equipment under analysis, experience with similar cases and proposition of alternative testing;

- Data interpretation: experience to judge and filter all type of interference on the gathered data as a result either of a problem or an inherent characteristic of the equipment;

- Reporting: ability to explain and write down on a technical report the gamma scan, its limitations, the problems found and propositions of solutions; and

- Interpersonal: team work with the scanning crew and other parties involved on the project, relationship with industrial safety crew, radiation myth, communication and persuasion abilities, oratory skills, multi language and technical terms mastery, leadership and stillness.

The combination of these characteristics that compound a typical profile of gamma scan specialist are so restrict that historically it is one of the biggest difficulties that the industry faces. On these circumstances the industry of gamma scan has invested on some solutions:

- Field work: automatized or automatic movement systems, wireless detectors and pre-adjusted electronics; and

- Data view: automatic report and plot generation, on-line web visualization of data gathering.

- Even though there was a clear advance with some of these improvements, there are some remarks:

- User friendly equipments and procedures normally implies on less flexible systems and thus harder to adjust in the field;

- As a result of an easier training, less experience and more subject to mistakes crews reach the field;

- Distance monitoring do not eliminate the presence of an specialist on a gamma ray scan job, as many tests cannot be repeated; and

- Not rare, some improvements resulted in loss of quality of the collected data.

\subsection{Computed Tomography}

The processes of obtaining a space image of an object through some of its projections are called reconstruction. The human brain is highly specialized on converting a bidimensional image into a tridimensional map. Thus, as example, it is possible to know a chair spatially is simply looking to it, as the human brain combines two bidimentional images onto a stereoscopic image. The process of reading a technical drawing is similar, a tridimentional image, or spacial notion, of an object can be built with bidimensional views of the object. It is possible to infer 
a tridimensional object through its orthogonal projections.

A mathematic process that permits an image reconstruction was published only in 1963/64 by the South African Allan Cornack and implemented on the first tomographic machine in 1972, at EMI laboratories, by Godfrey Hounsfield. This work awards then a Nobel Medicine Prize in 1979. Nowadays medicine, research and laboratory tomographs have a high degree of sophistication with good imagem quality and high reconstruction velocity. The first tomographs used the radiation attenuation principles, but other physical principles can be used as electrical resistivity and sound propagation speed.

\subsubsection{Physical Principles}

Vision is human's most important sense. As an example, it is easier to recognize a circle with a drawing than through its equation. Similarly, any object (a patient, a distillation column, a tree or a casted iron piece) can be easily analyzed with images where the eventual problems can be visualized (a cancer, an obstruction, a crack or a foundry fail). That's is why a good image reconstruction is important.

There are several physical principles that can be used on a tomography:

- Radiation attenuation: conventional tomography $[8,9,10,11,12]$;

- Velocity of sound: seismic, acoustic and ocean tomography [13];

- Electrical properties: resistivity, impedance and capacitance tomography [14]; and

- Light absorption: optical tomography;

Usually any physical property of an object that can be measured and varies only with its constitution is analyzed. The equation 1 of radiation attenuation can be expressed as:

$$
I=I_{0} \cdot f(\mu, x)
$$

Were "I" and "Io" are respectively the initial and final radiation intensities, " $\mu$ " is linear attenuation coefficient for a given median and energy and " $\mathrm{x}$ " is the object thickness [15]. If the physical property varies

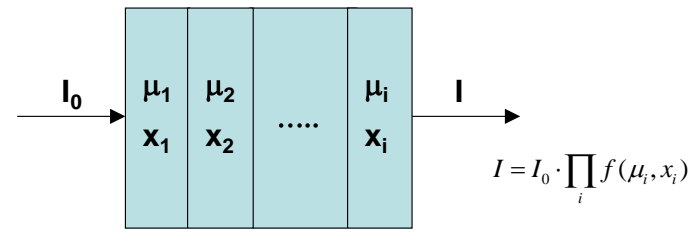

Fig. 3 Radiation attenuation along a path.

along the path on the object, the function can be expressed as a product of functions as it is shown in Fig. 3. The process of image reconstruction calculates the property distribution within a region, with a limitated number of measurements using a mathematical or iterative algorithm.

\subsubsection{Conventional Tomography Basics}

In principle, as long as the emission and detection coordinates are known, it is possible to obtain a tomographic image of any spatial arrangement. On most of the cases, the layout of the apparatus imposes a geometry or the design starts with a know geometry for construction convenience or due to the data treatment routine. Specifically for this work, the conventional tomograph uses the radiation attenuation principle, expressed by the Beer-Lambert law.

There are several tomographic equipment configurations. Fig. 4 shows the general arrangements of the five tomography generations, where the differences basically reside on increasing complexibility with reducing data time acquisition and flexibility [16]. Thus a 1st generation apparatus is versatile, but it can take hours of sampling, on the other hand there are already 5th generation tomographic machines registering ten thousands frames per second [17].

\subsection{Tricom’s Tomography Project}

During the 2008 and 2009 years, several laboratory experiments were carried out at TRICOM's installations, with the objective of obtaining knowledge and test solutions to implement industrial tomography systems. As a result, it was possible to validate models, procedures and designs for tomography systems of $1 \mathrm{st}$ and 2 nd generation for small equipments (up to $50 \mathrm{~cm}$ diameter) and medium 


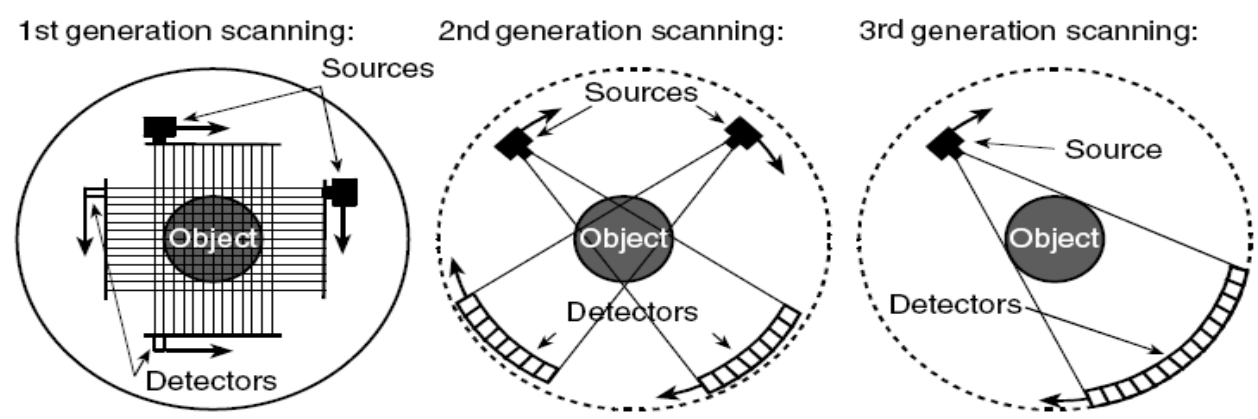

4th generation scanning: Instant, non-scanning:

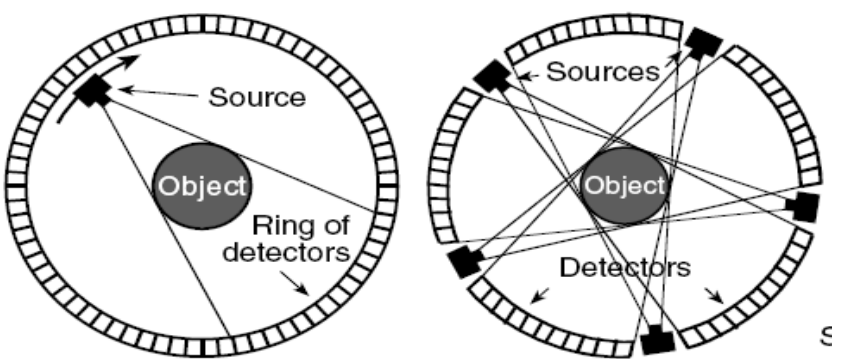

Fig. 4 General tomographs types as shown in Radioisotope Gauges for Inndustrial Process Measurements [18].

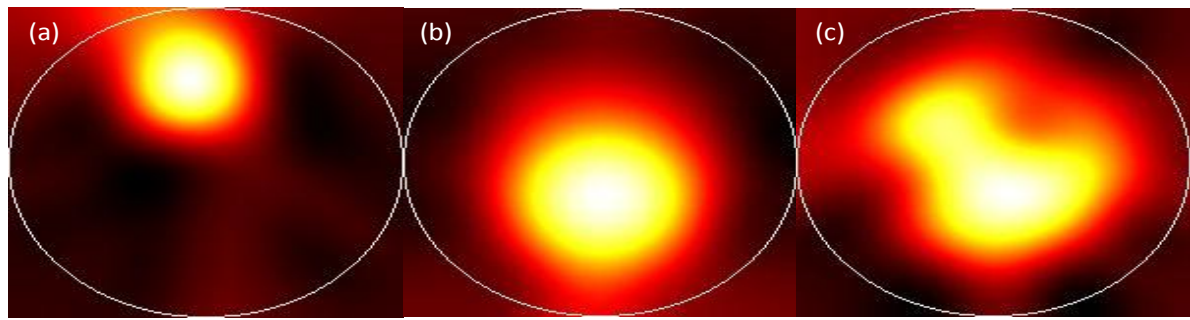

Fig. 5 Reconstructed tomography images obtained on a metalical vessel: (a) empty with a plumb cylinder, (b) plumb cylinder on water and (c) empty pipe (air) and polyurethane cylinder on water. Color represents relative densities.

and large equipments.

Initially, to simulate some of the conditions usually found in the industry; several arrangements of lead, steel or polyurethane cylinders and different medias (air and water) were tested on a 200 liter metal vessel. The Fig. 5 illustrates some of the reconstructed images obtained with a 2nd generation tomography system, using a $17 \mathrm{~m} \mathrm{Ci} \mathrm{Co-60} \mathrm{source,} \mathrm{with} 1$ or 2 inches NaTl detectors.

All reconstructions were done with an iterative algebraic method originated from ART (Algebraic Reconstruction Technique). This algorithm accepts any spatial arrangement between source and detector and also permits that the set of data be incomplete, which is relevant for real field situations. Depending on the applied image filter, the algorithm can privilege smooth or sharp density transitions. The algorithm uses concept similar to the Compressed Sense Theory, recently developed.

Nowadays, Tricom's industrial tomography system is capable of obtaining images with several source-detector arrangements, as can be seen on Fig. 6 . Linear, circular, fan-type source to detector relative montions are among the geometries that can be employed. The reconstruction technique opened the possibility to wider options of simetric, assimetric or missing cords layouts.

Some industrial scale services results performed by TRICOM in 2009 [19] and 2010 are shown on Fig. 7. Nowadays, Tricom's industrial tomography project is in the phase of automation, with the construction of 1st and 2nd generations' tomography. 

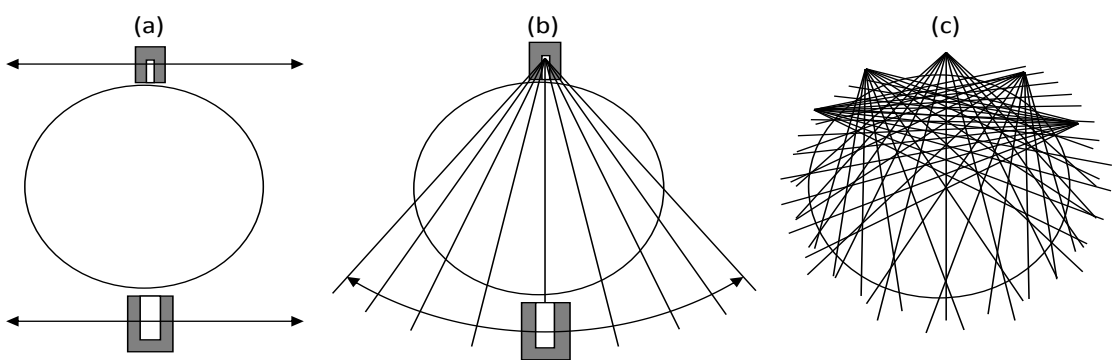

Fig. 6 Some of Tricom’s industrial tomographys layouts possibilities: (a) linear, (b) fan, (c) assimetric.

(a)

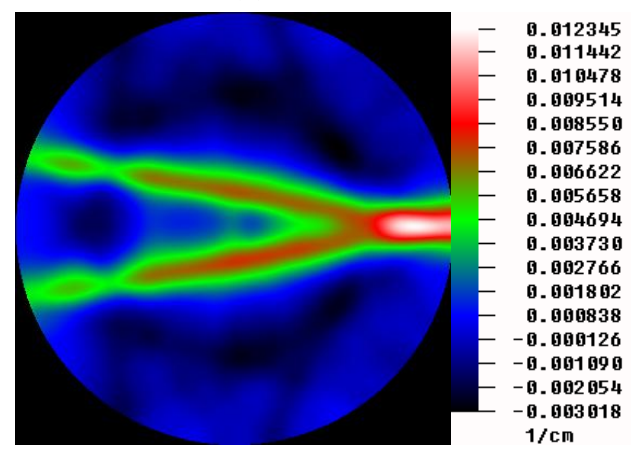

(b)

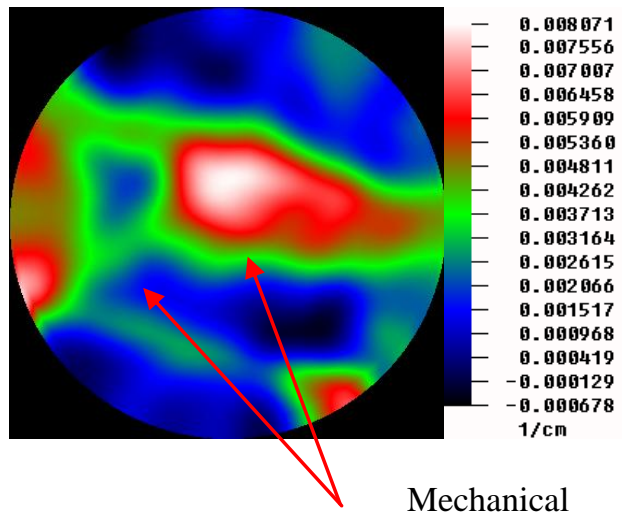

Damage

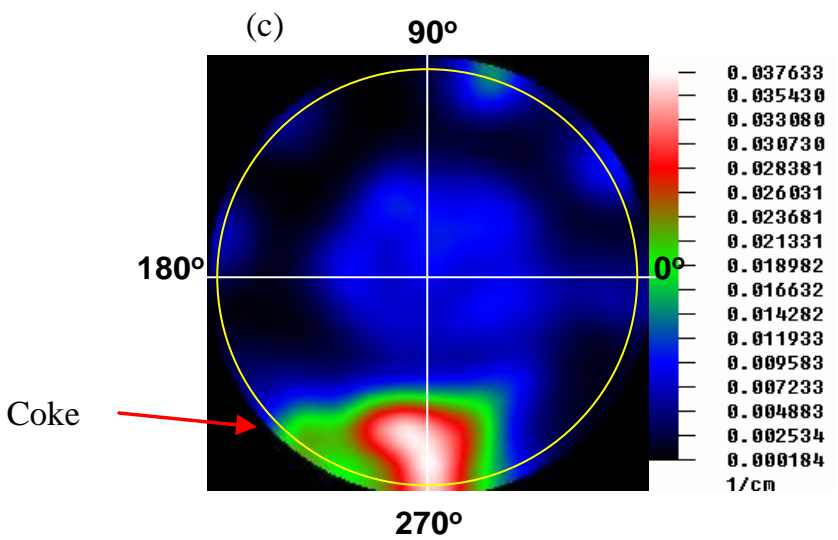

Fig. 7 Some of Tricom's industrial tomography results: (a) Simulated ideal image of a 9 m diameter distillation column vapor distributor, 9 sources $x 17$ detectors incomplete layout, (b) tomographic image of the real vapor distributor, (c) tomographic image of a $2 \mathrm{~m}$ diameter transfer line, 9 sources $\mathrm{x} 17$ detectors.

The effort on the development of this technology represents the milestone of the work presented on this work, from the knowledge with the hardware setup, thought the data acquisition procedures, until the simulation and reconstruction software.

\section{Objectives}

\subsection{Image Improved Gamma Scans}

In this work, we propose to obtain a two dimensional longitudinal density profile of industrial equipments representing an advance over the conventional gamma ray profiling techniques with some advantages:

- Dimensional: a two dimensional density distribution image would ease the visualization and identification of problems, process and phenomena on an equipment;

- Positioning: as a second spatial dimension is included, the number of longitudinal profiles needed 
are reduced. Furthermore, features hidden on a conventional (gamma scan) technology, due to the mean density values, would be revealed on an image technology. Similarly, density profiles or equipments that cannot be scanned with gamma ray profile have now possibilities of testing;

- Interpretation: image results are much easier to analyze and present compared to the conventional technique. This might result on a better acceptance of the inspection by the customer and also easier the training of field personal.

\subsection{Project Phases}

The project goal is to develop an industrial equipment imaging system using the gamma ray absorption technique. The project was divided into three phases:

- Data simulation: study of optimum experimental parameters and image reconstruction;

- Experimental testing: verifying the effect of parameters change and reconstructed image quality; and

- Field testing: equipment, material and procedures optimization and possibilities.

\section{Results and Discussion}

In this article we describe the results obtained in phases I and II of the project.

\subsection{Phase I - Simulation}

Several resources and tools from Tricom's previous experience in industrial tomography system were revised or adapted for this new technology. One direct application was the ability to simulate irradiations and reconstruct images which opened possibilities to:

- Compare several source-detectors positioning arrangements with resulting image quality;

- Fine tune reconstruction algoritm parameters.

- Reduce personal radiation exposition

Figs. 8 and 9 show examples of two simulated column arrangements, the resulting gamma ray scanning, and the reconstructed image of the column. On Fig 8 and 9 the images in the left represents two types of typical distillation columns cross sections, with tray and packing assembly. The simulations are numerically performed were each pixel color represents different $\mu$ (linear attenuation coefficients). In those simulations air, water, stell, stell packing and
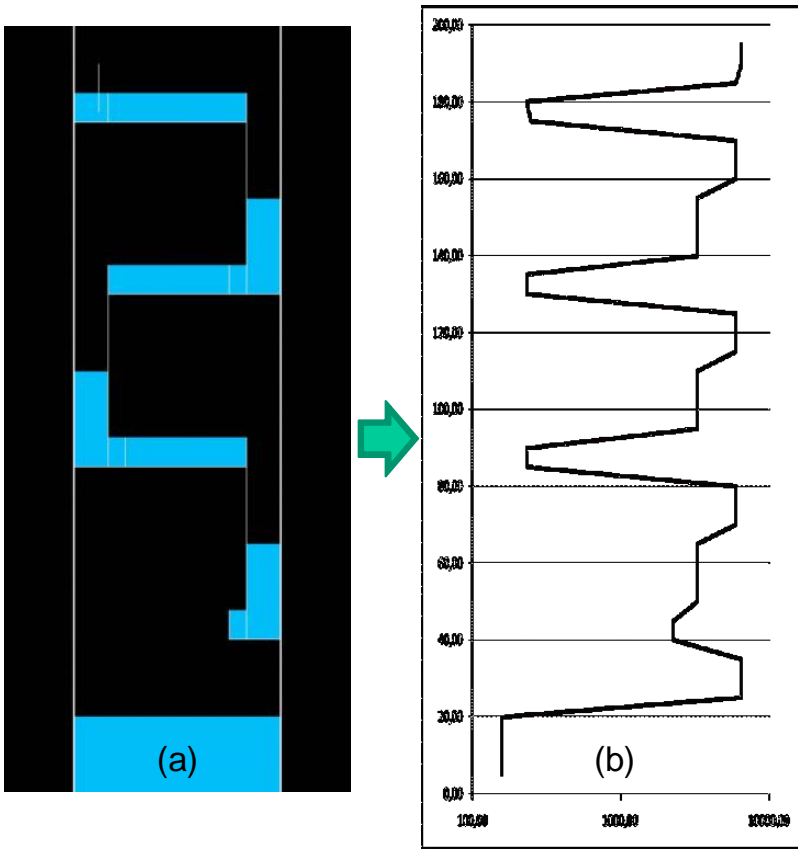

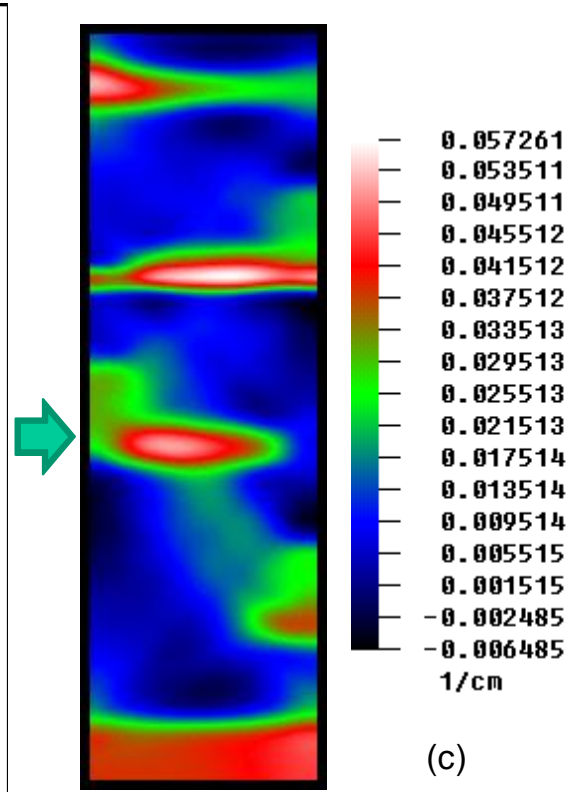

Fig. 8 Computed simulated column arrangement (a), resulting gamma ray profile (b) and reconstructed tomographyc image of the trayed column $(c)$. 

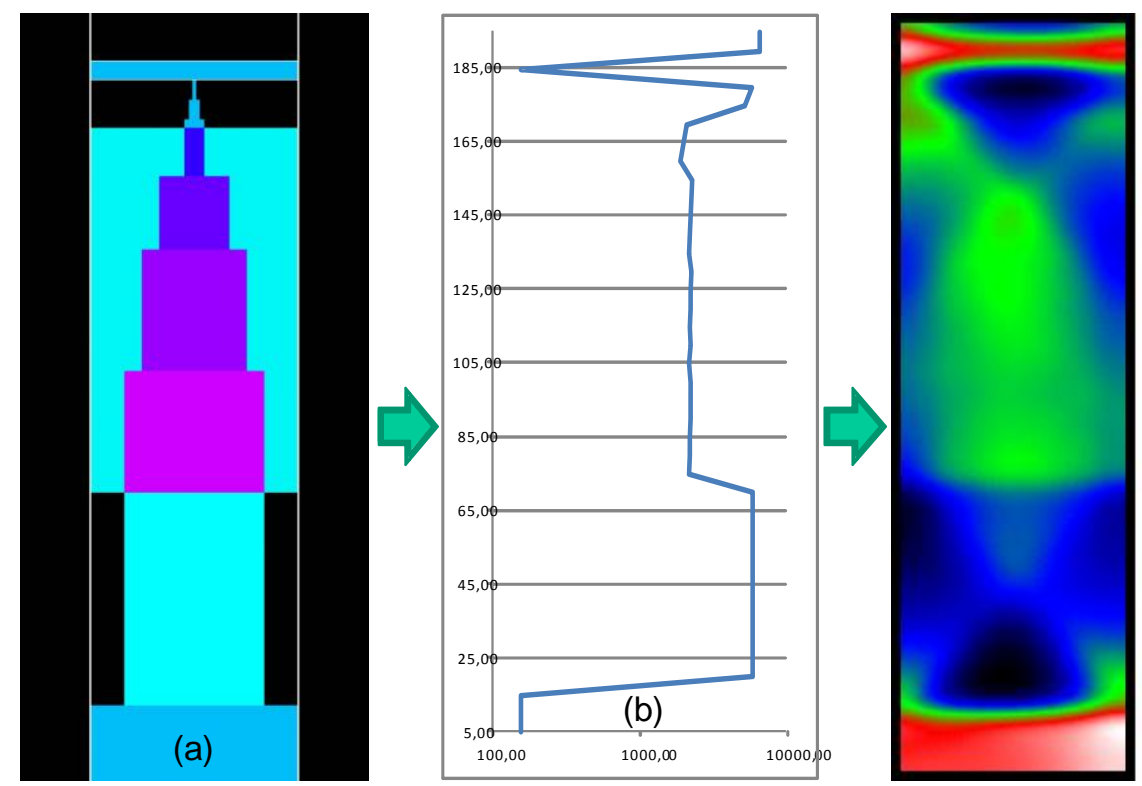

0.648694

0.045683

0. 042472

0. 039261

0. 036050

ง. 932839

0. 029628

0. 026416

0. 023205

0.019994

0.016783

0. 013572

0. 010361

0. 097150

0. 093938

0.009727

$-6.002484$

$1 / \mathrm{cm}$

(c)

Fig. 9 Computed simulated column arrangement (a), resulting gamma ray profile (b) and reconstructed tomographyc image of a packed column (c).
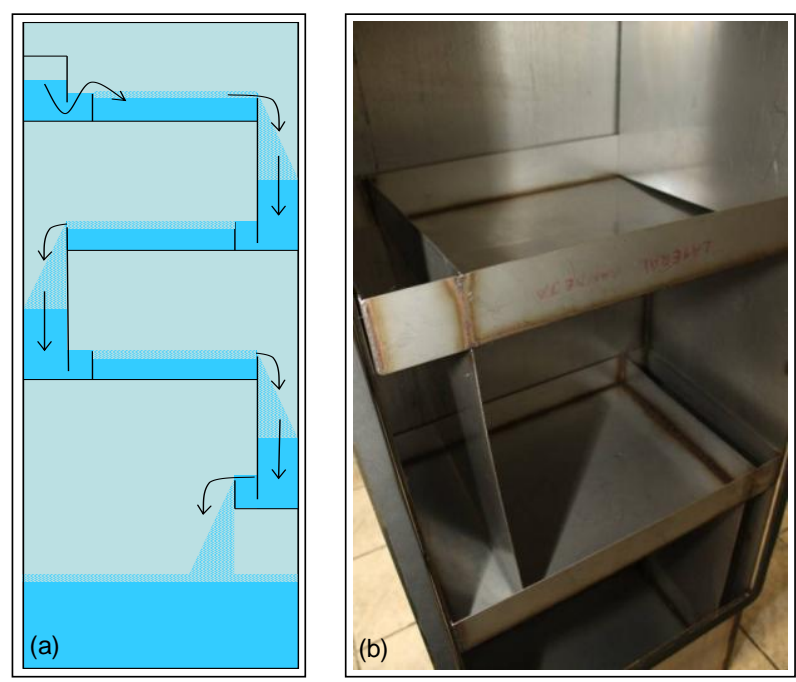

Fig. 10 Liquid flow path scketch in a one pass trayed column (a) and detail of the experimental trayed column built (b).

liquid distribution were considered. The software simulates the count rate obtained from a Cobalt 60 source with $\mathrm{NaTl}$ detectors.

\subsection{Phase II - Experimental Testing}

Images obtained from two practical experiments will be presented in this article. A $485 \mu \mathrm{Ci}$ Co-60 source was employed to irradiate a 1 pass trayed column model as shown in Fig 10. Eletronic collimation was employed to register only high energy fotons.

\subsubsection{Experiment 1}

A 1 inch diameter $\mathrm{x} 1$ inch tick $\mathrm{NaI}(\mathrm{Tl})$ detector with 1 inch window colimator were used in this experiment. Count rate though the air was 14,106 counts/minute, count rate though liquid (water) was 414 counts/minute and background count rate was 207.6 counts/minute. Count time were arbitrarily limited to 10 seconds so all the data could be sampled in approximately 4 hours to mimetic the available time on real field jobs. Source and detector movements were set to $10 \mathrm{~cm}$ increments. The tomographic image was reconstructed from 355 irradiation positions and can be seen on Fig. 11 with the corresponding trayed column layout and gamma scan profile.

\subsubsection{Experiment 2}

A larger 2 inch diameter $x 2$ inch tick $\mathrm{NaI}(\mathrm{Tl})$ detector with 2 inch window collimator were used in the second experiment. Count rate though the air was 63,180 counts/minute, count rate though liquid (water) was 2,380 counts/minute and background count rate was 1,050 counts/minute. Count time were arbitrarily limited to 3 seconds so all the data could be sampled in approximately 4 hours and 21 minutes. Source and detector movements were set to $5 \mathrm{~cm}$ increments. The data file obtained generated three set 

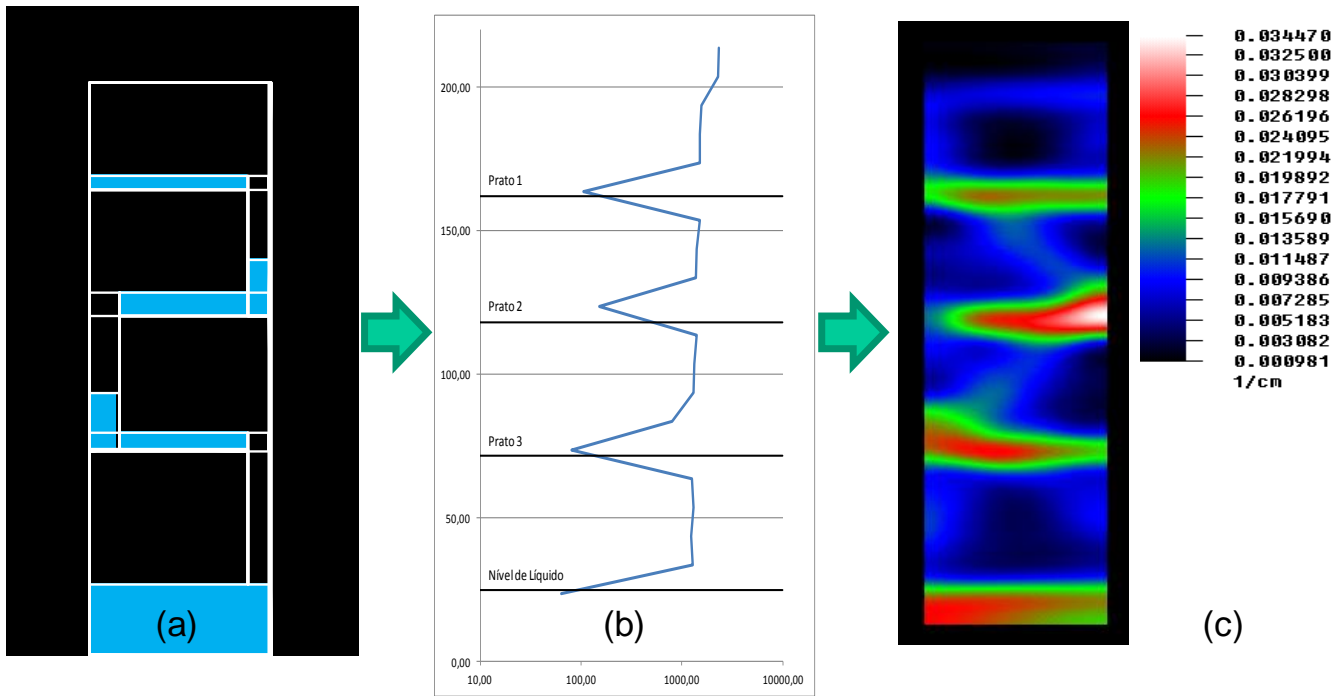

(c)

Fig. 11 Experiment 1: 1 inch diameter $x 1$ inch thick NaI(TI) detector with 1 inch collimation window: trayed column layout (a), resulting gamma ray profile (b) and reconstructed tomographyc image (c).
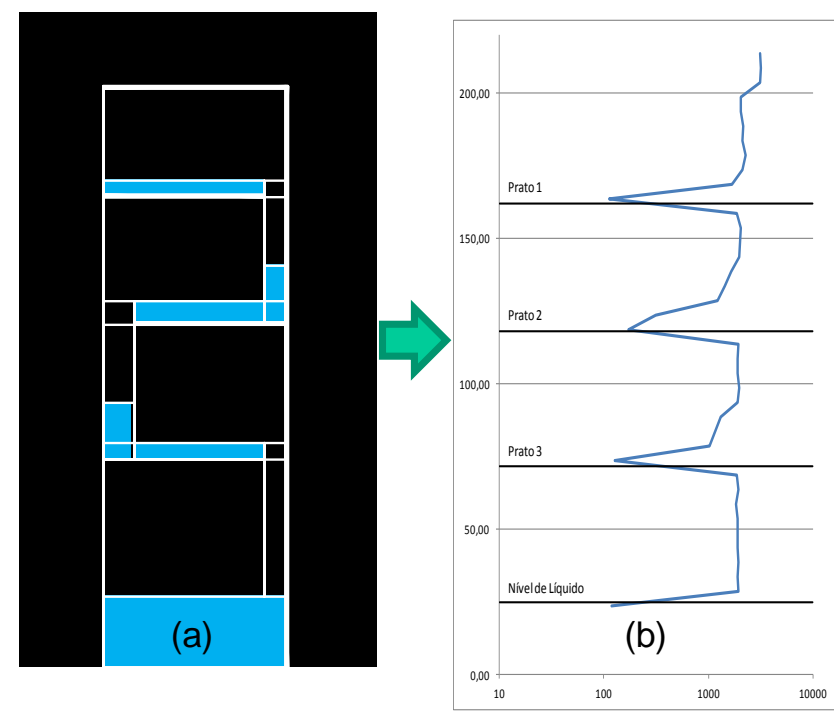

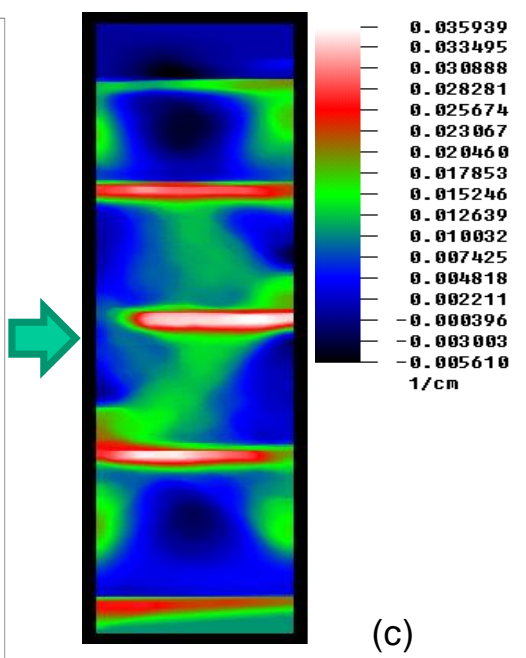

(c)

Fig. 12 Experiment 2: 2 inch diameter $x 2$ inch thick NaI(TI) detector with 2 inch collimation window: trayed column layout (a) with resulting gamma ray profile (b) and reconstructed tomographyc image (c).

of data with $5 \mathrm{~cm}, 10 \mathrm{~cm}$ and $15 \mathrm{~cm}$ movement increments which resulted on three tomographic images reconstructed from 1388, 356 and 149 irradiation positions respectively. On Fig. 12 the results for the $5 \mathrm{~cm}$ set of data are shown with the corresponding trayed column layout and gamma scan profile.

\subsubsection{Images Comparition}

The tomographic images obtained on the experiment 2 were compared, as shown in Fig. 13, to understand the influence of source and detector movement increments on the image quality.
The $10 \mathrm{~cm}$ movement increment reconstructed images for 1 inch and 2 inches detectors were compared as shown in Fig. 14.

\subsection{Discussion}

The bidimentional images obtained with tomographic reconstruction tools were much easier to understand as heir interpretation are very intuitive, as it can be seem on Fig. 15. With the conventional gamma ray scan plot some of the same informations can be also obtained, but that would require much more 


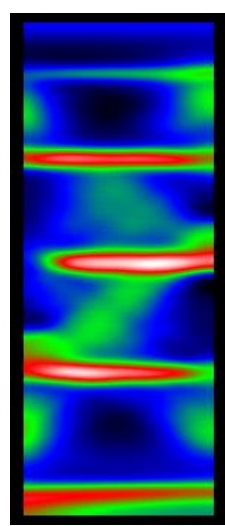

(a)

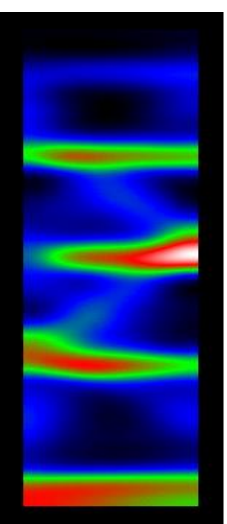

(b)

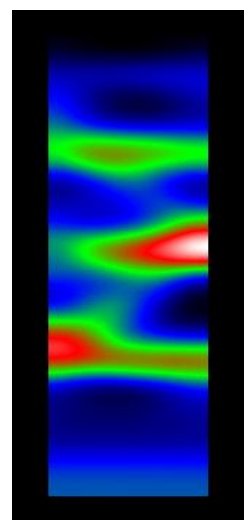

(c)

Fig. 13 Experimental reconstructed tomographyc images with varing irradiation increments: (a) $5 \mathrm{~cm}$, (b) $10 \mathrm{~cm}$ and (c) 15 cm.
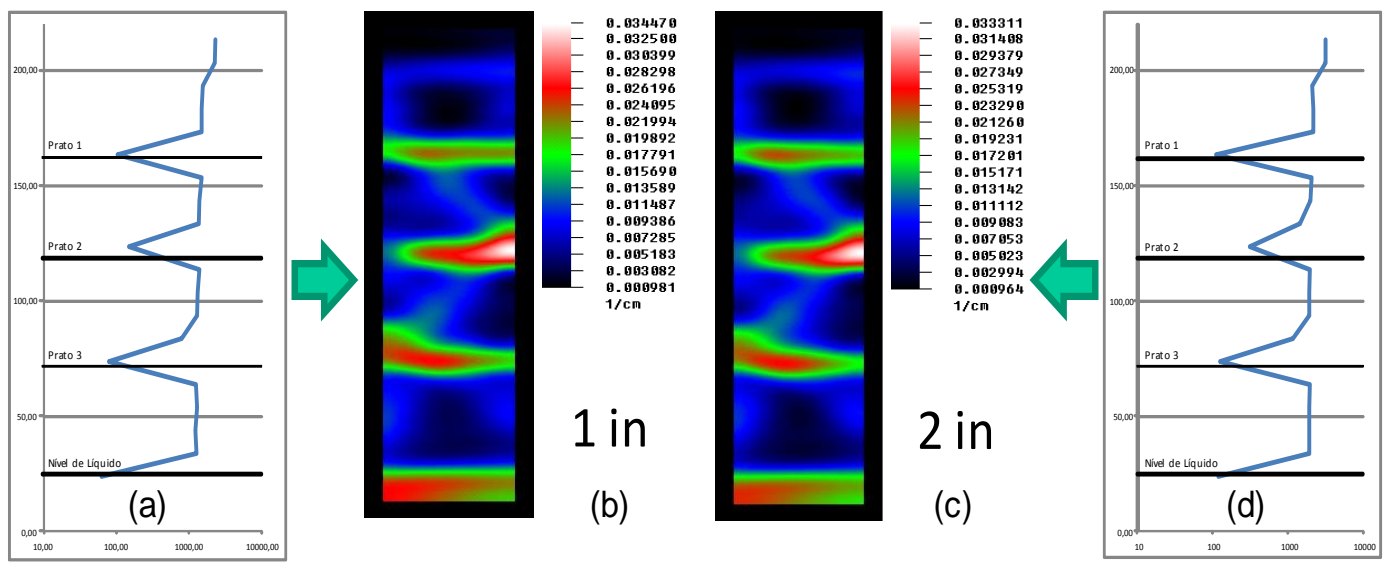

Fig. 14 Gamma ray profile with 1 inch $\mathrm{NaI}(\mathrm{Tl})$ detector, 1 inch window and $10 \mathrm{~cm}$ increment (a), resulting tomographic image (b), tomographic image with 2 inches NaI(T) detector, 2 inches window and $10 \mathrm{~cm}$ increment (c) and corresponding gamma ray profile (d).

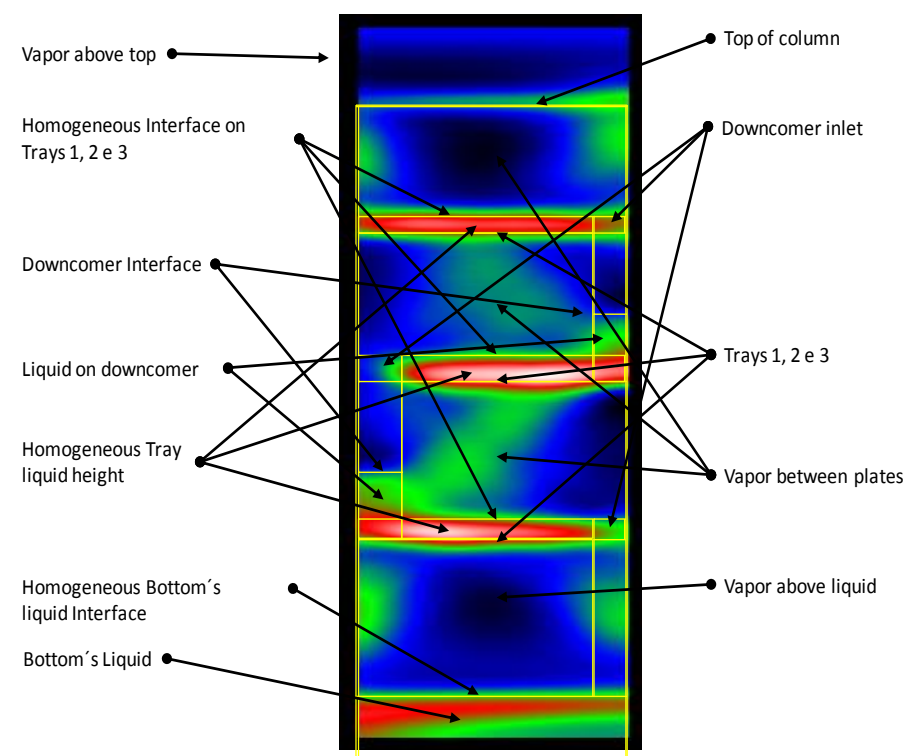

Fig. 15 Mechanical anda process diagnostics features observed on a tomographic image. 
knowledge from the reader. On the other hand, some of the features observed in Fig. 15 could be indicated only with the aid of a tomographic image, as it introduces second spacial axis information: homogenity of phases, interface appearance, spacial positioning.

As it can be seem on Fig. 13 the quality of the image diminishes with the increase of the source and detector movement increments. The resolution (understand here as the minor detectable feature observed) appears to have the same magnitude order than the movement increments.

Surprisingly the quality of the images obtained with 1 and 2 inches detectors were very similar although they had totally diverse statistical basis. One hypothesis suggests that even individually weak, the reconstruction program when dealing with hundreds of measurements counter compensate the error in the data.

The experiments showed that images can be obtained with different source and detector movement increments or $\mathrm{NaI}(\mathrm{Tl})$ crystal sizes., That would indicate that good images can be obtained with different phisical arrangements (movement, increments) and equipments (source, detectors). An important part of the choose would be related with the quality of the required image, available time physical space for the test.

\section{Conclusion}

The inicial objective of this work was truly achieved with tomographic images of process equipment revealing the bidimentional density distribution. Features hidden on a conventional gamma ray density profile were seem with this technique adding new perspective on thoubleshotting process coluns and other industrial equipments were a conventional gamma scanning would only offer limited informations.

Although promising there are some fields that need improvements or futher development such as softwares, equipments, filters, data acquisition, calibration, etc. The simulation tools developed proven to be very useful on fine tunning the results and also planning the irradiation process saving time and personal exposition. The experience gathered indicated also concepts to be employed when adapting the technologie from labscale to real field work.

\section{Acknowledgments}

The authors gratefully acknowledge the TRICOM Technology Ltd., Polytechnic Scholl of Sao Paulo University (EPUSP) and IPEN-CNEN/SP for theirs financial, scientific and technological support during this R\&D Project, without which it would be impossible to carry out this work.

\section{References}

[1] R.B. Eldridge, Advanced hydraulic and mass transfer models for distillation column, Optimization and design, The University of Texas and Oak Ridge National Laboratory, 2006, page 3-14.

[2] J.S. Charlton, Radioisotope Techniques for Problem Solving in Industrial Process Plants, Gulf Pub. Co. Houston, 1986, pages 239 - 243.

[3] M.I. Haraguchi, Online tests for distillation columns, reactors and industrial furnaces, in: 4th Congress of Equipment and Automation for Chemical Industry, Sao Paulo/SP, Brazil, 1999, pages 4 -10.

[4] M.I. Haraguchi, L.T. Pless, D. Strandmeier, Diagnosis of distillation columns, in: XVI Meeting of producers and consumers of industrial gases, Salvador/BA, Brazil, 2001, pages 2-6.

[5] L. Pless, S. Xu, Flooding phenomenon in distillation columns and its diagnosis, in: Petrobras Distillation Seminar, Belo Horizonte, Brazil, 2001, page 1.

[6] N.F. Urbanski, M.R. Resetarits, M.S.M. Shakur, et al., Gamma scanning a column containing closely spaced trays, in: Annual Meeting AIChE 1999 - Separations Topical Conference, Session \#T1007 - Distillation Hardware and Applications II, Dallas, Texas, USA, 1999, pages 1-12.

[7] M.P. Sanches, M.I. Haraguchi, F.S. Beckmann, W.A.P. Calvo, Radiological safety in the gamma scans procedures, in: INAC, Santos, Brazil, 2007, page 4.

[8] IAEA, IAEA-TECDOC-1589-Industrial Process Gamma Tomography, Final report of a coordinated research project, http://www-pub.iaea.org/MTCD/publications /PDF/te_1589_web.pdf, October 3, 2008, page 3. (ISBN 978-92-0-104508-9). 
[9] J. Kim, S. Jung, A study on industrial gamma ray CT with a single source-detector pair, KAERI, Nuclear Engineering and Technology, 38 (4) (2006) 383-390.

[10] S.X. Xu, G. Kennedy, C. Conforti, et al. (1999). Troubleshooting Industrial Packed Columns by Gamma-Ray Tomography. CE Expo'99, Houston, 1999, page 1 .

[11] S.X. Xu, Quantitatively measure and assess misdistribution in industrial packed towers, in: CE Expo, 2000 , pages $1-5$.

[12] S.X. Xu, Gamma CAT-scans for distillation columns - from theory to practice, in: 4th Topical Conference on Separation Science and Technology, AIChE Annual Meeting, Dallas, 1999, pages 1-6.

[13] T. Wiens, P. Behrens, Turbulent flow sensing using acoustic tomography, in: Inter Noise, Otawa, Canada, 2009, page 2 .

[14] A.J. Peyton, M.S. Beck, A.R. Borges, et al. (1999). Development of electromagnetic tomography (emt) for industrial applications. Part 1: Sensor design and instrumentation, in: 1st World Congress on Industrial Process Tomography, Buxton, Greater Manchester, 1999, page 306.

[15] IAEA, IAEA-TECDOC-1459-Technical Data on Nucleonic Gauges, http://www-pub.iaea.org/MTCD /publications/PDF/te_1459_web.pdf, 2005, pages 15 and 16.

[16] G.A. Johansen, P. Jackson, Radioisotope Gauges For Industrial Process Measurements, John Wiley\& Sons, Ltd. 2004, page 244.

[17] IAEA, IAEA-TECDOC-1589-Industrial Process Gamma Tomography, Final report of a coordinated research project, http://www-pub.iaea.org/MTCD/publications /PDF/te_1589_web.pdf, October 3, 2008, page 14. (ISBN 978-92-0-104508-9).

[18] G.A. Johansen, P. Jackson, Radioisotope Gauges For Industrial Process Measurements, John Wiley\& Sons, Ltd. 2004 (page 243).

[19] M.I. Haraguchi, H.Y. Kim, R.O. Machado, Industrial computered tomography, in: XXVIII - National Congress of Non-Destructive Testing and Inspection, Santos/SP, Brazil, 2010, pages 14, 16 and 18 


\section{APÊNDICES}


Apêndice 1 - Desenhos de conjunto do sistema de imageamento 


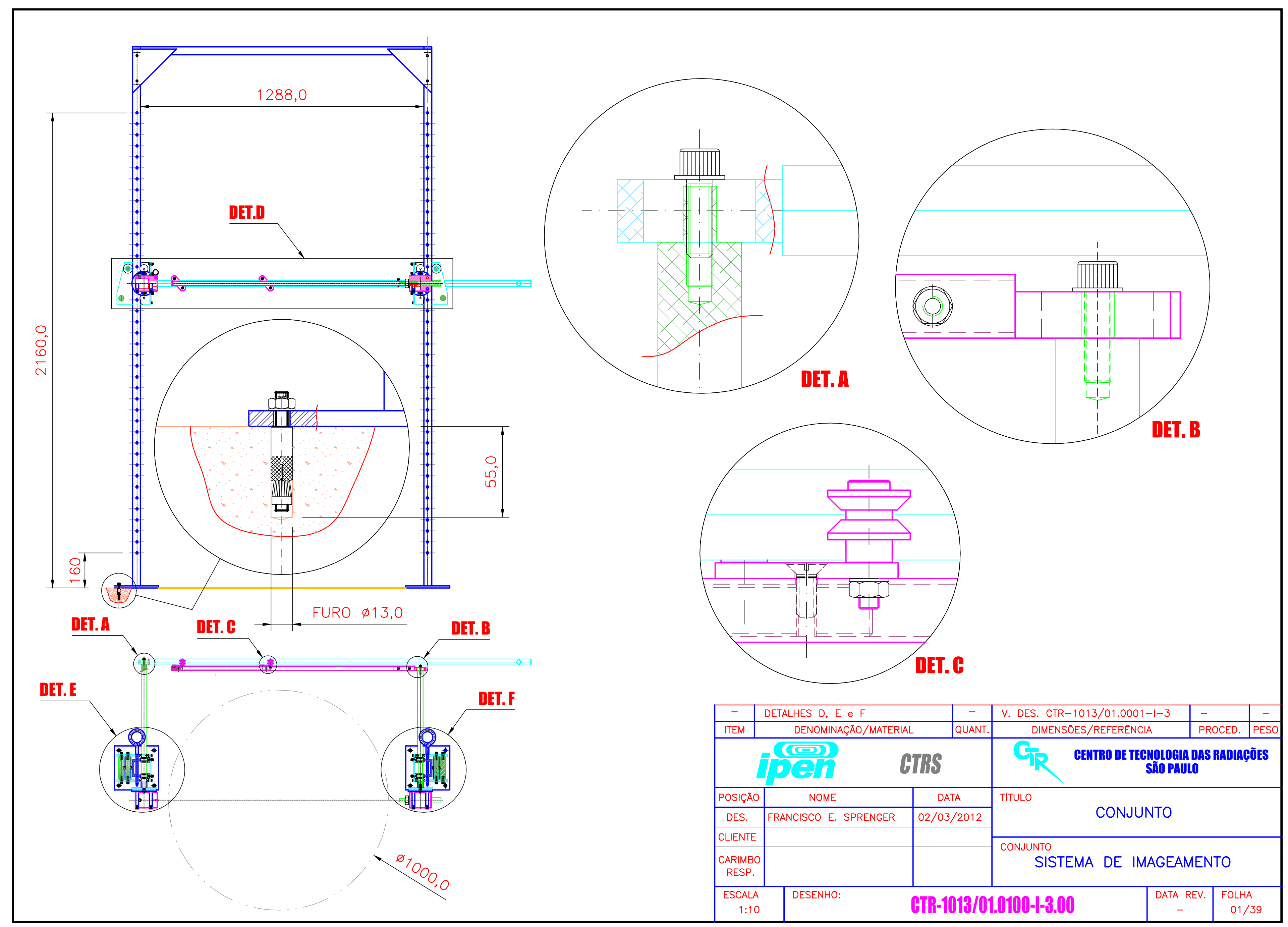




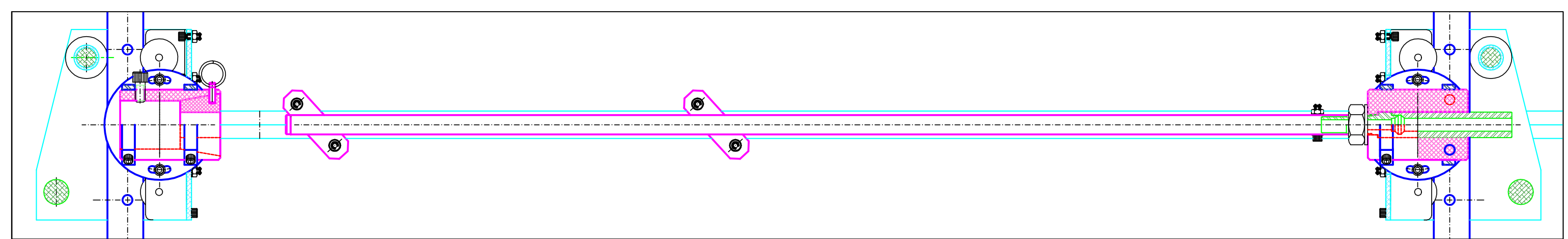

DET. D
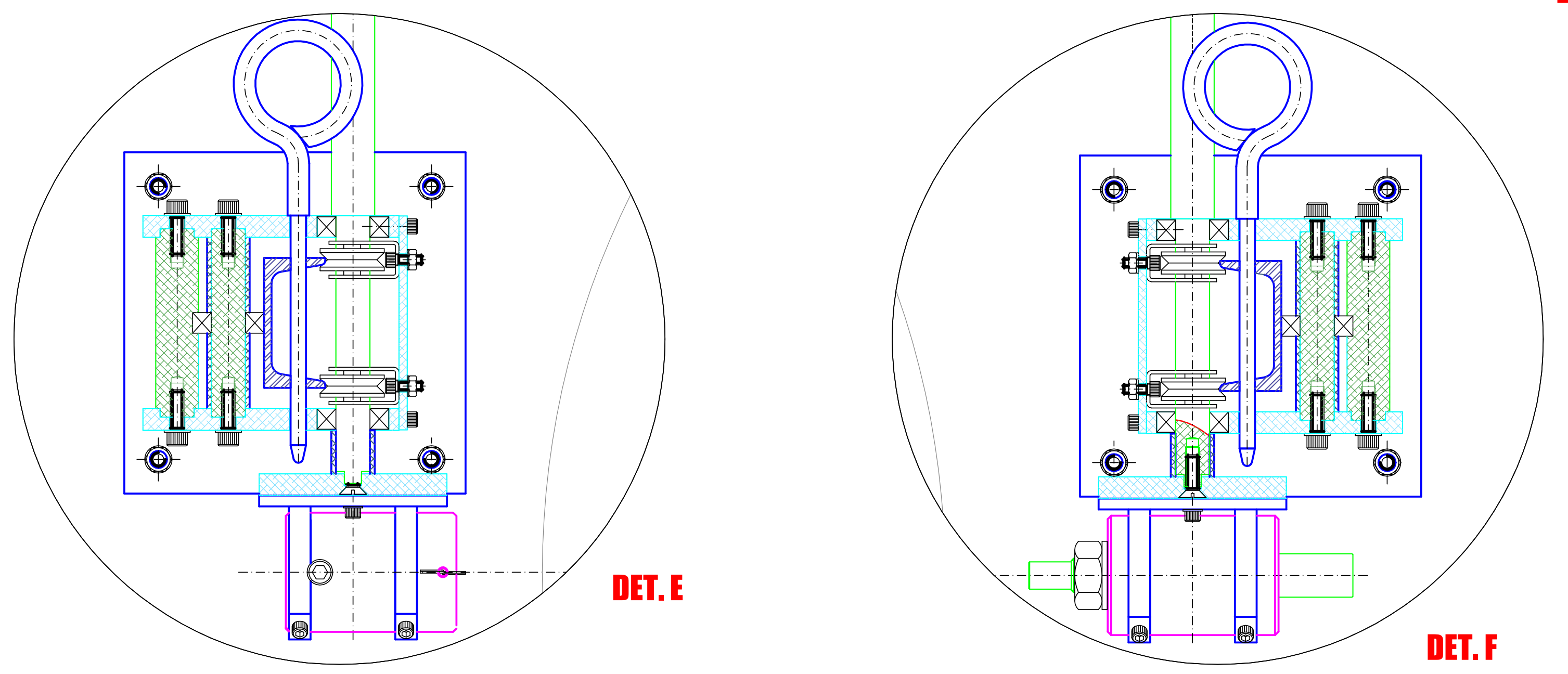

\begin{tabular}{|c|c|c|c|}
\hline & ब्था & CTRS & 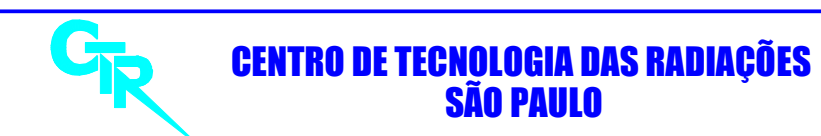 \\
\hline POSIÇAO) & NOME & DATA & 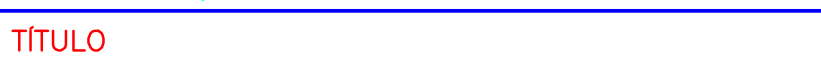 \\
\hline DES. & FRANCISCO E. SPRENGER & $07 / 03 / 2012$ & CONJUNTO-DETALHES \\
\hline $\begin{array}{c}\text { CLENTE } \\
\text { CARIBO } \\
\text { RESPP }\end{array}$ & & & $\begin{array}{l}\text { CONUUNTO } \\
\text { SISTEMA DE IMAGEAMENTO }\end{array}$ \\
\hline $\begin{array}{r}\text { ESCALA } \\
1: 10\end{array}$ & \begin{tabular}{|l|l|l|} 
DESENHO: \\
\end{tabular} & CTR-1013/I & \begin{tabular}{|l|l} 
DATA REV. & FOLHA \\
& $02 / 39$
\end{tabular} \\
\hline
\end{tabular}


Apêndice 2 - Cálculo do raio de isolamento convencional 


\begin{tabular}{|c|c|c|}
\hline Numero máximo de posições & 1179 & \\
\hline Tempo de contagem por pos & $2 \mathrm{seg}$ & \\
\hline Tempo troca posição & $5 \mathrm{seg}$ & \\
\hline Tempo total $(\mathrm{T})$ & $8253 \mathrm{seg}$ & 2,2925 horas \\
\hline
\end{tabular}

\begin{tabular}{|lc}
\hline Fonte & Co-60 \\
Atividade $(\mathrm{A})$ & $2 \mathrm{mCi}$ \\
$\Gamma$ & $13,2[\mathrm{R} . \mathrm{cm} 2 / \mathrm{h} . \mathrm{mCi}]$ \\
dose restritiva de 0,3 mSv/ano & $0,03 \mathrm{R} / \mathrm{ano}$ \\
considerando 1/10 para operação & $0,003 \mathrm{R} / \mathrm{dia}$ \\
$\mathrm{H}$ para o tempo T & $0,001309[\mathrm{R} / \mathrm{h}]$ \\
\hline
\end{tabular}

$$
H=\frac{\Gamma \cdot A \cdot T \cdot f \cdot B}{d^{2}} \Rightarrow d=\sqrt{\frac{\Gamma \cdot A \cdot T \cdot f \cdot B}{H}}
$$

\begin{tabular}{|c|c|c|c|c|}
\hline \multirow{14}{*}{$\begin{array}{l}\text { Fator de colimação (f) } \\
\text { Build Up (B) }\end{array}$} & \multicolumn{2}{|c|}{ na direção de irradiação $B=f=$} & 1 & \\
\hline & \multicolumn{4}{|c|}{ perpendicularmente ao colimador: } \\
\hline & \multirow{3}{*}{\multicolumn{2}{|c|}{$\begin{array}{l}\text { espessura colimador chumbo }(x) \\
\mu \text { chumbo } \\
{[1 / \mathrm{cm}] \quad 0,666}\end{array}$}} & 2,25 & $\mathrm{~cm}$ \\
\hline & & & & \\
\hline & & & & \\
\hline & \multicolumn{3}{|l|}{ Buld up Chumbo } & \\
\hline & $\alpha 1$ & $\alpha 2$ & B & \\
\hline & $3,600561-0,034977$ & 0,111819 & 1,5950 & \\
\hline & \multirow{2}{*}{\multicolumn{2}{|c|}{$\begin{array}{l}\text { espessura colimador aço }(x) \\
\mu \text { aço } \\
{[1 / \mathrm{cm}] \quad 0,419908}\end{array}$}} & 1,25 & $\mathrm{~cm}$ \\
\hline & & & & \\
\hline & $\begin{array}{ll}A & \alpha 1\end{array}$ & $\alpha 2$ & B & \\
\hline & $-0,057169$ & $-0,019729$ & 1,4736 & \\
\hline & \multirow{2}{*}{$f=e^{-\mu \cdot x}$} & $B=$ & 1,551626 & \\
\hline & & & 0,132207 & \\
\hline
\end{tabular}

\begin{tabular}{|l|l|}
\hline distancia de isolamento: & $\begin{array}{c}\text { na direção de irradiação } \\
\mathrm{d}=\end{array} \quad 2,2 \mathrm{~m}$ \\
\cline { 2 - 3 } & $\begin{array}{cc}\text { perpendicularmente ao colimador: } \\
\mathrm{d}=\end{array} \quad 1,0 \mathrm{~m}$ \\
\hline
\end{tabular}


Apêndice 3 - Depósito do pedido de patente junto ao Instituto Nacional de Propriedade Industrial (INPI) 


\section{DEPÓSITO DE PEDIDO DE PATENTE OU DE CERTIFICADO DE ADIÇÃO}

\section{Ao Instituto Nacional da Propriedade Industrial:}

O requerente solicita a concessão de um privilégio na natureza e nas condições abaixo indicadas

\section{Depositante (71):}

1.1 Nome: COMISSÃO NACIONAL DE ENERGIA NUCLEAR

1.2 Qualificaçâo: AUTARQUIA FEDERAL,

1.3 CNPJ/CPF: 00402552000126

1.4 Endereço Completo: RUA GENERAL SEVERIANO,90 - BOTAFOGO

1.5 CEP: $22294-901$

1.6 Telefone: 21 2173-2169

1.8 E-mail:

$凶$ continua em folha anexa

\section{Natureza: Invenção Modelo de Utilidade}

Escreva, obrigatoriamente, e por extenso, a Natureza desejada: INVENÇÃO

\section{Título da Invenção ou Modelo de Utilidade ou Certificado de Adição(54):}

"SISTEMA DE IMAGEAMENTO DE EQUIPAMENTOS INDUSTRIAIS"

continua em folha anexa

4. Pedido de Divisão: do pedido $N^{\circ}$

Data de Depósito:

\section{Prioridade:}

$\mathrm{O}$ depositante reivindica a(s) seguinte(s):

\begin{tabular}{|l|l|l|}
\hline Pais ou organização de origem & Número de depósito & Data do depósito \\
\hline & & \\
\hline & & \\
\hline
\end{tabular}

\section{Inventor (72):}

Assinale aqui se o(s) mesmo(s) requer(em) a näo divulgação de seu(s) nome(s)

6.1 Nome: WILSON APARECIDO PAREJO CALVO

6.2 Qualificação: TECNOLOGISTA SENIOR

6.3 CPF: 062993808-37

6.4 Endereço completo: RUA DES. JULIO CESAR DE FARIA, 80 SÃO PAULO/SP

6.5 CEP: 05595-030

6.6 Telefone: 11 3133-9765

6.8 E-Mail: WAPCALVO@IPEN.BR 
7. Declaração na forma do item 3.2 do Ato Normativo $n^{0} 127 / 97$ :

7.1 Declaro que os dados fornecidos no presente formulário são idênticos ao da certidăo de depósito ou documento equivalente do pedido cuja prioridade está sendo reivindicada.

em anexo

8. Declaração de divulgação anterior não prejudicial: (Periodo de Graça):

(art. 12 da LPI e item 2 do $A N n^{0} 127 / 97$ )

em anexo

9. Procurador (74)

9.1 Nome: FRANCISCO RONDINELLI JUNIOR

9.2 CNPJ/CPF: $519509287-72 \quad 9.3$ API/OAB:

9.4 Endereço completo: RUA GENERAL SEVERIANO, 90 - BOTAFOGO - RIO DE JANEIRO

9.5 CEP: $22294-901 \quad 9.6$ Telefone: $21 \quad 2173-2169 \quad 9.7$ Fax: $212173-2163$

9.8 E-Mail:

10. Listagem de sequências Biológicas (documentos anexados) (se houver):

Listagem de sequências em arquivo eletrônico: $\quad \quad \quad \quad n^{0}$ de CDs ou DVDs (original e cópia).

Código de controle alfanumérico no formato de código de barras: fl.

Listagem de sequências em formato impresso: fls.

Declaraçăo de acordo com o artigo da Resoluçăo INPI n² 228/09: fls.

11. Documentos anexados (assinale e indique também o número de folhas):

(Deverá ser indicado o $n^{\circ}$ total de somente uma das vias de cada documento)

\begin{tabular}{|c|c|c|c|c|c|c|c|}
\hline$凶$ & 11.1 Guia de Recolhimento & 1 & fls. & 凶 & 11.5 Relatorio descritivo & 9 & fls. \\
\hline 凶 & 11.2 Procuração & 3 & fls. & 凶 & 11.6 Reivindicaçōes & 5 & fls. \\
\hline 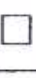 & 11.3 Documentos de Prioridade & & fls. & $\square$ & 11.7 Desenhos & & fls. \\
\hline & 11.4 Doc de contrato de trabalho & & fls. & 凶 & 11.8 Resumo & 1 & fls. \\
\hline & \multicolumn{5}{|c|}{$\begin{array}{l}11.9 \text { Outros que não aqueles definidos no campo } 11 \text { (especificar) } \\
\text { ANEXO I E PORTARIA CNEN } 73 \mathrm{DE} 17 / 10 / 08\end{array}$} & 2 & fls. \\
\hline
\end{tabular}

12. Total de folhas anexadas (referentes aos campos 10 e 11): 21 fls.

13. Declaro, sob penas da Lei, que todas as informações acima prestadas são completas e verdadeiras.

RIO DE JANEIRO, 26 SETEMBRO 2012

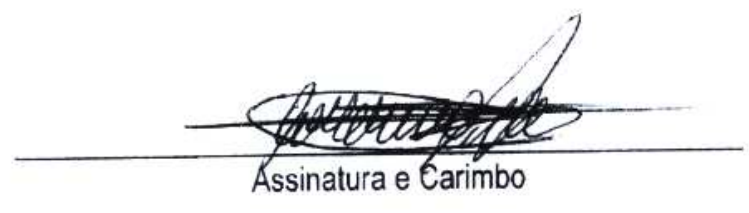

Local e Data 